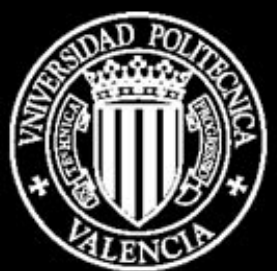

UNIVERSIDAD POLITECNICA DE VALENCIA

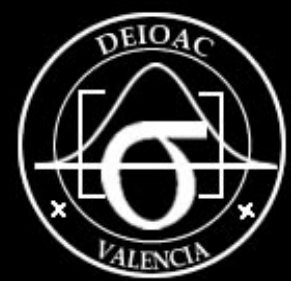

DEPARTAMENTO DE ESTADÍSTICA E INVESTIGACIÓN OPERATIVA APLICADAS Y CALIDAD

\title{
Modelo Bioeconómico Para La Evaluación Del Impacto De La Genética y Otras Variables Sobre La Cadena Cárnica Vacuna En URuguay
}

Tesis Doctoral

Juan Manuel

Soares de Lima Lapetina 


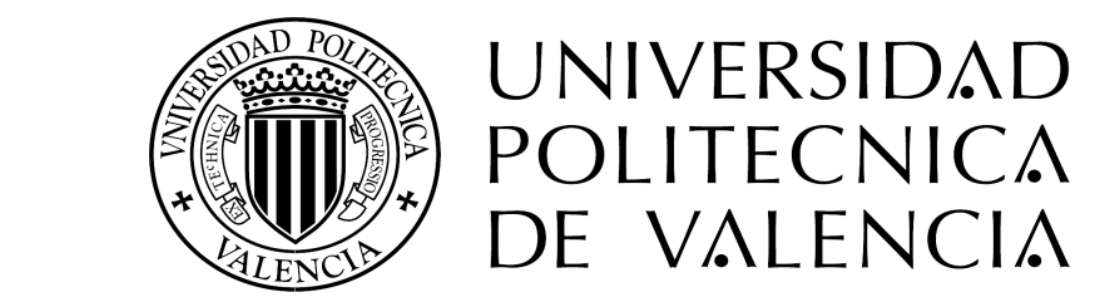

DEPARTAMENTO DE ESTADÍSTICA E INVESTIGACIÓN OPERATIVA APLICADAS Y CALIDAD

Modelo bioeconómico para la evaluación del impacto de la genética y otras variables sobre la cadena cárnica vacuna en Uruguay

Tesis Doctoral

Juan Manuel Soares de Lima Lapetina Valencia - 2009 



\title{
UNIVERSIDAD POLITÉCNICA DE VALENCIA \\ DEPARTAMENTO DE ESTADÍSTICA E INVESTIGACIÓN OPERATIVA APLICADAS Y CALIDAD
}

\begin{abstract}
Esta tesis ha sido escrita y presentada como uno de los requisitos para optar al grado de Doctor en el Departamento de Estadística e Investigación Operativa Aplicadas y Calidad de la Universidad Politécnica de Valencia.
\end{abstract}

Valencia, julio de 2009

\section{El Doctorando}

Fdo: Juan Manuel Soares de Lima Lapetina

El Director de tesis

Fdo: Rafael Plá López 

A mis padres, Juan Carlos y Myrtha y a mi hermana Diana 



\section{AGRADECIMIENTOS}

A quienes lo hicieron posible...

Al Instituto Nacional de Investigación Agropecuaria (INIA Uruguay) por brindarme esta oportunidad de formación y parte de los recursos económicos necesarios para llevarla adelante.

A la Agencia Española de Cooperación Internacional para el Desarrollo (AECID) por la financiación de mi estancia durante la mayor parte de mi período en España.

Al Director Regional de INIA Tacuarembó, Gustavo Ferreira y al Director del Programa Nacional de Producción de Carne y Lana, Fabio Montossi por las gestiones realizadas para sacar adelante mi capacitación.

A Rafael Plá por su guía y soporte metodológico de este trabajo.

A los evaluadores de esta tesis, por su profesionalidad y su contribución a la mejora sustancial de este documento

A quienes me apoyaron desde Uruguay...

A Gustavo Ferreira y especialmente a Fabio Montossi, por su presencia constante y su apoyo en momentos de desaliento, actitudes que trascienden su papel como jefe.

A mis padres y mi hermana Diana por el apoyo y preocupación permanentes, y en especial a mi padre por encargarse de todo durante mi estancia en España.

A mi familia política, Paula, Jacques, Anna, Ernesto, José María y Marla Elisa por su interés y afecto siempre presentes.

A quienes contribuyeron a mi bienestar en España...

A Andrés Campos, Hernando Solano, José María González y Marco de Luna y en una segunda etapa a Diego García, Adriana Villa y Nora Monsalve, mis compañeros y amigos del Departamento de Estadística e Investigación Operativa Aplicadas y Calidad de la UPV. Entre todos supimos crear una combinación óptima de trabajo y distensiones que hizo más llevaderas las prolongadas jornadas de trabajo a lo largo de estos años.

A Mariam Pascual, nuestra "embajadora" en España, siempre pendiente de mi esposa y de mí.

A Marcia del Campo, mi esposa, por su compañía y estímulo permanente, y por sus invalorables aportes a la corrección y depuración de este documento. 



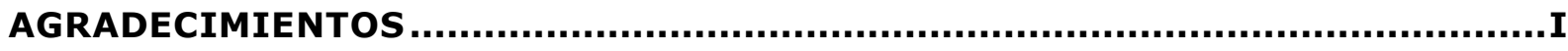

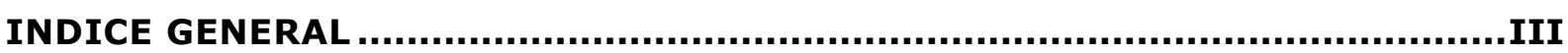

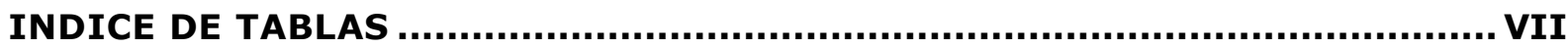

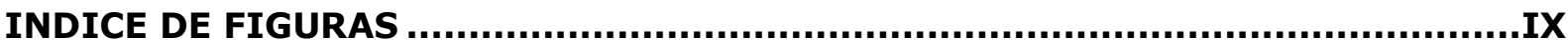

INDICE DE ACRÓNIMOS................................................................... XIII

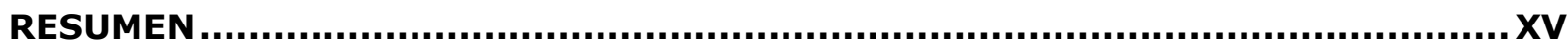

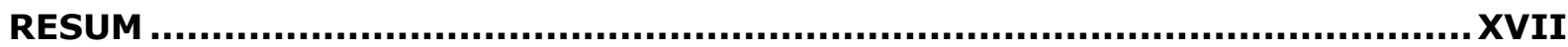

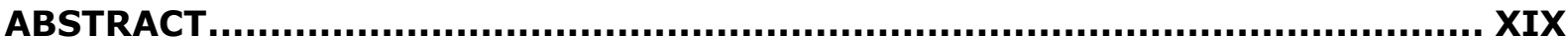

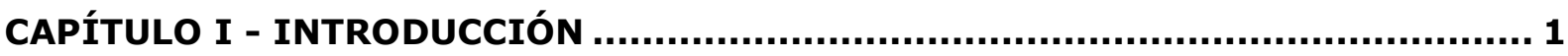

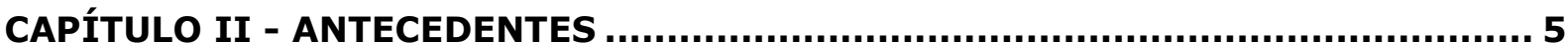

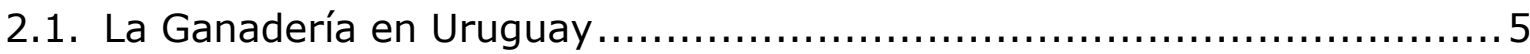

2.1.1. Situación actual de la ganadería de carne........................ 5

2.1.2. Los sistemas de producción ........................................6 6

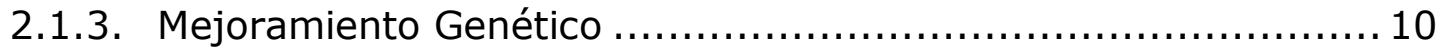

2.1.4. Índices de Selección ........................................ 11

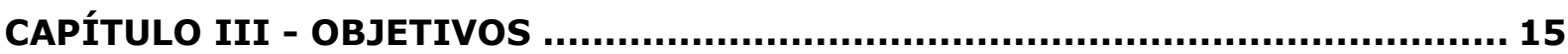

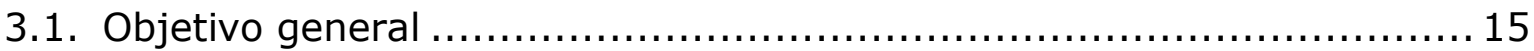

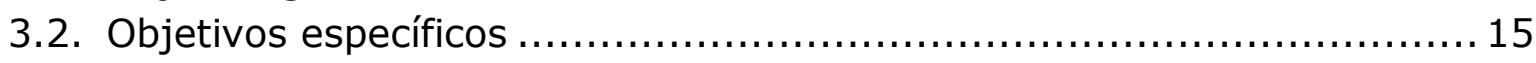

CAPÍTULO IV - REVISIÓN BIBLIOGRÁFICA ............................................ 19

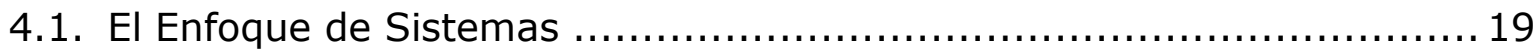

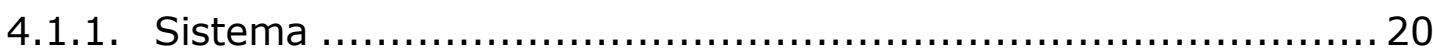

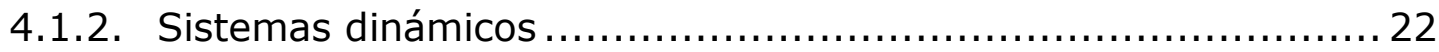

4.2. El análisis de sistemas en Producción Animal ............................ 23

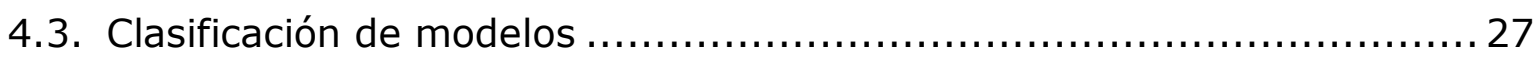

4.3.1. Modelos de simulación ........................................ 29

4.3.2. Modelos de optimización ............................................ 30

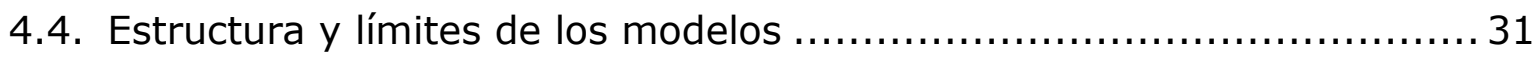

4.5. Enfoques adoptados para la modelación de los procesos .................. 33

4.5.1. Crecimiento y desarrollo.......................................... 33

4.5.1.1. La curva de crecimiento ................................ 33

4.5.1.2. Requerimientos energéticos y estimación de ganancias de peso vivo ................................................ 37

4.5.2. Consumo en pastoreo y factores que lo afectan................. 42

4.5.2.1. Predicción del consumo en pastoreo ...................... 42

4.5.2.2. Consumo potencial ....................................... 44

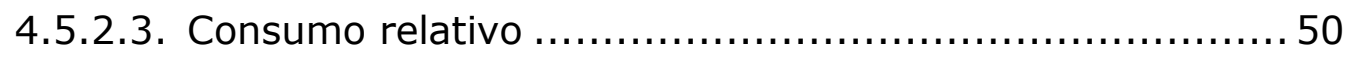

4.5.2.4. Métodos de clasificación del forraje y simulación de pastoreo selectivo ....................................... 53

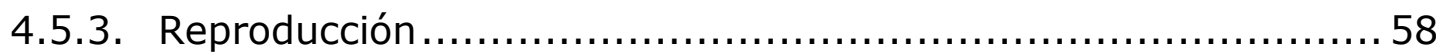

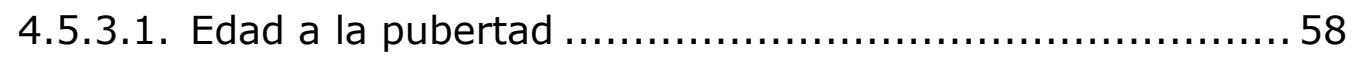




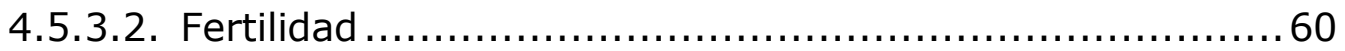

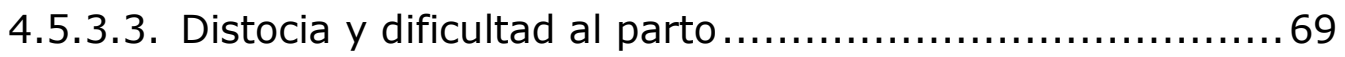

4.5.4. Producción de leche ................................................. 71

4.5.5. Modelos bioeconómicos .............................................. 72

4.5.5.1. Modelos de evaluación de características genéticas.........74 74

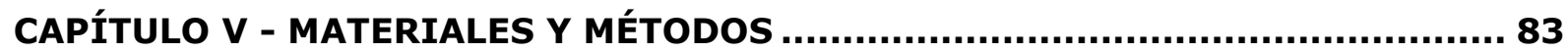

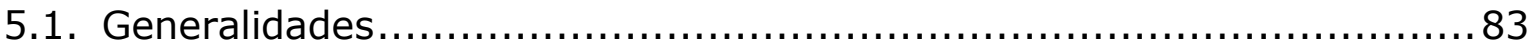

5.2. Descripción de los sistemas productivos a simular ............................ 85

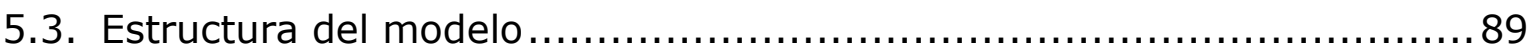

5.4. Modelo Animal .................................................................. 91

5.4.1. Consumo potencial ..................................................... 93

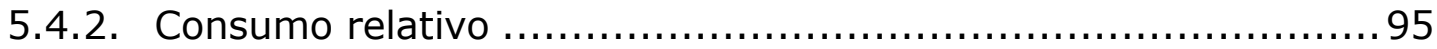

5.4.2.1. Disponibilidad de forraje....................................... 95

5.4.2.2. Calidad del forraje y selectividad ............................. 96

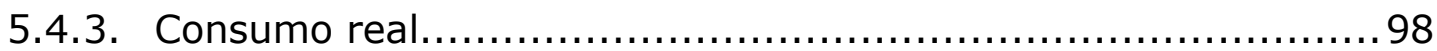

5.4.3.1. Consumo de pastura ........................................... 98

5.4.3.2. Consumo de suplementos..................................... 98

5.4.3.3. Tasa de Sustitución .............................................. 99

5.4.4. Energía aportada por la dieta ........................................ 100

5.4.5. Requerimientos energéticos de mantenimiento ................... 101

5.4.6. Balance energético y estimación del cambio de peso vivo ....... 102

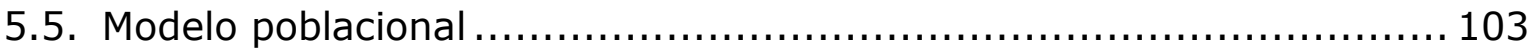

5.5.1. Variables ............................................................... 107

5.5.2. Evolución de categorías en stock ................................... 111

5.5.3. Nacimientos.......................................................... 113

5.5.3.1. Estimación de la fecha de parto............................... 114

5.5.4. Mortalidad ............................................................. 119

5.5.5. Descarte de vacas del rebaño de cría ................................ 119

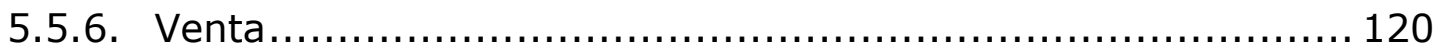

5.5.6.1. Venta de hembras excedentes ............................. 120

5.5.6.2. Venta de vacas de descarte y novillos ....................... 123

5.5.6.3. Rendimiento de canal.......................................... 128

5.5.7. Compras ................................................................. 130

5.6. Variables de manejo consideradas........................................ 130

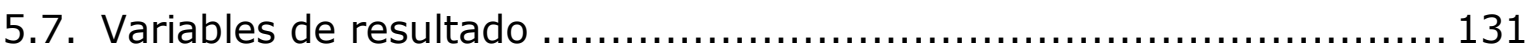

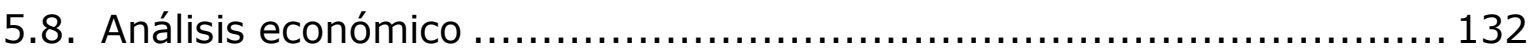

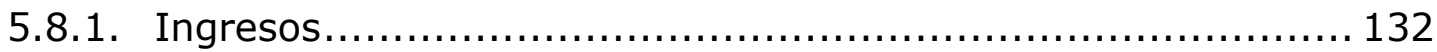

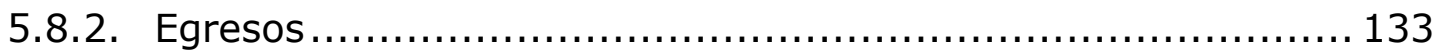

5.8.2.1. Compra de animales ........................................... 133

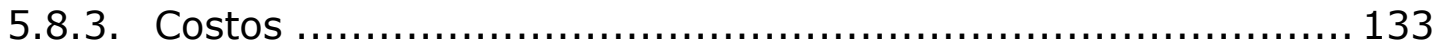

5.8.3.1. Costos de alimentación ...................................... 133

5.8.3.2. Costos de sanidad ............................................. 134

5.8.3.3. Mano de Obra .................................................. 134

5.8.3.4. Costos de comercialización .................................... 135

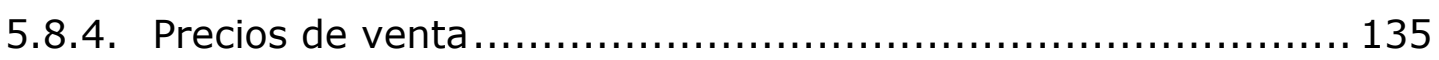


5.9. Validación del modelo....

5.10. Análisis de variables que afectan los resultados económicoproductivos

5.11. Estimación de pesos económicos (índice de selección) ................... 139

5.11.1. Especificación del sistema de producción ........................... 139

5.12. Análisis de sensibilidad y escenarios .................................. 142

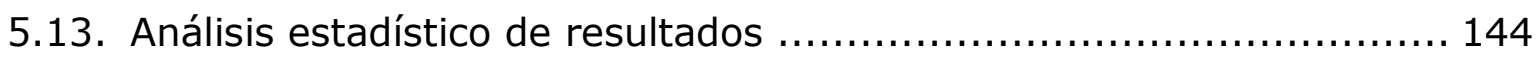

CAPÍTULO VI - RESULTADOS Y DISCUSIÓN .......................................... 147

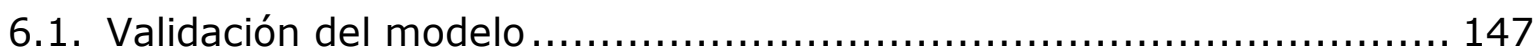

6.1.1. Validación a escala país......................................... 147

6.1.2. Validación a nivel predial...................................... 149

6.1.3. Validación a nivel de comportamiento individual................ 151

6.2. Variables determinantes de los resultados económico-productivos ..... 154

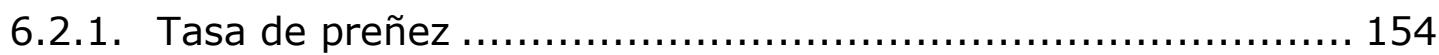

6.2.1.1. Efecto sobre la estabilización del sistema ................. 155

6.2.1.2. Efecto sobre la productividad del sistema ............... 157

6.2.1.3. Efecto sobre el retorno económico del sistema ............ 159

6.2.2. Edad de cubrición de novillas ................................. 161

6.2.2.1. Efecto sobre la recuperación de stock .................. 161

6.2.2.2. Efecto sobre la productividad y el retorno económico del sistema....

6.2.3. Categoría de hembras a vender ............................. 164

6.2.4. Diagnóstico de gestación y políticas de descarte................. 165

6.2.5. Orientación productiva y grado de intensificación ............... 177

6.2.6. Categoría a comprar en sistemas de cebo .................... 183

6.2.7. Relaciones de precios....................................... 185

6.3. Importancia relativa de las variables analizadas sobre el sistema ...... 189

6.4. Valor económico de caracteres genéticamente mejorables .............. 193

6.5. Análisis de sensibilidad ................................................ 197

6.5.1. Sensibilidad a variables analizadas en el modelo ................... 197

6.5.2. Sensibilidad a los precios de productos e insumos ............... 199

6.5.3. Análisis de sensibilidad conjunto .............................. 202

6.6. Análisis de escenarios.............................................. 205

6.7. Algunas consideraciones a nivel de la cadena cárnica uruguaya ........ 207

CAPÍTULO VII - CONCLUSIONES............................................................ 215

CAPÍTULO VIII - REFERENCIAS BIBLIOGRÁFICAS................................. 219

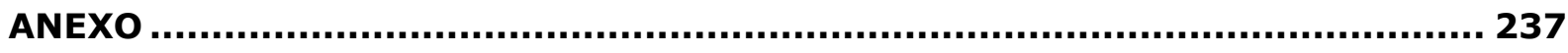



Tabla 1. Número de explotaciones con ganadería y superficie total, según orientación productiva. Año agrícola 2006/07

Tabla 2. Ejemplo de un catálogo de reproductores Hereford

Tabla 3. Consumo estimado de forraje de una oveja Merino en lactación con un consumo potencial de $2.13 \mathrm{~kg} \mathrm{MS} /$ día y digestibilidad de la dieta seleccionada en una pastura con $0.8 \mathrm{t} \mathrm{MS/ha} \mathrm{de} \mathrm{forraje} \mathrm{verde}$ (digestibilidad media $=70 \%$ ) y $0.4 \mathrm{t} \mathrm{MS} / \mathrm{ha}$ de forraje seco (digestibilidad media $=45 \%$ )

Tabla 4. Mortalidad en función del sexo del ternero, el número de parto de la madre y la dificultad al parto

Tabla 5. Coeficientes parciales (b) y parciales estándar ( $b^{\prime}$ ) de regresión del peso al nacer de los terneros sobre la facilidad de parto y otras características de crecimiento.

Tabla 6. Peso vivo (PV) al parto, peso al nacer (PN), escore de distocia (ED), peso (PD) y edad al destete (ED) y peso al destete corregido a los 205 días $\left(\mathrm{PDC}_{205}\right)$ según condición corporal al parto (CCP) de novillas.

Tabla 7. Valores económicos estimados para las diferentes características, expresados por unidad de desvío estándar genético aditivo por vaca

Tabla 8. Valores económicos $(\mathrm{VE}, \$ \mathrm{R} / \mathrm{Kg})$ de las características evaluadas en los dos sistemas

Tabla 9. Valores económicos, pesos y pesos relativos del índice de selección desarrollado para fertilidad, peso adulto, peso al destete (maternal y directo), ganancia posdestete y rendimiento carnicero

Tabla 10. Valores Económicos (VE) y Variación económica-genética (VEG) de distintos conjuntos de rasgos en diferentes sistemas de producción, para razas multipropósito.

Tabla 11. Bases de datos de INIA utilizadas en la estimación de parámetros a utilizar en el modelo.

Tabla 12. Variables de nivel del modelo

Tabla 13. Variables de entrada del modelo. 108

Tabla 14. Variables de salida del modelo M2 (Ventas)

Tabla 15. Variables intermedias calculadas

Tabla 16. Tasas de mortalidad en novillas con distintos grados de dificultad al parto y sus terneros....

Tabla 17. Espesores de grasa subcutánea $(\mathrm{mm})$ sugeridos según edad y sistema de terminación de los novillos

Tabla 18. Precios utilizados para el cálculo del ingreso bruto $(€ / \mathrm{kg})$

Tabla 19. Variables y niveles utilizados para la generación de resultados 138

Tabla 20. Rasgos biológicos determinantes del ingreso y características derivadas a evaluar

Tabla 21. Medianas, distribuciones ajustadas y parámetros estimados para las series de precios utilizadas en el análisis de sensibilidad

Tabla 22. Existencias de vacunos en Uruguay a julio de 2007, total de animales faenados ese año y estimaciones del modelo para ambos registros 
Tabla 23. Coeficientes técnicos de la ganadería uruguaya y parámetros ajustados en el modelo

Tabla 24. Indicadores productivos y económicos promedio según orientación de distintos grupos de productores en Uruguay. Valores reales y estimados por el modelo.

Tabla 25. Descripción del ensayo de cebo de novillos utilizado en la validación del modelo

Tabla 26. Ajuste del modelo expresado como porcentaje de las estimaciones que se desvían $5 \%$ o menos del valor real.

Tabla 27. Efecto de la edad de primera cubrición sobre los resultados productivos y económicos de un sistema de cría

Tabla 28. Efecto de la utilización del diagnóstico de gestación y la eliminación de vacas multíparas de rebaño de cría sobre la productividad y el margen bruto económico de un sistema de cría extensivo y uno de ciclo completo de similares características

Tabla 29. Tasa mínima de preñez general del rebaño para asegurar la reposición de hembras según estratos de edades de vacas y política de descarte de vacas jóvenes.

Tabla 30. Tasa de preñez en vacas multíparas y valores resultantes en cuanto a vacas de cría totales y terneros vendidos según intensificación del sistema de cría. Valores expresados en cabezas e índice entre paréntesis (Indice $100=60 \%$ de procreo)

Tabla 31. Indicadores productivos resultantes de las combinaciones entre Orientación Productiva y Nivel de Intensificación....

Tabla 32. Indicadores reproductivos, producción de peso vivo, extracción y margen bruto obtenido con 2 relaciones de precios, de un sistema de cría difiriendo en el grado de intensividad.

Tabla 33. Productividad física y económica de sistemas de cebo con animales comprados a diferentes edades.

Tabla 34. Ponderación económica de características relevantes para los sistemas definidos expresado en variación de MB $(€)$ para un establecimiento de 1000 ha.

Tabla 35. Determinación de variables asociadas a escenarios de alta productividad y alto margen bruto

Tabla 36. Efecto de la suplementación en novillas pre-cubrición sobre el sistema de cría 
Figura 1. Caracterización general de la ganadería en Uruguay. Ejercicio 2006/2007 ..... 6

Figura 2. Faena de novillos según edad. Período 1994-2008 ............................ 9

Figura 3. Clasificación modificada de modelos para sistemas agropecuarios basada

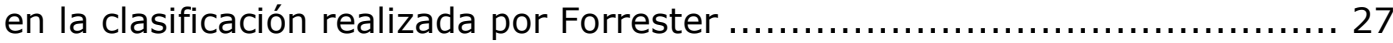

Figura 4. Relación entre el peso de un animal y su edad............................... 33

Figura 5. Relación entre la tasa de crecimiento promedio y la tasa de crecimiento relativa y la edad de los animales. ............................................ 36

Figura 6. Factores que afectan el crecimiento del ganado. .............................. 37

Figura 7. Consumo potencial estimado para vacunos de $A=500 \mathrm{~kg}$ (línea sólida) o $400 \mathrm{~kg}$ (línea punteada) en relación al tamaño relativo para animales de $\mathrm{RC} \leq 1$.

Figura 8. Disponibilidad relativa y atributos que la componen, en ovinos, en relación con la disponibilidad de materia seca de la pastura. La línea segmentada representa el tiempo relativo destinado al pastoreo, la línea punteada indica la tasa de bocado relativa, y la línea sólida es su producto, la disponibilidad relativa de forraje para el animal

Figura 9. Consumo de forraje estimado para ovejas $(A=50 \mathrm{~kg})$ pastoreando gramíneas templadas con diferente digestibilidad.

Figura 10. Estimación de la digestibilidad de la dieta según disponibilidad de forraje para 4 pasturas con distinta digestibilidad promedio

Figura 11. Estimación del consumo en vacas lecheras en función del índice de área foliar de la pastura .

Figura 12. Influencia de la condición corporal al parto (CCP) sobre la tasa de preñez: $Y=1.28-0.986 \mathrm{CCP}+0.248 \mathrm{CCP}^{2}-0.016 \mathrm{CCP}^{3}$

Figura 13. Porcentaje de vacas que manifiesta su primer celo a los $40,60,80,100$ y 120 días post parto según el nivel de energía preparto (PrePartoBajo, PrePartoAlto $)$ y el nivel energético postparto $(A=$ alto, $M=$ medio, $B=$ bajo $) \ldots . .63$

Figura 14. Porcentaje acumulado de animales en estro a los 20, 40 y 60 días de cubrición, según cond. corporal al parto $(\mathrm{CCP}=4,5$ ó 6$)$ y ganancias posparto (GPP=moderada, alta).

Figura 15. Producción de leche estimada entre los 50 y 200 días de lactancia en novillas de raza Hereford y Angus

Figura 16. Índice de aumento relativo de la producción de carne y el ingreso neto ante incrementos en la preñez (índice base preñez $60 \%=1$ ).

Figura 17. Esquema general de la dinámica de los sistemas ganaderos de Uruguay ..... 85

Figura 18. Evolución de indicadores de la cría vacuna. Terneros destetados por vaca cubierta y novillas cubiertas por primera vez con 2 años o menos

Figura 19. Porcentaje de vacas por estrato de edad según combinación de total de estratos $(4,8)$ y porcentaje de procreo $(65 \%, 85 \%)$

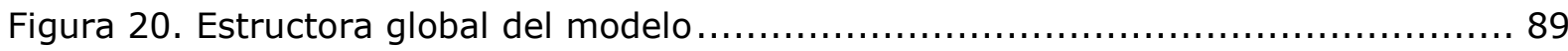

Figura 21. Representación esquemática de los tres bloques del modelo y sus flujos ..... 91

Figura 22. Diagrama de los factores y procesos involucrados en la estimación de las ganancias de peso vivo 
Figura 23. Valores calculados del índice de selectividad en función de la disponibilidad y digestibilidad de la pastura.

Figura 24. Estructura general del modelo y submodelos

Figura 25. Evolución del número total de Vacas de cría sin control de stock en función de dos tasas de preñez (65 y $80 \%$ ).

Figura 26. Esquema del mecanismo de generación de reemplazos del ciclo de cría .....112

Figura 27. Probabilidad condicional de concepción en el $1^{\text {er }}$ (PCM1), $2^{\text {do }}$ (PCM2) y $3^{\text {er }}$ mes de cubrición (PCM3) y probabilidad de preñez global (PPVC1) en novillas de primer cubrición que ingresan al servicio con diferentes pesos ... 116

Figura 28. Funciones de densidad de probabilidad de diferentes niveles de distocia asociada a los diferentes peso de los terneros al nacer para $\mathrm{RC}=1$ y $\mathrm{Pn} \sim$ $\mathrm{N}(37.5,5)$.

Figura 29. Esquema de venta de excedente de hembras.

Figura 30. Esquema del efecto de la venta sobre un grupo de animales

Figura 31. Efecto de la remoción de animales sobre la distribución resultante de un grupo de novillos, en dos años (A1 y A2) y dos meses consecutivos (M1 y

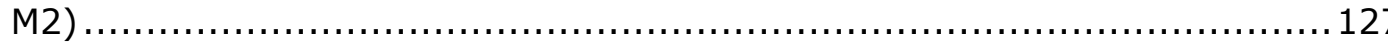

Figura 32. Rendimiento en $2^{a}$ balanza estimado en función del área de ojo del bife. Novillo de $500 \mathrm{~kg}$ PV y EGS de $5 \mathrm{~mm}$

Figura 33. Valores estimados de rendimiento en $2^{\mathrm{a}}$ balanza para un novillo de $P V=500 \mathrm{~kg}, 2-3$ años de edad según sistema de cebo y AOB...

Figura 34. Evolución reciente de los precios de terneros y novillos expresada en $€ / \mathrm{kg}$ en pie y relación entre ambos valores.

Figura 35. Evolución de peso real (observado) y estimado por el modelo para el experimento realizado en el año 2006.

Figura 36. Evolución de peso real (observado) y estimado por el modelo para el experimento realizado en el año 2007.

Figura 37. Evolución del número de VC en función del porcentaje de preñez con 4 estratos de edades....

Figura 38. Evolución del número de VC en función del porcentaje de preñez con 8 estratos de edades

Figura 39. Productividad de 2 sistemas de cría y 2 de ciclo completo de diferente intensividad en el uso de insumos en función de la tasa de parición global del rebaño

Figura 40. Retorno económico de 2 sistemas de cría y 2 de ciclo completo de diferente intensividad en el uso de insumos en función de la tasa de parición global del rebaño

Figura 41. Evolución de stock de vacas de cría según política de cubrición

Figura 42. Productividad (PPV; kg PV/ha) y Margen Bruto (MB; $€ /$ ha) de 2 sistemas de cría y 2 de ciclo completo de diferente intensividad en el uso de insumos en función de la edad de primera cubrición de las novillas

Figura 43. Efecto de la categoría de hembras destinada a venta sobre la estructura del rebaño y el Margen Bruto del sistema.

Figura 44. Efecto de la tasa de procreo de vacas de más de 2 partos sobre la productividad y el margen bruto de un sistema de cría intensiva según el número de estratos de edad y la relación de precios ternero/novillo (RTN) .. 169 
Figura 45. Efecto de la tasa de procreo de vacas de más de 2 partos sobre la productividad y el margen bruto de un sistema de cría extensivo según el número de estratos de edad y la relación de precios ternero/novillo (RTN) .. 171

Figura 46. Efecto de la interacción entre la edad de cubrición de novillas y la tasa de partos de vacas multíparas sobre la productividad de: A) un sistema de ciclo completo extensivo y, B) un sistema de cría intensivo

Figura 47. Ingresos por venta de diferentes categorías y margen bruto de un sistema de cría intensiva según \% de preñez global

Figura 48. Relación entre la tasa de procreos de vacas jóvenes y multíparas sobre el margen bruto en diferentes escenarios de precios

Figura 49. Margen bruto (MB) e ingreso por ventas de cada categoría según orientación productiva y nivel de intensificación

Figura 50. Composición de edades de novillos vendidos según sistema.....

Figura 51. Indicadores de eficiencia biológica en los sistemas contrastados

Figura 52. Eficiencia de conversión de forraje en peso vivo, expresada como $\mathrm{Kg} \mathrm{MS}$ de forraje necesarios para lograr una ganancia diaria de 500 grs. de peso vivo

Figura 53. Efecto de la relación de precios de compra (ternero) y venta (novillo) sobre el margen bruto de un establecimiento de cebo.

Figura 54. Margen bruto de un sistema extensivo de cría en función de relaciones de precios Ternero/Novillo y niveles de preñez

Figura 55. Ingreso por ventas de distintas categorías y margen bruto, en función de relaciones de precios Ternero/Novillo, para una siituación de preñez $=60 \% 188$

Figura 56. Efecto de la relación de precios ternero/novillo sobre el margen bruto en sistemas de ciclo completo con dos niveles de intensificación y dos niveles reproductivos.

Figura 57. Análisis de componentes principales. Representación de las principales variables asociadas al resultado económico-productivo de sistemas de cría extensiva

Figura 58. Análisis de componentes principales. Representación de las principales variables asociadas al resultado económico-productivo de sistemas de cría intensiva

Figura 59. Análisis de componentes principales. Representación de las principales variables asociadas al resultado económico-productivo de sistemas de ciclo completo extensivo

Figura 60. Análisis de componentes principales. Representación de las principales variables asociadas al resultado económico-productivo de sistemas de ciclo completo intensiva

Figura 61. Ingresos por ventas de las diferentes categorías y margen bruto en un sistema extensivo de cría con diferentes niveles de preñez

Figura 62. Efecto del peso al nacer sobre el margen bruto relativo en sistemas de cría y ciclo completo

Figura 63. Sensibilidad del margen bruto a las principales variables analizadas en sistemas de cría intensivos y extensivos

Figura 64. Sensibilidad del margen bruto a las principales variables analizadas en sistemas de ciclo completo intensivos y extensivos. 
Figura 65. Variabilidad de los resultados económicos expresados como Margen Bruto en función de los precios de productos y principales insumos

Figura 66. Análisis de sensibilidad de la producción de peso vivo a diferentes variables según orientación productiva y nivel de intensificación

Figura 67. Análisis de sensibilidad del margen bruto a diferentes variables según orientación productiva y nivel de intensificación

Figura 68. Evolución de la productividad (PPV) y el margen bruto (MB) a partir de la implementación del diagnóstico de gestación y posterior descarte y cebo de vacas adultas vacías

Figura 69. Efecto de la suplementación con pienso sobre la evolución de peso vivo en novillas durante su segundo invierno (julio-setiembre) 
INDICE DE ACRÓNIMOS

AFRC Agricultural and Food Research Council

ARC Agricultural Research Council

ARU Asociación Rural del Uruguay

CNES California Net Energy System

CNCPS Cornell Net Carbohydrate and Protein System

DICOSE Dirección de Contralor de Semovientes

DIEA Dirección de Estadísticas Agropecuarias

FUCREA Federación Uruguaya de Grupos CREA

INAC Instituto Nacional de Carnes

INIA Instituto Nacional de Investigación Agropecuaria

IPA Instituto Plan Agropecuario

MGAP Ministerio de Ganadería, Agricultura y Pesca

NRC National Research Council

OPYPA Oficina de Planeamiento Y Políticas Agropecuarias

TGS Teoría General de Sistemas 



\section{RESUMEN}

La ganadería constituye uno de los sectores fundamentales de la economía uruguaya. En el año 2008 Uruguay fue el $7^{\text {mo }}$ exportador de carne vacuna y $4^{\text {to }}$ exportador de carne ovina del mundo. La investigación agropecuaria a nivel nacional reviste una importancia acorde a la del sector, habiendo generado un gran volumen de información a lo largo de los años. Sin embargo, el conocimiento desarrollado en diferentes áreas, suele carecer de un enfoque integrado que permita evaluar el impacto productivo y fundamentalmente económico de diferentes opciones tecnológicas sobre el sistema de producción como unidad básica. Paralelamente, la evaluación genética de ganado vacuno, se dispone a desarrollar un índice de selección para ser aplicado en las principales razas de producción de carne del país. Para llevar a cabo esta tarea, resulta fundamental la aplicación de un enfoque sistémico en la evaluación del peso económico relativo de las variables que inciden en la estructura de ingresos y costos de los sistemas de producción ganaderos.

En este trabajo se desarrolla un modelo bioeconómico dinámico, con el objetivo de disponer de una herramienta adaptada a las condiciones productivas de Uruguay con la cual evaluar alternativas de producción, reproducción y manejo sobre la productividad y el retorno económico de los establecimientos ganaderos y de la cadena cárnica uruguaya en su conjunto.

El modelo es centralmente determinístico, incorporando componentes estocásticos en la simulación de ciertos eventos. Posibilita la simulación de las fases de cría, recría y cebo en forma independiente, o como procesos integrados dentro de un mismo sistema de producción.

En función de coeficientes técnicos ingresados y características de la pastura, el modelo simula procesos a nivel individual (consumo, cambio de peso vivo), los cuales se integran a nivel de rebaño generando una evolución en el número y peso de las categorías, en forma mensual. De esta forma se genera un volumen de ventas, constituido por hembras excedentes del rebaño de cría y animales cebados para matadero, que es valorizado a precios de mercado y determina el ingreso económico del sistema.

Los resultados de la aplicación del modelo ponen en evidencia la importancia de algunas variables clave, que actúan dinamizando el sistema, como la edad de las novillas al primer servicio. Asimismo, se destaca la alta sensibilidad de todos los sistemas, a los precios de venta de los productos. 
Se verifican complejas interacciones entre algunas variables como la tasa de preñez, cuyo efecto y magnitud es altamente dependiente de la categoría, de las políticas de descarte de vacas del rebaño y de los precios de las categorías de venta.

El cebo como alternativa de producción determina un mayor retorno económico, en virtud de constituir un proceso más eficiente desde el punto de vista biológico. Sin embargo, su potencial productivo es altamente sensible a los recursos alimenticios disponibles.

En lo que respecta a la importancia relativa de los caracteres susceptibles de mejora genética, la heterogeneidad de los sistemas de producción dificulta el arribo a conclusiones generalizables. La tasa de preñez, la tasa de crecimiento en machos y el rendimiento de res, aparecen como las variables de mayor relevancia en este aspecto, aunque se debe profundizar en lo que respecta a la variación genética potencial de estas características. El bajo coste de la alimentación en sistemas extensivos y la importancia del cebo de las vacas de descarte en los sistemas de cría, determinan un peso económico positivo de algunos caracteres como el consumo y el peso adulto, los cuales son usualmente reportados con valores cercanos a cero o negativos en la literatura internacional.

En sectores de ganadería extensiva fundamentalmente, aún se visualizan alternativas de bajo coste y alto retorno, como la generalización en la aplicación del diagnóstico de gestación y consiguiente descarte de hembras vacías.

El modelo posibilita la consideración simultánea de numerosas variables que inciden en los sistemas de producción de carne vacuna, pudiendo ser utilizado como apoyo a la investigación y extensión en ganadería a nivel de establecimientos, así como para la evaluación de políticas de diversa índole a nivel regional o nacional. 
RESUM

La ramaderia constitueix un dels sectors fonamentals de l'economia uruguaiana. L'any 2008 Uruguai va ser el $7^{\text {è }}$ exportador de carn vacuna i $4^{t}$ exportador de carn ovina del món. La investigació agropecuària a nivell nacional revisteix una importància d'acord amb la del sector, havent generat un gran volum d'informació al llarg dels anys. Malgrat tot, el coneixement desenvolupat en diferents àrees, sol no tindre un enfocament integrat que permeta avaluar l'impacte productivament i fonamentalment econòmic de diferents opcions tecnològiques sobre el sistema de producció com a unitat bàsica. Paral-lelament, l'avaluació genètica de bestiar vacú, es disposa a desenvolupar un índex de selecció per a ser aplicat en les principals races de producció de carn del país. Per a dur a terme aquesta tasca, resulta indispensable l'aplicació d'un enfocament sistèmic en l'avaluació del pes econòmic relatiu de les variables que incideixen en l'estructura d'ingressos i costos dels sistemes de producció ramaders.

En aquest treball es desenvolupa un model bioeconòmico dinàmic, amb l'objectiu de disposar d'una ferramenta adaptada a les condicions productives d'Uruguai amb la qual avaluar alternatives de producció, reproducció i maneig sobre la productivitat i el retorn econòmic dels establiments ramaders i de la cadena càrnica uruguaiana en el seu conjunt.

El model desenvolupat és centralment determinìstic, incorporant components estocàstics en la simulació de certs esdeveniments. Possibilita la simulació de les fases de cria, recria i engreix en forma independent, o com a processos integrats dins d'un mateix sistema de producció.

En funció de coeficients tècnics ingressats i característiques de la pastura, el model simula processos a nivell individual (consum, canvi de pes viu), els quals s'integren a nivell de ramat generant una evolució en el numbre i pes de les categories, en forma mensual. D'aquesta manera es genera un volum de vendes, constituït per femelles excedents del bestiar de cria i animals engreixats per a escorxador, que és valorat a preus de mercat $\mathrm{i}$ determina l'ingrés econòmic del sistema.

Els resultats de l'aplicació del model posen en evidència la importància d'algunes variables clau, que actuen dinamitzant el sistema, com l'edat de les jònegues al primer servei. Així mateix, es destaca l'alta sensibilitat de tots els sistemes, als preus de venda dels productes.

Es verifiquen complexes interaccions entre algunes variables com la taxa de prenyat, l'efecte i magnitud de la qual és altament dependent de la categoria, de les polítiques de descart de vaques del ramat i dels preus de les categories de venda. 
L'engreix com a alternativa de producció determina un major retorn econòmic, en virtut de constituir un procés més eficient des del punt de vista biològic. No obstant, el seu potencial productiu és altament sensible als recursos alimentaris disponibles.

Pel que fa a la importància relativa dels caràcters susceptibles de millora genètica, I'heterogeneïtat dels sistemes de producció dificulta arribar a conclusions generalitzables. La taxa de prenyat, la taxa de creixement en mascles i el rendiment de l'animal, apareixen com les variables de major rellevància en aquest aspecte, encara que s'ha d'aprofundir pel que fa a la variació genètica potencial d'aquestes característiques. El baix cost de l'alimentació en sistemes extensius i la importància de l'engreix de les vaques de descart en els sistemes de cria, determinen un pes comparativament major d'alguns caràcters com el consum i el pes adult, els quals són usualment referits amb pesos econòmics molt baixos o negatius en la literatura internacional.

En sectors de ramaderia extensiva, encara es visualitzen alternatives de baix cost $\mathrm{i}$ alt impacte, com la generalització en l'aplicació del diagnòstic de gestació i consegüent descart de femelles buides.

El model possibilita la consideració simultània de nombroses variables que incideixen en els sistemes de producció de carn vacuna, podent ser utilitzat com a suport a la investigació i extensió en ramaderia a nivell d'establiments, així com per a l'avaluació de polítiques de diversa índole a nivell regional o nacional. 


\section{ABSTRACT}

Livestock is one of the most important sectors of the Uruguayan economy. In 2008 Uruguay ranked $7^{\text {th }}$ in beef export and $4^{\text {th }}$ in sheep meat export in the world. Agricultural research has generated a large amount of scientific information over the past years. However, the scientific information developed in different areas, often lacks an integrated approach in order to evaluate the productive and economic impact of different technological options, on the production system as the basic unit. In addition, the national genetic evaluation program for cattle is developing a selection index for the beef breeds used in Uruguay. To develop a selection index, the application of a systemic approach for assessing the economic weights of the variables affecting the structure of revenues and costs of livestock production systems, is essential.

This thesis develops a dynamic bio-economical model. The objective was to create a flexible tool, to evaluate the productivity and economic return of livestock systems - that apply different productive, reproductive and management alternatives- and of the Uruguayan meat chain as a whole.

The model is centrally deterministic, incorporating stochastic components in the simulation of certain events. It allows the simulation of the stages of breeding, stocking and fattening either independently or as an integrated process within a production system.

Considering technical coefficients and pasture characteristics, the model simulates processes at the individual level (feed intake, body weight change), generating a monthly growth rate, thus the evolution into the next category, which are integrated at a herd level. As a consequence, a sale volume is produced, consisting of surplus females from the breeding herd and fattened animals for slaughter. This sale volume is valued at market prices and determines the income of the system.

The results of applying the model highlight the importance of key variables with a great impact over the whole system, such as age at first mating. The high sensitivity of all the systems to sales prices is also relevant.

Complex interactions have been detected between variables like pregnancy rate whose effect and magnitude are highly dependent on the category, culling strategies and sales prices.

Fattening is the alternative of greater economic return since it's a biologically more efficient process. However, its potential is highly sensitive to the availability of forage resources. 
Regarding the relative importance of characters capable of genetic improvement, the diversity in production systems make difficult to arrive to general conclusions. Pregnancy rate, growth rate in males and dressing percentage, appears to be the most important variables, although further research about the potential variation of these characteristics, is needed. The low cost of feeding in extensive range systems and the relevance of fattening culled cows in cow-calf systems, determine a positive economic value of characters such as feed intake and adult weight, which are reported to have a low or even negative impact according to the international literature.

Pregnancy diagnosis and culling of barren cows still seem to be alternatives of low cost and high impact, mostly in extensive production systems.

The model allows simultaneous consideration of many variables affecting beef production systems. It can be used as a research and extension support in livestock production systems and for the evaluation of policies at a regional or national level. 
CAPITULO I - INTRODUCCIÓN 



\section{CAPÍTULO I - INTRODUCCIÓN}

La economía de Uruguay se encuentra fuertemente amparada en el sector agropecuario y dentro de éste, tienen especial relevancia la ganadería vacuna y ovina. $\mathrm{A}$ pesar de su limitada escala, en el año 2008 Uruguay fue el $7^{\text {mo }}$ exportador de carne bovina y el $4^{\text {to }}$ de carne ovina del mundo (Global Trade Atlas, 2009).

Ante la importancia económica, productiva y social del sector, el Instituto Nacional de Investigación Agropecuaria (INIA) como institución líder en la generación de información científica para el agro, se ha fijado como meta "Promover, con un enfoque integral, la innovación científico-tecnológica del sector agropecuario uruguayo de forma de mejorar su competitividad a nivel nacional e internacional" (Objetivo estratégico del Instituto Nacional de Investigación Agropecuaria, INIA Uruguay, www.inia.org.uy). Para lograr esta mejora de la competitividad del sector, la Investigación se plantea entre otros objetivos, "Desarrollar tecnologías, bajo un enfoque de cadena, que permitan diversificar, diferenciar y valorizar productos y procesos, buscando mejorar la capacidad competitiva del modelo agro-industrial exportador del país y su inserción comercial en un entorno globalizado, a través de mantener y ampliar mercados, y de cumplir con las crecientes exigencias internacionales de los estándares de calidad, normativas sanitarias, inocuidad y bienestar animal $\left(1^{\mathrm{er}}\right.$ objetivo específico del INIA).

La investigación en Uruguay ha generado un gran volumen de información, brindando herramientas para superar restricciones que operan a distintos niveles productivos de la cadena cárnica uruguaya. A pesar de ello, en algunos sectores productivos ha existido tradicionalmente una baja adopción de tecnología. Una hipótesis que permitiría explicar en parte este comportamiento, es la dificultad de estos sectores de dimensionar adecuadamente el impacto económico de la inclusión de tecnología en estos sistemas de producción.

Es necesario contar con herramientas que permitan al investigador, al extensionista y eventualmente al productor agropecuario, visualizar claramente el efecto de alternativas tecnológicas en escenarios complementarios a los utilizados durante la etapa experimental, especialmente cuando la aplicación de cierta tecnología o estrategia de manejo tiene efectos indirectos sobre el sistema. De esta manera se consigue validar una técnica o tecnología, cuantificar su impacto objetivamente, analizar la sensibilidad a su uso y desde el punto de vista del sector primario, reducir la incertidumbre de su aplicación a escala comercial.

Los modelos de simulación son una herramienta conceptual importante que permite la verificación ex ante de teorías e hipótesis establecidas, particularmente en sistemas de alta complejidad (Peck, 2004). 
El desarrollo de modelos obliga a la revisión e integración del conocimiento disponible en determinada área, permite evaluar la concordancia de esta información y facilita la toma de decisiones para seleccionar la mejor alternativa que se puede lograr con una combinación de recursos y precios determinada. Permite evaluar el potencial productivo de los sistemas bajo diferentes escenarios y alternativas de manejo, reduciéndose de esta manera el tiempo que requiere la experimentación a nivel de campo.

Más allá de la productividad y de las fronteras territoriales, la ganadería de hoy presenta ramificaciones en áreas que trascienden la exclusiva generación de alimentos. Ello se ha reflejado en la existencia de una importante pluralidad de líneas de investigación, entre las que se destacan las implicaciones de la ganadería como agente de conservación medioambiental (deforestación, protección de incendios) o implicado en su degradación (sobreexplotación, erosión, producción de gases de efecto invernadero); la obtención de productos de calidad; la contaminación de recursos hídricos originada por sistemas intensivos; la problemática del bienestar animal, especialmente en el caso de sistemas de producción intensivos y el papel de la actividad ganadera en proyectos de desarrollo rural como elemento fundamental para la valorización de zonas desfavorecidas.

Todo ello lleva a que la investigación deba desarrollar mecanismos de descripción de los sistemas que permitan analizar su posible evolución con relación a las modificaciones del entorno. Por eso, una de las líneas de investigación que más se ha desarrollado en los últimos años es la simulación mediante la construcción de modelos. Su interés en el estudio de los sistemas de producción animal radica en las enormes posibilidades que alberga a la hora de considerar de manera simultánea una gran cantidad de variables que definen las características del sistema y su entorno (Ruiz y Oregui, 2001). 
CAPITULO II - ANTECEDELITLS 



\section{CAPÍTULO II - ANTECEDENTES}

\subsection{La Ganadería en Uruguay}

\subsubsection{Situación actual de la ganadería de carne}

La ganadería vacuna y ovina, constituye un factor de fundamental importancia en la dinámica económica y social del sector agropecuario uruguayo. Ocupa el 96\% de la superficie dedicada a la producción agropecuaria (15.7 millones de hectáreas), involucra al $82 \%$ de los establecimientos agropecuarios (46.8 mil), emplea el $53 \%$ de la fuerza de trabajo rural (83 mil) y constituye el principal ingreso económico para el $57 \%$ de los establecimientos rurales (32.3 mil) (Caputi, 2005).

El stock ganadero del país es de aproximadamente 12 millones de vacunos y 11 millones de ovinos (DICOSE, 2008).

El Producto Bruto Interno (PBI) Agroindustrial representa el 58.1\% del PBI Nacional, mientras que el PBI Agropecuario contribuye en un 35.2\% al primero (DIEA, 2008). En lo que tiene que ver con su participación en las exportaciones, en el año 2008 se exportaron 860 millones de euros de carne bovina, representando un $20 \%$ del total de las exportaciones del Uruguay (Global Trade Atlas, 2009; Unión de Exportadores del Uruguay, 2009).

Dentro de estas actividades ganaderas, los bovinos de carne tienen una participación cada vez más significativa, debido al crecimiento sostenido de las existencias vacunas y a la disminución de más del $40 \%$ en las existencias ovinas registrado en la última década.

La producción de carne vacuna ha mostrado una tendencia creciente en los últimos 10 años, sobreponiéndose a eventos negativos como los brotes de Fiebre Aftosa o la evolución cambiaria desfavorable hasta el año 2002. Esta tendencia creciente se sostiene mediante inversiones en mejoramientos de pasturas y otras mejoras tecnológicas, además de la ocupación de los espacios disponibles debido a la disminución de existencias ovinas.

Si bien la coyuntura económica es favorable, es menester posicionarse a la vanguardia en lo que tiene que ver con la mejora de la competitividad del sector, tanto a nivel nacional como hacia el exterior. Esto permitirá un mayor aprovechamiento de la situación favorable y la capacidad de afrontar los nuevos desafíos en cuanto a requerimientos asociados a calidad del producto, seguridad alimentaria y bienestar animal. 


\subsubsection{Los sistemas de producción}

La ganadería en Uruguay se desarrolla principalmente sobre campos de pastoreo extensivo, en su mayoría naturales y en menor medida sobre praderas sembradas de gramíneas y/o leguminosas, según la época del año. Los sistemas pastoriles se caracterizan por el pastoreo conjunto de bovinos y ovinos, sin estabulación. Los elevados precios internacionales de la carne y la apertura de nuevos mercados, han provocado en los últimos años, una intensificación de los sistemas, mayoritariamente los de cebo con la consiguiente diversificación en las opciones de producción, de forma de mejorar la eficiencia de producción y atributos de calidad de la carne. Hoy coexisten en el país sistemas pastoriles exclusivamente basados en el campo natural, con sistemas muy intensivos de cebo en estabulación y toda una gama de situaciones tecnológicas intermedias.

En la Figura 1 se presenta una caracterización general de la ganadería en el país.

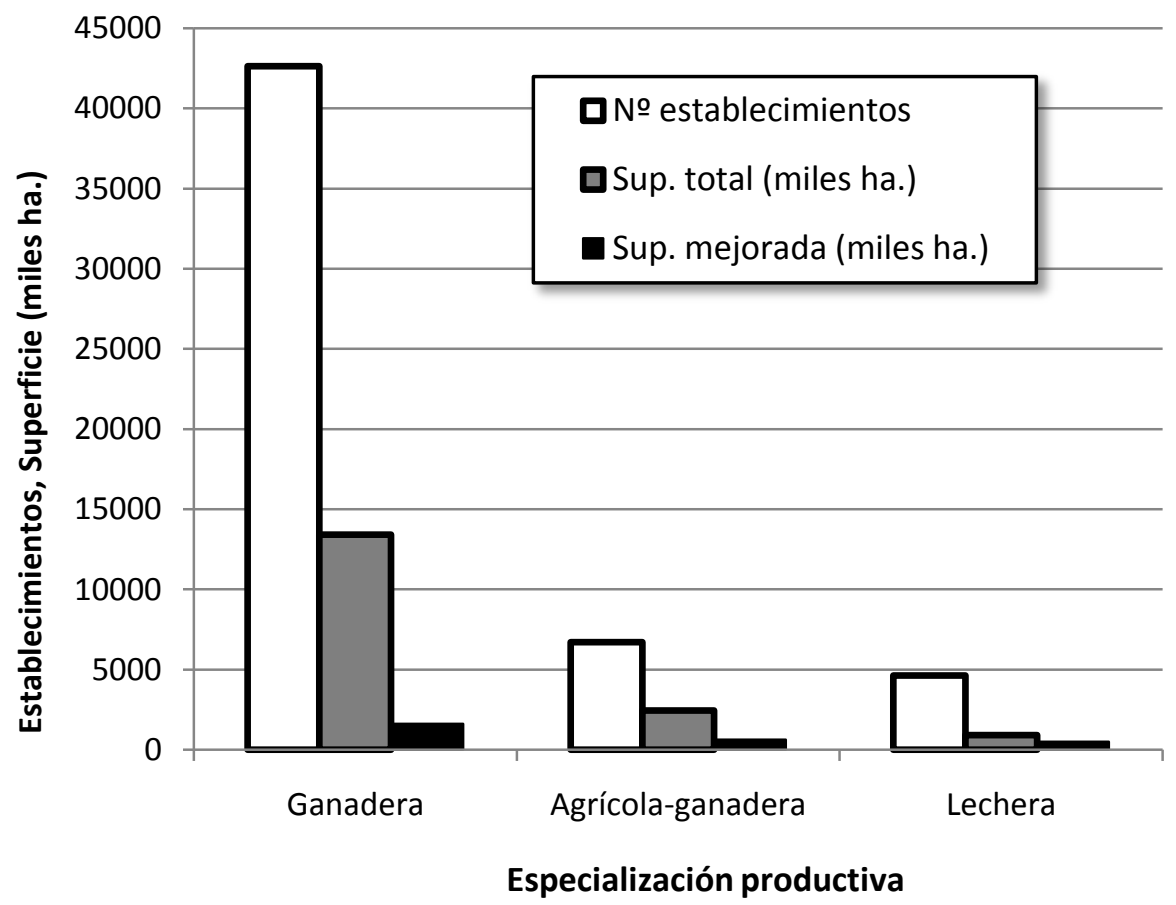

Figura 1. Caracterización general de la ganadería en Uruguay. Ejercicio 2006/2007. Fuente: DIEA, (2008)

Los sistemas de producción se pueden agrupar en tres grandes categorías:

- Cría: se cuenta con un rebaño de vacas, produciéndose terneros que se venden a otros productores para continuar su ciclo de cebo 
- Ciclo Completo: se cuenta con un rebaño de vacas cuyos terneros son criados y cebados para finalmente ser vendidos al matadero

- Invernada o Cebo: no hay vacas de cría por lo cual no hay producción propia de animales. Se compran terneros o novillos (machos castrados) provenientes de los sistemas de cría para completar su desarrollo y cebo finalizando con su venta a matadero

Estos sistemas, en el orden en que fueron descritos, se encuentran usualmente asociados a niveles crecientes en el uso de insumos, lo cual a su vez se corresponde con una distribución o regionalización dentro del territorio nacional, esencialmente en base a la capacidad de uso de los suelos. En la Tabla 1 se presenta la superficie y el número de establecimientos dedicados a cada actividad ganadera.

Tabla 1. Número de explotaciones con ganadería y superficie total, según orientación productiva. Año agrícola 2006/07

\begin{tabular}{l|cccc}
\hline \multirow{2}{*}{ Orientación ganadera } & \multicolumn{2}{|c}{ Explotaciones } & \multicolumn{2}{c}{ Sup.Total (miles ha) } \\
\cline { 2 - 5 } & \multicolumn{1}{c}{$\left(\mathrm{N}^{\circ}\right)$} & $(\%)$ & $\left(\mathrm{N}^{\circ}\right)$ & $(\%)$ \\
\hline TOTAL & 49325 & $\mathbf{1 0 0}$ & $\mathbf{1 5 8 6 1}$ & $\mathbf{1 0 0}$ \\
Criadores & 26717 & 54 & 7863 & 50 \\
Ciclo Completo & 6773 & 14 & 3807 & 24 \\
Invernadores (Cebo) & 6909 & 14 & 2550 & 16 \\
Sólo ovinos & 1101 & 2 & 101 & 1 \\
Sin animales & 7825 & 16 & 1539 & 10 \\
\hline
\end{tabular}

Fuente: Elaborado por DIEA,en base a la Declaración Jurada de DICOSE en Junio de 2007.

La Tabla 1 pone de manifiesto la relevancia económica y social que posee la cría vacuna en Uruguay. Esta actividad ocupa el 50\% del área ganadera del país (7.8 millones de hectáreas) y el valor de su principal producto, los terneros (machos), representa alrededor de 280 millones de euros al año. Asimismo, en el año 2007 representó el 54\% de las explotaciones ganaderas, lo cual confirma su importancia también desde el punto de vista social.

La producción sobre pasturas naturales determina pérdidas de peso en el invierno, por lo cual el rebaño de cría suele perder varios puntos de condición corporal en la escala de 1 a 8 puntos utilizada en el país (Earle, 1976). La baja disponibilidad de forraje en esa época del año, se suma a los requerimientos elevados por la gestación de las vacas. La mayor producción de forraje nativo en la primavera y verano (setiembre - marzo) difícilmente 
compensa las exigencias nutricionales de la producción de leche de las vacas en este período, por lo cual esta categoría tiene pocas posibilidades de recuperar el peso y condición corporal antes del destete (abril-mayo), cuando a su vez resta muy poco tiempo para que la disponibilidad de forraje decaiga nuevamente. De esta forma los indicadores productivos nacionales son bajos, puntualmente la tasa de destete (terneros destetados/vaca cubierta) no ha logrado superar el $65 \%$ salvo en años excepcionales (DIEA, 2008).

En lo que concierne a la productividad, en general es sensiblemente inferior a la de los sistemas de cebo y en menor medida a los de ciclo completo. Tradicionalmente ha estado asociada a suelos comparativamente menos productivos, no aptos para agricultura, más extensivos en el uso de los recursos y por lo general con bajos niveles de adopción tecnológica, entendiendo tecnología como el "conjunto de teorías y de técnicas que permiten el aprovechamiento práctico del conocimiento científico",(www.rae.es). En el contexto agropecuario nacional, se engloban en el término aspectos relativos a nuevas variedades forrajeras y su utilización, estrategias de manejo del pastoreo, métodos de siembra de pasturas así como otras técnicas de utilización en el rebaño como diagnóstico de gestación, control del amamantamiento (destete precoz, destete temporario), manejo diferencial del rebaño de cría según condición corporal, técnicas de alimentación diferencial del ternero (creep-grazing, creep-feeding) y muchas otras opciones.

Si bien la tasa de destete ha sido tradicionalmente baja, en los últimos años se ha verificado una reducción en la edad de primera cubrición, el cual constituye un parámetro muy relevante desde el punto de vista de la eficiencia del proceso (Caputi y Murguía, 2003). El porcentaje de novillas cubiertas con 2 o menos años de edad ha aumentado desde $42 \%$ en el año 1996 a 57\% en él último año agrícola (DICOSE, 2008).

En este contexto, las razones que han motivado el relativo estancamiento de la cría y las posibles soluciones para superar dicho estancamiento, son temáticas de debate constante en Uruguay.

En general los sistemas productivos que utilizan pasturas mejoradas están enfocados al cebo de novillos, siendo muy escasos los sistemas puramente de cría que las utilizan. En caso de que así sea, usualmente se las destina en primera instancia al cebo de las vacas que se descartan del rebaño y en segundo término a la recría de hembras para lograr una cubrición a edad más temprana.

Los sistemas de cebo utilizan mayoritariamente pasturas naturales, pero en muchos casos se encuentran ligados a cultivos agrícolas y/o agrícolas-forrajeros en forma complementaria a la ganadería (Figura 1). En lo que respecta a los indicadores técnicos, ha 
existido una evolución positiva en los últimos años, caracterizada por un descenso en la edad media de sacrificio, la cual desciende de 4.5 a 3.7 años entre mediados de los años ochenta y finales de los años noventa (Figura 2). Este factor mejora la eficiencia del cebo a través de las relaciones entre el flujo y el stock: la mayor velocidad de rotación de stock, determina que se necesiten menos animales para generar el mismo flujo (o el mismo stock para generar un flujo mayor (Caputi, 2005).

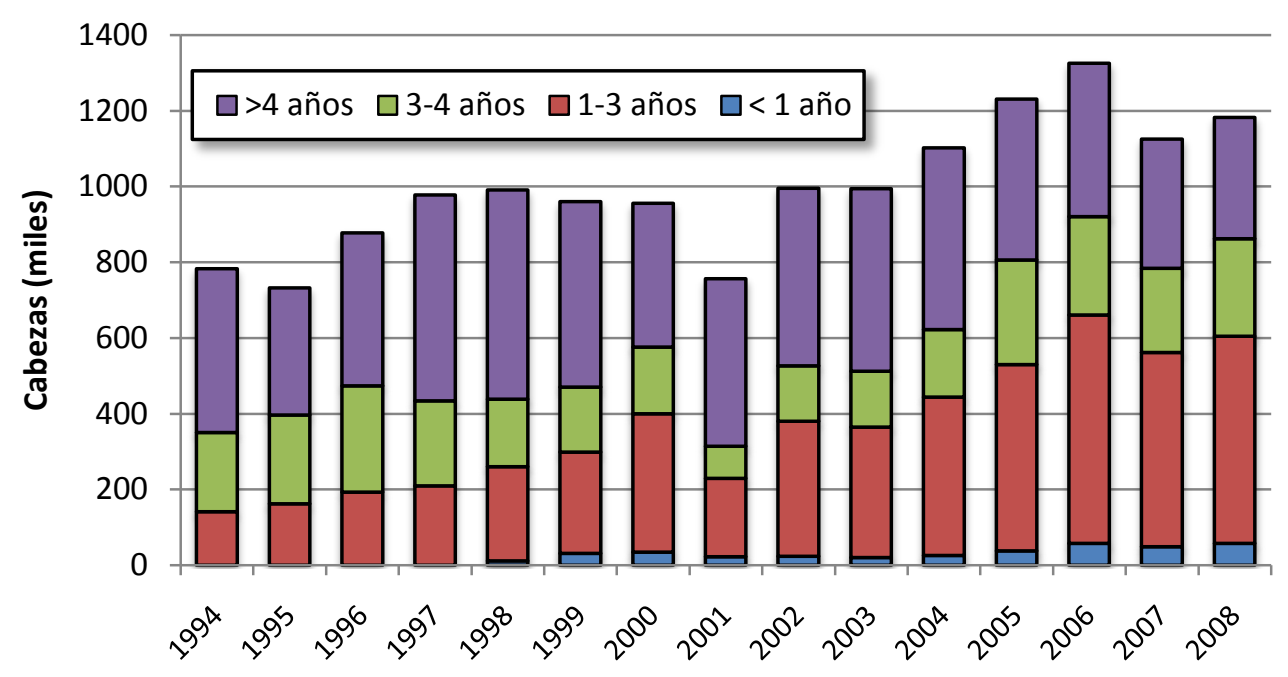

Figura 2. Faena de novillos según edad. Período 1994-2008 Fuente: INAC (2009)

El sacrificio en vacunos ha tenido un crecimiento sostenido desde el año 2001, alcanzando un volumen de 2.2 millones de cabezas en el año 2008. La composición de animales sacrificados es en promedio: $51 \%$ de novillos, $46 \%$ vacas y el restante $3 \%$, terneros y toros.

Parte de esta reducción en la edad de sacrificio, se debe a la incorporación de sistemas de producción intensivos, con pasturas artificiales y suplementación con pienso y/o granos y sub-productos agroindustriales.

Los sistemas de Ciclo Completo representan situaciones intermedias, donde se desarrolla un sistema de cría y se ceba todo o parte de los animales machos y hembras de descarte sobre el campo nativo o sobre pasturas o cultivos forrajeros implantados en las zonas más fértiles del establecimiento. 


\subsubsection{Mejoramiento Genético}

Las razas británicas constituyen el $75 \%$ del rebaño nacional (Hereford, Aberdeen Angus, Shorthorn). Estas son razas precoces, es decir que dependiendo del nivel de alimentación, pueden alcanzar su punto de terminación a cualquier edad permitiendo su comercialización temprana.

Uruguay es un país con una larga tradición en el mejoramiento genético del ganado vacuno, en donde se ha avanzado significativamente en la información disponible para el productor. Numerosas sociedades de criadores se agrupan en la Asociación Rural del Uruguay (ARU), entidad responsable de manejar toda la información oficial del ganado con Pedigree, así como de promover la incorporación de técnicas de selección de reproductores.

Desde principios de los años 90, se realizan evaluaciones genéticas para varias características de valor económico relevante, en las principales razas de ganado de carne del país. El trabajo de la ARU, el INIA y la Facultad de Agronomía en conjunto con las Sociedades de Criadores de las diferentes razas, ha permitido el desarrollo de estas evaluaciones. Como resultado, se dispone de información objetiva del valor de cría de los reproductores vacunos, así como de la estimación precisa del progreso genético realizado.

La Evaluación Genética Poblacional (EGP) consiste en la estimación del mérito o valor genético de los animales pertenecientes a una determinada población (ej. un conjunto de rebaños de una raza dada) considerando tanto la información productiva de estos animales como su genealogía. La mitad del valor genético estimado es igual a la Diferencia Esperada de la Progenie (DEP), definida, para determinada característica, como la diferencia que se espera observar entre el promedio productivo de los hijos de un animal evaluado y el de la progenie de otro animal cuya DEP es cero (Ciappesoni, com pers), siendo ésta la forma en que se presentan las evaluaciones genéticas para vacunos para carne en Uruguay. Actualmente, como resultado de la EGP se presenta información genética para las características peso al nacer, peso al destete, peso a los 15 y 18 meses, habilidad lechera, área de ojo de bife, espesor de grasa subcutánea y circunferencia escrotal. Acompañando esta información se presenta la exactitud (ACC), valor que oscila entre 0 y 1 y representa la precisión en la determinación de cada característica en función del número de registros del individuo evaluado y sus parientes, así como de otros parámetros genéticos (Tabla 2). 
Tabla 2. Ejemplo de un catálogo de reproductores Hereford

\begin{tabular}{c|ccccccccccccc}
\hline NOMBRE & $\begin{array}{c}\text { HBU } \\
\text { CRIADOR }\end{array}$ & NACIDO & ROD. & $\begin{array}{c}\text { HIJOS } \\
\text { HIJAS }\end{array}$ & $\begin{array}{c}\text { ACC } \\
\end{array}$ & & ACC & ACC & ACC & ACC & $\begin{array}{c}\text { AOB } \\
\text { ACC }\end{array}$ & $\begin{array}{c}\text { GRASA } \\
\text { ACC }\end{array}$ & $\begin{array}{c}\text { C.ESC. } \\
\text { ACC }\end{array}$ \\
\hline CEIBAL 1964 & 1384876 & $22 / 09 / 03$ & 1 & 19 & 0.3 & 3.8 & 10.3 & 16.3 & 3.6 & 1.328 & 0.220 & 0.22 \\
$\begin{array}{c}\text { P:ADVANCE } \\
\text { 9012-5 }\end{array}$ & & & & 0 & 0.55 & 0.42 & 0.20 & 0.26 & 0.22 & 0.12 & 0.12 & $\left({ }^{* *}\right)$ \\
\hline
\end{tabular}

Las evaluaciones genéticas y su principal "producto" las DEPs, proveen a los productores de una herramienta uniforme para la comparación de animales a través de distintas categorías, orígenes y años.

\subsection{4. Índices de Selección}

La DEP es una herramienta muy potente en los planes de mejoramiento genético, pero su utilización puede plantear algunas interrogantes:

- Ante un animal con 8 características evaluadas, ¿qué característica se debe hacer pesar más?

- ¿Es preferible un animal con un valor muy alto en una característica aunque en las otras sea bajo, o un animal promedio en todas ellas?

- Y la principal interrogante, ¿qué animal redituará un mayor beneficio económico en un rebaño de determinadas características y en un escenario definido?

Una posible respuesta a estas interrogantes, lo constituye la creación de un índice multicarácter que condense toda la información genética de un animal en un solo valor, en el cual basar las decisiones de selección. En esencia, la teoría de estos índices se basa en que el beneficio de la selección sobre un grupo de individuos es la suma de las ganancias genéticas logradas para varios caracteres.

Un Índice de selección es un método utilizado para hacer selección de manera simultánea por varias características, el cual toma en consideración además de los aspectos genéticos, la importancia económica de las características involucradas. Este índice está conformado esencialmente por dos ecuaciones: en la primera se incluyen las características que se desea mejorar, es decir, las que comprenden el objetivo de selección y se denomina genotipo agregado y la segunda se constituye con las características sobre las que se hace la selección, las cuales se denominan criterios de selección. Cuando se desarrolla un Índice se busca producir el mayor impacto posible en el genotipo agregado al aplicar selección sobre los criterios de selección, lo cual se logra maximizando la correlación entre esas dos 
ecuaciones, por lo cual también es conveniente referir el concepto de respuesta o respuesta directa que es el progreso obtenido en una característica producto de la selección por ella misma (Yáñez, 2005).

Actualmente, en respuesta a la demanda de los productores ganaderos agrupados en las principales sociedades de criadores, el INIA ha comenzado a trabajar en la generación de índices de selección para algunas de las razas más importantes de ganado de carne del país.

Si bien Uruguay es un país relativamente pequeño, existen diferentes sistemas de producción, manejos, objetivos de selección y características de interés económico. Si a esto se le suman las correlaciones genéticas que pueden existir entre caracteres y la dificultad de asignar valor monetario a ciertas características como circunferencia escrotal (efecto indirecto sobre edad a la pubertad en hembras) o grasa de cobertura (dependiendo del objetivo y punto de partida, su aumento puede ser positivo o negativo) se enfrenta un sistema complejo, con un alto número de variables en juego e interactuando fuertemente entre sí.

El enfoque de sistemas es una metodología que permite una aproximación al análisis de este tipo de problemas, donde es necesario considerar un elevado número de variables, combinar datos físicos o biológicos con información sobre sistemas de producción, economía y gerencia; permite determinar interacciones entre estos factores y predecir el desempeño animal ante diferentes escenarios. La simulación dinámica se plantea como la herramienta adecuada para desarrollar un modelo que represente el comportamiento de estos sistemas a lo largo del tiempo, haciendo posible el análisis de los resultados económicos resultantes de la modificación de variables en dichos sistemas. 
CAPITULO III - OBJETIVOS 



\section{CAPÍTULO III - OBJETIVOS}

\subsection{Objetivo general}

El objetivo del presente trabajo es diseñar, desarrollar y validar mediante el enfoque de Dinámica de Sistemas, un modelo de simulación para ser utilizado como herramienta de análisis y de apoyo a la investigación y a la toma de decisiones en los sistemas ganaderos vacunos de Uruguay.

\subsection{Objetivos específicos}

Aunque el desarrollo del modelo es el principal objetivo de esta tesis, la utilidad real del mismo está asociada a las respuestas que de él puedan obtenerse. A continuación se plantean objetivos específicos asociados al desarrollo del modelo y a su posterior uso en el marco de este trabajo, aunque debe tenerse en cuenta que esta herramienta tendrá un ámbito de utilización que trasciende el de esta tesis doctoral.

$\checkmark$ desarrollar ecuaciones para la estimación del crecimiento, cebo y reproducción de vacunos para carne en función de información obtenida a partir de la investigación nacional e internacional

$\checkmark$ generar procedimientos de cálculo para la estimación de la dinámica del rebaño en el corto, mediano y largo plazo

$\checkmark$ validar el modelo desarrollado contrastándolo con información de sistemas reales

$\checkmark$ cuantificar el impacto biológico de variables asociadas al manejo, alimentación, orientación productiva y sus interacciones sobre los sistemas ganaderos

$\checkmark$ determinar niveles óptimos de estas variables para distintos escenarios de producción y mercado

$\checkmark$ evaluar diferentes escenarios de producción/mercado sobre el resultado productivo y económico

$\checkmark$ determinar el impacto productivo y económico asociado a las características vinculadas a la evaluación genética de las principales razas de producción de carne en Uruguay

$\checkmark$ evaluar alternativas de incremento del beneficio económico de la producción vacuna uruguaya 

CAPITULO IV - RLVIISIOON BIBLIOGRAFTCA 



\section{CAPÍTULO IV - REVISIÓN BIBLIOGRÁFICA}

\subsection{El Enfoque de Sistemas}

"Si alguien se pusiera a analizar las nociones y muletillas de moda hoy por hoy, en la lista aparecería "sistemas" entre los primeros lugares. El concepto ha invadido todos los campos de la ciencia y penetrado en el pensamiento y el habla populares y en los medios de comunicación de masas. El razonamiento en términos de sistemas desempeña un papel dominante en muy variados campos, desde las empresas industriales y los armamentos hasta temas reservados a la ciencia pura. Se le dedican innumerables publicaciones, conferencias, simposios y cursos. En años recientes han aparecido profesiones y ocupaciones, desconocidas hasta hace nada que llevan nombres como proyecto de sistemas, análisis de sistemas, ingeniería de sistemas y así por el estilo" (Bertalanffy, 1976).

En un sentido amplio, la Teoría General de Sistemas (TGS) se presenta como una forma sistemática y científica de aproximación y representación de la realidad y, al mismo tiempo, como una orientación hacia una práctica estimulante para formas de trabajo interdisciplinarias.

En las últimas décadas se ha asistido al surgimiento del "sistema" como concepto clave en la investigación científica. La tendencia a estudiar sistemas como entidades más que como conglomerados de partes es congruente con la tendencia de la ciencia contemporánea a no aislar ya fenómenos en contextos estrechamente confinados sino, al contrario, abrir interacciones para examinarlas y examinar segmentos de la naturaleza cada vez mayores. Bajo la bandera de investigación de sistemas (y sus abundantes sinónimos) hemos presenciado también la convergencia de muchos más adelantos científicos especializados contemporáneos. Esta indagación, como tantas otras, está imbricada en un esfuerzo cooperativo que abarca una gama creciente de disciplinas científicas y de ingeniería (Bertalanffy, 1976).

Como paradigma científico, la TGS se caracteriza por su perspectiva holística e integradora, en donde lo importante son las relaciones y los conjuntos que a partir de ellas emergen. En tanto práctica, la TGS ofrece un ambiente adecuado para la interrelación y comunicación fecunda entre especialistas y especialidades (Arnold y Osorio, 1998).

Es un método de investigación, una forma de pensamiento que hace énfasis sobre el sistema total, esforzándose por optimizar su eficacia, en lugar de hacerlo únicamente sobre los subsistemas que lo componen. Se soporta principalmente en la visión de no ser reduccionista en su análisis y se lo considera un medio para solucionar problemas de cualquier tipo (Murdick y Munson, 1988). 
Bajo este paradigma se desarrollaron diversas tendencias, entre las que estacan la cibernética, la teoría de la información y la dinámica de sistemas (Ramos, 2008):

- La cibernética es una ciencia interdisciplinaria que trata de los sistemas de control y de comunicación de los sistemas humanos y mecánicos, incluyendo los ordenadores.

- Teoría de la información es una rama de la teoría matemática de la probabilidad y la estadística que estudia la información y todo lo relacionado con ella: canales, compresión de datos, criptografía y temas relacionados.

- La Dinámica de Sistemas puede ser útil en situaciones donde actores se enfrentan a sistemas complejos, con muchas partes interactuando, de modo no-lineal y con relaciones temporales complejas y causalidades circulares.

Si bien el campo de aplicaciones de la TGS no reconoce limitaciones, sus raíces están en el área de los sistemas naturales (organismos) y en el de los sistemas artificiales (máquinas) (Ramos, 2008).

Los objetivos originales de la Teoría General de Sistemas son los siguientes:

a. Impulsar el desarrollo de una terminología general que permita describir las características, funciones y comportamientos sistémicos.

b. Desarrollar un conjunto de leyes aplicables a todos estos comportamientos

c. Promover una formalización (matemática) de estas leyes.

La Teoría General de Sistemas se basa en dos pilares básicos: los aportes semánticos y los aportes metodológicos. En lo que respecta a los primeros, las sucesivas especializaciones de las ciencias obligan a la creación de nuevas palabras, éstas se acumulan durante sucesivas especializaciones llegando a formar casi un verdadero lenguaje que sólo es manejado por los especialistas. De esta forma, surgen problemas al tratarse de proyectos interdisciplinarios, ya que los participantes del proyecto son especialistas de diferentes ramas de la ciencia y cada uno de ellos maneja una semántica diferente.

Para solucionar estos inconvenientes, la Teoría de los Sistemas pretende introducir una semántica científica de utilización universal (Yourdon, 1993).

\subsubsection{Sistema}

En las definiciones más corrientes se identifican los sistemas como conjuntos de elementos y las relaciones entre ellos y el entorno. 
El aspecto más importante del concepto de sistema es la idea de un conjunto de elementos interconectados para formar un todo, que presenta propiedades y características propias que no se encuentran en ninguno de los elementos aislados. Es lo que se denomina emergente sistémico: una propiedad o característica que existe en el sistema como un todo y no en sus elementos particulares.

La delimitación de un sistema depende del interés de la persona que pretende analizarlo. El sistema total está representado por todos los componentes y relaciones necesarios para el logro del objetivo planteado por quien lo diseña, dado cierto número de restricciones. El objetivo del sistema total define la finalidad para la cual fueron ordenados todos los componentes y relaciones del sistema, mientras que las restricciones son limitaciones que se introducen en su operación y permiten hacer explícitas las condiciones bajo las cuales deben operar. Los componentes necesarios para la operación de un sistema total se denominan subsistemas, formados por la unión de nuevos subsistemas más detallados. Así, tanto la jerarquía de los sistemas como el número de subsistemas dependen de la complejidad intrínseca del sistema total (Ramos, 2008).

Cabe aclarar que los elementos o partes que componen el sistema no se refieren al campo físico (objetos) sino más bien al funcional. De este modo, los elementos o partes pasan a ser funciones básicas realizadas por el sistema. Dichos elementos pueden ser enumeradas en: entradas, procesos y salidas.

- Entradas

Las entradas son los ingresos del sistema que pueden ser recursos materiales, recursos humanos o información. Ellas constituyen la fuerza de arranque que suministra al sistema sus necesidades operativas.

- Proceso

El proceso es lo que transforma una entrada en salida. Como tal puede ser una máquina, un individuo, una computadora, un producto químico, una tarea realizada por un miembro de la organización, etc.

No siempre es necesario conocer la forma en que se efectúa la transformación de las entradas en salidas. Si se conoce, este proceso se denomina "caja blanca". No obstante, en la mayor parte de las situaciones no se conoce en detalle este proceso debido a la complejidad de esa transformación. En ese caso la función de proceso se denomina "caja negra". La caja negra se utiliza para representar a los sistemas cuando no se conocen los elementos o cosas que componen al sistema o proceso, pero se sabe que a determinadas 
entradas corresponden determinadas salidas y con ello se puede inducir, presumiendo que ante determinados estímulos, las variables funcionarán en cierto sentido.

Salidas

Las salidas de los sistemas son los resultados que se obtienen de procesar las entradas. Al igual que estas últimas, las salidas pueden adoptar la forma de productos, servicios e información. Las mismas son el resultado del funcionamiento del sistema o alternativamente el propósito para el cual éste existe.

Las salidas de un sistema pueden convertirse en entrada de otro que la procesará para convertirla en otra salida, repitiéndose este ciclo indefinidamente.

Relaciones

Las relaciones son los enlaces que vinculan entre sí a los objetos o subsistemas que componen un sistema complejo.

Variables

Cada sistema y subsistema contiene un proceso interno que se desarrolla sobre la base de la acción, interacción y reacción de distintos elementos que deben necesariamente conocerse. Dado que dicho proceso es dinámico, suele denominarse como variable a cada elemento que compone o existe dentro de los sistemas y subsistemas.

Pero no todas las variables tienen el mismo comportamiento sino que, por el contrario, según el proceso y las características del mismo, asumen comportamientos diferentes dentro del mismo proceso de acuerdo al momento y las circunstancias que las rodean.

Cuando las variables no tienen cambios ante alguna circunstancia específica, toman el nombre de parámetros.

Cuando las variables activan a las demás y logran influir decisivamente en el proceso para que este se ponga en marcha, se llaman operadores (Yourdon, 1993).

\subsubsection{Sistemas dinámicos}

La dinámica de sistemas es una teoría que trata la aproximación a la modelización de la dinámica de sistemas complejos, tales como las poblaciones biológicas o los sistemas económicos, en los que las partes interaccionan activamente unas con otras. Sus fundamentos datan de principios de la década de 1960 por Jay Forrester, de la MIT Sloan School of Management con el establecimiento del MIT System Dynamics Group. 
El término dinámico se emplea por oposición a estático, para expresar el carácter cambiante de aquello que es adjetivado con este término. Al hablar de dinámica de un sistema, se alude a que las distintas variables que se pueden asociar a sus partes, sufren cambios a lo largo del tiempo como consecuencia de las interacciones que se producen entre ellas (García, 2003).

Lo que distingue a la dinámica de sistemas de otras aproximaciones al estudio de los mismos problemas, es el uso de bucles de realimentación. La construcción de modelos por la dinámica de sistemas parte de la distinción esencial entre variables de nivel y flujos. Con estos elementos se edifican modelos que describen sistemas internamente conectados por bucles de realimentación; sistemas que expresan el carácter no lineal que se suele encontrar en los problemas del mundo real (García, 2003).

\subsection{El análisis de sistemas en Producción Animal}

El método científico, al ser aplicado en ciencia animal, tiende a la simplificación o reducción del número de variables involucradas en un determinado proceso, de forma que el mismo pueda ser examinado en detalle. Este enfoque es muy útil a las subdisciplinas dentro de la ciencia animal, pero puede tener el efecto adverso sobre la comprensión global del sistema de producción, manteniéndola en un plano subjetivo. La idea que ha prevalecido es la de que si se analiza cada una de las "partes" con suficiente nivel de detalle, el "todo" de alguna manera cuidará de sí mismo (Cartwright, 1979).

La teoría sistémica constituyó un cambio radical en la visión y el análisis de la realidad. Hasta su aparición cualquier fenómeno era estudiado aplicando el método cartesiano, es decir mediante principios de reduccionismo. Esto es, su análisis y desglose en las partes más elementales, de modo que al ir profundizando en el estudio de los fenómenos se asiste a un proceso de especialización, con la consiguiente pérdida de visión de conjunto, y el alejamiento del problema real inicial (Ruiz y Oregui, 2001). Los principios de Descartes: no dar como verdad lo que no se conoce como tal, dividir los problemas en partes más simples a resolver, estudiarlos comenzando por lo más simple, exhaustividad del desmembramiento, son sustituidos por el principio de la pertinencia, el del globalismo, que supone que el objeto a conocer por nuestra inteligencia es una parte inmersa y activa en el seno de un gran todo; por el precepto teleológico (¿cuál es el proyecto o finalidad?) o por el de la agregatividad según el cual toda representación es simplificadora de la realidad (Olaizola y Gibon, 1997).

Frente a tal actitud reduccionista, la teoría sistémica aporta un enfoque expansionista según el cual todos los objetos y acontecimientos son parte de otros mayores. Por tanto, 
como un sistema es más que la suma de sus componentes, no bastaría con estudiar cada uno de éstos de manera individualizada y agregarlos después, sino que sería más lógico llevar a cabo un trabajo multidisciplinar (Ruiz y Oregui, 2001).

El fundamento esencial de este enfoque es que el comportamiento de un sistema no puede ser entendido a través de la comprensión de sus elementos en forma aislada. Desde un punto de vista sistémico, la respuesta a alteraciones sobre la unidad de producción debe ser estudiada mediante la evaluación del impacto de cada decisión sobre el funcionamiento del sistema en su conjunto, es decir sobre su comportamiento. Se postula que dicho comportamiento está determinado por las interacciones entre sus elementos y no es una respuesta directa a la alteración de un componente aislado (Feldkamp, 2004).

En el desarrollo de los aspectos conceptuales sistémicos en producción animal, se destacan los aportes de investigadores franceses en la década de los ' 80 congregados en el Departamento de Systèmes Agraires et Développement (SAD) del INRA Tolouse. También en esa época en el Reino Unido un equipo de investigadores comienza a desarrollar trabajos sobre "farming systems" (Olaizola y Gibon, 1997).

Aunque el concepto de sistema en producción animal pueda ser inespecífico y en consecuencia susceptible de ser aplicado a cualquier ámbito de actividad, los numerosos autores que han aportado al desarrollo de esta teoría, aunque desde ópticas diferenciadas, destacan aspectos que podrían considerarse básicos y que son comunes a todas las aproximaciones. Entre éstos (Dent y Blackie, 1979) se destacan:

- Un sistema puede ser plenamente definido por una serie de elementos o entidades identificables e interrelacionadas entre sí y por los límites de su autonomía organizacional.

- Es una estructura jerárquica que comprende un número de subsistemas definidos de manera autónoma, a la vez que cada uno de ellos engloba a otros de rango inferior e igualmente autónomos.

- Sus principales características emergen con el paso del tiempo, por lo cual su comprensión requiere la consideración explícita de dicha variable.

- Los sistemas abiertos son sensibles al entorno o ambiente dentro del cual existen, el cual además de ser cambiante es usualmente impredecible.

El análisis de los sistemas desde esta perspectiva consiste en el estudio de las partes a través del conocimiento del todo, enfatizando sobre las relaciones que se establecen entre los distintos elementos que lo componen (Ruiz y Oregui, 2001).

Las investigaciones realizadas bajo este marco conceptual se dirigen fundamentalmente a profundizar en el estudio del funcionamiento de las explotaciones mediante el análisis de subsistemas, el análisis de las prácticas de los agricultores y por el enriquecimiento progresivo del concepto de "sistema-familia-explotación". Este concepto 
representa uno de los principales aportes de la escuela francesa de sistemistas (Ruiz y Oregui, 2001), y puede ser definido como un todo organizado que no responde a criterios simples y uniformes de optimización y es a partir de la visión que tienen los agricultores de sus objetivos y de su situación, desde donde se pueden comprender sus decisiones y sus necesidades (Olaizola y Gibon, 1997).

Este enfoque es también aplicable a los sistemas ganaderos de Uruguay, especialmente los extensivos, que en su mayoría representan sistemas de produccióndecisión de índole familiar, y cuya heterogeneidad ha determinado la realización de estudios de agrupación de tipos homogéneos de funcionamiento (tipologías) (Ferreira, 1997).

Las explotaciones así definidas son susceptibles a un elevado número de factores de índole biofísica, sociológica, económica, ecológica y política, constituyendo un entorno sumamente dinámico, lo que lleva a los elementos que componen el sistema a alcanzar una serie de equilibrios inestables que hace imposible la descripción del mismo en términos mecánicos ni mediante relaciones lineales.

En el contexto del sistema familia-explotación y a un nivel individual, la actividad ganadera constituye un subsistema dentro del mismo. Engloba al conjunto de instalaciones y técnicas que permiten la obtención de productos de origen animal en condiciones compatibles con el objetivo del ganadero y en el marco de las restricciones y limitaciones propias de cada explotación. Dependiendo de su orientación productiva, puede constituir un subsistema único o estar combinado con otro agrario (Ruiz y Oregui, 2001).

En ganadería vacuna, los componentes de la producción de carne se encuentran interrelacionados generalmente en forma no lineal y por lo tanto, cuando se busca evaluar el efecto de diferentes alternativas sobre el resultado productivo o económico del sistema, dichos componentes deben ser abordados en forma simultánea e integral. El estudio de procesos de producción integrados requiere de un esfuerzo interdisciplinario, tanto dentro del campo de la ciencia animal como entre ésta y otras disciplinas. La eficiencia productiva es una función de factores tradicionalmente estudiados en nutrición, fisiología, genética, producción de pasturas y campo nativo, economía y marketing. Aunque esta interacción se ha tenido en cuenta, la complejidad de la producción de carne es tal, que si no se logra una aproximación formal, disciplinada y ordenada, es difícil esperar resultados óptimos consistentes.

Los pasos involucrados en la aplicación del análisis de sistemas son (Heady, 1976):

1. Especificación del problema y definición de objetivos

2. Definición de los límites del sistema y el nivel de detalle a modelar 
3. Formulación del modelo en término de sus componentes y las relaciones funcionales entre ellos

4. Recolección de datos para caracterizar cuantitativamente los componentes y sus relaciones

5. Especificación detallada del modelo en forma cuantitativa

6. Programación del modelo en lenguaje computacional

7. Validación del modelo contra información experimental y otras fuentes reales de conocimiento

8. Experimentación o simulación de resultados bajo diferentes escenarios

9. Análisis de los resultados

Independientemente de los resultados, el hecho de establecer objetivos, definir la función objetivo y conceptualizar y validar el modelo, puede ser una experiencia provechosa y reveladora para el investigador, proporcionándole la oportunidad de organizar su conocimiento y profundizar su comprensión del sistema que de otra forma es muy difícil alcanzar (Cartwright, 1979).

En lo que respecta a la aplicación de la teoría de sistemas en investigación, al desarrollo del análisis sistémico y a su aplicación a la producción animal, se han producido paralelamente a la visión que la sociedad actual tiene de una agricultura no relacionada exclusivamente con la generación de alimentos. Esto se ha reflejado en la existencia de una importante pluralidad de líneas de investigación, entre las que se destacan (Ruiz y Oregui, 2001):

$\checkmark$ Implicaciones de la ganadería como agente de conservación medioambiental (deforestación, protección de incendios, etc.) o de su degradación (sobreexplotación, erosión, etc.)

$\checkmark$ Contaminación de recursos hídricos originada por sistemas de producción intensivos o actividades ligadas a éstos

$\checkmark$ Problemática del bienestar animal, especialmente en el caso de sistemas de producción intensivos

$\checkmark$ Papel de la actividad ganadera en proyectos de desarrollo rural como elemento de valorización de zonas desfavorecidas

$\checkmark$ Obtención de productos de calidad

Todo ello lleva a que la investigación deba desarrollar mecanismos de descripción de los sistemas que permitan analizar su posible evolución con relación a las modificaciones del entorno. El interés de la investigación de estos sistemas mediante la construcción de modelos radica en las enormes posibilidades que alberga a la hora de considerar de manera 
simultánea una gran cantidad de variables que definen las características del sistema y su entorno (Ruiz y Oregui, 2001).

\subsection{Clasificación de modelos}

Brockington (1979) realiza una simplificación de la clasificación general de modelos de Forrester adecuándola a las condiciones de la producción animal (Figura 3).

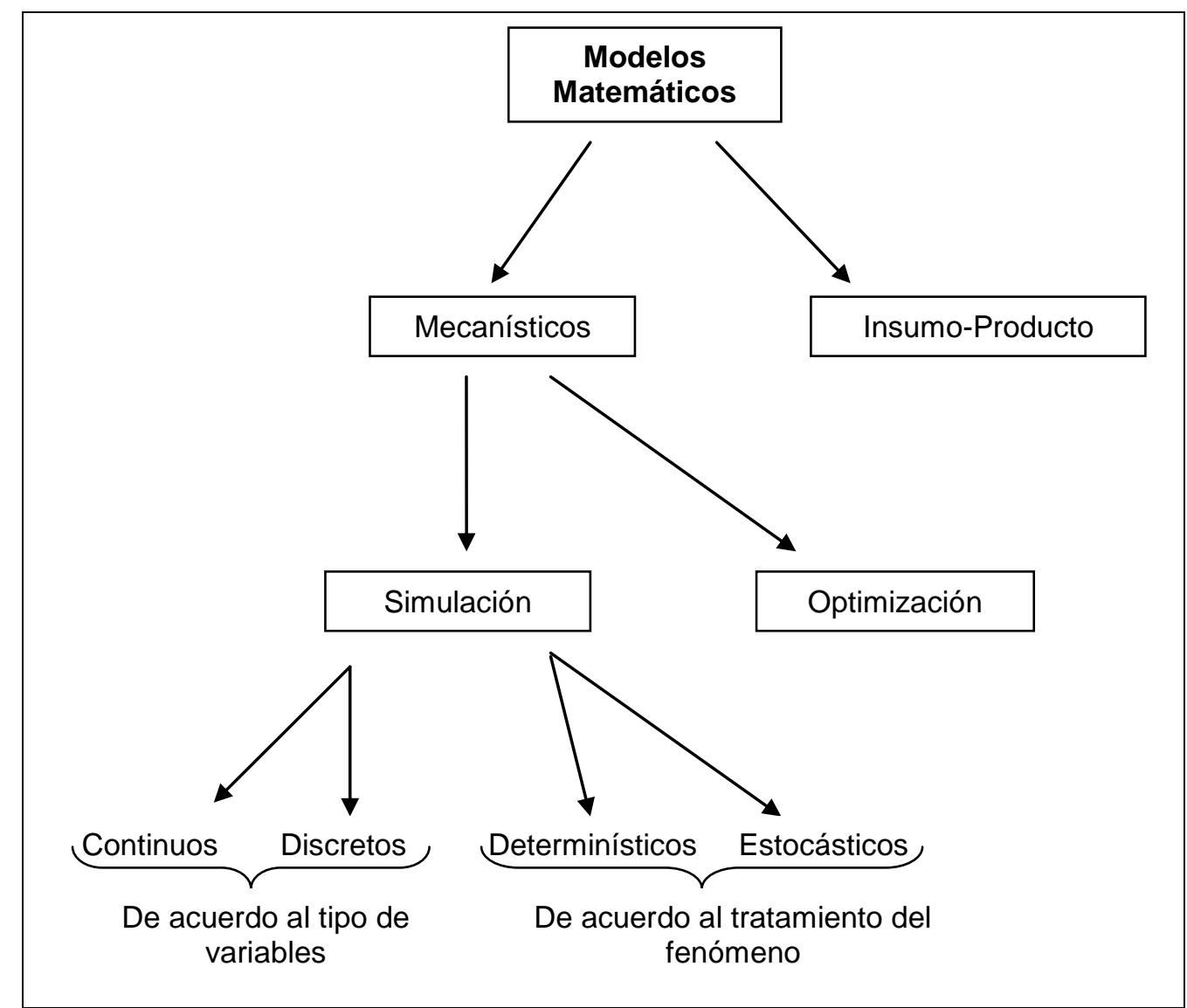

Figura 3. Clasificación modificada de modelos para sistemas agropecuarios basada en la clasificación realizada por Forrester

Fuente: Brockington (1979)

Los modelos de insumo-producto representan la forma más elemental desde el punto de vista biológico aún cuando matemáticamente pudieran ser muy complejos. En estos modelos se distingue la entrada, la caja negra que representa el sistema y la salida. Esta última es producto de la actividad del proceso que se estudia mediante el modelo: en esta modelación no se conoce absolutamente nada acerca de los procesos internos del sistema y es por esta razón que reciben también el nombre de caja negra. El uso de estos modelos implica un objetivo más restringido que la comprensión del sistema. Los resultados de estos 
modelos son tan puntuales que para lograr respuestas más flexibles es necesario introducirse en modelos más complejos que tengan un mayor grado de elaboración racional. Por este camino se llega a los modelos mecanísticos, los cuales se fundamentan en principios e hipótesis. Los modelos mecanísticos tienen un significado biológico que no se puede lograr con uno de insumo-producto, pero como contrapartida este último grupo de modelos son más precisos.

De acuerdo a los propósitos perseguidos y a las técnicas empleadas, estos modelos se pueden clasificar en modelos de simulación y de optimización. Los modelos de simulación constituyen una técnica más adecuada cuando se desea conocer la producción a obtener con los recursos que se cuenta en el sistema. Por el contrario, cuando lo que interesa es usar la combinación de recursos más eficientes para un nivel dado de producción, los modelos de optimización serán los más adecuados. En general, el problema que se presenta en la realidad es más bien del primer tipo, motivo por el cual la simulación ha sido ampliamente usada. No obstante, hoy en día ya existen estudios para trabajar con ambos tipos de modelos en forma conjunta (Brockington, 1979).

Otra clasificación discrimina entre modelos empíricos y modelos mecanísticos. Dicha clasificación se basa en el distinto grado en que los modelos describen los mecanismos funcionales subyacentes de los procesos de interés. Existe desacuerdo y a veces competencia entre las dos respectivas escuelas de pensamiento: la empírica asegura que éstos, basados en datos, tienen un mayor valor práctico debido a la alta complejidad de los fenómenos bajo análisis. Los racionalistas se basan en el mayor potencial cognitivo y predictivo de los modelos mecanísticos, capaces de generar nuevos conocimientos. La realidad es que no hay modelos puramente mecanísticos o empíricos y ambos han encontrado diversas y exitosas implementaciones y desarrollos en diferentes áreas científicas (Ter-Mikaelian et al., 1997).

También es posible tratar los modelos de simulación dentro del campo de los modelos estocásticos o determinísticos (Brockington, 1979). Son modelos determinísticos aquellos que hacen predicciones definidas a partir de variables determinadas; es decir aquellos en los que no entran en juego procesos aleatorios (Bernués et al, 1995). Se conoce como modelos estocásticos los que introducen elementos de incertidumbre y de aleatoriedad en el comportamiento del sistema (Ruiz y Oregui, 2001).

Los sistemas agropecuarios, dada la variabilidad genética y edáfica y la influencia de variables exógenas aleatorias como la lluvia, la temperatura, etc., deberían tratarse como modelos estocásticos, aunque en muchas ocasiones la falta de información adecuada hace 
que la mayor parte de los estudios sean planteados en forma determinística, en virtud de que se desconoce la variabilidad de la muestra (Brockington, 1979).

\subsubsection{Modelos de simulación}

La investigación en producción animal ha estado asociada a la investigación en sistemas a diferentes niveles de agregación. El término sistema se aplica a un grupo de objetos interrelacionados que debido a múltiples interacciones y cambios en el tiempo, es demasiado complejo de comprender, sin la ayuda de algún formalismo descriptivo. Este formalismo descriptivo es el modelo (Pittroff y Cartwright, 2002).

El uso de la simulación para el análisis de sistemas es usado como un procedimiento estándar en muchas áreas de la agricultura, debido a las numerosas ventajas que conlleva su utilización (Dent y Blackie, 1979):

$\checkmark$ posibilita el estudio de sistemas en situaciones en que la experimentación tradicional sería impracticable, muy costosa o perturbadora del propio sistema bajo análisis;

$\checkmark$ hace posible la creación y exploración del funcionamiento de sistemas que no existen en el mundo real;

$\checkmark$ permiten el estudio de efectos a largo plazo al ser el investigador quien fija el horizonte temporal;

$\checkmark$ su desarrollo obliga al investigador a examinar el sistema en forma objetiva, lo que supone llevar adelante una revisión crítica y exhaustiva de sus conocimientos.

Estas características hacen de los modelos de simulación una herramienta adecuada en la evaluación técnica y económica de posibles estrategias de gestión tanto a nivel de la explotación individual como a escala regional, y por tanto pueden constituir un valioso apoyo en los procesos de toma de decisiones (Bernués et al, 1995).

Puesto que la tendencia a la especialización continúa en forma sostenida, la necesidad de integración de los resultados de la investigación y la necesidad de traducir conocimiento empírico en entendimiento cuantitativo, es cada vez más evidente. Pittroff y Cartwright (2002) sostienen que la falta de progreso en términos de conocimiento funcional integrado en disciplinas aisladas (nutrición, fisiología del crecimiento, fisiología reproductiva, inmunología) es lo que obstaculiza el desarrollo y la aplicación de modelos. Por otro lado, algunas carencias de conocimientos identificadas por modeladores muchas veces no 
encuentran eco en la investigación respecto a diseñar experimentos que den respuesta a dichas interrogantes. Paralelamente, la tendencia actual hacia la globalización en todas las áreas de negocios, incluidos los negocios agropecuarios, ha significado un aumento de la competencia, tanto en intensidad como diversidad. Por tal motivo se debe disponer de métodos y herramientas con las cuales identificar debilidades y fortalezas de sus sistemas productivos, de forma de ir adaptándose a un medio ambiente altamente dinámico y de dar sentido estratégico a la dirección de la empresa, para enfrentar de manera exitosa la competencia de los diferentes mercados (Aguilar et al., 2002).

Un modelo de simulación desarrollado con el objetivo de estudiar y resolver los problemas expuestos, se transforma en una poderosa herramienta para enfrentar el medio cambiante, entorno en el que se desarrollan los sistemas de producción animal, donde hay que considerar un alto número de factores (genéticos, ambientales, nutricionales y sanitarios) que inciden en su productividad. El uso de modelos de simulación que permiten predecir los potenciales de producción de los sistemas bajo diferentes escenarios productivos, permite evaluar técnica y económicamente diferentes alternativas, reduciéndose de esta manera el tiempo que lleva la experimentación a nivel de campo.

El nuevo paradigma ya no es producir más o producir en forma sencillamente rentable, es producir en armonía con el medio ambiente y creando valor para la empresa pecuaria. Tal paradigma hoy en día sólo puede ser resuelto y evaluado con la ayuda de modelos de simulación predictivos (Aguilar et al, 2002).

\subsubsection{Modelos de optimización}

La creación de valor en cualquier empresa está directamente relacionada con el uso adecuado de los recursos y con su capacidad para implementar y evaluar innovaciones que le creen una ventaja competitiva en el mercado. Tal situación es posible representarla con modelos matemáticos y buscar su óptimo mediante diferentes técnicas numéricas o matemáticas.

La optimización de sistemas de producción pecuaria mediante modelos matemáticos ha tenido gran desarrollo en las últimas décadas, destacándose una gran cantidad de modelos matemáticos propuestos y una evolución de la/s función/es objetivo a optimizar (Aguilar et al, 2002).

Los modelos bioeconómicos de optimización se han aplicado en casi todas las áreas relacionadas con producción agrícola y animal. Sin embargo, su uso y aplicación se restringe a sistemas de gran tamaño, cuando el sistema modelado presenta variables de 
decisión con gran cantidad de interrelaciones no lineales. Los métodos evolutivos han sido parte de la respuesta a este problema así como la interacción entre modelos de simulación que proporcionan datos de diferentes alternativas productivas a modelos de toma de decisiones multicriterio (Herrero et. al., 1999).

Desde esta perspectiva, los modelos de simulación soslayan la gran mayoría de los problemas de los modelos matemáticos de optimización pero no son capaces de buscar óptimos: es la parte no estructurada de la solución que los usuarios del modelo deben resolver con pruebas o experimentos que los aproximen a la mejor solución.

La premisa principal cuando se utiliza un modelo de optimización, es que se debe confrontar si el problema se acomoda a la estructura del modelo que se utiliza. Ello es absolutamente opuesto al planteamiento de un modelo de simulación, que por definición se diseña y construye en torno a un objetivo, lo cual asegura que el modelo se diseña adaptándolo a las condiciones del problema (Aguilar et al, 2002).

Esta característica asegura que un modelo de simulación validado representa el problema del sistema en estudio. Es posible ver que desde la perspectiva de fidelidad del modelo con el sistema estudiado, los modelos de simulación presentan una ventaja por definición. Su desventaja está en que el modelo debe ser validado, o sino sólo será una colección de ecuaciones matemáticas que no se sabe si representan el sistema estudiado (Aguilar et al, 2002).

Para que sea más provechoso, el procedimiento de optimización debería mostrar una región (en lugar de un punto) donde se encuentra la solución óptima. No parece lógica una única solución con modelos de producción animal, considerando que estos modelos se basan en una serie de supuestos difíciles de reconstruir en la práctica. La situación más probable es que los valores de las variables utilizadas en el modelo no sean exactamente los mismos que los de la realidad, puesto que estos están afectados por factores de riesgo como condiciones climáticas, las cuales no pueden ser exactamente predeterminadas (Joandet y Cartwright, 1975).

\subsection{Estructura y límites de los modelos}

Los modelos pueden describir los sistemas de producción desde diferentes puntos de vista. Un sistema de producción de ganado puede ser visto como un sistema de pastoreo con los animales como un factor externo influenciando la dinámica de una pastura (modelos de manejo de pastoreo). Se puede describir como un sistema de cría en donde se aplican programas de mejoramiento genético (modelos de mejoramiento genético). Un sistema 
ganadero puede considerarse como parte de un establecimiento agrícola-ganadero, es decir como un subsistema pecuario compitiendo con otros subsistemas por la asignación de recursos (modelo de gestión de establecimientos). La producción animal puede ser conceptualizada como una población animal agrupada en unidades de gestión (modelo rebaño). Los sistemas ganaderos pueden agregarse en un sector de la economía nacional para planificación de políticas en un contexto macroeconómico (modelo sectorial).

Los límites específicos y el nivel de resolución determinan en gran medida la capacidad analítica de un modelo y deben ser definidos en conformidad con los objetivos del modelo (Joandet y Cartwright, 1975).

Uno de los modelos bioeconómicos de mayor trascendencia en las últimas décadas es el desarrollado por Sanders y Cartwright $(1979 a, b)$ en la Universidad de Texas A\&M (USA). Es un modelo determinístico enfocado a simular producción de carne en vacunos, bajo un amplio rango de situaciones productivas y ambientes y con diferentes genotipos. Para simular el desempeño de los animales, el modelo combina tres diferentes subrutinas que gestionan el crecimiento, la reproducción y la mortalidad. En la subrutina de crecimiento se especifican las características del alimento en cuanto a calidad y disponibilidad, las cuales en interacción con el tamaño del animal, grado de madurez, estado o condición corporal, estado fisiológico y potencial genético, determinan el consumo y el desempeño en crecimiento y, en el caso de vacas lactantes, en producción de leche. Estos cálculos se realizan en una base mensual.

Tomando como base este trabajo, muchos autores han realizado reestructuras del mismo para ajustarlo o adecuarlo a situaciones particulares. Bourdon y Brinks (1987a) analizan los efectos del crecimiento, la producción de leche y el sistema de producción sobre la eficiencia biológica y económica de la producción de carne en pastoreo en Colorado, USA. Algunas modificaciones significativas fueron la especificación del potencial genético del animal mediante tres parámetros (peso al nacer, peso al año y peso adulto), en lugar de utilizar el peso adulto únicamente. La subrutina de consumo también fue reestructurada para permitir la ingestión preferente de ciertos alimentos. El valor del porcentaje de grasa corporal usado como indicador de tamaño adulto fue de $13 \%$ en contraste con el de $25 \%$ utilizado por Sanders y Cartwright en el modelo original. Además de éstos, se realizaron algunos otros ajustes relativos a la facilidad de parto, heterosis para producción de leche y requerimientos de mantenimiento en situaciones de bajas temperaturas. 


\subsection{Enfoques adoptados para la modelación de los procesos}

La creación de un modelo como el presentado en los objetivos de este trabajo, requiere de la integración de un alto número de subprocesos o componentes del sistema a simular. Por ello, es necesario conceptualizar matemáticamente los procesos relativos al crecimiento y cebo, la reproducción y la dinámica del rebaño. A continuación se presenta una breve revisión de enfoques sobre la modelación matemática de estos procesos.

\subsubsection{Crecimiento y desarrollo}

\subsubsection{La curva de crecimiento}

Si el peso de un animal es graficado en función de su edad, se observa una curva sigmoide (Figura 4).

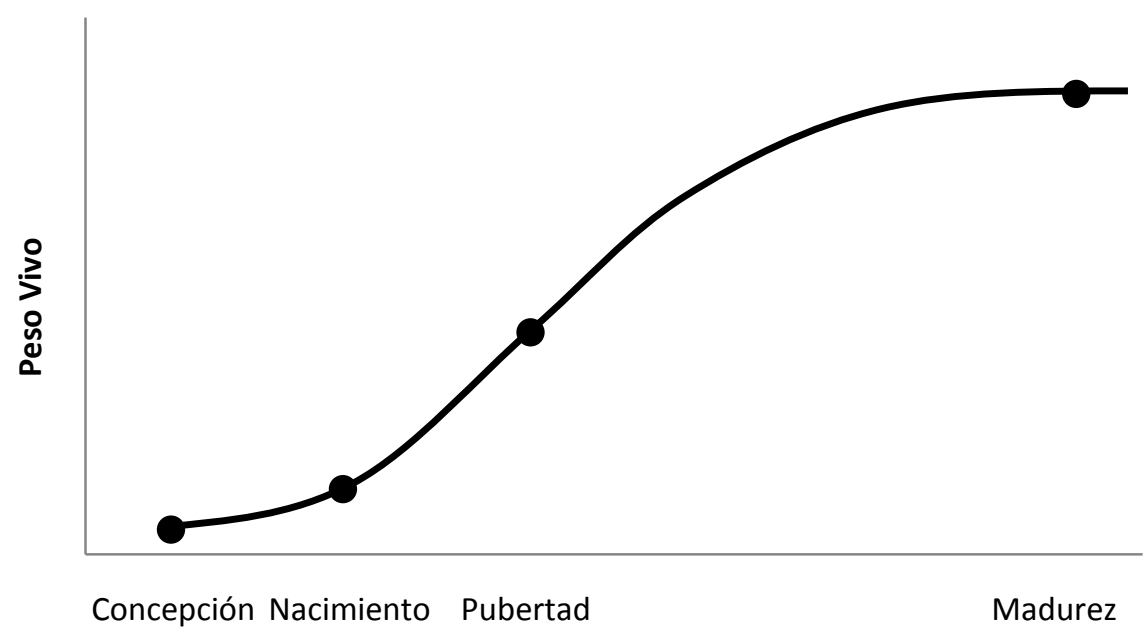

Figura 4. Relación entre el peso de un animal y su edad.

Fuente: Adaptado de Warriss (2000)

El peso aumenta lentamente en primera instancia, la tasa de aumento alcanza un máximo y luego disminuye en animales adultos. Esta curva de crecimiento puede ser derivada para la mayoría de los animales. El punto de inflexión, donde la curva cambia de forma cóncava a convexa es definido como el punto máximo de crecimiento. Los alimentos consumidos por el animal se utilizan para dos procesos: el mantenimiento de los tejidos y el crecimiento de nuevo tejido; como el crecimiento es más acelerado en el punto de inflexión, también es más eficiente, ya que la proporción del total de energía disponible para el animal 
que se utiliza para el mantenimiento de su cuerpo es relativamente menor. En cualquier momento, el crecimiento es determinado por el balance entre fuerzas de aceleración y retraso, de tal forma que el punto de máximo crecimiento es donde las dos fuerzas se encuentran en equilibrio. Esto ocurre en la pubertad en mamíferos, momento en el cual el animal normalmente se encuentra aproximadamente a un $30 \%$ del peso adulto (Warriss, 2000).

También es usual describir el crecimiento mediante la ecuación de Brody (1945) el cual se vale de una función exponencial negativa (la tasa de crecimiento es siempre decreciente). Según este autor, el peso de un animal ( $W$ a una determinada edad $(t)$ puede ser descrito de la siguiente forma:

$W_{t}=A \cdot\left(1-B \cdot e^{-k \cdot t}\right)$

Donde:

$A$ es el peso adulto del animal

$B$ es un parámetro tiempo-escalar

$k$ es un parámetro asociado al crecimiento

$t$ es la edad del animal

El peso adulto $(A)$, es definido como el peso vivo alcanzado por un animal cuando ha completado su desarrollo óseo y su condición corporal se encuentra en el centro del rango de variación o score ${ }^{1}$. El valor de $A$ entonces, será mayor por ejemplo en razas más grandes como Charolais respecto a Hereford, en machos enteros (sin castrar) frente a novillos (machos castrados) y en éstos a su vez respecto a hembras de la misma raza (CSIRO, 2007).

Koots y Gibson (1998) realizaron estimaciones de estos parámetros utilizando 218 registros de peso de 103 vacas Hereford provenientes del Elora Beef Research Center de la Universidad de Guelph (Canadá). Para estos animales se estimaron los valores de $A=589 \pm$ $4 \mathrm{~kg}$ y el parámetro $\mathrm{k}=0.0027 \pm 0.0001$. El parámetro $B$ se estimó como la diferencia entre $A$ y el peso promedio al nacer expresado como proporción de $A(B=(589-37.9) / 589=0.936)$, puesto que cuando $\mathrm{t}=0, \mathrm{~W}_{\mathrm{t}}=$ peso al nacer. El valor de $B$ encontrado es similar al del rango de 0.921 a 0.933 reportado para vacas cruza Aberdeen-Angus por Montano-Bermúdez y Nielsen (1990), mientras que el valor hallado para $k$ se encuentra fuera del rango de 0.0019 a 0.0022 obtenido en el mismo trabajo. Los autores consideran que el alto valor encontrado para este parámetro $(0.0027)$ podría ser debido al alto régimen alimenticio de estos animales, que determinó elevados índices de condición corporal para este grupo de vacas.

\footnotetext{
${ }^{1}$ La escala de condición corporal utilizada en Uruguay consta de 8 categorías, donde 1 es el animal muy flaco y 8 es un animal excesivamente gordo. Se asume que el centro de la escala correspondería a un animal con una condición corporal de 4.5
} 
Sanders y Cartwright (1979b) utilizan una ecuación similar, definiendo la variable $k$ en 0.0024, mientras que Bourdon y Brinks (1987a) modifica el modelo de los autores anteriores asumiendo un crecimiento lineal hasta el año de edad (pubertad), tras lo cual se ajusta la curva post-inflexión de Brody (1945) desde pubertad a madurez. El parámetro $k$ de esta curva es estimado como:

$$
k=\frac{Y W-B W A}{365 \cdot(A-Y W)}
$$

\section{Donde:}

$Y W=$ peso al año de edad $B W A=$ peso al nacer $A=$ peso adulto

La tasa de crecimiento puede ser descrita de diferentes maneras. La tasa de crecimiento promedio (TCP) durante un período de tiempo se calcula dividiendo el aumento de peso durante determinado período por la longitud de ese período:

$$
T C P=\left(w_{2}-w_{1}\right) /\left(t_{2}-t_{1}\right)
$$

donde $w_{1}$ es el peso en el comienzo del período $t_{1}$ y $w_{2}$ es el peso al final $\left(t_{2}\right)$.

Este método proporciona la tasa de crecimiento en términos de $\mathrm{g}^{*}$ día $^{-1} \mathrm{o} \mathrm{kg}^{*}$ semana $^{-1}$ por ejemplo. La tasa de crecimiento relativo $(T C R)$ es calculada como el incremento de peso en un período de tiempo dividido sobre el peso inicial.

$$
T C R=\left(w_{2}-w_{1}\right) / w_{1}
$$

Esta expresión proporciona la tasa de crecimiento expresada como un aumento proporcional, por ejemplo un porcentaje, durante el período de tiempo definido. La curva sigmoide resultante de graficar el peso absoluto en función de la edad es sólo una forma de expresar el crecimiento. Trazando TCP o TCR contra edad se generan diferentes tipos de curvas (Figura 5). 

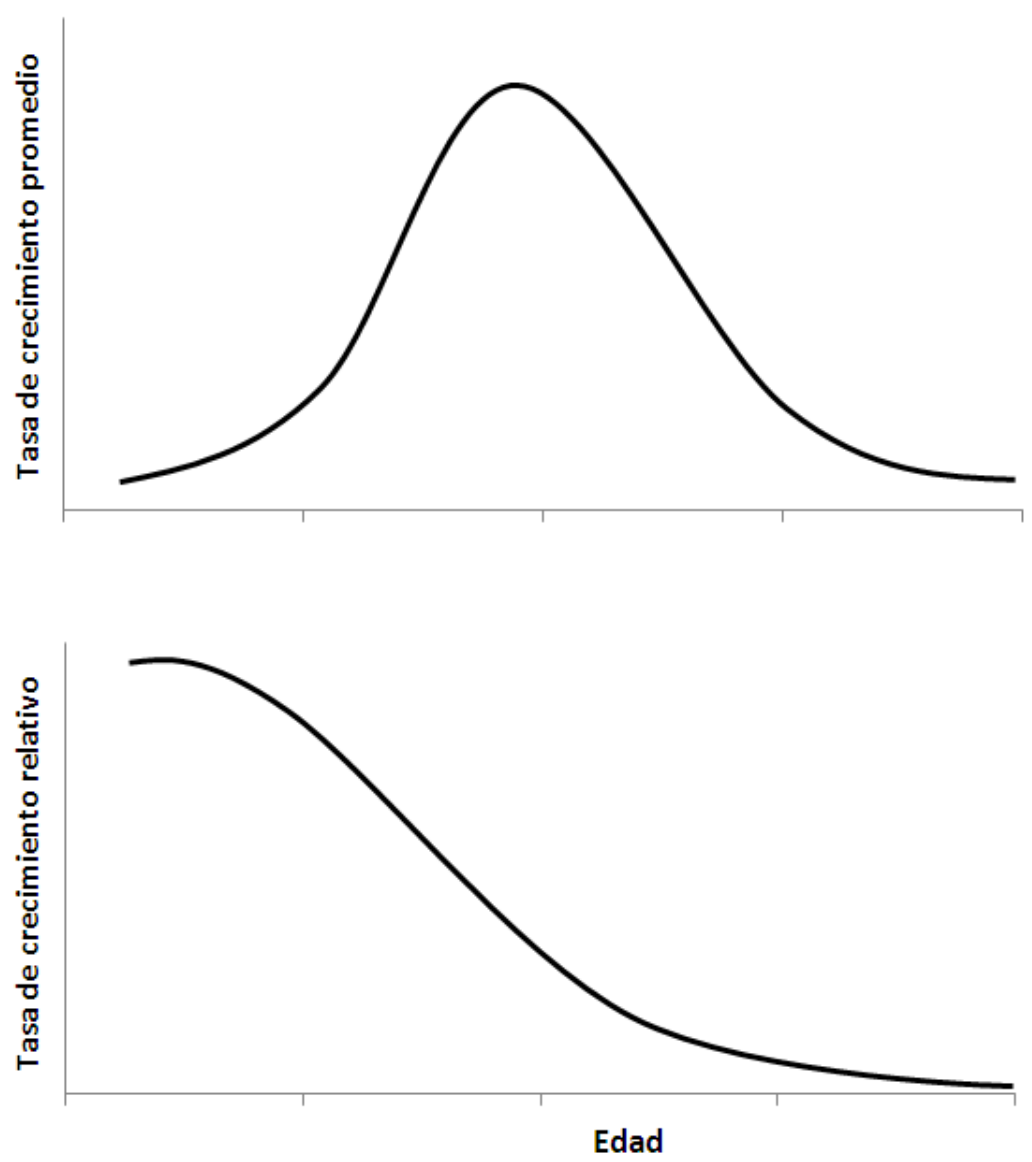

Figura 5. Relación entre la tasa de crecimiento promedio y la tasa de crecimiento relativa y la edad de los animales.

Fuente: Adaptado de Warriss (2000)

El gráfico de tasa de crecimiento promedio muestra que el animal crece más rápido en el período medio de su vida. La tasa relativa de crecimiento disminuye progresivamente durante toda la vida, lo que refleja el hecho de que el aumento de la masa corporal, expresado como una proporción de la ya existente, se reduce con el tiempo. En muchos sistemas de cría, las tasas de crecimiento son directamente influenciadas por el sistema de alimentación. Por ejemplo, el ganado vacuno para carne puede mantenerse durante el invierno ingiriendo cantidades relativamente pequeñas de alimentos de mala calidad cuando su crecimiento se desacelera o detiene totalmente. Durante la primavera siguiente, este período de "depósito" es sustituido por un período de terminación cuando la disponibilidad de pastos nuevos altamente nutritivos, permite la ocurrencia de un acelerado crecimiento compensatorio (Warriss, 2000).

Existen muchos factores que afectan el crecimiento del ganado (Brorsen et al.,1983); en el diagrama de la Figura 6, los autores ilustran los principales procesos involucrados. 


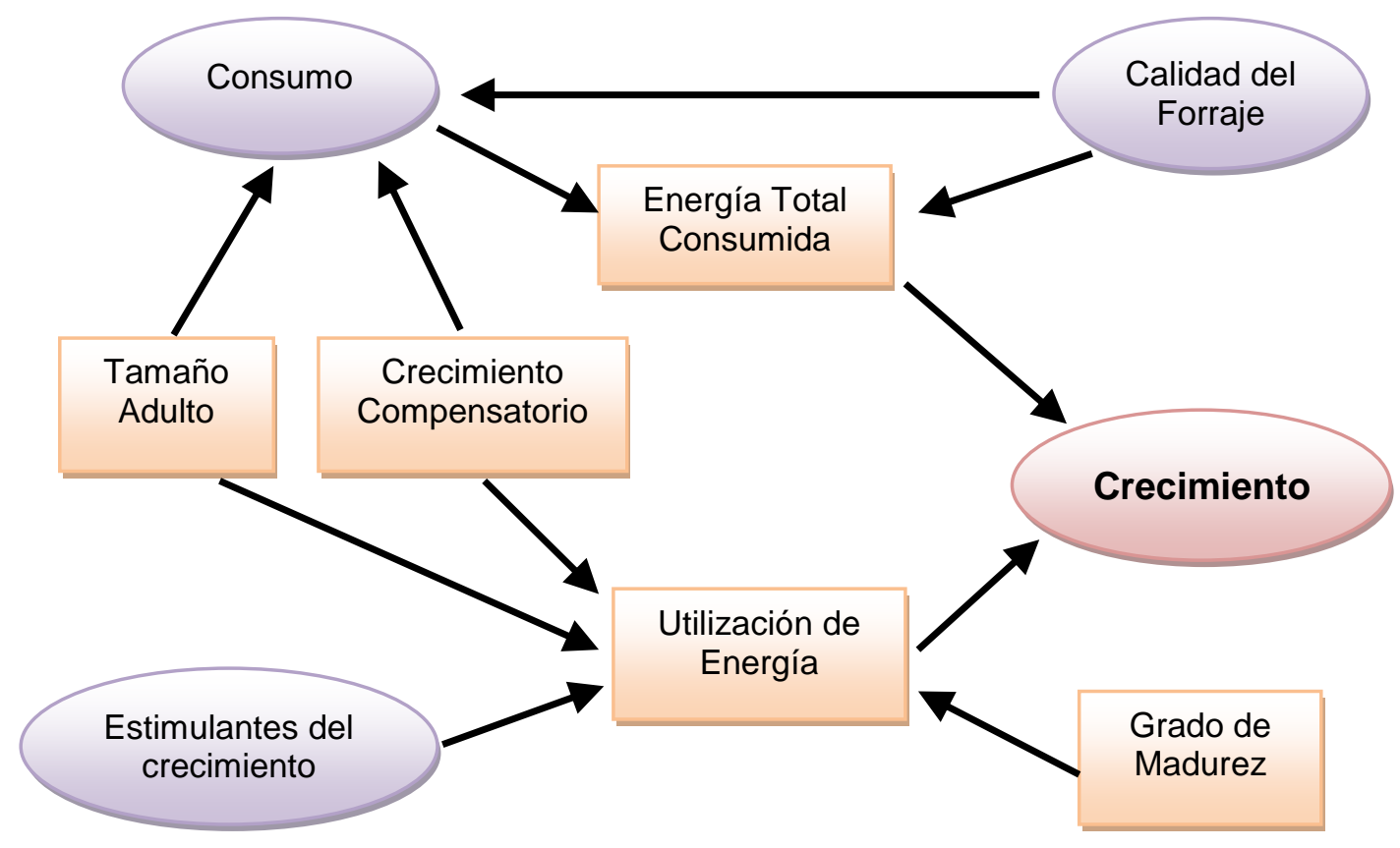

Figura 6. Factores que afectan el crecimiento del ganado.

Fuente: Brorsen et al. (1983)

\subsubsection{Requerimientos energéticos y estimación de ganancias de peso vivo}

A nivel general, los enfoques sobre esta área consideran la existencia de un metabolismo basal o de mantenimiento, el cual para ser satisfecho requiere de un nivel de consumo energético que suele ser expresado en función del peso metabólico del animal. Estos requerimientos varían entre razas, edad, sexo, estado fisiológico, nivel de actividad y condiciones climáticas, entre otros. Se ha estimado que alrededor del 70 a $75 \%$ del total de los requerimientos en producción de carne vacuna es usado en funciones de mantenimiento (Ferrell y Jenkins, 1985). Ante determinado consumo energético, se satisfacen en primera instancia estas necesidades básicas, para luego destinarse a producción (carne, leche, lana) el excedente energético.

Existen innumerables modelos que describen el crecimiento animal en base a diferentes enfoques: modelos empíricos como lo son los sistemas de alimentación (-CNESFox y Black, 1977; INRA, 1989; SCA, 1990; AFRC, 1994; NRC, 1996), modelos mecanísticos a cualquier nivel de agregación o modelos mixtos (-CNCPS- Fox et al., 2004).

Dentro de los sistemas de alimentación es posible diferenciar los que actúan a nivel de energía metabolizable (SCA, 1990; AFRC, 1994) de los que lo hacen a nivel de energía neta (-CNES- Fox y Black, 1977; INRA, 1989; NRC, 1996). 
Sin embargo, tanto unos como otros sistemas encuentran limitaciones al no reconocer la complejidad de las interacciones existentes entre la dinámica del tracto gastrointestinal y el metabolismo animal. Entre otros aspectos, no tienen en cuenta que los diferentes alimentos, incluso con similar contenido de energía, producen mezclas completamente diferentes de ácidos grasos volátiles que promueven distintas funciones metabólicas. A igual edad y nivel de consumo, los diferentes genotipos asignan los nutrientes asimilados a diferentes funciones. Así, algunos genotipos priorizan la producción de leche, mientras que otros priorizan la deposición de grasa. Además, la relación entre el consumo y la priorización en la deposición de tejidos es muy compleja. En resumen, los sistemas biológicos son altamente interactivos y cualquier simplificación puede inducir a errores, especialmente cuando los modelos tratan de simular condiciones muy diferentes. Algunos problemas respecto a los límites a la generalización fueron parcialmente resueltos a través de factores de corrección, los cuales captan una parte de la variabilidad hasta ahora no representada. Fox y Black (1984) utilizan un conjunto de factores de corrección que mejoran significativamente las estimaciones. Sin embargo, enfoques más mecanísticos, como el seguido por Oltjen et al. (1986) tuvieron mejores aproximaciones a la realidad (Oltjen et al., 1986, Fox et al., 1988). Por otra parte, los modelos mecanísticos generalmente requieren un volumen de datos que no es fácil de encontrar en condiciones prácticas. Además, algunos enfoques empíricos como los de Fox et al. (1988), luego adoptados por NRC (1996) hacen estimaciones que, sin ser muy precisas, podrían considerarse de un nivel muy aceptable. La implementación de enfoques mecanísticos basado en procesos o de modelos empíricos depende de los objetivos perseguidos y la disponibilidad de datos.

En general, con cada nuevo sistema se logra un avance en precisión de las estimaciones al añadirse nuevos términos a los modelos existentes. Estos términos son agregados utilizando conceptos mecanísticos y representaciones de funciones biológicas a niveles cada vez más bajos de agregación. De este modo, ha sido el énfasis en la biología de los procesos involucrados lo que ha incrementado la precisión de cada nuevo modelo, y no sólo un ajuste empírico (Ferrel y Oltjen, 2008).

Más recientemente, Fox et al. (2004) desarrollan el Cornell Net Carbohydrate and Protein System (CNCPS), el cual toma en cuenta además de las características del alimento, las necesidades de los animales en diferentes estados fisiológicos (lactancia, gestación, crecimiento), las reservas corporales y los efectos ambientales. Desde el punto de vista energético, el CNCPS utiliza las tasas de degradación y pasaje de carbohidratos y proteínas para predecir el nivel de fermentación ruminal, la producción de proteína microbiana, la absorción posruminal y el aporte total de energía metabolizable y de proteína al animal. El CNCPS ha sido usado exitosamente en establecimientos de producción de 
carne y lecheros para la formulación de piensos. En experimentos con evaluaciones de consumo individual este sistema pudo captar el $89 \%$ de la variación en la ganancia diaria. En vacas lecheras, el CNCPS estimó con $90 \%$ de precisión la producción de leche (Fox et al., 2004).

CSIRO (2007) estima los requerimientos energéticos de mantenimiento en función del peso vivo, la edad, la cantidad de energía ingerida en la dieta, la eficiencia neta de utilización de esta energía y el gasto de energía dedicado al pastoreo. En el cálculo de este último término, intervienen parámetros asociados a la topografía del terreno, la dotación animal, la disponibilidad de forraje verde y el consumo total de pastura.

Al igual que en el caso del consumo potencial, los requerimientos de mantenimiento presentan casos especiales, en los cuales se requiere un ajuste de los mismos. Las hembras en gestación y en lactancia tienen mayores costos de mantenimiento derivados del desarrollo del feto y la producción de leche respectivamente. Para ambos casos se utilizan funciones de ajuste, propuestas por CSIRO (2007) que se presentan más adelante en esta revisión. Dichos ajustes son los adoptados en este trabajo de tesis.

Para mejorar la predicción del crecimiento y composición de tejidos considerando diferentes genotipos y trayectorias de crecimiento, se han desarrollado numerosos modelos mecanísticos, algunos de los cuales discriminan entre la deposición de distintos tejidos, permitiendo no sólo describir el crecimiento en cuanto a peso vivo, sino su composición corporal a lo largo del tiempo (Oltjen et al., 1986; Di Marco et al., 1989; Keele et al., 1992; France et al., 1996; Hoch y Agabriel, 2004; Tedeschi et al., 2004). Estos modelos generalmente están basados en relaciones y conceptos biológicos que determinan el crecimiento al ser agregados a nivel individual. Es esperable que este enfoque provea de resultados con mayor nivel de precisión y aplicabilidad que los obtenidos a través de modelos empíricos (García et al., 2008).

El Modelo de Crecimiento de Davies (Oltjen et al., 1986) es un modelo mecanístico y dinámico que predice la cantidad de proteína y grasa depositada así como la producción de calor. La deposición de proteína es modelada mediante el proceso de proliferación celular (hiperplasia) e hipertrofia. El modelo estima la energía retenida en la proteína sintetizada y el calor producido asociado al mantenimiento. Posteriormente, la energía disponible para la deposición de grasa es estimada por la diferencia respecto al consumo de energía metabolizable, asumiendo determinados valores de eficiencia.

El Modelo de Crecimiento de INRA (Hoch y Agabriel, 2004), predice la síntesis y degradación de proteína y grasa, diferenciando la carcasa de otros tejidos. La fase de síntesis de ambos componentes es dependiente de la edad fisiológica del animal y del 
aporte de energía que recibe. Por su parte, la degradación de energía y proteína depende del nivel anterior de estos componentes. El consumo de energía metabolizable es el motor del modelo.

Cuando el crecimiento es continuo ambos modelos realizan un buen ajuste predictivo, superior al obtenido con NRC y ARC (Oltjen et al., 1986), pero muestran ciertas limitaciones tanto en el balance entre la deposición de grasa y proteína, como en el valor de grasa depositada, debido a la gran sensibilidad de esta variable al contenido energético de la dieta. Por otra parte, en el caso del modelo de Davies, la estimación de la cantidad de proteína sintetizada es obtenida a partir del valor de ADN corporal, siendo éste un dato muy difícil de obtener (García et al., 2008). Por su parte, el INRA requiere el ingreso de 26 parámetros para simular el crecimiento de un animal (Hoch and Agabriel, 2004). Los autores hacen hincapié en la dificultad de predicción del consumo a la hora de incrementar la precisión de estos modelos (García et al., 2008).

Se han desarrollado muchos modelos para predecir el desempeño animal en condiciones de feed lot (estabulación) y climas templados, con resultados aceptables. Sin embargo, sistemas como el NRC no son adecuados para predecir el comportamiento de novillos a pastoreo en climas tropicales (Tobias et al., 2006). Estos autores desarrollaron un modelo determinístico para predecir el cambio de peso de novillos, considerando la ingesta de energía y proteína de forrajes y suplementos y realizando modificaciones en los requerimientos extra asociados a la actividad y al estrés calórico. Las estimaciones obtenidas por el modelo no lograron buenos ajustes a los datos observados. El modelo no predijo satisfactoriamente las pérdidas de peso, mientras que en animales con balance positivo, las ganancias fueron subestimadas alrededor de un $70 \%$ del valor observado. La falta de ajuste es atribuida a la dificultad en la estimación de los requerimientos energéticos para el pastoreo y a los efectos ambientales sobre el metabolismo basal. Otras restricciones sugeridas son el uso de valores de energía de la dieta estimados por técnicas in vitro, aunque otros autores han utilizado exitosamente esta técnica (Fernandez-Rivera et al., 1989). Los autores concluyen que podrían lograrse mejores ajustes en estos modelos si se logran mejores estimaciones de consumo en pastoreo y mejores estimaciones de las fracciones energía y proteína de la dieta.

Resultados similares, con alta variabilidad en el ajuste de las estimaciones, obtuvieron Maquivar et al. (2006) en Costa Rica, cuando intentaron estimar la ganancia de peso de novillas suplementadas utilizando el sistema NRC. Estos autores también concluyen que se requieren modificaciones del modelo NRC relacionadas con los requerimientos de energía bajo condiciones de pastoreo en trópico húmedo, a fin de mejorar la exactitud de la predicción del comportamiento animal en esas condiciones. 
Silveira (2002) desarrolló en modelo mecanístico y dinámico (PAMPA CORTE) para simular el desempeño de novillos en crecimiento y cebo posdestete. El modelo considera dos etapas: a) consumo y digestión del alimento y b) variación asociada de peso vivo, procesos que son simulados en base a información de diferentes fuentes (ARC, 1980; SCA, 1990; AFRC, 1994; NRC, 1996). La relación utilizada entre la disponibilidad de forraje (por debajo de $1200 \mathrm{~kg} / \mathrm{MS}$ ) y el consumo es la adoptada por NRC (1996). Se realizaron simulaciones sin considerar la capacidad selectiva de los animales y considerando un $5 \%$ y un $10 \%$ de selectividad. Los resultados simulados por el modelo presentaron una buena aproximación a los datos reales, principalmente cuando la selectividad fue considerada.

Recientemente, Trevisan et al. (2009) realizaron un experimento tendiente a verificar la confiabilidad del modelo PAMPA CORTE en la predicción del desempeño de novillos en diferentes pasturas cultivadas (Avena strigosa, Lolium multiflorum, Pennisetum americanum) en el sur de Brasil. Para ello se contrastaron datos de literatura con los resultados provistos por el modelo. Los autores reportan altos ajustes $\left(r^{2}>0.90\right)$ en todas las situaciones estudiadas.

En el sur de Brasil, Beretta et al. (2002) evaluaron por medio de la simulación, la productividad y eficiencia de sistemas de producción de ganado de carne, al variar la edad de sacrificio (ES) de los novillos (54, 42, 36, 30, 24 y 18 meses) y los pesos de compra y venta de los animales. Para ello utilizaron un modelo estático determinístico, representando los sistemas en equilibrio. La información referida al manejo alimenticio fue caracterizado en cada caso mediante información bibliográfica, según la ES establecida. Los resultados obtenidos indicaron una respuesta en productividad de tipo cuadrática con valores mínimos de $65 \mathrm{~kg} \mathrm{PV} /$ ha cuando la edad de sacrificio fue de 54 meses hasta un máximo de 343 $\mathrm{kgPV} / \mathrm{ha}$ en la ES más baja (18 meses). El costo energético por kgPV producido se incrementó en $1.19 \mathrm{Mcal} \mathrm{EM} / \mathrm{kg}$ por cada mes de incremento en la ES. A iguales ganancias de peso vivo, la reducción en los pesos de compra y venta de los novillos incrementó la productividad del sistema.

En general, los modelos que simulan evolución de peso vivo se han desarrollado para animales en crecimiento y/o cebo. Villalba et al. (2006) desarrollaron un modelo estocástico para representar los sistemas de manejo de vacas de montaña en los Pirineos españoles. El modelo considera aspectos productivos y reproductivos y fue desarrollado con el objetivo de evaluar diferentes estrategias de alimentación invernal en esas condiciones productivas. La simulación fue realizada a nivel individual, tomando en cuenta factores nutricionales y fisiológicos y generando un valor diario para las variables: grasa total en la vaca, peso vacío de la vaca y peso del ternero. Las salidas del modelo eran: peso vivo de la vaca (derivado del valor de peso vacío), condición corporal de la vaca (derivado de la grasa total), peso vivo 
del ternero y estado fisiológico de la vaca. La validación del modelo registró coeficientes de determinación del orden de 0.72 a 0.94 entre los valores de peso vivo observados y los estimados mediante el modelo. Similares resultados fueron obtenidos en la validación de la condición corporal. En lo que respecta a las opciones de alimentación, los autores concluyen que es posible restringir hasta un $25 \%$ la energía aportada a las vacas en el período de estabulación invernal de manera sostenible.

\subsubsection{Consumo en pastoreo y factores que lo afectan}

Es frecuente encontrar trabajos en donde se asume el valor de consumo como un porcentaje constante del peso vivo (Brorsen et al.,1983). Esta asunción crea problemas cuando la calidad del forraje varía en forma importante. Los experimentos en producción animal indican que la ingesta de forraje de baja digestibilidad está afectada por la capacidad del rumen y la tasa de pasaje, determinando un incremento en el consumo al aumentar la digestibilidad del forraje. Por otra parte, en condiciones de alimentos de alta digestibilidad, el consumo es función de los requerimientos energéticos del animal, disminuyendo al incrementarse la digestibilidad del alimento. La capacidad del rumen está directamente correlacionada con el peso corporal, mientras que los requerimientos energéticos se encuentran más estrechamente relacionados con el peso metabólico $\left(\mathrm{Peso}^{0.75}\right)$ (Brorsen et al.,1983).

\subsubsection{Predicción del consumo en pastoreo}

La gran importancia que se le brinda a la predicción del consumo voluntario en ganado se debe a su gran impacto sobre el desempeño productivo (Ingvartsen, 1994).

En el manejo de los rumiantes en estabulación, la necesidad de conocer el consumo de los animales es mínima, y el único fin es el de asegurase de que son capaces de consumir una dieta determinada. Las dietas son formuladas buscando que sean equilibradas con el objetivo de asegurar que los animales ingieran la mayor cantidad posible, a fin de diluir los requerimientos de mantenimiento y maximizar la tasa de conversión (Poppi, 1996). Sin embargo, la producción en condiciones de pastoreo está determinada principalmente por el consumo voluntario que realicen los animales por lo cual la estimación de sus necesidades nutricionales para alcanzar un nivel meta de producción, debe comenzar con esta información (CSIRO, 2007). 
El SCA (1990), con su paquete informático Grazfeed, es el único sistema de alimentación que utiliza el consumo como punto de partida para la estimación del desempeño de animales en pastoreo (Poppi, 1996).

Ingvartsen (1994) propone una clasificación de los modelos de consumo en cuatro categorías: a) modelos de regresión, b) sistemas complejos, que asumen efectos de índole física y nutricional, c) sistemas de llenado, que postulan un valor de llenado para cada alimento y una capacidad total del animal en función del peso y d) sistemas dinámicos.

Las teorías convencionales se basan en controles metabólicos y físicos del apetito, pero no tienen en cuenta la influencia que las características "no nutricionales" de la vegetación ejercen bajo condiciones de pastoreo. Diariamente el animal dedica un tiempo limitado al pastoreo, por lo cual necesita lograr una alta tasa de consumo para que su ingesta total no esté restringida. La producción ganadera sobre pasturas predominante en Argentina depende en gran medida de la cantidad y calidad del forraje producido, de la capacidad del animal para cosecharlo y utilizarlo eficientemente, y de la capacidad del productor para manejar los recursos a su disposición, siendo la cantidad de alimento consumido el principal factor que determina la productividad animal (Galli et al., 1996).

CSIRO (2007) propone un sistema de predicción del consumo en base a dos factores: el consumo potencial del animal y el consumo relativo, determinado por las características de la dieta ofrecida. Se asume un pastoreo selectivo de los animales, planteando el forraje disponible como una colección de grupos o clases de diferente calidad y asumiendo que el animal intenta satisfacer su consumo potencial con cada uno de estos grupos sucesivamente, comenzando con el de más alta calidad.

(a) el consumo potencial del animal

Es definido como la cantidad de alimento consumido cuando al animal se le ofrece comida abundante, siendo capaz de seleccionar una dieta con una digestibilidad de la materia seca de al menos 0.8 o un valor de energía metabolizable de al menos 11 megajoulios de energía metabolizable por kilogramo de materia seca de forraje (MJ EM/kg MS) (CSIRO, 2007). El consumo potencial medio está determinado por su tamaño corporal y estado fisiológico. Este potencial puede reducirse por enfermedad o estrés térmico.

(b) el consumo relativo asociado a la oferta de forraje

Expresa la proporción de la ingesta potencial que el animal puede lograr en las actuales condiciones de pastoreo. En general, está en función de dos factores: el nivel al cual la composición química de la dieta seleccionada restringe el consumo y 
las características físicas de la pastura que limitan la capacidad del animal de cosechar forraje en el tiempo disponible para el pastoreo.

El consumo real de un alimento se calcula como el producto del consumo potencial y el relativo. Para animales en estabulación, este cálculo es un sencillo procedimiento porque la ingesta relativa es simplemente una función de la composición de la dieta, un atributo estable que fácilmente pueden medirse. En pastoreo, la estimación del consumo es mucho más complicada. La pastura es una heterogénea colección de componentes de plantas (hoja, tallo) de diferente valor nutritivo y la cantidad y calidad de estos componentes cambia continuamente a través del crecimiento y la maduración. Esto significa que para estimar el consumo relativo, es necesario describir la pastura en términos cuantitativos y luego predecir tanto el efecto de la distribución espacial de los componentes de la planta sobre la capacidad de los animales para cosecharlos, como el efecto del pastoreo selectivo sobre la calidad de la dieta ingerida (CSIRO, 2007).

La suplementación con concentrados o ensilajes puede aumentar la ingesta de pasturas de baja calidad o dietas deficientes en nitrógeno u otros nutrientes, pero en general, el suplemento deprime la ingesta de la dieta basal. El nivel de sustitución de forraje por concentrado se calcula incorporando el suplemento en el cálculo de la ingesta relativa, según la composición y cantidad del suplemento y la demanda de energía de los animales (CSIRO, 2007).

\subsubsection{Consumo potencial}

a) Tamaño de animales y su relación con el consumo

El máximo consumo voluntario que un animal puede lograr, está dado por una combinación de la demanda potencial de energía del animal y su capacidad física de consumo, ambas claramente proporcionales al tamaño del animal. Sin embargo, el peso no es un predictor confiable del tamaño corporal ya que su efecto se encuentra confundido con la etapa de desarrollo y la condición corporal (CSIRO, 2007).

El enfoque utilizado por estos autores se basa en predecir el consumo potencial mediante dos variables: (i) el peso adulto $(A)$, definido como el peso del animal cuando alcanza madurez esquelética y tiene una condición corporal en el centro de la escala y ii) el tamaño relativo $(Z)$ definido como el tamaño real de un animal en relación a su tamaño adulto. Este tamaño relativo se estima como la proporción del peso normal $(N)$ respecto al peso adulto $(A)$. 
El peso normal $(N)$ en un animal en crecimiento, es decir su peso cuando su condición corporal se encuentra en el centro de la escala, sigue un patrón con el tiempo similar al descrito por Brody (1945):

$N=A-(A-B) \cdot e^{\left(-k \cdot T \cdot A^{-0.27}\right)}$

donde:

$A=$ peso adulto $(\mathrm{kg})$,

$B=$ peso al nacer $(\mathrm{kg})$,

$T=$ edad del animal (meses),

$k=0.47$ para ovinos y 0.35 en bovinos

En animales con crecimiento interrumpido, el tamaño y en consecuencia el peso normal $(N)$ puede aumentar lentamente, es decir con un valor bajo para $k$, a pesar de que el animal no gane o incluso pierda peso (CSIRO, 2007).

Por este motivo, es necesario calcular el tamaño relativo (Z). Éste se calcula entonces como la proporción del peso normal respecto de $A$, una proporción que no puede superar 1 (cuando se alcanza la madurez esquelética), y su condición relativa $(R C)$ se calcula como la proporción del peso vivo actual $(W)$ respecto al peso normal $(M)$. Se deduce que peso vivo actual puede considerarse como una componente del peso adulto $(A)$, el tamaño relativo y la condición corporal relativa.

$$
W=A \cdot R C \cdot Z=A \cdot \frac{W}{N} \cdot \frac{N}{A}
$$

Utilizando valores de $A$ y $Z$ estimados en la forma descrita anteriormente, la ecuación [1.7] (Figura 7) debería predecir adecuadamente el consumo potencial (I) expresado en kg MS/día, de un animal destetado, no lactante y dentro de la zona termoneutra de temperatura (Figura 7). Esta ecuación implica que la ingesta potencial alcanza un máximo cuando el tamaño relativo de los animales es 0.85 (Graham y Searle, 1972). Para valores de $R C>1$, el consumo potencial se reduce al multiplicar I por un factor de condición CF, (ecuación [1.8]) en animales no-lactantes (CSIRO, 2007).

$I=j \cdot A \cdot Z 1.7-Z \cdot C F$

donde:

j toma valores sugeridos de 0.040 para ovinos y 0.025 para bovinos

$C F=R C \cdot \frac{1.5-R C}{0.5}$ para $R C>1$, de lo contrario $C F=1$ 


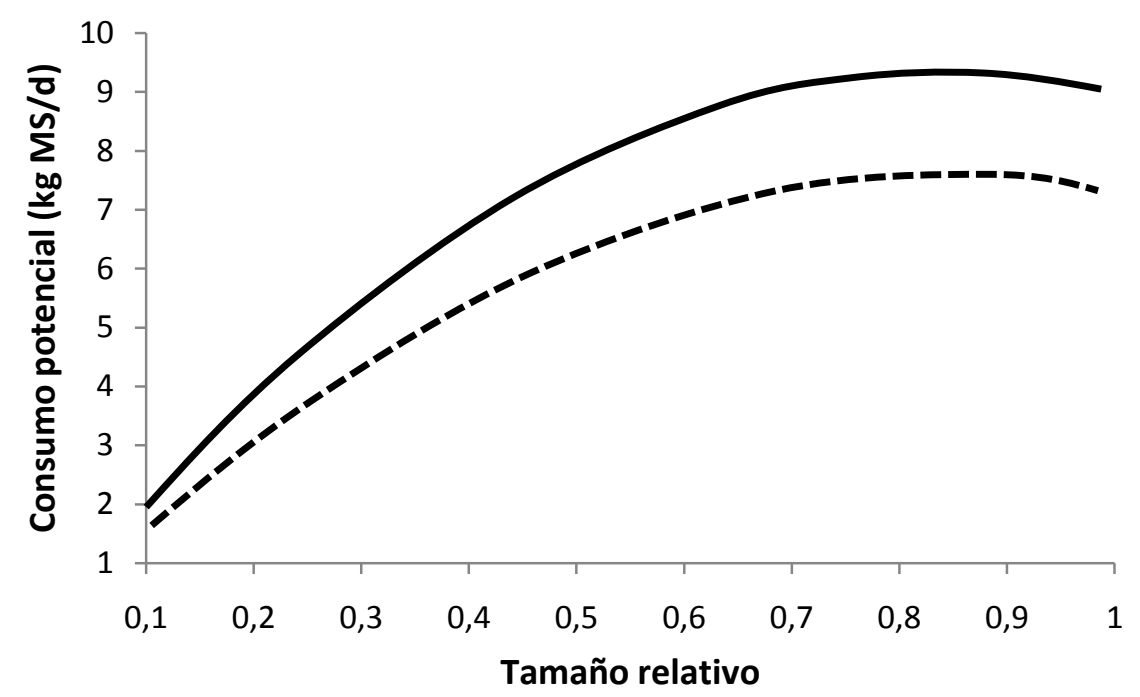

Figura 7. Consumo potencial estimado para vacunos de $A=500 \mathrm{~kg}$ (línea sólida) $0400 \mathrm{~kg}$ (línea punteada) en relación al tamaño relativo para animales de $R C \leq 1$.

Fuente: CSIRO (2007)

La ecuación [1.7] fue desarrollada en forma empírica para una amplia base de datos y sus predicciones para animales maduros en condiciones normales son similares a los de ARC (1980). La principal debilidad del sistema ARC es que el consumo potencial es estimado en función de $\mathrm{W}^{0.75}$, independientemente del peso adulto de los animales o su condición corporal. Así un animal joven de alto $A$ puede ser indistinguible de un animal maduro en malas condiciones o un animal maduro de bajo A. Igual limitante presenta el sistema francés (INRA, 1989) y el norteamericano (NRC, 1996); ambos basan su predicción de consumo sobre $\mathrm{W}^{0.75}$ independientemente del grado de madurez de los animales, aunque el sistema americano hace ajustes para tres categorías de tamaño adulto (frame) y para alta condición corporal.

Adicionalmente, el uso de 0.75 como exponente de $W$ ha sido cuestionado por diversos autores quienes encontraron evidencia de valores superiores según razas (CSIRO, 2007).

Fox y Black (1977) afirman que las diferencias entre razas en la tasa de ganancia se deben a variaciones en peso adulto y no a la raza per se. Resultados de investigación sugieren que las diferencias en la eficiencia energética entre las razas británicas y las razas de gran tamaño europeas son pequeñas cuando los animales son comparados en la misma etapa de crecimiento (Klosterman, 1972). 


\section{b) Crecimiento compensatorio}

El crecimiento compensatorio es la habilidad de un animal que ha sufrido un período de subnutrición, para reanudar crecimiento a una tasa mayor a la normal para animales de la misma edad cronológica (Brorsen et al., 1983).

Este efecto ha sido atribuido tanto a un aumento en el consumo, como a un incremento en la utilización de energía.

Con base en una revisión de literatura realizada por Brorsen, se ha determinado que la mitad de incremento en ganancia del crecimiento compensatorio, es debida a un incremento del consumo y la mitad es debida a la mayor digestibilidad de la extrusa (incrementos en energía neta, EN y energía neta de ganancia de peso, ENg).

Las respuestas compensatorias de crecimiento son altamente variables, pero en general, durante la realimentación los animales recobrarán el $50 \%$ de la diferencia en ganancia ocurrida durante el período de restricción alimenticia. Los experimentos también indican que ese máximo crecimiento compensatorio ocurrirá sólo con una dieta alta de energía (Fox y Black, 1977). Los multiplicadores para el consumo, para la EN y para la ENg utilizadas por el CNES, son obtenidos de las siguientes ecuaciones:

CMULT $=\frac{1.042-0.4294(\text { PREVGDP })}{0.947+0.05362(P R E V G D P)}$

GMULT $=\frac{1.0516-0.0524(P R E V G D P)}{0.9356-0.0655(P R E V G D P)}$

$$
\text { PREVGDP }=\left(\begin{array}{lr}
G P \rightarrow & \text { si } D \leq 60 \\
G P \cdot\left(1-\frac{D-60}{180}\right)+G A \cdot\left(\frac{D-60}{180}\right) \rightarrow & \text { si } 60<D<180 \\
G M \rightarrow & \text { si } D \geq 180
\end{array}\right)
$$

donde:

PREVGDP = ganancia diaria de peso previa

CMULT = multiplicador del consumo; consumo=consumo estimado $\times$ IMULT

$G M U L T=$ multiplicador de la EN y la $\mathrm{EN}_{\mathrm{g}}$

$G P=$ ganancia diaria de peso vivo en los últimos 120 días previo a la entrada al sistema actual de pastoreo

$G A=$ GDP desde el inicio del sistema actual de pastoreo

$D=$ días desde el inicio del sistema actual de pastoreo

GM = GDP de los últimos 180 días

Estas ecuaciones incorporan más información para estimar ganancia compensatoria que el método usado por Fox y Black (1977) que proponen un multiplicador para todo el 
período de alimentación. En el modelo desarrollado por estos autores, las restricciones de crecimiento previas son descartadas y la capacidad de realizar crecimiento compensatorio se desarrolla dentro del modelo. Los animales cuyo crecimiento se ha visto limitado, al ser colocados en pastura de trigo recobran la mitad de la diferencia de peso entre ellos y sus contemporáneos sin restricción. Una respuesta ligeramente menor es obtenida con forrajes de inferior calidad. El crecimiento compensatorio calculado por el modelo es intencionalmente estimado en un valor ligeramente menor que el real. Este ajuste es introducido para eliminar el poco realista "efecto telaraña" en el cual el aumento es reducido debido al pasado crecimiento compensatorio, luego la ganancia es incrementada debido a esta reducción y en consecuencia se genera un ciclo continuo. Aun con sus fallas, el ajuste considerando crecimiento compensatorio contribuye en gran medida a la habilidad predictiva del modelo (Brorsen et al., 1983).

El modelo planteado por CSIRO (2007) permite que animales inmaduros en recuperación de un período de desnutrición exhiban crecimiento compensatorio. En esos animales, el tamaño relativo aumenta muy levemente durante la subnutrición pese a una caída en $W$, de modo que cuando la comida no sea limitante, la diferencia entre la ingesta potencial estimada según el valor de $Z$ y los requerimientos de mantenimiento previsto por el valor de $W$, será mayor que el de un animal bien alimentado del mismo tamaño relativo.

Los sistemas alimentación (INRA, 1989, NRC, 1996) permiten aceptables predicciones de crecimiento con un limitado número de parámetros, aunque dentro del rango de situaciones para las que fueron creados. Sin embargo, no son adecuados para representar procesos como el crecimiento compensatorio (García et al., 2008).

\section{c) Estado fisiológico del animal}

\section{i. Preñez}

El desarrollo del feto implica un aumento notorio en la demanda de energía adicional de los animales preñados, pero no hay evidencia de un aumento en su consumo voluntario de alimentos (CSIRO, 2007). Weston (1982) informa de diferencias considerables entre los diferentes autores que van desde aumento del $26 \%$ a descenso de 16 a $25 \%$, pasando por numerosos autores que no encontraron diferencias en consumo entre gestantes y no gestantes.

Forbes (1971) sugirió que el espacio ocupado por el feto en la cavidad abdominal restringe la capacidad del retículo-rumen a tal punto que la ingesta sólo se mantiene gracias a una disminución en el tiempo medio de retención de extrusa en el intestino. Por otra parte, 
la reducción del consumo que se observa comúnmente algunas semanas antes del parto, se debe, probablemente, a cambios hormonales.

\section{ii. Lactancia}

Trabajos revisados por el Agricultural Research Council (ARC, 1980) muestran que el consumo potencial de materiales fibrosos por vacas y ovejas se incrementa hasta un $60 \%$ durante la lactancia. La magnitud de este incremento depende del tiempo desde el parto y el número de crías. El aumento de la ingesta se da posterior al aumento en la producción de leche y no llega a un pico hasta unos tres a cuatro meses después del parto (Aguirrezabala y Oficialdegui, 1993).

CSIRO (2007) plantea una ecuación para predecir un factor de ajuste de la ingesta de alimentos por animales lactantes. Este factor es dependiente del momento al cual se verifica el pico de consumo, de la condición corporal de la vaca y del potencial de producción de leche. Al adoptarse dicho factor de ajuste en este trabajo de tesis, su desarrollo se presenta en la sección correspondiente a los Materiales y Métodos utilizados.

\section{iii. Animales lactantes}

El consumo potencial de forraje por terneros no destetados, en sus primeras semanas de vida depende del desarrollo del rumen más que del peso vivo (CSIRO, 2007). Se propone un coeficiente de ajuste del consumo potencial a partir de la proporción de leche en la dieta y la edad. Su desarrollo se discute en la siguiente sección.

\section{iv. Enfermedades y factores climáticos}

Las enfermedades reducen el consumo potencial de los animales, siendo las parasitosis de particular relevancia en animales en pastoreo. Análisis con diferentes parásitos intestinales revelan un patrón muy complejo de respuestas dependiendo del nivel de infección y el desarrollo de resistencia (CSIRO, 2007). Los factores climáticos, en especial el estrés térmico, afectan el consumo voluntario en una magnitud dependiente del grado de aislamiento, del nivel de actividad metabólica del animal y de la calidad de la dieta. Estudios con animales estabulados muestran un incremento o disminución consistente del consumo cuando la temperatura ambiente baja o sube respectivamente, más allá de la zona termoneutra. 
Por su parte, Fox et al. (1988) postulan que los requerimientos estándar de mantenimiento suelen ser aplicados indiscriminadamente para condiciones muy contrastantes en cuanto a tipo de animales, manejo y ambiente y proponen ajustes en los requerimientos tomando en cuenta combinaciones entre temperatura ambiente, velocidad del viento, espesor del cuero (según razas), cantidad de pelo, actividad y plano nutricional actual y previo. En situaciones ambientales extremas, estos autores encontraron diferencias de hasta 4 veces respecto a los valores sugeridos por el National Research Council (NRC).

Sin embargo, existen pocos resultados obtenidos en condiciones de pastoreo, donde la flexibilidad del comportamiento del animal les permite mitigar los efectos de condiciones climáticas extremas al buscar sombra o refugio. Revisiones realizadas por Weston (1982) y NRC (1981) indican que aunque los efectos pueden ser importantes, es muy difícil realizar previsiones para animales en pastoreo.

El ajuste para altas temperaturas usado en el modelo GrazFeed (CSIRO), opera cuando la temperatura promedio supera los $25^{\circ} \mathrm{C}$ y la temperatura nocturna supera los $22^{\circ} \mathrm{C}$. El consumo potencial de forraje se reduce en $2 \%$ por cada grado de aumento de la temperatura promedio. Si la temperatura ambiente cae por debajo de la temperatura crítica del animal, el consumo potencial se incrementa en $1 \%$ por cada grado de temperatura. Este efecto se reduce con la lluvia, hasta desaparecer al llegar a los $20 \mathrm{~mm}$ por día (CSIRO, 2007).

\subsubsection{Consumo relativo}

El consumo relativo o la proporción respecto al consumo potencial que debe ser satisfecha por la pastura está determinado por el producto de dos factores: el nivel al cual la composición química de la pastura restringe su consumo (ingesta relativa), y las características físicas del tapiz que limitan la capacidad del animal para cosechar el forraje en el tiempo disponible para el pastoreo (disponibilidad relativa). Si la pastura fuera una masa homogénea con valores únicos para estas características físicas y químicas, el consumo relativo sería simplemente producto de las dos. Sin embargo, la pastura suele ser muy heterogénea y para predecir el consumo es necesario simular la selectividad en pastoreo y su efecto sobre el consumo de nutrientes (CSIRO, 2007). 


\section{a) Calidad de la pastura}

Las principales características que determinan el consumo de forraje por rumiantes son aquellas que limitan la tasa de pasaje de dicho forraje a través del retículo-rumen. La construcción y validación de modelos que simulan las tasas de digestión y pasaje de la ingesta, como funciones de la composición química y física del alimento consumido, es un campo activo de investigación. Un submodelo de este tipo debería ser un componente básico de cualquier modelo de consumo, pero el nivel de precisión logrado hasta ahora no es suficiente para describir el proceso en animales en pastoreo, con serias dificultades para relacionar las variables a predecir con variables medibles en la pastura (CSIRO, 2007).

De cualquier manera, las características de la pastura que determinan la desaparición de la ingesta del rumen, se encuentran asociadas con la digestibilidad de la dieta, la cual es una característica más fácilmente estimable. Numerosas revisiones (CSIRO, 2007) han demostrado relaciones lineales entre la digestibilidad aparente y el consumo voluntario dentro de un amplio rango de estados de madurez de pasturas.

Mediciones realizadas en gramíneas tropicales (C4) indican que aunque la digestibilidad de estas especies es cerca de un 15\% menos que la de las especies C3 con un mismo grado de madurez, el consumo voluntario es proporcionalmente mayor a igual digestibilidad. Existe evidencia de una alta asociación lineal $\left(r^{2}=0.81\right)$ entre la digestibilidad de la materia seca de varias especies C4 y el consumo que los animales realizan (CSIRO, 2007).

b) Cantidad de forraje y estructura del tapiz

En el caso de un animal estabulado o un ovino sobre una pastura conteniendo al menos 2 tt MS/ha (alrededor de 3 tt MS/ha en el caso de un vacuno), el consumo está determinado exclusivamente por los factores ya mencionados: el consumo potencial y la calidad de la dieta seleccionada. Sin embargo, cuando el nivel de forraje desciende por debajo de estos valores, se torna cada vez más difícil para el animal satisfacer su consumo potencial en el tiempo diario que dedica al pastoreo. Existen numerosos modelos mecanicistas que describen en forma detallada el proceso de pastoreo a través del tamaño de bocado y la tasa de bocado en relación con la estructura del tapiz (Brereton et al., 2005; Montossi et al, 2000). Aunque actualmente se requiere un conocimiento muy detallado de las características estructurales y espaciales de la pastura para su aplicación práctica, estos modelos podrán jugar un papel importante en un futuro.

CSIRO (2007) plantea una relación exponencial entre la disponibilidad relativa $(F)$, y la cantidad de forraje disponible $(B)$, con la hipótesis de que cada unidad de cambio en el 
consumo respecto a la cantidad de forraje disponible es proporcional al apetito insatisfecho a ese nivel de forraje.

$$
\begin{aligned}
& d F / d B=1-F \quad \text { lo cual determina: } \\
& F=1-\mathrm{e}^{(-a \cdot B)}
\end{aligned}
$$

El parámetro a varía con la estructura del tapiz y el tipo de animal, siendo necesario para predecir el consumo tomar en cuenta las interacciones entre la densidad de la pastura y el proceso de pastoreo, expresado como la tasa de bocado $(\mathrm{g} / \mathrm{min})$ y el tiempo dedicado al pastoreo (h/día). El modelo considera estas variables como valores relativos, es decir como proporciones de los valores que deberían tener si la oferta de forraje no limitase el consumo. La relación entre la disponibilidad relativa $F$, y la combinación de la tasa de bocado $E$ con el tiempo relativo destinado a pastoreo $T$, puede ser expresada algebraicamente con la forma general presentada en la siguiente ecuación:

$$
F=E \cdot T=1.0-\mathrm{e}^{-b \cdot B} \cdot\left(1.0+C \cdot \mathrm{e}^{-d \cdot B^{2}}\right)
$$

donde los valores de $b, c$ y $d$ varían con la densidad de la pastura

Cuando hay alta disponibilidad, tanto $E$ como $T$ tienen un valor de 1.0. Cuando la disponibilidad comienza a disminuir, $E$ desciende y $T$ aumenta para compensar, pudiendo mantener el valor de consumo por un tiempo. Pero aunque el valor de $E$ pueda caer en situaciones extremas hasta cerca de cero y usualmente hasta una cuarta parte de su valor máximo, $T$ no puede crecer en similar magnitud y tiene una cota superior, por lo cual el producto, la disponibilidad relativa, se reduce progresivamente al disminuir la cantidad de forraje (Figura 8). 


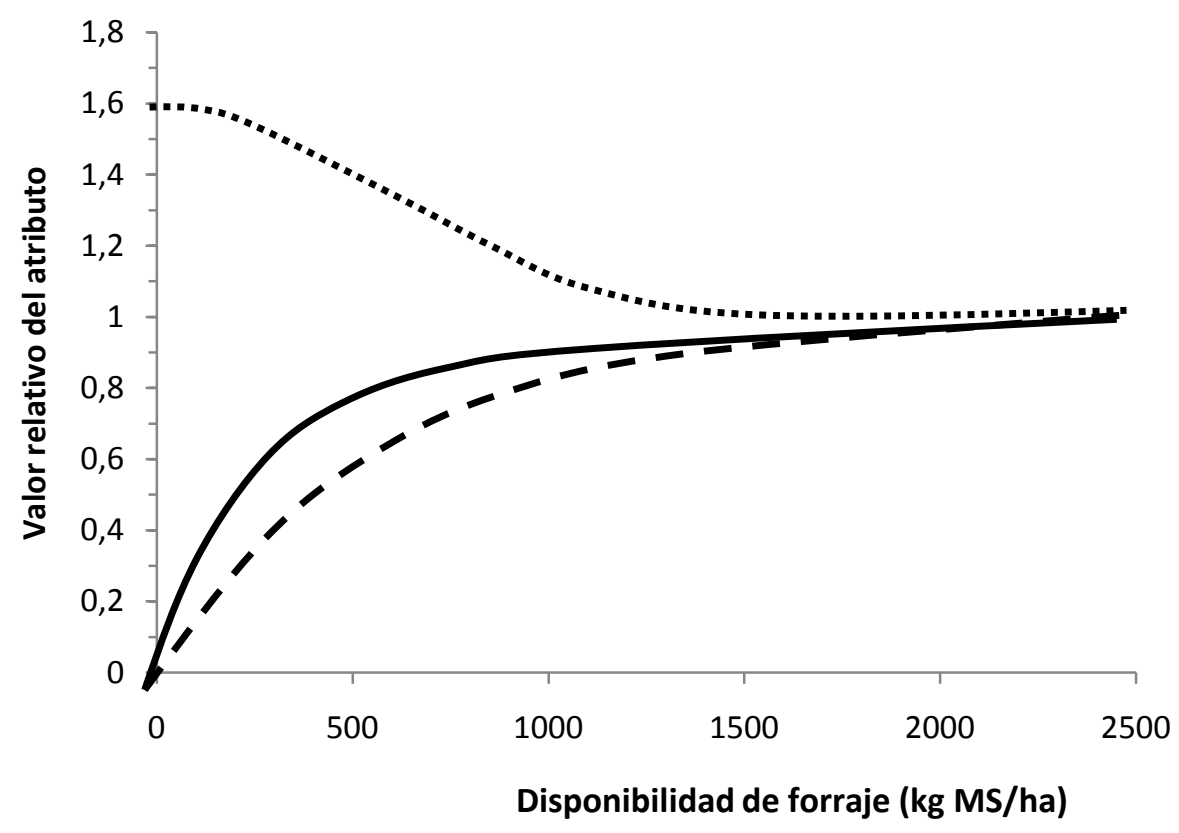

Figura 8. Disponibilidad relativa y atributos que la componen, en ovinos, en relación con la disponibilidad de materia seca de la pastura. La línea segmentada representa el tiempo relativo destinado al pastoreo, la línea punteada indica la tasa de bocado relativa, y la línea sólida es su producto, la disponibilidad relativa de forraje para el animal Fuente: CSIRO (2007)

\subsubsection{Métodos de clasificación del forraje y simulación de pastoreo selectivo}

Al aplicar los factores mencionados anteriormente para predecir el consumo relativo, no es correcto tratar la pastura como si fuera una masa homogénea de material con cantidad y calidad conocidas. Los animales en pastoreo seleccionan material vivo en preferencia a material muerto, joven frente a viejo, y hoja en lugar de tallo. Si se intenta simular el proceso de selección, el forraje debe ser clasificado en una forma que se corresponda con la que percibe y come el animal cuando pastorea (CSIRO, 2007).

Estos autores plantean una aproximación consistente en clasificar la pastura en seis grupos o clases, cada uno de los cuales tiene una digestibilidad fija (entre 0.3 y 0.8). Se asume que el animal, para satisfacer su consumo potencial, ingiere cada uno de estos grupos en sucesión, comenzando con la clase más digestible. La medida en que esto sea factible de realizar depende tanto de la cantidad como de la digestibilidad de la pastura en cada grupo. Cuanto mayor sea la proporción de la ingesta potencial satisfecha por determinado grupo de calidad, menor será el volumen a ingerir del siguiente grupo de menor digestibilidad, y así sucesivamente. El consumo relativo total es la suma de la ingesta relativa lograda en cada uno de los grupos mencionados, según las siguientes ecuaciones: 


$$
F_{d}=U C_{d} \cdot R R_{d} \cdot R T_{d} \text { con } d=1 \ldots 6
$$

donde:

$$
\begin{aligned}
& U C_{d}=\max \left(0,1-\sum_{k=1}^{d-1} F_{k}\right) \\
& R R_{d}=1-\mathrm{e}^{-1+0.35 \Phi_{d} \cdot a \cdot H F_{d} \cdot B_{d}} \\
& R T_{d}=1-0.6 \cdot \mathrm{e}^{-1+0.35 \Phi_{d} b \cdot H F_{d} \cdot B_{d}{ }^{2}} \\
& H F_{d}=0.2+0.8 H R_{d}
\end{aligned}
$$

$a=1.12$ para ovinos $; 0.78$ para vacunos

$b=1.12$ para ovinos $; 0.74$ para vacunos

La función para calcular la disponibilidad relativa en cada grupo, $F_{d}$ (ecuación [1.14]) se aplica a cada grupo a su vez, comenzando con la más digestible. UC $_{d}$ representa la proporción de la ingesta potencial no satisfecha por el material seleccionado anteriormente en la secuencia. Los exponentes de las ecuaciones [1.16] y [1.17], que estiman la tasa relativa de ingestión y el tiempo relativo destinado a comer para el grupo $d$, aumentan al incrementarse la proporción de pastura que se encuentra en dicho grupo $\left(\Phi_{d}\right)$. Además, si la pastura tiene una menor o mayor altura que el valor medio asumido de $3 \mathrm{~cm} / \mathrm{t} \mathrm{MS} / \mathrm{ha}$, entonces el ratio de la altura real sobre la altura estándar $\left(H R_{d}\right)$ reducirá o incrementará, respectivamente, la disponibilidad de forraje a un peso determinado. No se asume que las leguminosas sean seleccionadas con preferencia a las gramíneas ya que la evidencia de este hecho es bastante discutida, pero su presencia en la pastura determina un aumento de la digestibilidad relativa del forraje, hasta un máximo de 17\% (CSIRO, 2007).

Sin embargo, en el cálculo del consumo relativo para el grupo $d\left(R_{d}\right)$, al aparecer como factores $F_{d}$ y $R Q_{d}$, el efecto de la proporción de leguminosas en la pastura disminuye a la vez que lo hace la disponibilidad de la misma (ecuación [1.19]). Un ejemplo del cálculo de ingesta relativa se plantea en la Tabla 3. La relativa disponibilidad del primer grupo reduce la capacidad insatisfecha, UC del animal para comer de la segunda clase y por lo tanto el valor de $F$ calculado para la segunda clase se multiplica por el nuevo valor de $U C$. Este proceso continúa hasta que todas las clases han sido considerados o la capacidad relativa del animal ha sido satisfecha. El valor de la disponibilidad relativa de cada una de las clases es multiplicado por el apropiado $R Q$ para generar el valor de consumo relativo $(R l)$ de forraje de ese grupo. El consumo relativo acumulado a partir de todos los grupos se multiplica por el consumo potencial para obtener el consumo real de materia seca. 
Tabla 3. Consumo estimado de forraje de una oveja Merino en lactación con un consumo potencial de $2.13 \mathrm{~kg}$ MS/día y digestibilidad de la dieta seleccionada en una pastura con 0.8 t MS/ha de forraje verde (digestibilidad media=70\%) y 0.4 t MS/ha de forraje seco (digestibilidad media $=45 \%$ )

\begin{tabular}{l|cccccc}
\hline & \multicolumn{7}{c}{ CLASES } \\
\hline & $\mathbf{1}$ & $\mathbf{2}$ & $\mathbf{3}$ & $\mathbf{4}$ & $\mathbf{5}$ & $\mathbf{6}$ \\
Digestibilidad de la materia seca (\%) & 80 & 70 & 60 & 50 & 40 & 30 \\
Ingesta relativa & 1.0 & 0.83 & 0.66 & 0.49 & 0.32 & 0.15 \\
Disponibilidad de forraje (t MS/ha) & 0.24 & 0.36 & 0.23 & 0.16 & 0.15 & 0.06 \\
Disponibilidad relativa ${ }^{A}$ & 0.39 & 0.34 & 0.11 & 0.05 & 0.03 & 0.01 \\
Consumo relativo & 0.39 & 0.28 & 0.07 & 0.02 & 0.01 & 0.00 \\
Consumo relativo acumulado & 0.77 & & & & & \\
Consumo de forraje (kg MS) & 1.63 & & & & & \\
Digestibilidad media de la dieta (\%) & 73 & & & & & \\
\hline
\end{tabular}

Fuente: CSIRO, 2007

La digestibilidad de la dieta es calculada según las contribuciones de los diferentes grupos a la dieta total. La Figura 9 muestra el efecto estimado de $B$ y $D$ sobre el consumo de materia seca y la Figura 10 ilustra el efecto directo de B sobre la capacidad de los animales para seleccionar una dieta de digestibilidad superior que la media del material ofrecido.

$$
R_{d}=F_{d} \cdot R Q_{d}\left(1+0.17\left(\sum_{d=1}^{6} F_{d}\right)^{2} \cdot P_{\text {legum }}\right)
$$

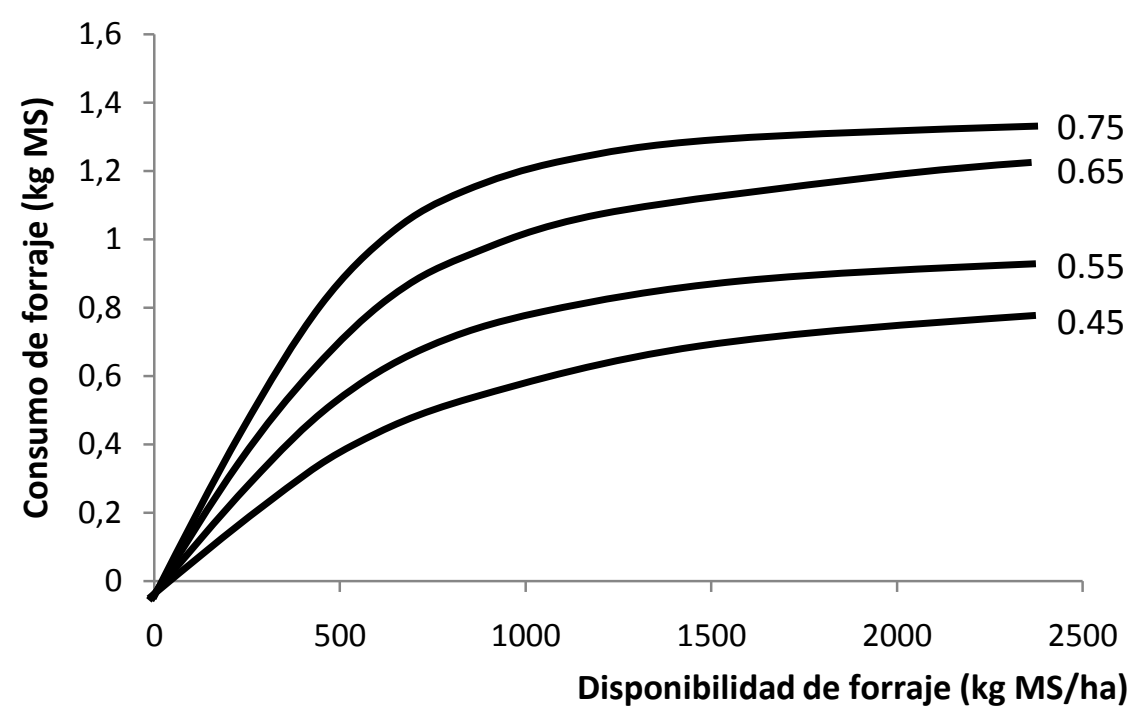

Figura 9. Consumo de forraje estimado para ovejas ( $A=50 \mathrm{~kg}$ ) pastoreando gramíneas templadas con diferente digestibilidad

Fuente: CSIRO (2007) 


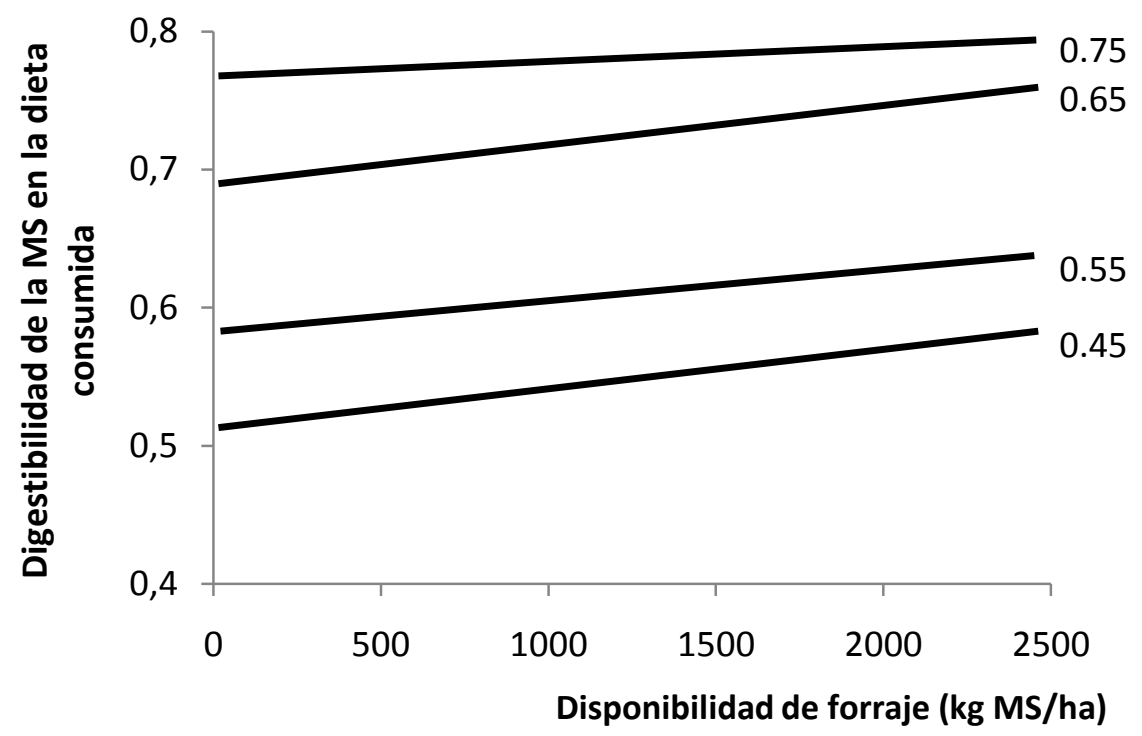

Figura 10. Estimación de la digestibilidad de la dieta según disponibilidad de forraje para 4 pasturas con distinta digestibilidad promedio

Fuente: CSIRO (2007)

Herrero et al. (2000) sostienen que, aunque el comportamiento de los animales en pastoreo es uno de los métodos más comunes de estimación del consumo, su implementación práctica puede ser muy dificultosa debido a la imposibilidad de predecir el tiempo de pastoreo bajo determinadas situaciones. Por otra parte, este método no es aplicable si los animales son suplementados, al verificarse efectos aún no comprendidos de la suplementación sobre el comportamiento pastoril.

En los sistemas de producción sobre pasturas, el consumo animal constituye el principal determinante de la productividad. La predicción del mismo con una precisión adecuada se transforma, así, en una herramienta fundamental para la planificación de la empresa pecuaria en el mediano y largo plazo.

El consumo animal es influenciado por una serie de variables propias del animal y otras relacionadas con el ambiente, principalmente con la comunidad vegetal que es pastoreada. Estos factores interactúan en forma compleja. En consecuencia, el consumo animal es cambiante y su cambio depende de la multiplicidad de factores intervinientes. Cuando el consumo es influido solamente por factores del animal, se habla de consumo potencial. La influencia de los factores relativos a la pastura resultará en el consumo voluntario, que será el consumo real de los animales (Aguirrezabala y Oficialdegui, 1993).

Enfoques con distinto grado de complejidad han sido aplicados para la estimación del consumo en pastoreo (Illius et al., 1992; Herrero et al., 2000; Brereton et al., 2005). 
Herrero et al. (2000) proponen un ajuste de la función de consumo de Johnson y Parsons (1985), la cual adaptan para captar la variación asociada a diferentes arquitecturas de forraje y peso de los animales. La función de consumo resultante es dependiente del consumo potencial (I), del índice de área foliar (IAF) y de los parámetros $q$ y $K$, asociados a la arquitectura o distribución espacial de la pastura y al tipo de animal respectivamente, según la ecuación:

$$
\text { Consumo }=1 \cdot \frac{\left(\frac{I A F}{K}\right)^{q}}{1+\left(\frac{I A F}{K}\right)^{q}}
$$

En la Figura 11 se presenta la representación gráfica de la función de consumo para ganado lechero asumiendo valores de $15 \mathrm{kgMS}$ para el consumo potencial, $q=3$ y $\mathrm{K}=2$ según valores sugeridos por los autores.

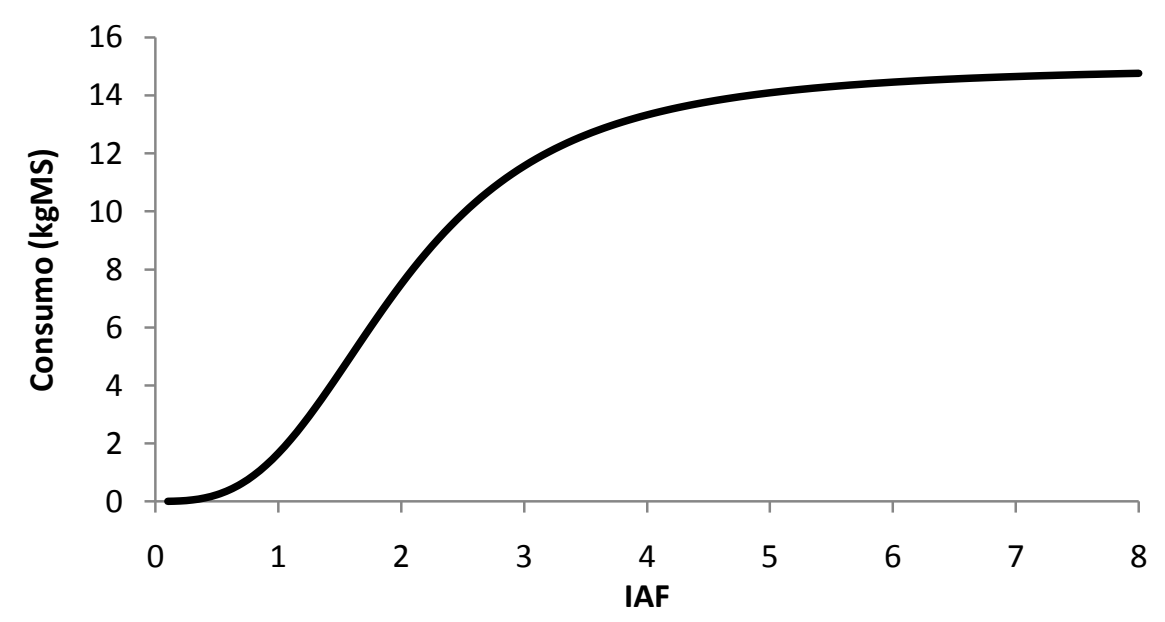

Figura 11. Estimación del consumo en vacas lecheras en función del índice de área foliar de la pastura

Fuente: Adaptado de Herrero et al. (2000)

Dicha función fue adaptada a parámetros relativos a la disponibilidad y arquitectura del tapiz, en virtud de la dificultad práctica inherente a la estimación del índice de área foliar a nivel de campo.

Illius et al. (1992) analizan las pautas de selectividad en ovejas, las cuales acceden a parcelas con diferentes alturas de forraje y composición de gramíneas y leguminosas. Los 
animales prefirieron las parcelas de mayor altura y contenidos intermedio de leguminosas. La tasa de consumo fue coincidente con los patrones de preferencia.

Brereton et al. (2005) desarrollaron un complejo modelo mecanístico que describe la utilización de forraje en sistemas de pastoreo rotativo. Para ello representan el proceso dinámico que ocurre al ser removidos por el animal los estratos superiores de la pastura, de mayor valor nutritivo. Este modelo es luego utilizado como componente de un sistema de simulación dinámica lechero (Dairy_Sim; Holden et al., 2007).

Trabajos de investigación recientes, se apoyan en tecnologías emergentes en el área de producción animal, como son los sistemas de información geográficos (SIG) aplicados al análisis de patrones de pastoreo a nivel regional y a la generación de un índice de potencial pastoril a través de la ponderación de distintas variables (Bernués et al.,2005). La evaluación de la situación pastoril de una zona mediante el análisis de imágenes satelitales de resolución variable, es otra área de trabajo que ha ganado terreno en los últimos años, habiendo sido aplicada con relativo éxito tanto a nivel regional (Oesterheld et al., 1998; Kurtz et al., 2009) como a nivel de parcelas (Phillips et al., 2009) y en evaluaciones a distinta escala temporal.

\subsubsection{Reproducción}

\subsubsection{Edad a la pubertad}

La edad a la cual se llega a la pubertad (EP) tiene un importante efecto en la producción de carne, particularmente cuando el primer parto se da a los 2 años de edad y especialmente en sistemas intensivos que utilizan un período de cubrición reducido (Ferrel, 1982).

Las novillas no sólo deben preñarse, sino que deben hacerlo temprano en el período de cubrición para maximizar la eficiencia productiva. El desempeño reproductivo de vacas primíparas es dependiente del tiempo en que paren su primer ternero; las que conciben temprano en su primera estación de reproducción tienen mayor productividad a lo largo de su vida que aquellas que conciben más tarde en la primera cubrición (Lesmeister et al., 1973). Además, las novillas que paren un ternero con 2 años producen más terneros durante su vida productiva que las que lo hacen por primera vez a los 3 años (NúñezDominguez et al., 1991).

La mayoría de novillas tienen el potencial para alcanzar la pubertad y concebir satisfactoriamente al año de edad siempre que hayan tenido un manejo y nutrición 
adecuados. Sin embargo, el costo de lograrlo puede diferir en forma importante entre razas y entre novillas dentro de una misma raza. Las novillas con la habilidad innata para alcanzar pubertad a temprana edad pueden manifestar estro y preñarse a menor costo que novillas con pubertad más tardía.

En machos, el estimador de la EP más utilizado es la circunferencia escrotal, característica que a su vez, se encuentra correlacionada con la EP en hembras, teniendo la ventaja de que es una característica relativamente fácil de medir (Martin et al., 1992).

Notter (1977) simuló niveles crecientes de fertilidad en un mismo genotipo, obteniendo valores incrementales de eficiencia económica. Una menor edad de entrada a la pubertad resultó en un aumento muy leve en la eficiencia, aunque los autores infieren que este hecho pudo estar relacionado con las edades relativamente bajas simuladas.

Bourdon y Brinks (1987b) utilizaron como base el modelo de producción de carne de la Universidad de Texas A\&M desarrollado por Sanders y Cartwright (1979a) con el objetivo de comparar la eficiencia biológica y económica de diferentes genotipos difiriendo en fertilidad, específicamente en la edad en la pubertad (AAP) y la máxima probabilidad de concepción (PCA), analizando también la importancia relativa de la fertilidad sobre la eficiencia de producción.

El genotipo base estuvo caracterizado por un peso adulto de $525 \mathrm{~kg}$, un potencial de producción de leche de $12 \mathrm{~kg} /$ día, edad potencial a la pubertad (AAP) de 365 días y máxima probabilidad de concepción (PCA) de 0.75 .

Otros genotipos simulados fueron uno de pubertad tardía ( $A A P=425$ días) y uno de mayor fertilidad $(\mathrm{PCA}=0.85)$.

Comparada con el genotipo base, el genotipo de pubertad tardía mostró una tasa muy inferior de preñez para novillas, la tasa de preñez en vacas fue algo menor, la tasa de reemplazo de la vacas mayor, la fecha de parto más tardía y en consecuencia los pesos al destete de los terneros fueron levemente menores. Al tener más edad y mayor tamaño al parto, en el genotipo tardío la ocurrencia de distocia y pérdidas al parto fue algo menor. El porcentaje de destete del sistema no fue afectado en forma apreciable ya que el porcentaje de preñez permitió mantener un número suficiente de novillas de reemplazo preñadas. La eficiencia tanto biológica como económica fue menor en el genotipo de pubertad tardía, aunque estas diferencias fueron mínimas. 


\subsubsection{Fertilidad}

Existe consenso general en que la mejora del desempeño reproductivo del rebaño (fertilidad y sobrevivencia de terneros), determina una mejora en eficiencia global de producción en ganado de carne (Bourdon y Brinks, 1987b).

Estos autores reportan que cuando la máxima probabilidad de concepción fue incrementada de 0.75 a 0.85 , las tasas de preñez simuladas tanto para reemplazos como para vacas de cría aumentaron, a la vez que disminuyó la tasa de reemplazo. La fecha promedio simulada de parto fue ligeramente más tardía debido a la menor proporción de novillas en el rebaño, (las cuales paren más temprano). Al incrementarse la fertilidad, menos reemplazos son necesarios; como consecuencia, el tamaño del rebaño se incrementa, a la vez que se producen más novillas excedentes para la venta o cebo y menos vacas de descarte (Bourdon y Brinks, 1987b).

La eficiencia biológica disminuye con el aumento de fertilidad. La eficiencia económica generalmente disminuyó cuando la proporción de precios pagados por vacas de rechazo respecto al alimento para cebo fue la manejada como "estándar" o mayor. Solamente cuando los animales alimentados fueron especialmente valiosos respecto al valor de las vacas de rechazo, el aumento de la fertilidad se tradujo en un incremento en eficiencia. Mientras estos resultados económicos simplemente pueden ser producto de manipulaciones en las relaciones de precios y los costos de producción usados en la simulación, la disminución en la eficiencia biológica al incrementarse la fertilidad sugiere otra explicación. Puesto que todas las vacas falladas fueron descartadas en esta simulación, el potencial genético para fertilidad afectó directamente las tasas del reemplazo y la estructura de edad del rebaño. El aumento en la fertilidad dio como resultado una edad promedio mayor de las vacas. Los autores conjeturan que las vacas adultas son menos eficientes biológicamente que las novillas debido a una mayor proporción de la energía requerida para el mantenimiento, preñez, lactación y recuperación de peso.

Esta argumentación y los resultados del modelo obtenidos están en acuerdo general con resultados de Taylor et al. (1985) quienes refieren a la ineficiencia biológica de mantener vacas adultas. La conclusión que extraen los autores es que desde el punto de vista puramente de la eficiencia biológica, los rebaños deberían mantenerse jóvenes y la longevidad en sí no debería ser especialmente importante.

Un descenso en las tasas de preñez no implica necesariamente una pérdida de producto, sino un cambio en el origen de éste, cambiando novillas excedentes para venta o cebo, por vacas de descarte (Bourdon y Brinks, 1987b). 
En contraposición, Formigoni et al. (2005) encontraron valores económicos importantes para la característica "permanencia en el rebaño", modelada a partir de la disminución de la tasa de descarte de vacas. Sin embargo, dichos autores consideran el costo de reposición de novillas a precios de mercado. En esta situación, cuando el precio de la novilla de reemplazo excede el valor de la vaca de descarte, el hecho de descartar una vaca más tiene un valor económico negativo. En este trabajo, también se estudió el valor económico de la probabilidad de preñez a los 14 meses, obteniéndose para esta característica un valor positivo de aproximadamente 300 dólares por unidad porcentual de preñez en esta categoría.

A la hora de realizar una simulación que incorpore aspectos reproductivos, es importante tener en cuenta los aspectos fisiológicos y nutricionales asociados a estos procesos.

Una reducción en el consumo de energía antes del parto aumenta el intervalo partoprimer celo (Wiltbank et al., 1962). Las reservas de grasa al momento del parto en vacas de carne, influyen en el desempeño reproductivo subsiguiente (Wiltbank et al., 1964).

Basados en el análisis de regresión de vacas multíparas de varios estudios, se ha comprobado que las vacas que mantienen el peso corporal (PC) antes del parto, exhiben estro antes que vacas que pierden PC (Dunn y Kaltenbach, 1980). Las respuestas al cambio de PC preparto pueden depender de la condición corporal (CC) en el parto.

Las tasas de preñez en vacas en buena condición corporal al parto son poco afectadas por cambios leves en PC, tanto antes o después del parto, mientras que pérdidas importantes de PC después de parir pueden reducir las tasas de preñez. Las ganancias de PC postparto acortan el período hasta el primer ciclo estral en vacas de baja CC, especialmente si perdieron PC antes del parto (Dunn y Kaltenbach, 1980).

El cambio del peso corporal durante la preñez es confundido con el crecimiento del feto, por consiguiente, la utilización de la CC es una herramienta útil para cuantificar el estatus de energía de vacas de carne (Wiltbank et al., 1962).

Selk et al. (1988) evaluaron las relaciones entre la nutrición preparto, la CC, los cambios en PC y el desempeño reproductivo. Para ello, se asignaron un total de 329 vacas Hereford a cuatro planos nutritivos a lo largo de 5 años de ensayo, a fin de que los animales mantuvieran peso (M) o, luego de perder un 5\% del PC en el período hasta 8 semanas antes del parto, perdieran (PP), mantuvieran (PM), o ganaran peso (PG) en el período posterior, y así evaluar sus efectos en la preñez siguiente y en el momento de reinicio de la actividad ovárica postparto. 
El experimento tuvo como objetivos, 1) evaluar relaciones entre la variación de PC y condición corporal en diversos momentos antes del parto con el desempeño reproductivo en vacas de carne y, 2) comparar la importancia relativa de la CC y cambios en PC y CC sobre el desempeño reproductivo de los animales.

Los principales resultados de este experimento fueron:

- El tratamiento M determinó el mayor valor de preñez (71.3\%) frente a $41.8 \%$ de PP, $51.3 \%$ de $\mathrm{PM}$ y $58.3 \%$ del tratamiento $\mathrm{PG}$, con variaciones anuales estrechamente relacionadas con la $\mathrm{CC}$ al parto.

- La posibilidad de mantener o ganar peso luego de la pérdida del $5 \%$ de PC (tratamientos PM y PG) determinó un incremento en la tasa de preñez respecto al tratamiento PP, no detectándose diferencias entre ellos.

- La fecha de parto tuvo influencia sobre la tasa de preñez, debido a que vacas que paren antes, presentan mayor oportunidad de retornar a la actividad ovárica y concebir antes del fin de la cubrición respecto a aquellas que paren tardíamente.

- Tanto la CC previa al parto como el cambio de peso y el cambio en CC preparto, influyeron significativamente sobre la tasa de preñez.

- Los análisis de regresión indicaron que una respuesta cúbica fue la que mejor describió la relación entre CC preparto y tasa de preñez (Figura 12).

- Los tratamientos no afectaron el período entre parto e inicio de la actividad luteal, el porcentaje de vacas con actividad ovárica a los 85 días postparto o el período partoconcepción.

- La extrema variación entre años, pone de manifiesto la importancia de realizar análisis utilizando varios años de registros.

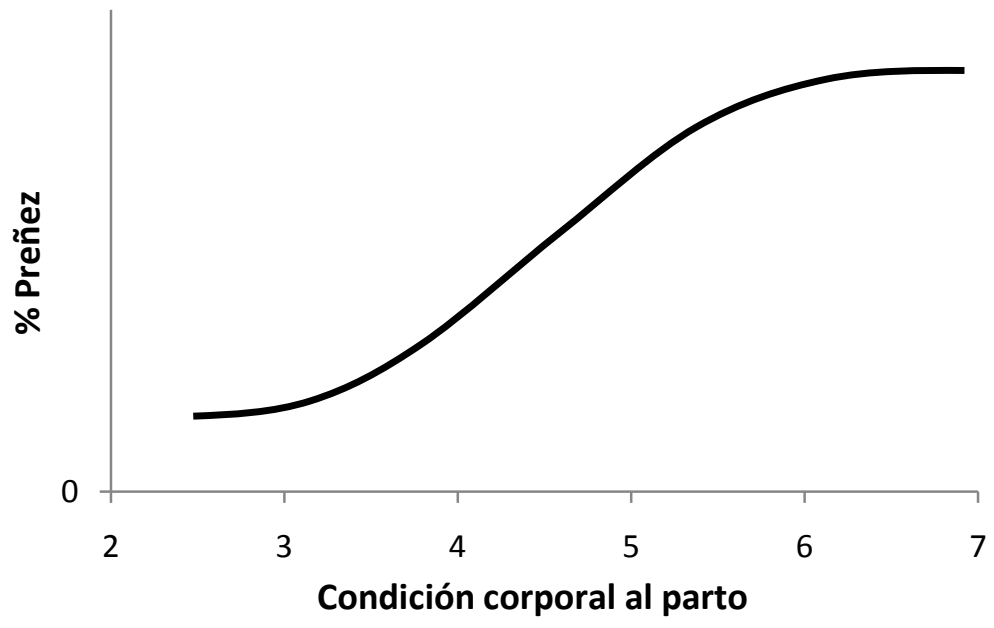

Figura 12. Influencia de la condición corporal al parto (CCP) sobre la tasa de preñez: $Y=$ $1.28-0.986 C C P+0.248 C C P^{2}-0.016 C C P^{3}$

Fuente: Selk et al. (1988) 
Resultados similares reportan Dunn et al. (1969) trabajando con 240 novillas a las cuales suministraron dos niveles de consumo de energía preparto y tres niveles postparto. Un nivel bajo de energía preparto retrasó la aparición del primer celo luego del parto. Paralelamente, la variación de energía suministrada postparto determinó marcadas diferencias en la tasa de concepción de las vacas. La tasa de concepción fue baja (64\% y $72 \%)$ con niveles bajos y moderados de energía respectivamente después del parto, mientras que las vacas alimentadas ad libitum en el postparto tuvieron altas tasas (87\%) de concepción. Este efecto se manifestó temprano en el período de cubrición, con valores de preñez a los 20 días de iniciado el mismo (80 días postparto) de 54, 42 y 33\% para los animales asignados a dietas de alta, moderada y baja energía respectivamente.

El intervalo parto-concepción en vacas de alto plano de alimentación preparto fue menor (77 días) respecto a aquellas asignadas a un plano de alimentación bajo (85 días).

Tanto el nivel energético preparto como postparto tuvieron influencia en la aparición del primer celo. En la Figura 13 se observa el porcentaje de animales que manifiesta su primer celo por tratamientos.

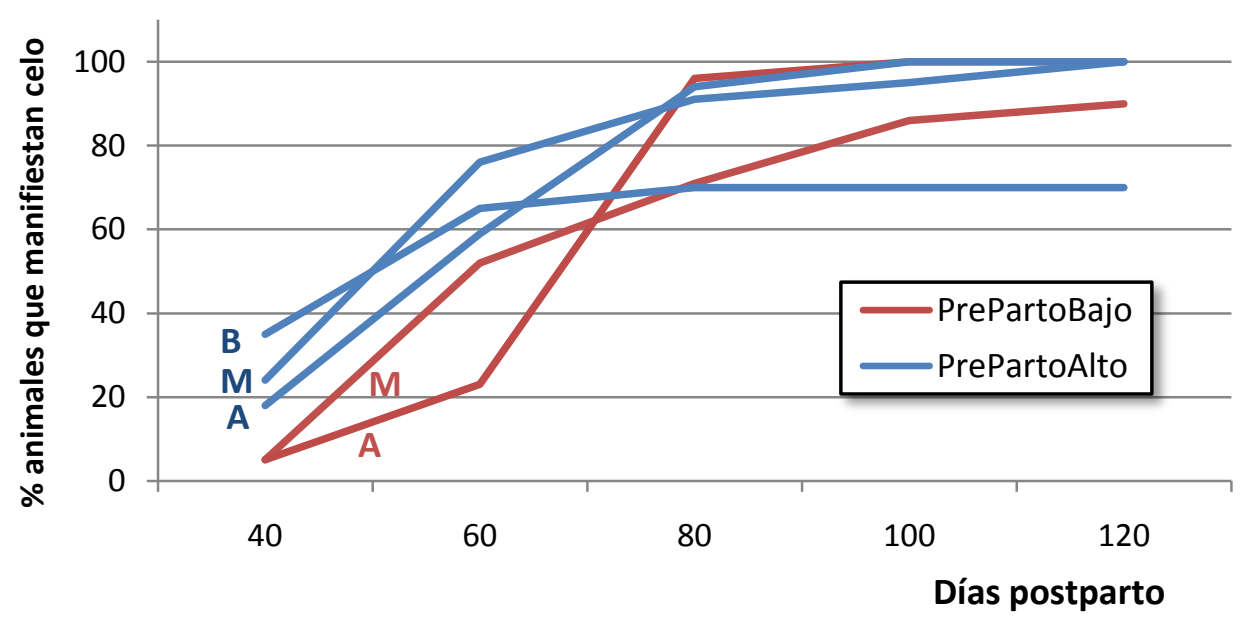

Figura 13. Porcentaje de vacas que manifiesta su primer celo a los 40,60, 80, 100 y 120 días post parto según el nivel de energía preparto (PrePartoBajo, PrePartoAlto) y el nivel energético postparto ( $A=$ alto, $M=$ medio, $B=$ bajo)

Fuente: Dunn et al. (1969)

La alimentación preparto tiene la mayor influencia en las primeras etapas, decreciendo la misma a partir de los 80 días.

El nivel de energía postparto tiene su mayor efecto en las etapas tempranas y tardías del período postparto. 
La tasa de preñez observada a los 120 días se encuentra aparentemente asociada con las ganancias de peso postparto, puesto que el grupo bajo-alto es el que presenta las mayores ganancias de peso y análogamente las mayores tasas de preñez. En contraste, el grupo alto-bajo, que pierde peso en el período posparto, es el que exhibe los índices de preñez más bajos.

Spitzer et al. (1995) analizaron los efectos de la condición corporal al parto (CCP) y la ganancia de peso posparto sobre parámetros reproductivos y productivos usando 240 vacas primíparas (21 y 28 meses de edad), con un período de cubrición de 60 días. El experimento abarcó tres años y fue realizado en tres estados de USA. Las vacas fueron aleatoriamente adjudicadas a tres grupos 90 días antes del parto y alimentadas para lograr CCP de 4, 5, o 6 ( 1 = flaca en extremo, 9 = obesa) al momento del parto. Luego del parto, la mitad de estas vacas (dentro de cada estado) fueron alimentadas en grupo, con el objetivo de lograr ganancias de peso posparto (GPP) del orden de $0.45 \mathrm{~kg} / \mathrm{d}$ (plano moderado), o $0.90 \mathrm{~kg} / \mathrm{d}$ (plano alto) hasta el comienzo de la cubrición. Las vacas pariendo con CCP de 4, 5, o 6 respectivamente, tuvieron terneros con pesos al nacer progresivamente más pesados (con $p$ $<.05)$, pero la CC no tuvo efecto sobre el peso al destete real o ajustado a los 205 días de los terneros. Vacas con altas ganancias de peso postparto tuvieron terneros más pesados al destete $(P<.05)$, tanto en valores reales como ajustados a los 205 días, que aquellas vacas con ganancias moderadas de peso. La mayor CCP resultó en más vacas en estro $(P<0.05)$ y más vacas preñadas $(P<0.05)$ a los 40 y 60 d de cubrición. La mayor ganancia del peso posparto determinó un incremento en la actividad luteal al inicio de la cubrición $(P<0.05)$, así como la aparición de celo y las tasas de preñez a los 20, 40, o 60 d de cubrición (Figura 14).

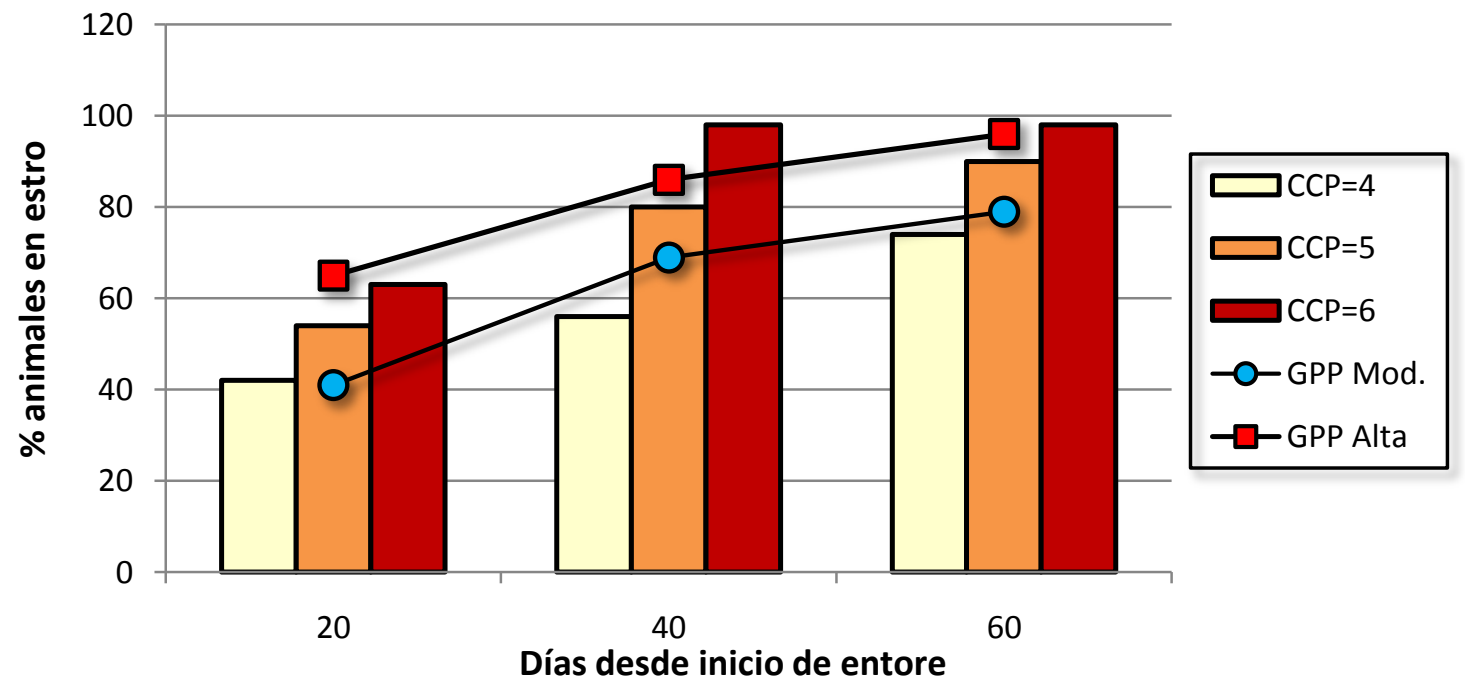

Figura 14. Porcentaje acumulado de animales en estro a los 20, 40 y 60 días de cubrición, según cond. corporal al parto $(C C P=4,5$ ó 6) y ganancias posparto (GPP=moderada, alta) Fuente: Adaptado de Spitzer et al. (1995) 
Estos resultados indican que vacas primíparas pariendo con mayor CCP tienen terneros más pesados al nacer, sin aumentar la incidencia de distocia.

Vacas pariendo con alta CCP, tienen mayor probabilidad de exhibir estro y quedar preñadas en períodos de cubrición cortos. El cambio del peso posparto parece tener un efecto aditivo en las respuestas en estro y tasa de preñez, así como sobre los pesos al destete reales y ajustados a los 205 días.

Sanz et al. (2004) analizan los efectos de 18 variables productivas y reproductivas registrados en 549 vacas de las razas Brown Swiss y Pirenaica sobre el intervalo posparto (IPP). En el análisis se utilizaron técnicas multivariantes (análisis de correspondencia múltiple). Las variables que mayor incidencia tuvieron sobre el IPP, explicando un 59\% de la inercia total fueron: 1) nivel de alimentación preparto (19\% de inercia), 2) nivel de alimentación posparto (asociado a nro. de partos, 16.4\%), 3) frecuencia de amamantamiento (13\%) y 4) dificultad al parto (10.5\%).

La complejidad de las interacciones entre las decisiones de los agricultores y la respuesta del animal (a nivel individual y de rebaño) determina la relevancia del uso de modelos informáticos. El principal objetivo de estos modelos es el de simular las consecuencias de diferentes medidas de manejo del rebaño sobre la producción de carne vacuna usando diferentes escalas de tiempo (Agabriel y Ingrand, 2004).

El grado de complejidad puede ser muy variable, tanto en lo que refiere al nivel al cual modelar los procesos como a la escala de tiempo empleada. Es prácticamente imposible incluir todos los procesos biológicos (la fisiología animal y la dinámica del rebaño operan en diferentes escalas de tiempo) y un sistema muy completo no garantiza resultados exactos. El desafío es escoger una representación apropiada de la biología de los animales que sea necesaria y útil cuando el objetivo es el de construir el simulador a nivel de rebaño (Agabriel y Ingrand, 2004).

Si el objetivo es evaluar estrategias de manejo a nivel de rebaño, no es necesario modelar, por ejemplo, procesos de digestión y metabolismo. En este caso, los módulos individuales pueden centrarse en los procesos de reproducción y crecimiento y asociarse a un nivel de producción general. Si, por el contrario, el objetivo es estimar el consumo energético a nivel de rebaño, se hace necesario diferenciar el consumo y metabolismo energético en las diferentes categorías y respuestas fisiológicas (Agabriel y Ingrand, 2004).

Sanders y Cartright (1979 a,b) desarrollaron un modelo determinístico, donde analizan el efecto de distintas variables sobre la producción de un sistema de cría. Los autores simulan el comportamiento reproductivo para cada clase de hembras en servicio en cada mes del año. La fertilidad de las novillas es concebida como el producto de su grado de 
madurez fisiológica, condición corporal, tasa de ganancia de peso y potencial genético reproductivo. En vacas es función de la condición corporal, la tasa de ganancia de peso, el nivel de lactancia, el tiempo desde el parto y el potencial genético reproductivo.

Para ello se definen tres variables: 1) PEST, definida como la proporción de hembras que no presentaron celo el mes anterior y que lo manifiestan en el mes actual, 2) CCYC, la fracción de hembras que manifestaron celo el mes anterior y repiten durante el mes actual y, 3) PCON, definida como la tasa de concepción de las hembras que manifiestan celo.

Para el cálculo de estas tres variables se definen 4 términos, CFW, CFDW, CFM y CFT. El primero de ellos (CFW) es utilizado para corregir la ocurrencia de estro según la condición de los animales, definida como la relación entre el peso actual y un peso teórico $W M$, el cual representa el peso mínimo requerido, a una edad determinada, para alcanzar la máxima fertilidad:

si $W \geq W M \Rightarrow \quad C F W=1$

si $3 / 4 W M \leq W<W M \Rightarrow \quad C F W=\frac{\left(\frac{W}{W M}-0.75\right)}{1-0.75}$

si $W<3 / 4 W M \Rightarrow \quad C F W=0.001$

El segundo término, CFDW, es una medida del plano nutritivo actual y para su cálculo es necesario estimar previamente $D W M$, definido como la mínima ganancia necesaria para lograr la máxima fertilidad:

$D W M=G W M+0.01 \cdot(W M-W)$

La diferencia entre esta ganancia y la actual es utilizada para la estimación de CFDW:

$C F D W=1-\frac{100 \cdot(D W M-D W)}{W M}$,

donde $D W$ es la ganancia diaria actual

El último término (CFM) involucra un ajuste por grado de madurez en novillas y se calcula como:

$C F M=\frac{\left(\frac{W M}{A 8 \cdot A}-A 9\right)}{1-A 9}$,

\footnotetext{
${ }^{2}$ Se ha detectado una incoherencia en esta ecuación: si W/WM $=0.75 \Rightarrow C F W=0$, lo cual no es coherente puesto que a valores menores de este cociente, CFW $>0$
} 
donde $A 8$ y $A 9$ toman valores estimados por los autores de 0.6 y 0.67 respectivamente y $A$ es el peso adulto. En el cálculo de PEST, 0.85 veces CFM es la fracción de hembras del grado de madurez definido, con CFW y CFDW ambos fijados en 1, que alcanzarán la pubertad (manifestar celo por primera vez), a lo largo del actual mes. Como se desprende de la ecuación, estos valores utilizados de $A 8$ y $A 9$ determinan que las novillas no manifestarán celo a menos que alcancen un valor de $W M$ igual al $40 \%$ de su peso adulto y que el grado de madurez no representará un factor determinante de su fertilidad hasta que $W M$ no represente un $60 \%$ del peso adulto.

CFT corrige la tasa de fertilidad por el tiempo desde el parto en vacas, calculado como:

$$
C F T=1-e^{-A 5 \cdot(30 \cdot(j-1)) \cdot 3.9} \text {, }
$$

donde $A 5^{3}=0.0000009$ y j es el mes de lactancia. CFT actúa corrigiendo la fertilidad en función del tiempo que se necesita para que el tracto reproductivo se recupere del proceso del parto. Este parámetro se fuerza a tomar valor 1 en novillas y vacas que han parido 40 más meses antes del mes corriente.

La fracción de hembras que entran en celo en el mes actual no habiéndolo hecho el mes previo se calcula entonces como:

$$
P E S T=0.85 \cdot C F W \cdot C F D W \cdot C F M \cdot C F T
$$

La porción de hembras que manifestaron celo el mes anterior y repiten durante el mes actual CCYC, se calcula:

$$
C C Y C=C F W^{0.1} \cdot C F D W^{0.1}
$$

la proporción de hembras de determinada clase en entrar en celo durante el mes actual es:

$$
A C C=C C Y C \cdot A C C+P E S T \cdot(1-A C C),
$$

siendo el $A C C$ a la derecha de la ecuación [1.28], la proporción de animales de la clase que entraron en celo el mes anterior. PCON, definida como la fracción de hembras que entran en celo durante el mes actual, se calcula como:

$$
P C O N=0.75 \cdot C F T^{0.5} \cdot C F W^{0.2} \cdot C F D W^{0.2} \cdot M B(T)
$$

donde $M B(T)$ es igual a 1 durante la cubrición y a 0 en otro momento del año. El coeficiente 0.75 es variable según el sistema de producción.

\footnotetext{
${ }^{3}$ Aparentemente existe una inconsistencia en el valor de este coeficiente, el cual restringe totalmente la posibilidad de ocurrencia de celo. Posiblemente el valor correcto sea cercano a 0.009 .
} 
En 1984, Kahn y Lehrer proponen algunos ajustes al modelo desarrollado por Sanders y Cartright en 1979. Son destacables las modificaciones que aplican a los coeficientes de corrección CFW y CFDW:
si $W \geq 0.9 W M \Rightarrow$
$C F W=1$

de otra manera:

$C F W=-0.35+1.5 \cdot \frac{W}{A} \quad C F W \geq 0$

Los autores registran diferencias en este parámetro de 0.85 vs 0.2 del modelo original, para valores del cociente $W / W M$ de alrededor de 0.8 .

En el caso del coeficiente CFDW:

$$
C F D W=1-0.6 \cdot W L \quad C F D W \geq 0,
$$

siendo $W L$ la pérdida de peso ( $\mathrm{kg} / \mathrm{día})$

Asimismo, estos autores incorporan algunos otros aspectos como el efecto del amamantamiento, esterilidad y la edad de las vacas sobre la probabilidad de concepción y su distribución, basados en información proveniente de un rebaño comercial en Israel.

Blanc y Agabriel (2008) desarrollaron un modelo para estudiar los efectos de decisiones de manejo y características de los animales sobre el desempeño reproductivo y la distribución de partos en vacas Charolais. Los intervalos parto-primer celo, duración de celo, parto-concepción e intervalo interpartos fueron simulados mediante procedimientos estocásticos y reglas empíricas, siendo afectados por diversos factores como estrategias de alimentación, época y duración del período de cubrición. El modelo fue contrastado con información de 139 vacas primíparas en lo que respecta a su capacidad de predecir la duración del anestro postparto. El modelo explicó sólo el 39\% de la variación individual observada, resultado que pone de manifiesto la necesidad de profundizar en aspectos como la influencia de las combinaciones entre la condición corporal al parto y la duración de la cubrición sobre el anesto posparto. Se destaca la influencia de la fecha de parto sobre la duración del período parto-primer celo, aunque su efecto no es del todo claro, manejándose hipótesis de índole nutricional, así como la influencia del fotoperíodo sobre la actividad ovárica. 


\subsubsection{Distocia y dificultad al parto}

La distocia y dificultades al parto tienen una gran importancia en la producción de carne. Un parto difícil, requiriendo asistencia, conduce a un aumento en los costos veterinarios y de mano de obra. Sin embargo, la principal implicancia es una disminución de la productividad debido a la mortalidad de terneros y vacas y al atraso en el retorno de las vacas a la actividad reproductiva, lo cual muchas veces redunda en el descarte de vacas que no logran preñarse en el período de cubrición (Wang et al., 2001).

Nix et al. (1997) estudiaron los factores que afectan la mortalidad y la distocia en ganado de carne, analizando para ello, una base de datos con 2191 registros de partos controlados entre 1981 y 1993. La dificultad al parto fue registrada por un escore de 4 categorías: $1=\sin$ asistencia, 2 = tracción leve, 3 = tracción mecánica fuerte y 5 = cesárea. Aparte de la raza de madre y padre y factores genéticos individuales, otros caracteres que influyeron sobre la mortalidad de los terneros fueron el sexo de los mismos, el número de partos de la madre y la dificultad al parto (Tabla 4).

Tabla 4. Mortalidad en función del sexo del ternero, el número de parto de la madre y la dificultad al parto

\begin{tabular}{l|ccc}
\hline \multicolumn{1}{c|}{ Variable } & Muertos $(\boldsymbol{n})$ & Vivos $(\boldsymbol{n})$ & \% Mortalidad \\
\hline Sexo & & & \\
$\quad$ macho & 71 & 1051 & $6.75^{\mathrm{a}}$ \\
$\quad$ hembra & 28 & 1041 & $2.62^{\mathrm{b}}$ \\
№ parto & & & \\
$\quad$ primíparas & 27 & 359 & $6.99^{\mathrm{a}}$ \\
$\quad$ multíparas & 72 & 1733 & $3.99^{\mathrm{b}}$ \\
Score de dificultad al parto & & & \\
1 & 56 & 1982 & $2.75^{\mathrm{a}}$ \\
2 & 9 & 34 & $20.93^{\mathrm{b}}$ \\
3 & 32 & 74 & $30.19^{\mathrm{b}}$ \\
4 & 2 & 2 & $50.00^{\mathrm{c}}$ \\
\hline
\end{tabular}

Fuente: Nix et al. (1995)

El peso promedio al nacimiento de los terneros muertos y vivos fue igual ( $36 \mathrm{~kg})$ y el \% de partos con algún nivel de asistencia fue de $7.5 \%$.

El peso al nacer del ternero, ha demostrado ser el factor individual más determinante de la dificultad al parto (Burfening et al., 1978). Estos autores analizaron información de 
350000 registros de la evaluación genética de la raza Simmental, encontrando que el peso al nacer y el largo de gestación estuvieron positivamente correlacionados, pero el largo de gestación no tuvo efecto significativo sobre la dificultad al parto cuando la variación en el peso al nacer fue constante.

El efecto del peso al nacer sobre la facilidad de parto y otras variables asociadas al crecimiento puede apreciarse en la Tabla 5.

Tabla 5. Coeficientes parciales (b) y parciales estándar (b') de regresión del peso al nacer de los terneros sobre la facilidad de parto y otras características de crecimiento.

\begin{tabular}{l|cc}
\hline Item & $\boldsymbol{b} \pm$ ES & $\boldsymbol{b}^{\prime} \pm$ ES \\
\hline Facilidad de parto (score) & $0.048 \pm 0.002$ & $0.573 \pm 0.013$ \\
\% partos asistidos & $2.64 \pm 0.110$ & $0.298 \pm 0.014$ \\
Peso a los 205 d (kg) & $1.69 \pm 0.070$ & $0.321 \pm 0.014$ \\
Ganancia diaria (kg/d) & $0.0035 \pm 0.000$ & $0.140 \pm 0.014$ \\
\hline
\end{tabular}

Fuente: Adaptado de Burfening et al. (1978)

La edad y el número de parto de la vaca y el sexo del ternero, son los principales factores no-genéticos que determinan la ocurrencia de distocia. La estación de parto y el nivel nutricional de las vacas también están asociados a este problema, pero de una forma errática y probablemente en interacción entre sí (Berger, et al., 1992).

Basarab et al. (1993) reportan una precisión de 79.4\% en la predicción de dificultades al parto en novillas ( $n=3269$ ), utilizando para ello el cociente área pélvica/peso vivo al momento de la confirmación de preñez.

Colburn et al. (1997) analizaron los factores que afectan la dificultad al parto medido a través de un escore (SDP) de 5 categorías, $(1=$ sin asistencia, 2 = tracción leve, 3 = tracción mecánica, 4 = tracción mecánica fuerte y 5 = Cesárea), encontrando que el peso del ternero al nacer explicó la mayoría de la variación (33.4\%). Las siguientes variables en orden de importancia fueron el área pélvica a los 22 meses de edad, el ancho de pelvis y el ancho de hombros del ternero, sumando un $r^{2}$ total de $43 \%$. En este trabajo no se evidenciaron efectos del peso de las novillas sobre el escore y, a diferencia de lo encontrado por Laster et al.(1979), tampoco existió un efecto del escore sobre las tasas de preñez siguientes, aunque existió una tendencia a que las novillas del grupo 4 (tracción mecánica fuerte), registraran un atraso en la fecha de concepción de la segunda cría. 
Similares resultados reporta Johnson (1988) en 186 novillas Hereford donde el peso al nacer fue la principal variable en determinar el SDP $\left(r^{2}=0.33\right)$, con el área pélvica preparto ubicándose en segundo lugar $\left(r^{2}\right.$ acumulado $\left.=0.45\right)$. la ecuaciones de predicción que incluyeron todas las variables o solamente aquellas previas a la cubrición explicaron el $63 \%$ y el $25 \%$ de la variación del SDP, respectivamente.

Spitzer et al. (1995) generaron tres planos alimenticios preparto, logrando que las novillas llegaran en condición corporal al parto (CCP) de 4, 5 y 6 . Esto determinó pesos correspondientemente mayores al parto y mayores pesos al nacer de los terneros. Sin embargo no se encontraron diferencias en el escore de dificultad al parto (Tabla 6).

Tabla 6. Peso vivo (PV) al parto, peso al nacer (PN), escore de distocia (ED), peso (PD) y edad al destete (ED) y peso al destete corregido a los 205 días $\left(P D C_{205}\right)$ según condición corporal al parto (CCP) de novillas.

\begin{tabular}{c|ccccccc}
\hline CCP & $\mathrm{n}$ & $\begin{array}{c}\text { PV al parto } \\
(\mathrm{kg})\end{array}$ & $\begin{array}{c}\mathrm{PN} \\
(\mathrm{kg})\end{array}$ & ED & $\begin{array}{c}\text { PD } \\
(\mathrm{kg})\end{array}$ & ED (días) & $\begin{array}{c}\mathrm{PDC}_{205} \\
(\mathrm{~kg})\end{array}$ \\
\hline $\mathbf{4}$ & 73 & 338 & $28.9^{\mathrm{a}}$ & 1.2 & 192 & 227 & 187 \\
$\mathbf{5}$ & 107 & 375 & $30.4^{\mathrm{b}}$ & 1.2 & 193 & 224 & 193 \\
$\mathbf{6}$ & 60 & 424 & $32.4^{\mathrm{c}}$ & 1.2 & 197 & 228 & 198 \\
\hline
\end{tabular}

Fuente: Adaptado de Spitzer et al. (1995)

En relación al efecto de la dificultad al parto sobre el crecimiento posterior del ternero, los animales nacidos por cesárea tuvieron peses al destete menores y significativamente diferentes del resto de los grupos. Si bien este grupo fue el que evidenció el mayor peso al nacer, los autores postulan que la cirugía cesárea pudo haber afectado negativamente la producción de leche de las novillas, lo cual desaceleró el crecimiento de los terneros. Sin embargo, estos terneros mostraron ganancias compensatorias en el feedlot y tuvieron pesos similares de faena. Los únicos terneros que mostraron ganancias significativamente más bajas en el feedlot fueron los del grupo 1 (sin asistencia). Estos terneros fueron los más pequeños al nacer y pudieron haber tenido menos potencial genético de crecimiento.

\subsubsection{Producción de leche}

Freetly y Cundiff (1998) evaluaron el efecto de dos niveles nutricionales aplicados desde el destete hasta la cubrición en 550 novillas de diferentes razas puras y cruzas. Se estudió su efecto sobre el desempeño reproductivo, el crecimiento del ternero y la 
producción de leche de los animales hasta los 200 días de edad del ternero. La producción de leche en novillas Hereford y Angus se ajustó a una ecuación polinómica de tercer orden en función de la edad del ternero (Figura 15). La producción acumulada entre los 50 y los 200 días de edad del ternero fue de $842 \mathrm{~kg}$ y $905 \mathrm{~kg}$ para los animales Hereford y Angus respectivamente, aunque esta diferencia no fue significativa.

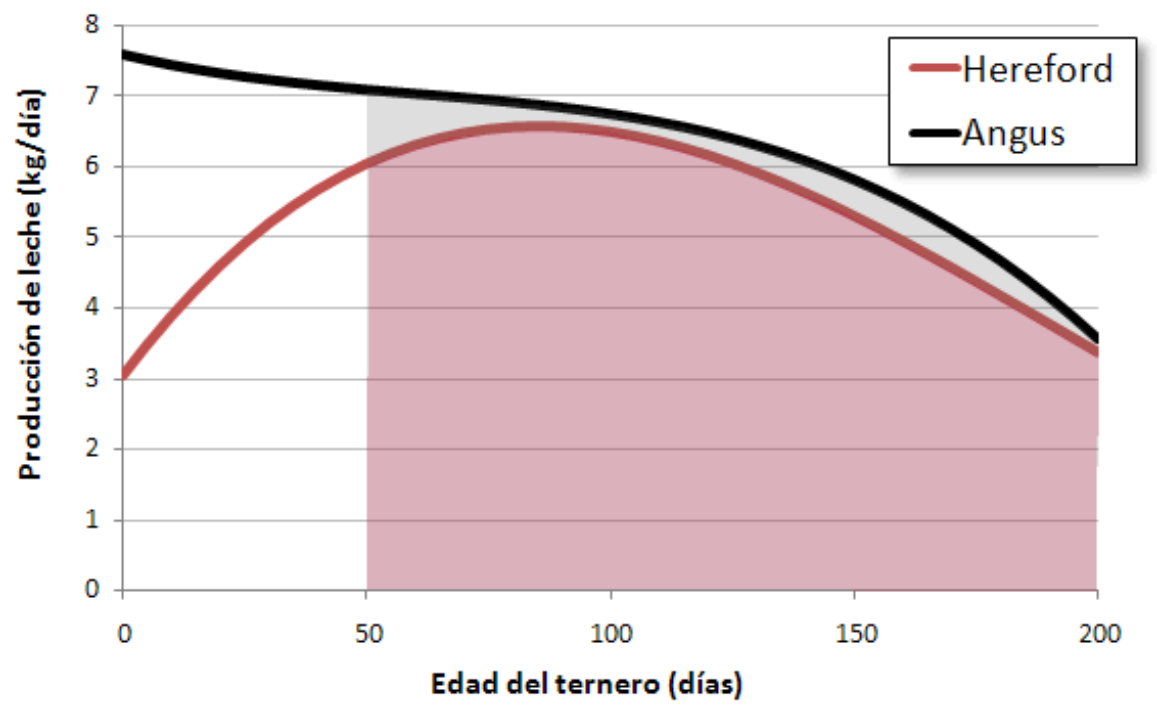

Figura 15. Producción de leche estimada entre los 50 y 200 días de lactancia en novillas de raza Hereford y Angus

Fuente: Adaptado de Freetly y Cundiff (1998)

\subsubsection{Modelos bioeconómicos}

Pang et al. (1999) desarrollan un modelo dinámico-determinístico para simular los efectos de diferentes factores productivos y alternativas de manejo sobre la eficiencia bioeconómica de los sistemas de producción de carne de Canadá. El modelo se compone de 4 submodelos: inventario de ganado, requerimientos nutricionales, producción de forraje y económico. El submodelo de requerimientos nutricionales se basa en el sistema NRC (1996). Los análisis de sensibilidad mostraron que el peso adulto de las vacas, la producción de leche, el peso al destete de terneros y los precios de los alimentos fueron los principales determinantes de los resultados económicos. Los autores destacan la potencialidad del modelo para la consideración simultánea de múltiples factores en un sistema integrado, lo que podría ser muy útil a extensionistas ganaderos y productores para evaluar los posibles efectos de diferentes estrategias de gestión y selección sobre la eficiencia bioeconómica.

En Uruguay, Cardozo y Ferreira (1994) desarrollaron un modelo determinísticodinámico de simulación de cebo de novillos en pastoreo. El modelo consta de un módulo biológico que simula el crecimiento y cebo de los animales a través del tiempo y de un 
módulo económico, el cual permite evaluar las opciones del modelo productivo desde el punto de vista económico-financiero. Inicialmente, se deben definir parámetros de la pastura, animales, económico-financieros y de manejo. El modelo posibilita estudiar los efectos de decisiones tomadas comúnmente en estas situaciones de producción, como ser el precio de compra a pagar por los animales, tipo de pastura a utilizar, edad y peso de animales a comprar, duración del ciclo de cebo para alcanzar el peso objetivo y dotación a manejar. La validación con datos experimentales no evidenció diferencias significativas respecto a los valores estimados por el modelo. Con todo, los autores concluyen la necesidad de profundizar el estudio de las relaciones planta-animal para mejorar la capacidad predictiva del modelo.

Ponssa et al. (2007) analizan, mediante un modelo de simulación, el impacto productivo y económico de diversas combinaciones de variables, con especial atención en la tasa de preñez, desde una perspectiva sistémica ${ }^{4}$. A partir de información obtenida de informantes calificados se construyó un modelo productivo cuyo análisis de sensibilidad corroboró la elevada incidencia de la tasa de preñez (además de la carga y el precio del ternero) sobre el Ingreso Neto. Otros resultados obtenidos indican que: a) para que se neutralice el efecto del incremento de la preñez sobre el Ingreso Neto, la relación de precios vaca-descarte/ ternero debería situarse en valores muy desfavorables para el ternero y b) al aumentar la tasa de preñez se incrementan paralelamente los requerimientos de energía del rebaño. En la Figura 16, se presentan los efectos del aumento de la tasa de preñez sobre la producción de carne y el ingreso neto de un establecimiento.

\footnotetext{
${ }^{4}$ El modelo fue desarrollado en Argentina, donde las condiciones de producción son muy similares a las existentes en Uruguay, lo que le confiere un valor añadido ya que los modelos de este tipo son relativamente escasos en la región.
} 


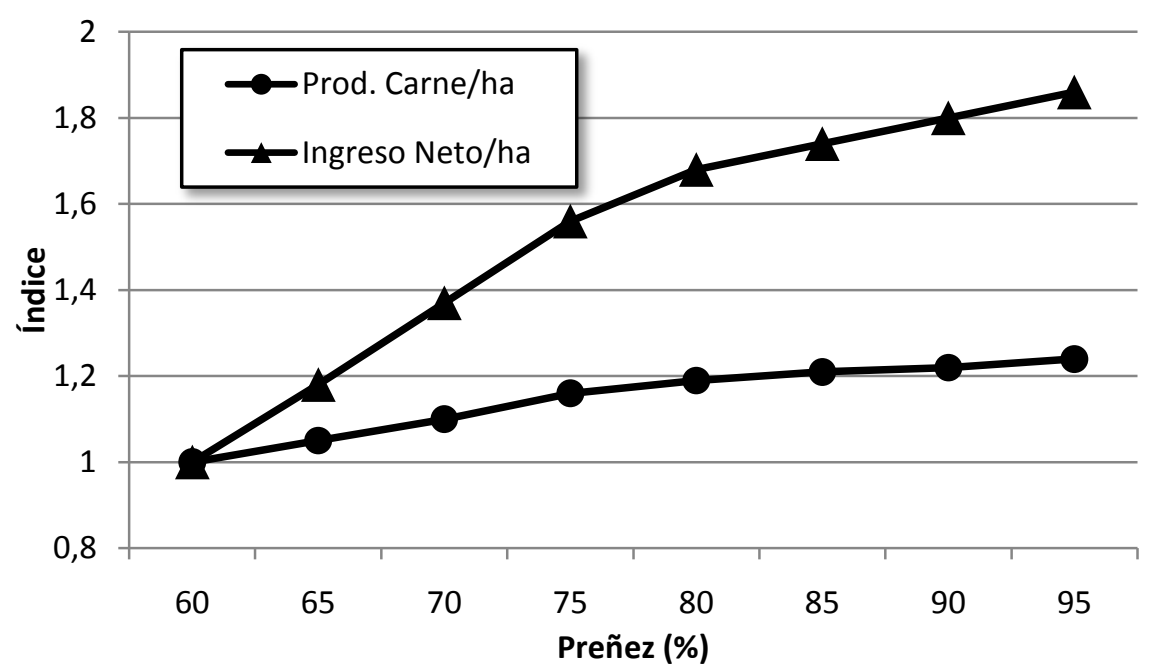

Figura 16. Índice de aumento relativo de la producción de carne y el ingreso neto ante incrementos en la preñez (índice base preñez 60\%=1)

Fuente: Ponssa et al. (2007)

Los autores explican el aumento proporcionalmente mayor del ingreso neto, por una mayor producción con una mayor proporción de animales jóvenes en las ventas (30 a 69\% al pasar de 60 a 95\% preñez), los cuales tienen un valor sensiblemente superior.

\subsubsection{Modelos de evaluación de características genéticas}

Koots y Gibson (1998) desarrollaron un modelo bioeconómico de un sistema integrado de producción de carne en Canadá, para obtener valores económicos de la mejora genética de múltiples características. El objetivo de selección propuesto fue el de maximizar el ingreso total del sistema. Las características que potencialmente podían influir en los ingresos y costos del sistema fueron: tamaño adulto, facilidad de parto (directa y maternal, en novillas y vacas separadamente), fertilidad de vacas, sobrevivencia de terneros, sobrevivencia de vacas, producción de leche, tasa de crecimiento residual post destete, consumo en animales en crecimiento y adultos, peso de faena residual y porcentaje de grasa de recorte a cobertura de grasa constante, marmoreo y porcentaje de carne. En la Tabla 7 se presentan los resultados obtenidos. 
Tabla 7. Valores económicos estimados para las diferentes características, expresados por unidad de desvío estándar genético aditivo por vaca

\begin{tabular}{l|c}
\hline Característica & Valor económico \\
\hline Tamaño adulto (kg) & 3.6 \\
Facilidad de parto (vacas) & 3.8 \\
Facilidad de parto (novillas) & 2.8 \\
Fertilidad de vacas (\%) & 14.7 \\
Sobrevivencia de terneros (\%) & 17.5 \\
Sobrevivencia de vacas (\%) & 3.7 \\
Pico de producción de leche (kg/día) & 0.5 \\
Ganancia de peso postdestete (kg/día) & 2.1 \\
Consumo animales adultos (Mcal/día) & -12.4 \\
Consumo animales en crecimiento (Mcal/día) & -13.2 \\
Peso de faena (kg) & 4.4 \\
Grasa de recorte (\%) & 13.6 \\
\hline
\end{tabular}

Fuente: Koots y Gibson (1998)

Se destaca la importancia económica relativa de la sobrevivencia de los terneros, características reproductivas, consumo y rendimiento de grasa.

En el año 2006, Yáñez et al. desarrollan un modelo determinístico dinámico para la simulación de un sistema doble propósito en Venezuela. La función objetivo establecida fue la maximización del Margen Bruto (MB) del sistema. El modelo se concibió compuesto de al menos 2 versiones principales que se articulan integradamente para alcanzar los objetivos de simulación. En la fase de experimentación se constató que en las condiciones que se realizó la simulación, las características que podrían integrar el objetivo de selección del sistema doble propósito fueron:

- Peso adulto de la vaca: se definió que esta variable se comportaba como la directriz del sistema, al afectar y definir una cantidad de variables de crecimiento, reproductivas y los requerimientos de energía neta. Los mayores ingresos por la venta de animales más pesados no compensaba el incremento en los costos de mantenimiento y crecimiento de esos animales. Hubo una relación inversa entre MB y peso adulto de la vaca, concluyendo que con el mejoramiento genético se debería buscar que el peso adulto de las vacas estuviese en valores medios/bajos.

- Producción de leche: el MB se hace positivo solo cuando la producción alcanza 14 litros diarios de leche, cambio que se hace difícil de alcanzar desde el punto de vista del mejoramiento genético en el corto-mediano plazo, ya que la mayoría de promedios diarios reportados para los diferentes grupos raciales usados en sistemas doble propósito en Venezuela, oscilan entre 4 y 9 L/día de lactancia. 
- Longevidad: fue evaluada a través de la vida productiva de las vacas y mostró escasa influencia sobre el MB. Igualmente, este indicador se incrementó al incrementarse la vida productiva de las vacas.

- Intervalo entre partos: fue estimado en función de los días vacía postparto, variable que tuvo una importancia marcada sobre el MB (negativa) y su control en el sistema de producción afectó considerablemente el comportamiento de las demás variables.

Jorge et al. (2006) desarrollaron un modelo bioeconómico para el cálculo del valor de diversas características de interés económico en sistemas de producción de ganado de carne en Brasil. Los registros productivos, los parámetros biológicos y económicos se obtuvieron de un rebaño de raza Nelore. El modelo fue desarrollado para dos modelos de producción: 1) ciclo completo con venta de reproductores y 2) cría, utilizando un modelo determinístico y estático usando planillas Excel para la realización de los cálculos.

Las variables de interés seleccionadas para estimar su valor económico en ambos sistemas de producción fueron:

- Peso al destete

- Peso adulto de la vaca

- Tasa de preñez

- Tasa de destete

El impacto de los cambios en los niveles genéticos de las características, sobre el ingreso anual de los sistemas, se evaluó incrementando el valor original de las características en un 1\%. Dicho incremento resultó en cambios positivos en los ingresos para todos los casos, con un mayor efecto al incrementar la tasa de destete en ambos sistemas (Tabla 8).

Tabla 8. Valores económicos (VE, $\$ R / K g)$ de las características evaluadas en los dos sistemas

\begin{tabular}{l|cc}
\hline Característica & Ciclo completo & Cría \\
\hline Peso al destete & 0.40 & 1.31 \\
Peso adulto & 0.09 & 0.09 \\
Tasa de preñez & 3.20 & 2.41 \\
Tasa de destete & 10.15 & 3.36 \\
\hline
\end{tabular}

Fuente: Jorge et al. (2006)

Respecto al peso adulto de la vaca, si bien el incremento fue leve, no presentó un impacto económico negativo como ha sido reportado en otros trabajos. Según los autores, 
esto es explicado por el bajo costo de mantenimiento de las pasturas asociado a buenos precios de las vacas que se descartan del sistema.

Werth et al. (1991) desarrollaron a) un modelo estocástico de reproducción y b) un modelo económico determinístico de simulación, para evaluar el efecto de interacciones entre las decisiones de manejo y los parámetros reproductivos, en cuanto a su influencia sobre el ingreso neto en un ciclo productivo anual con un rebaño de 1000 vacas.

El modelo estocástico se usó para determinar el desempeño del rebaño cuando el largo del período de cubrición (45, 70 y 120 días) interactuaba con 3 intervalos de anestro post parto (48, 65 o 90 días) y con 3 tasas de procreo en primíparas (60, 70 y $80 \%)$.

Se utilizaron 3 intervalos post parto (corto, moderado y largo) para reflejar diferencias en el desempeño reproductivo. Además, las novillas de reemplazo fueron cubiertas 3 semanas previo a la cubrición del rebaño general o al mismo momento que el resto. Se generaron 54 simulaciones. Las entradas del modelo económico fueron: desempeño del rebaño, precio de los alimentos y de los animales, costos no alimentarios y requerimientos de alimentación en un año de producción. Los requerimientos de alimentación se calcularon separadamente para cada intervalo post parto de manera de reflejar 3 diferentes escores de condición corporal (flaca, moderada, gorda) para que se correspondan con los 3 intervalos post parto (corto, medio y largo) simulados.

Con 70 días de cubrición, el ingreso neto fue mayor cuando el intervalo post parto fue corto o moderado. Cuando el intervalo post parto fue largo, el ingreso neto fue mayor con 120 días de cubrición, debido a que por el largo del período (120 días), las tasas de preñez fueron las más altas y los costos de mantenimiento fueron los menores para las vacas flacas.

En general, el ingreso neto fue mayor cuando las vacas se manejaron con un intervalo postparto de moderada duración.

Las novillas cubiertas 3 semanas antes que las vacas, mostraron el mayor retorno económico cuando los intervalos post parto fueron de larga duración.

Respecto a implicancias prácticas, el modelo demostró que vender un ternero liviano nacido tarde es más rentable que vender una vaca vacía y reemplazarla con una novilla. Sobre todo, prácticas de manejo tendientes a mantener un alto número de vacas adultas en el rebaño, determinan una mayor eficiencia tanto reproductiva como económica puesto que más terneros pesados son producidos respecto a la cantidad de alimento necesaria para mantenimiento y lactación.

Fernández-Perea y Alenda (2004) desarrollaron una ecuación de beneficio con características económicas y productivas de la raza Avileña Negra Ibérica, en un sistema de 
producción desde el nacimiento hasta la faena, con el objetivo de generar un índice de selección que maximice dicha función de beneficio para esta raza en España. El sistema estaba definido por el manejo del rebaño con vacas en amamantamiento y terneros en cebo.

Las características relevadas fueron:

- Fertilidad

- Peso adulto de la vaca

- Peso al destete, efecto directo y efecto maternal

- Peso post destete

- Rendimiento de carcasa de la vaca adulta

Los resultados obtenidos del trabajo se presentan en la Tabla 9.

Tabla 9. Valores económicos, pesos y pesos relativos del índice de selección desarrollado para fertilidad, peso adulto, peso al destete (maternal y directo), ganancia posdestete $y$ rendimiento carnicero

\begin{tabular}{l|ccc}
\hline & $\begin{array}{l}\text { Valor } \\
\text { económico }\end{array}$ & $\begin{array}{l}\text { Peso } \\
\text { económico } \\
\text { estandarizado }\end{array}$ & $\begin{array}{l}\text { Peso } \\
\text { económico } \\
\text { relativo (\%) }\end{array}$ \\
\hline Fertilidad (\%) & 7.8 & 21.1 & 16.0 \\
Peso adulto $(\mathrm{kg})$ & -3.6 & -73.9 & 56.0 \\
Peso al destete directo $(\mathrm{kg})$ & -0.4 & -4.6 & 3.5 \\
Peso al destete maternal $(\mathrm{kg})$ & -3.5 & -23.3 & 17.0 \\
Ganancia post destete (kg/día) & 64.6 & 6.3 & 4.7 \\
Rendimiento carnicero (\%) & 6.4 & 2.5 & 2.0 \\
\hline
\end{tabular}

Fuente: Fernández-Perea y Alenda (2004)

Mediante el índice de selección calculado, se seleccionaría por animales con menor peso adulto y menor ganancia pre destete, así como animales con mayores ganancias post destete y mejores características de carcasa. En conclusión, los autores afirman que la mejora de la fertilidad, la ganancia de peso post destete y las características relativas al rendimiento carnicero, tendrían un efecto positivo sobre la rentabilidad de los sistemas de producción de carne de la raza Avileña Negra Ibérica.

En Uruguay, Urioste et al. (1998) estimaron los valores económicos de los principales rasgos identificados en los objetivos de selección de razas carniceras en cuatro sistemas pastoriles de producción de bovinos de carne. 
Estas características fueron: tasa de destete, facilidad de parto (directa y materna), peso de venta (animales jóvenes y vacas), consumo de alimento (animales jóvenes y vacas) y rendimiento de canal.

Los sistemas simulados fueron dos sistemas de ciclo completo diferenciados por nivel de intensividad, un sistema de cría en campo natural y cebo independiente sobre un $40 \%$ de pasturas mejoradas y un sistema similar al anterior con cruzamientos con razas terminales. En la Tabla 10 se presentan los valores económicos obtenidos.

Tabla 10. Valores Económicos (VE) y Variación económica-genética (VEG) de distintos conjuntos de rasgos en diferentes sistemas de producción, para razas multipropósito

\begin{tabular}{|c|c|c|c|c|c|c|c|}
\hline \multirow{2}{*}{$\begin{array}{l}\text { Sistema } \\
\text { de } \\
\text { producción }\end{array}$} & \multirow{2}{*}{$\begin{array}{c}\text { Tasa de } \\
\text { Destete (\%) }\end{array}$} & \multicolumn{2}{|c|}{$\begin{array}{l}\text { Facilidad de parto } \\
\text { (\%) }\end{array}$} & \multicolumn{2}{|c|}{$\begin{array}{c}\text { Peso de venta } \\
\text { (kg) }\end{array}$} & \multicolumn{2}{|c|}{ Consumo (kg MS) } \\
\hline & & directa & materna & novillos & vacas & progenie & vaca \\
\hline \multicolumn{8}{|c|}{ Valores económicos (€/100 vacas) } \\
\hline Sistema 1 & 30.5 & 7.8 & 9.3 & 13.9 & 3.2 & -11.4 & -4.1 \\
\hline Sistema 2 & 107.9 & 12.4 & 14.9 & 18.5 & 5.9 & -2.9 & -1.4 \\
\hline Sistema 3 & 84.1 & 8.6 & 10.0 & 19.8 & 4.1 & -3.5 & -8.0 \\
\hline Sistema 4 & 99.7 & 10.7 & 21.1 & 16.0 & 4.1 & -3.9 & -10.0 \\
\hline \multicolumn{8}{|c|}{ Variación económica-genética } \\
\hline Sistema 1 & 46.9 & 25.9 & & 100 & & 88.0 & \\
\hline Sistema 2 & 117.3 & 29.1 & & 100 & & 18.2 & \\
\hline Sistema 3 & 92.6 & 20.1 & & 100 & & 67.9 & \\
\hline Sistema 4 & 125.8 & 39.2 & & 100 & & 95.7 & \\
\hline
\end{tabular}

Fuente: Urioste et al. (1998)

Los valores económicos para peso de venta y facilidad de parto (directa) fueron similares en todos los sistemas, pero variaron considerablemente para otros rasgos. La variación económica-genética para tasa de destete fue mayor que para peso de venta en tres de los cuatro sistemas, mientras que para consumo de alimento (animales jóvenes y vacas) fue mayor en dos de los cuatro. Para facilidad de parto (directa más materna) fue menor pero aún importante (25 a 50\% de la VEG para peso de venta), mientras que el valor más bajo se obtuvo para rendimiento de canal. El enfoque adoptado para tratar los rasgos de consumo de alimento (base alimenticia fija o variable) tuvo importantes repercusiones genéticas y económicas.

Comparado con la selección solamente por peso vivo, la selección por un objetivo completo (incluyendo además rasgos reproductivos y de consumo) fue económicamente ventajosa. El uso de índices que incluyeron mediciones en características reproductivas (día 
de parto y circunferencia escrotal) y de res (espesor de grasa dorsal y área del ojo del bife), condujo a incrementos en la ganancia genética medida en unidades económicas. La inclusión de rasgos de la res en el objetivo y medidas de ultrasonido en los índices, fue rentable para razas terminales (sistema 4).

En Brasil, Junior et al. (2006) estimaron, mediante un modelo bioeconómico determinístico-estático, los valores económicos de características de interés en ganado de carne. Para ello, se valieron de información empírica obtenida en un establecimiento de ciclo completo con venta de reproductores de la raza Nelore. El modelo simula un sistema de cría y un sistema de ciclo completo con venta de reproductores. Las características evaluadas fueron peso al destete (PD), peso adulto de las vacas (PAV), tasa de preñez (TP) y tasa de destete (TD). Para evaluar el impacto de los cambios en las características evaluadas sobre el ingreso anual del sistema de producción, se incrementaron en $1 \%$ los valores originales de dichas características. Este aumento resultó en incrementos en el beneficio, destacándose el aporte relativo de la TD. En orden de importancia lo siguieron las características TP, PD y PAV, tanto en el ciclo completo como en el sistema de cría.

En lo que respecta al rendimiento carnicero, el área del ojo del bife (sección transversal del músculo longissimus dorsi), puede ser un estimador in vivo de dicha variable. La ultrasonografía es una tecnología que ha adquirido gran importancia para la determinación objetiva de características de canal en el animal vivo. Es una tecnología rápida, repetible, relativamente de bajo costo y no destructiva que permite medir características antes del sacrificio o faena del animal (Faulkner et al., 1990). Según Herring et al. (1994) y Williams et al. (1997) estas medidas de la canal realizadas previo al sacrificio, utilizadas junto al peso vivo, permiten predecir la composición de la canal con gran exactitud.

Un estudio realizado por Realini et al. (2001) demuestra que las variables con mayor influencia sobre la predicción de kilogramos de cortes valiosos, fueron el peso vivo final y el área de ojo de bife determinado por ultrasonografía. En lo que tiene que ver con el rendimiento de cortes valiosos en porcentaje (cortes valiosos/peso de canal fría), dichos autores determinaron que su mejor predictor fue el área de ojo de bife determinado por ultrasonografía. Esta información no es coincidente con la reportada por Hamlin et al. (1995) y May et al. (2000), quienes sostienen que el área del músculo longissimus dorsi no es un buen predictor del rendimiento de cortes valiosos ni de la composición de la canal. 
CADITULO V - MATLIRIALES Y MHTODOS 



\section{CAPÍTULO V - MATERIALES Y MÉTODOS}

\subsection{Generalidades}

El modelo simula el comportamiento de un sistema de producción ganadero en todas sus etapas (cría, recría y cebo), considerando el desempeño animal, la dinámica del rebaño, estrategias de manejo y la componente económica.

Está desarrollado en Microsoft Excel, con algunos componentes creados en Visual Basic para Aplicaciones (VBA), específicamente funciones y procedimientos iterativos.

Es un modelo dinámico y básicamente determinístico, aunque para la simulación de algunos procesos como la venta de animales a matadero se manejan criterios estocásticos, tratándose al grupo de animales como una población cuyo peso sigue una distribución de probabilidad.

El intervalo de tiempo utilizado (time-step) es de un mes, habiéndose considerado como el mínimo período necesario para simular ciertos eventos que ocurren en algunos meses y/o cuya duración es inferior al año.

La utilización de Microsoft Excel responde a su integración con el software @Risk (Palisade Corporation), el cual utiliza métodos de Monte Carlo para generar puntos de una distribución definida para las variables de entrada. De esta forma, es posible obtener resultados probabilísticos con un modelo básicamente determinístico. Otro módulo de este programa permite realizar análisis de sensibilidad de una determinada variable resultado, en función de la distribución y dispersión de ciertas variables de entrada. Por otra parte, si bien el modelo en primera instancia será utilizado con objetivos de investigación, no se descarta su adaptación futura como software para ser utilizado por técnicos y eventualmente productores, lo cual es otro motivo de la utilización de esta planilla electrónica, cuyo uso está ampliamente generalizado.

El horizonte de simulación manejado es de 20 años. En función de la duración de los ciclos biológico-productivos involucrados se ha verificado que este lapso es suficiente para asegurar la estabilización de los procesos que se simulan.

Para la definición de parámetros a utilizar en el modelo, se buscó en primera instancia utilizar información nacional, con la premisa de que dicha información debería representar con mayor fidelidad que la bibliografía internacional, la situación de los rebaños de Uruguay. Para ello se analizó información originada en la estación experimental de Paysandú en el NW del país (INIA Glencoe) y en la estación experimental de Colonia (SW) (INIA La Estanzuela), abarcando información representativa de diversos sistemas productivos en lo 
que se refiere a la cría, recría y cebo de bovinos para carne. También se utilizó la base de datos de la evaluación genética Hereford del Uruguay con información proveniente de todo el país. En la Tabla 11 se presenta una descripción de las bases de datos analizadas y la información que se extrajo de ellas.

Tabla 11. Bases de datos de INIA utilizadas en la estimación de parámetros a utilizar en el modelo.

\begin{tabular}{|c|c|c|c|c|}
\hline $\begin{array}{l}\text { Base de } \\
\text { Datos }\end{array}$ & Abrev. & $\begin{array}{l}\text { Origen y } \\
\text { ubicación }\end{array}$ & Registros/años & Parámetros estimados \\
\hline $\begin{array}{l}\text { La Estanzuela } \\
(\text { INIA) }\end{array}$ & BDLE & $\begin{array}{l}\text { Colonia, } \\
\text { SW }\end{array}$ & $\begin{array}{l}44700 \text { registros de } \\
\text { peso en cebo } \\
\text { Años } 1998-2003\end{array}$ & $\begin{array}{l}\text { - tasas de crecimiento de } \\
\text { animales en cebo } \\
\text { - ganancias de peso estimadas } \\
\text { en función de la disponibilidad y } \\
\text { calidad de pastura }\end{array}$ \\
\hline $\begin{array}{l}\text { Glencoe } \\
\text { (INIA) }\end{array}$ & BDGL & $\begin{array}{l}\text { Paysandú, } \\
\text { NW }\end{array}$ & $\begin{array}{l}35243 \text { registros de } \\
\text { peso } \\
\text { Años 1995-2004 }\end{array}$ & $\begin{array}{l}\text { - } \text { pesos al nacer en machos y } \\
\text { - } \text { pembras } \\
\text { hembras } \\
\text { - probabilidad de preñez según } \\
\text { estado corporal } \\
\text { - incidencia de dificultad al parto } \\
\text { (DifPar) en novillas } \\
\text { - tasa de mortalidad en novillas } \\
\text { según escore de DifPar } \\
\text { - tasa de mortalidad en terneros } \\
\text { según escore de DifPar } \\
\text { - asociación entre peso al nacer y } \\
\text { DifPar }\end{array}$ \\
\hline $\begin{array}{l}\text { Evaluación } \\
\text { Genética } \\
\text { Hereford }\end{array}$ & BDEGH & $\begin{array}{l}\text { Todo el } \\
\text { país }\end{array}$ & $\begin{array}{l}206635 \text { registros } \\
\text { Años } 1980-2008\end{array}$ & $\begin{array}{l}\text { - Peso Adulto } \\
\text { - Tasa de crecimiento machos y } \\
\text { hembras } \\
\text { - Peso al nacer machos y } \\
\text { hembras } \\
\text { - asociación entre peso al nacer y } \\
\text { DifPar }\end{array}$ \\
\hline
\end{tabular}




\subsection{Descripción de los sistemas productivos a simular}

Para comprender la dinámica del modelo, sus variables y el objetivo del mismo, se hace necesaria en primera instancia, una descripción del sistema productivo que se va a modelar. A continuación se presenta un esquema general de los diferentes sistemas existentes en el país, indicando las categorías animales intervinientes y los flujos de entrada y salida de los mismos (Figura 17). Como se mencionó anteriormente, en los establecimientos ganaderos del país se pueden dar tres orientaciones productivas: Cría (Cria), Ciclo Completo (CiCo) y Cebo (Cebo).

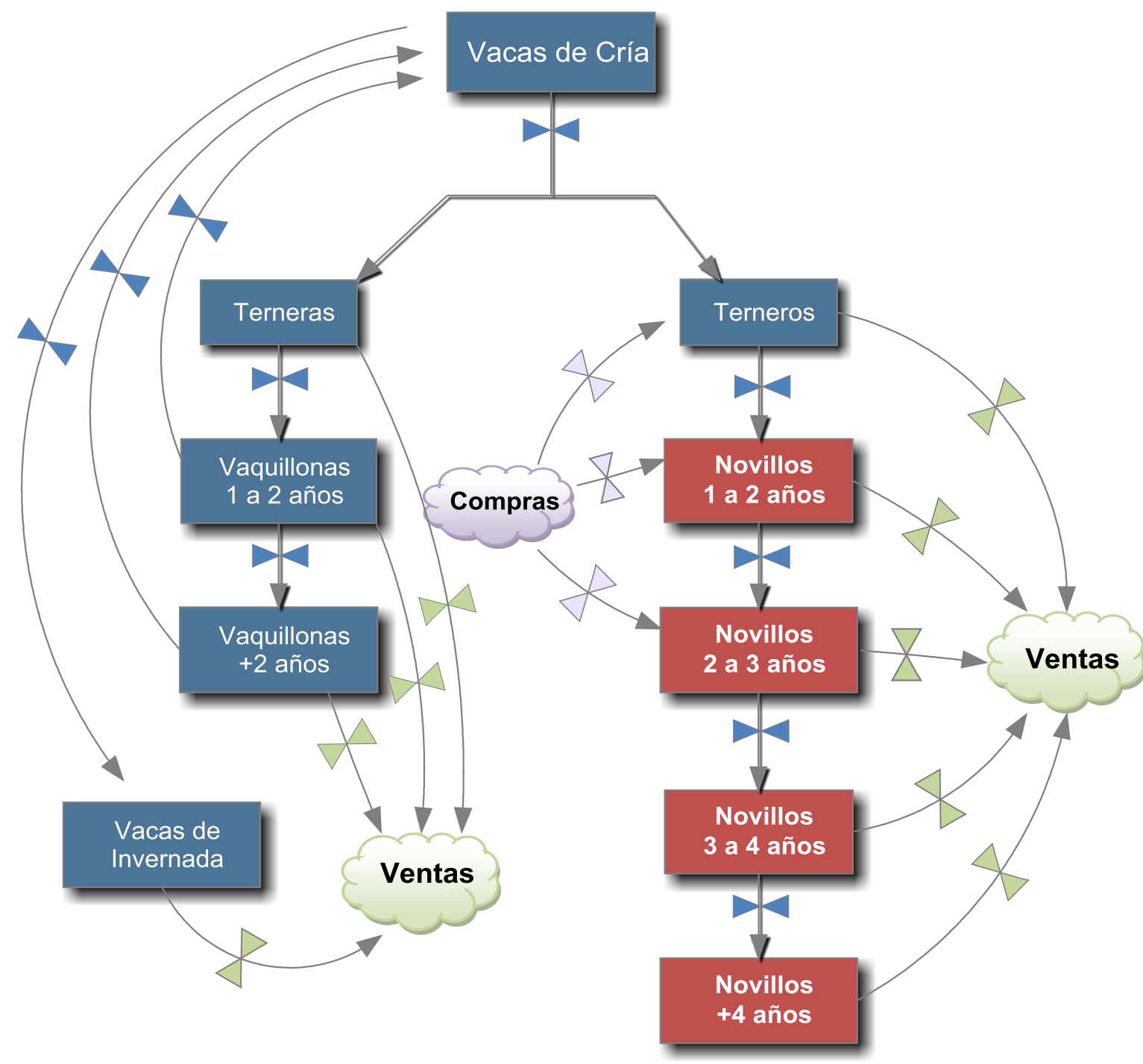

Figura 17. Esquema general de la dinámica de los sistemas ganaderos de Uruguay 
En el esquema de la Figura 17 se presenta en azul lo que correspondería a un ciclo exclusivamente de cría, donde los terneros machos y las hembras excedentes son vendidos inmediatamente después del destete a otros productores que continúan su recría y posterior cebo.

Como se ha mencionado, en Uruguay los indicadores de la cría vacuna, principalmente la tasa de destete (terneros destetados/vacas cubiertas; Figura 18) no han evolucionado en forma sustancial en los últimos años (Blasina, 2005; Caputi, 2005; Pereira y Soca, 1999).

Sin embargo, en la última década se ha logrado una disminución en la edad a la cual las novillas se cubren por primera vez (Figura 18) y una disminución de las vacas de descarte, lo cual ha contribuido a mejorar la eficiencia del sistema productivo (Caputi y Murguía, 2003).

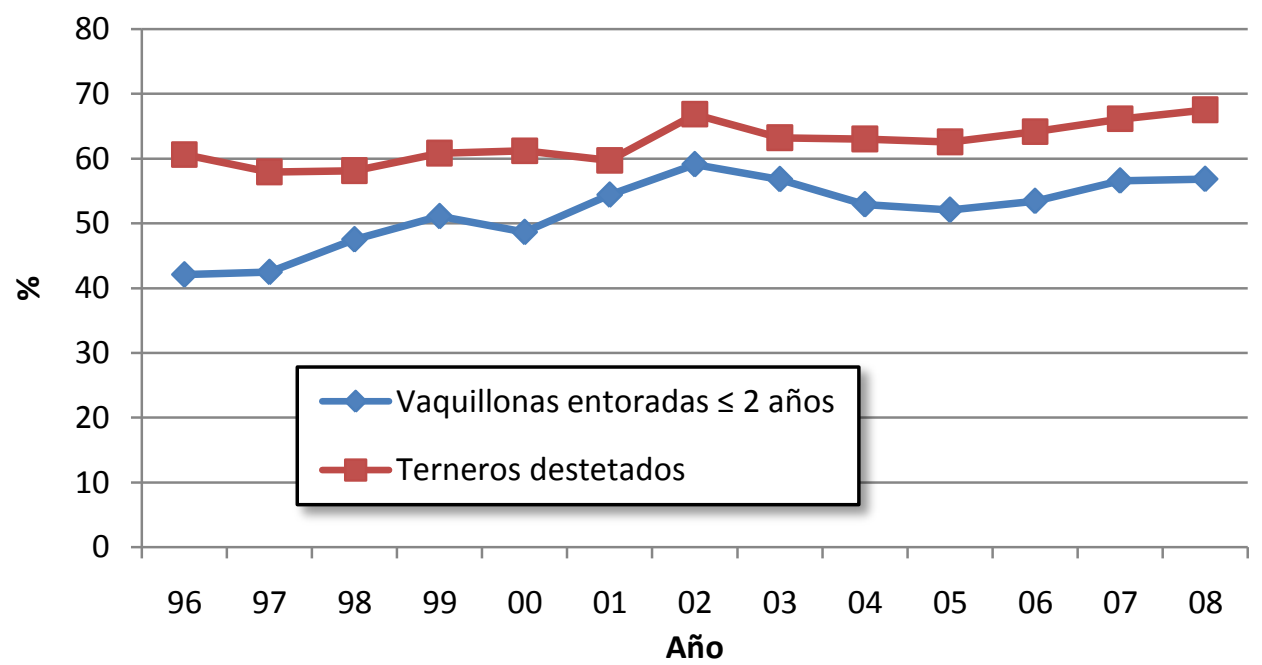

Figura 18. Evolución de indicadores de la cría vacuna. Terneros destetados por vaca cubierta y novillas cubiertas por primera vez con 2 años o menos

De igual forma que la reducción en la edad de cubrición disminuye el número de animales improductivos, el descarte del rebaño de aquellas vacas que no se preñan, determina un efecto de alivio similar en la carga del predio. En los sistemas productivos de Uruguay, los niveles de preñez del rebaño que se observan en la Figura 18 ponen de manifiesto el peso de este contingente de animales en el stock nacional. Sin embargo, existen aún muchos productores que no realizan diagnóstico de gestación y por lo tanto mantienen las vacas que no se preñan al menos hasta la estación de partos. En muchos 
casos, la detección de estas vacas no preñadas en esa fecha (próxima ya a la cubrición) no justifica su eliminación del rebaño.

Otra variable relevante en el sistema de cría es el número de estratos de edad en el rebaño. Por lo general, además de descartar las vacas falladas, la última categoría o estrato (vacas de última cría) se descarta en su totalidad destinándose a cebo. En la medida en que se reduce el número de estratos, o lo que es lo mismo, la edad a la que se descartan las vacas, se contará con un rebaño más joven, pero se requerirá de un mayor número de novillas de reposición anual y por lo tanto la tasa de preñez mínima para asegurar esta reposición del rebaño debe ser mayor. Asimismo, el número de vacas de cría totales se reduce, ya que con una misma tasa de preñez se incrementa la cantidad de hembras de descarte en proceso de cebo, puesto que las vacas de última cría (categoría que se descarta en su totalidad) representan una proporción mayor del total de vacas (Figura 19). Como se observa en el gráfico, la magnitud de esta última categoría respecto al total también es muy dependiente de la tasa de procreo.

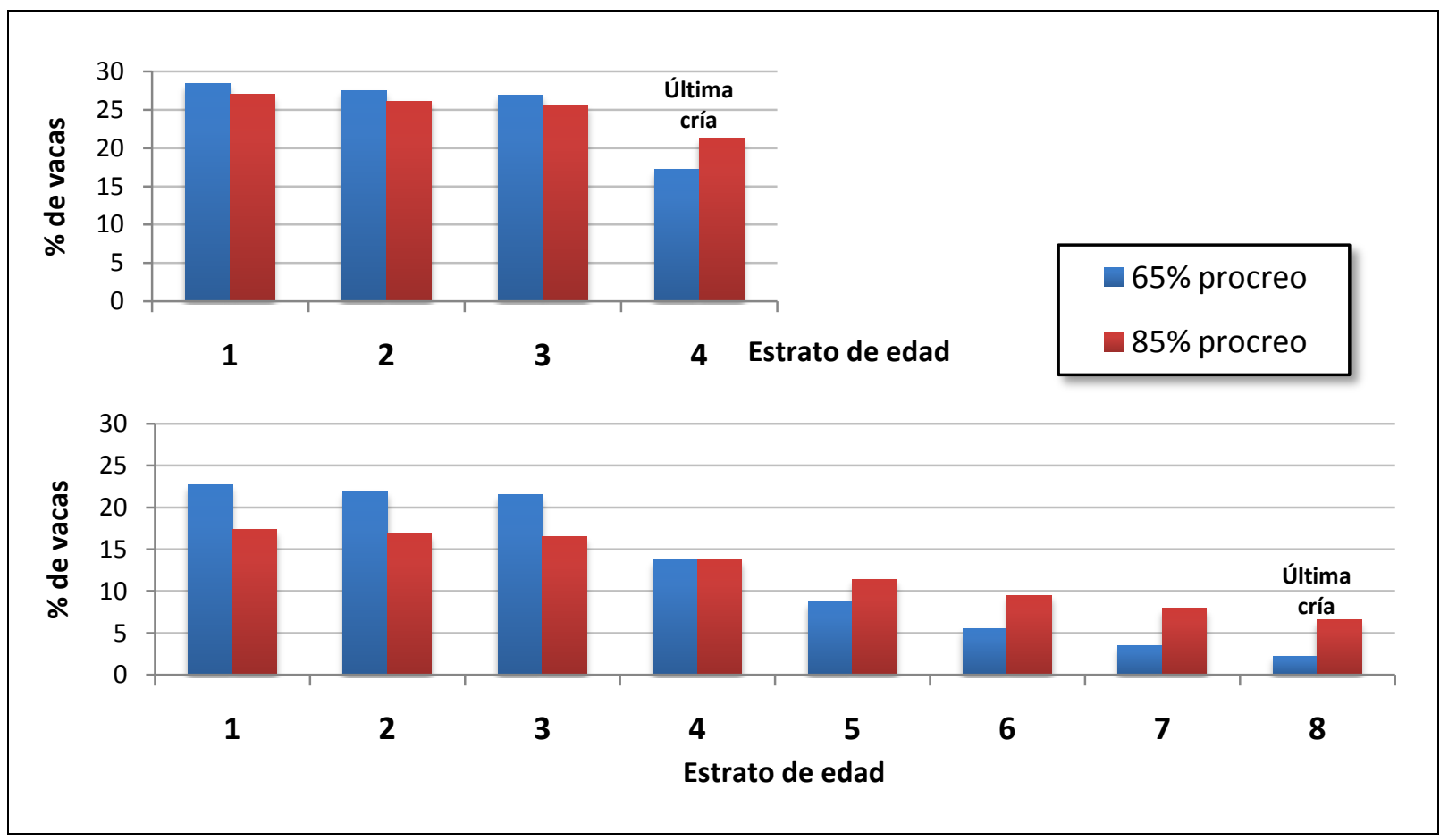

Figura 19. Porcentaje de vacas por estrato de edad según combinación de total de estratos $(4,8)$ y porcentaje de procreo $(65 \%, 85 \%)$

El óptimo productivo y económico de este número de estratos de edad dependerá a su vez de la edad de cubrición, de la política de reemplazos y por supuesto, de los precios de las vacas de descarte (gordas) y de los terneros. 
En el caso de un sistema de ciclo completo, el proceso de cría descrito se continúa en los recuadros en rojo (Figura 17), con la recría y cebo de los terneros, finalizando el ciclo con su venta a matadero a una edad dependiente de la intensividad en el uso de los recursos para el cebo. Las vacas de cría, finalizado su ciclo productivo, también se ceban y venden a matadero en cualquiera de los dos sistemas.

Los sistemas de cebo no realizan el proceso de cría, sino que compran animales a terceros (productores criadores), dedicándose exclusivamente al cebo y posterior venta de éstos. En los últimos años esta actividad ha tenido un incremento en su productividad, verificándose un aumento importante en el volumen total de faena, en la tasa de extracción y un descenso paralelo en la edad promedio de faena de los novillos. Entre otras razones, esta evolución responde al incremento del área mejorada, tanto en los predios ganaderos ( 8.1 vs $12 \%$ ) como en los agrícola-ganaderos (19.5 vs. $25 \%$ ), verificado en el período 1997 2007 (DIEA, 2008).

Debido a la simplicidad de este sistema en lo que se refiere al número de categorías que lo integran y al proceso productivo involucrado, las referencias a la metodología utilizada en el modelo se centrarán principalmente en los sistemas de Cria y CiCo, haciéndose expresa referencia cuando algún procedimiento se aplique al caso de sistemas de Cebo. De cualquier manera, la dinámica de este sistema es comparable a la etapa de cebo de un sistema de CiCo.

El sistema básico entonces tiene como ingreso principal los nacimientos de machos y hembras; el principal egreso es la venta de machos como terneros o novillos y como un subproducto de la cría se realizan ventas de vacas de descarte gordas y hembras excedentes en magnitud variable, dependiendo de la eficiencia del proceso.

La dinámica de sistemas en biología o ecología se ha utilizado frecuentemente para describir sistemas en estado silvestre o natural, donde la población en estudio alcanza algún tipo de equilibrio con su entorno. Lo más usual es que la misma se autorregule en función de los recursos que consume (mayor población $\boldsymbol{\Delta}$ disminución de alimento disminución de la población) o de la existencia de predadores que limitan su crecimiento (mayor población aumento de predadores disminución de la población). Si bien en los sistemas ganaderos pastoriles de Uruguay puede darse algún mecanismo similar, (por ej. un aumento de dotación animal disminuye el forraje disponible lo cual afecta el estado corporal de la vacas, que a su vez determina bajas tasas de preñez), la regla general es que el hombre regula el sistema para un funcionamiento lo más cercano posible al óptimo económico (no siempre equivalente al biológico). 


\subsection{Estructura del modelo}

Para facilitar la comprensión del funcionamiento del modelo, se lo ha dividido en tres bloques principales (Figura 20): a) Modelo Animal, conformado por los mecanismos de crecimiento y cebo que determinan el comportamiento productivo de los animales, b) Modelo Poblacional, donde se describirá la dinámica que determina la evolución del número de animales por categorías en los distintos momentos del año y las variables que lo afectan y c) Modelo Económico, constituido por una función de beneficio que determinará el resultado del sistema productivo en términos económicos.

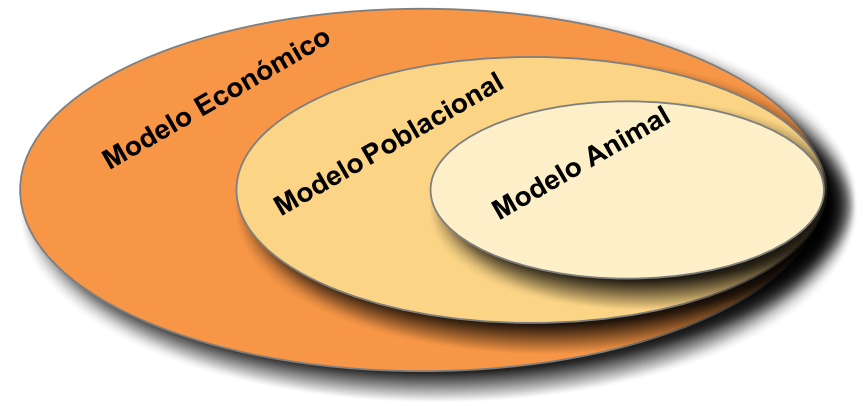

Figura 20. Estructora global del modelo

En el Modelo Animal, en función de una disponibilidad y calidad de forraje definidas, los animales son caracterizados por una ganancia (o pérdida) diaria de peso vivo. Debe aclararse que la unidad no es el individuo, sino la categoría en cada mes. Como se detallará más adelante, se manejan 37 categorías con una estimación propia de peso para cada mes y para cada año de los 20 de simulación, computándose por ende 8880 registros de consumo de diferentes alimentos, ganancia, peso, etc. (Figura 21).

El Modelo Poblacional estima básicamente, las cantidad de animales en cada categoría a lo largo del tiempo, en función de parámetros inherentes a la dinámica poblacional del modelo (tasas de preñez y mortalidad por categoría, estructura de edades, políticas de descarte de animales, orientación productiva del sistema -cría, cebo, cría + cebo- categorías de venta, etc). El número de animales por categoría calculados en cada mes se relaciona con el peso correspondiente, variable que como se mencionó constituye una salida del modelo animal. Igualmente se procede con el consumo por animal (Figura 21). De esta forma se estima el volumen total de $\mathrm{kg}$ en stock mensual y un volumen de alimento consumido por mes. Por un procedimiento estocástico que se verá más adelante, se define mes a mes, los animales factibles de destinar a venta, según el umbral de peso 
definido para ser comercializados y la categoría. Este volumen de peso a comercializar constituye una de las salidas de este sistema. Paralelamente, al contabilizar el consumo total de alimento de los animales en cada mes, se compara dicho valor con la disponibilidad de forraje existente, determinada por el área definida de pastoreo. De esta forma, si el consumo actual excede el disponible, la cantidad de animales es reducida hasta ajustar ambos valores. Este número de animales es hacia el que tenderá a estabilizarse el modelo, en un lapso de tiempo dependiente de los valores de inicio utilizados en la simulación y los parámetros introducidos en el modelo.

Finalmente, la producción estimada (representada por las ventas si se ha alcanzado la estabilización del stock), que constituye la salida del modelo poblacional, es utilizada por el Modelo Económico para el cálculo del ingreso y al descontar los costos directos, estimar el margen bruto del sistema. 


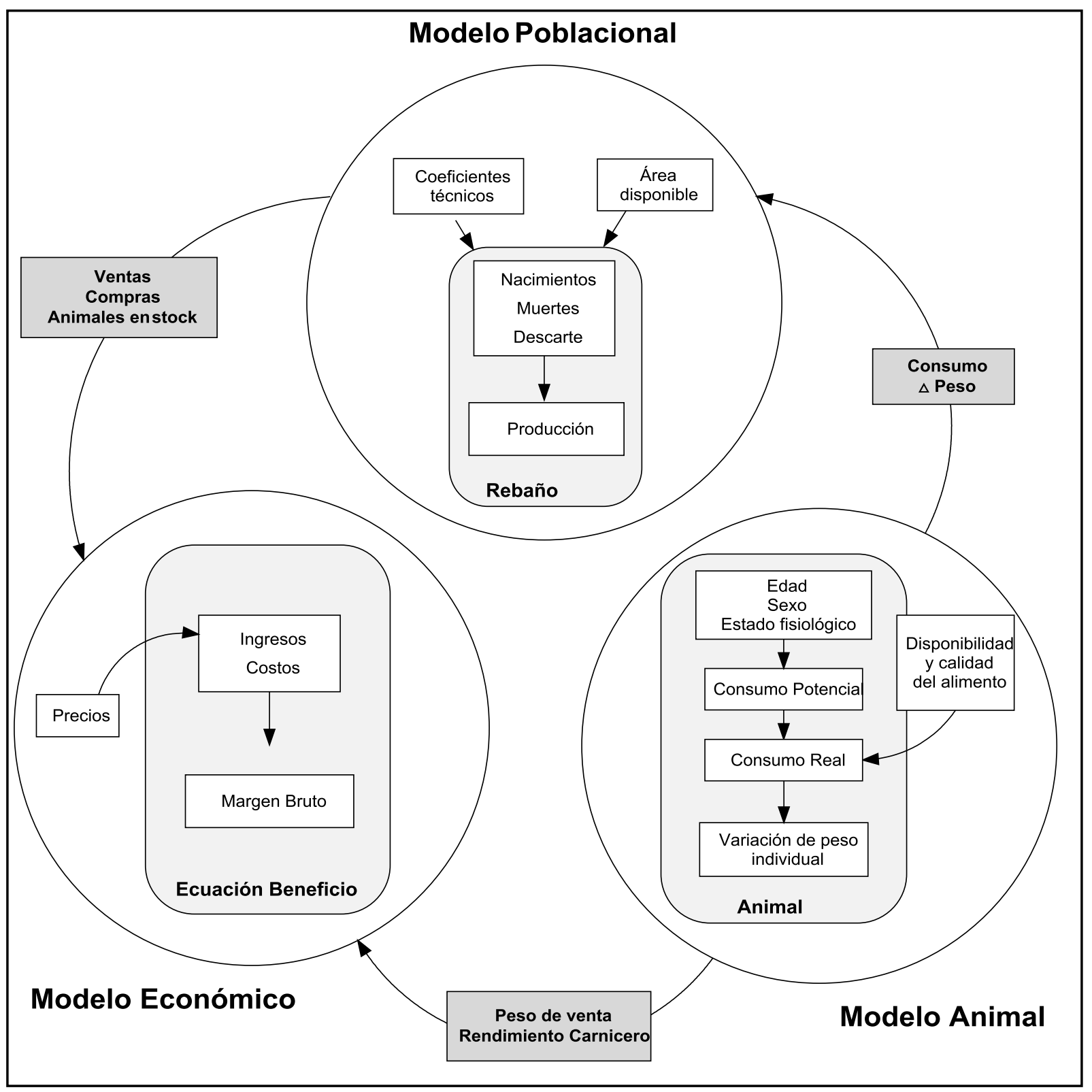

Figura 21. Representación esquemática de los tres bloques del modelo y sus flujos

\subsection{Modelo Animal}

Como se ha mencionado el modelo permite estimar el peso vivo $(P)$ de las distintas categorías en el mes $m$, a partir del peso del mes anterior, sumándole una ganancia diaria de peso (GDP) multiplicada por los días del mes (se asume 30.4 días promedio).

$$
P_{m}=P_{m-1}+G D P \cdot 30.4
$$

Para la estimación de las ganancias de peso, se utilizaron como base las ecuaciones desarrolladas por CSIRO (2007) en Australia. En dicha publicación se recoge información 
generada desde hace 17 años y actualizada anualmente. La relativa similitud geográfica con Uruguay, así como el uso generalizado del pastoreo a lo largo de todo el año en ese país, determinan una mayor coincidencia en sus estimaciones, respecto a otros países/sistemas donde prima la utilización de sistemas de cebo a corral (feedlot) o en estabulación permanente o estacional. Como se ha mencionado, en la medida que se contase con información sobre parámetros nacionales para utilizar en estas ecuaciones, se priorizó su aplicación respecto a los valores sugeridos por estos autores australianos, cuando dichos parámetros no diferían sustancialmente de los propuestos.

En la Figura 22 se esquematizan los factores manejados en este trabajo como determinantes de las ganancias para cada categoría y momento del año. El modelo actúa a nivel de energía metabolizable, la cual es la porción de energía de un alimento que puede ser utilizada por el animal para su metabolismo.

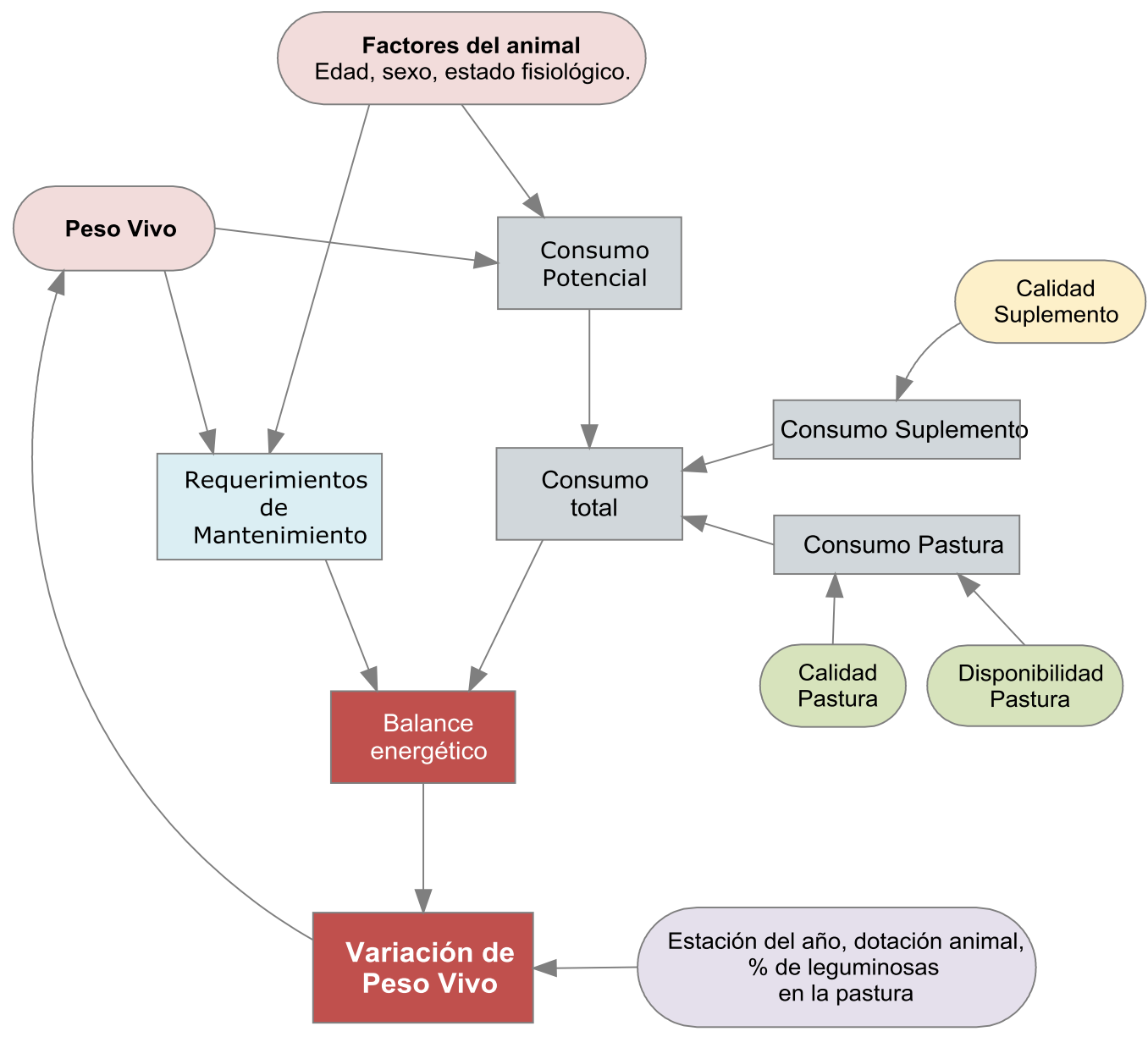

Figura 22. Diagrama de los factores y procesos involucrados en la estimación de las ganancias de peso vivo 


\subsubsection{Consumo potencial}

La estimación del consumo potencial $(I$ ) de los animales se basa en las ecuaciones de CSIRO (2007). Dicho consumo potencial es función del peso vivo de los animales, de su peso adulto, edad, madurez relativa y su condición corporal relativa. Para ello, se estima en primera instancia el peso normal $(N)$, definido como el peso cuando su condición corporal se encuentra en el centro de la escala y el cual sigue un patrón con el tiempo.

$N=A-(A-B) \cdot \mathrm{e}^{-k \cdot T \cdot A^{-0.27}}$

donde:

$$
\begin{aligned}
& A=\text { peso adulto }(\mathrm{kg}), \\
& B=\text { peso al nacer }(\mathrm{kg}), \\
& T=\text { edad del animal (meses), } \\
& k=0.35 \text { en bovinos }
\end{aligned}
$$

El tamaño relativo $(Z)$, representa la proporción del peso normal respecto al peso adulto $(A)$ en que se encuentra un animal en un momento determinado, pudiendo tomar un valor máximo de 1 si dicho animal ha alcanzado la madurez.

$$
Z=\frac{N}{A}
$$

La condición relativa $(R C)$ se calcula como la proporción del peso vivo actual $(P)$ respecto al peso normal $(M$ y es un indicador del estado corporal o nivel de terminación del individuo.

De esta manera el peso vivo actual $(P)$ puede considerarse como una componente del peso adulto, el tamaño relativo $(Z)$ y la condición corporal relativa.

$$
P=A \cdot R C \cdot Z=A \cdot \frac{P}{N} \cdot \frac{N}{A}
$$

Si $R C$ toma valores mayores a 1, en el caso de animales que se encuentren en grados de condición corporal por encima del valor medio de la escala, se asume que hay una depresión en el consumo en magnitud dependiente de un factor de corrección ( $C F$ ) estimado mediante la ecuación:

$$
C F=R C \cdot \frac{1.5-R C}{0.5} \text { para } R C>1 \text {, de lo contrario } C F=1
$$

Utilizando valores de $A$ y $Z$ estimados en la forma descrita anteriormente, es posible predecir el consumo potencial, I ( $\mathrm{kg} \mathrm{MS} / \mathrm{d}$ ) de un animal destetado, no lactante y dentro de la zona termoneutra de temperatura. 
$I=j \cdot A \cdot Z 1.7-Z \cdot C F$

donde:

$j$ toma valores sugeridos de 0.025 en el caso de bovinos (CSIRO, 2007)

De la ecuación [2.6] se desprende que la ingesta potencial alcanza un máximo cuando el tamaño relativo $(Z)$ de los animales es 0.85 .

En el caso de vacas en lactancia, se verifica un incremento en el consumo, derivado de los requerimientos energéticos extra asociados con la producción de leche. Dicho incremento está en función del tiempo de lactancia, del tiempo al cual se verifica el pico de consumo, de la producción de leche expresada en un valor relativo al potencial y de la condición corporal relativa de la vaca al momento del parto, variables que a través de la siguiente expresión, conforman el coeficiente $m$, el cual se utiliza como multiplicador en la ecuación de consumo [2.6].

$m=1+a \cdot M^{b} \cdot e^{b \cdot(1-M)} \cdot L \cdot D$

donde;

$M=\mathrm{T} / \mathrm{c}$,

T=día de lactancia,

$\mathrm{C}=$ tiempo al pico de consumo potencial (en días)

$L=$ parámetro de ajuste según la condición corporal relativa al parto de la vaca,

$D$ representa el cociente entre la producción de leche real y la potencial

Para ovinos y bovinos el coeficiente $L$ se calcula como $0.5+0.5^{*}$ condición corporal relativa al parto. En vacunos de carne, los parámetros $a, b$ y $c$ sugeridos son $0.42,1.7$ y 62 días, respectivamente.

En terneros, cuya principal fuente de alimentación es la leche materna, el consumo potencial de otro tipo de dieta se ve limitado al no tener el rumen completamente desarrollado. En este caso, el multiplicador aplicado a la ecuación de consumo, dependiente de la proporción de la dieta compuesta por leche y los días de edad, actúa deprimiendo el consumo potencial (ecuación [2.8]).

$p=\frac{1-P_{\text {leche }}}{1+\mathrm{e}^{-a \cdot(T-X)}}$

donde:

$P_{\text {leche }}=$ proporción de leche en la dieta,

$T=$ días desde el nacimiento,

$X=60$ días

$a=0.22$ 


\subsubsection{Consumo relativo}

A diferencia de las condiciones de producción en estabulación con alimentación ad libitum, las condiciones de pastoreo normalmente no son las óptimas para permitir el consumo en su valor potencial. Al existir limitantes en la disponibilidad y/o calidad del forraje, comienzan a operar factores que restringen el consumo en magnitud variable. El enfoque aquí aplicado es el de manejar un valor relativo de disponibilidad y digestibilidad (entre 0 y 1 ) considerando 1 como el valor que deben tener estas dos variables para no restringir el consumo de los animales. Paralelamente, ha sido ampliamente comprobado (Hodgson, 1981; Montossi et al., 2000; CSIRO, 2007) que los animales en pastoreo ingieren una dieta de calidad superior a la del forraje disponible (selectividad). Por tal motivo, además de la consideración de la disponibilidad y calidad de la pastura, se estima un índice de selección dependiente de éstas.

\subsubsection{Disponibilidad de forraje}

En la medida que la disponibilidad de la pastura desciende a valores inferiores $3 \mathrm{tt}$ MS/ha (CSIRO, 2007) se torna cada vez más difícil para el animal satisfacer su consumo potencial en el tiempo diario que dedica al pastoreo. Existen numerosos modelos mecanicistas que describen detalladamente los procesos de pastoreo a través del tamaño de bocado y la tasa de bocado en relación con la estructura del tapiz (Brereton et al., 2005; Montossi et al., 2000). Sin embargo, se requiere de un conocimiento muy detallado de las características estructurales y espaciales de las diferentes pasturas para su aplicación práctica y si bien hay profusa información generada en Uruguay por Montossi, et al. (2000) ésta sólo es aplicable para ovinos.

A modo de simplificación, es posible manejar una simple relación exponencial entre la disponibilidad relativa $(F)$ y la cantidad de forraje disponible $(B)$, resultante de la hipótesis de que cada unidad de cambio en el consumo respecto a la cantidad de forraje disponible es proporcional al apetito insatisfecho a ese nivel de forraje (CSIRO, 2007).

$$
\frac{d F}{d B}=1-F
$$

lo cual determina:

$$
F=1-\mathrm{e}^{-a \cdot B}
$$


El parámetro a varía con la estructura del tapiz y el tipo de animal. Aguirrezabala y Oficialdegui (1993) en Uruguay, proponen para el caso de vacunos un coeficiente $a=-0.001664$, el cual será adoptado en este trabajo.

En el modelo desarrollado, es necesario introducir valores de disponibilidad y digestibilidad para los 12 meses del año, tomando como supuesto que dichos valores se repiten en los años siguientes de simulación. Si bien esto podría ser considerado un enfoque simplista, se considera que en sistemas de pastoreo extensivos o semi-extensivos como los que priman en Uruguay, la alta variabilidad en las tasas de crecimiento del campo natural existente entre años responde a fenómenos climáticos, acumulación de agua en el suelo, etc., aspectos cuya modelación escapa a este trabajo. Por otra parte, el forraje es la base de la alimentación en pastoreo, por lo cual constituye un factor clave en la productividad de los animales. Se considera preferible utilizar valores fijos de forma de poder controlar el desempeño de los animales (objetivo central de este modelo) en función de variables de entrada de mayor interés, evitando centrar la variación del modelo en una variable cuya modelización y análisis escapa a los objetivos aquí planteados.

\subsubsection{Calidad del forraje y selectividad}

Las características de la pastura que determinan la desaparición de la ingesta del rumen, se encuentran asociadas con la digestibilidad de la dieta. Numerosas revisiones (Hogdson, 1981; CSIRO, 2007) han demostrado correlaciones positivas entre la digestibilidad y el consumo voluntario dentro de un amplio rango de estados de madurez de pasturas.

Por otra parte, los procesos de selectividad que realizan los rumiantes en pastoreo, determinan que la calidad (expresada como digestibilidad) del forraje seleccionado $\left(D_{f s}\right)$ sea mayor que la digestibilidad del forraje disponible $\left(D_{f d}\right)$.

A pesar de la existencia de literatura internacional sobre selectividad de la dieta en rumiantes, no es posible extrapolar los resultados obtenidos en el extranjero a la situación del Uruguay. Esto está relacionado a la diversidad de poblaciones de plantas y animales que están implicados en el proceso de selectividad animal y a la complejidad de sus interacciones (Montossi et al., 2000). La gran heterogeneidad del campo natural en cuanto a número de especies, ciclos biológicos, producción y calidad estacional, etc., determina que la selectividad sea un proceso multifactorial muy complejo. A partir del trabajo de Montossi et al. (2000) y de información no publicada aportada por sus autores (Montossi, com. pers., 
2008), se ajustó una ecuación que genera un índice de selectividad tomando en cuenta la disponibilidad y digestibilidad de la pastura.

$$
\begin{array}{rl}
I S=M A X & a \cdot \operatorname{Ln} D_{f d}-b+C+d \cdot B+1,1 \\
a & =-0.249 \\
b & =23.7 \\
C & =0.939 \\
d & =8.3 \times 10^{-5} \\
& D_{f d}=\text { digestibilidad del forraje disponible, \% } \\
B & =\text { disponibilidad de forraje, } \mathrm{kg} \mathrm{MS} / \mathrm{ha}
\end{array}
$$

Este índice es utilizado como multiplicador de la digestibilidad del forraje disponible, para estimar la digestibilidad del forraje seleccionado.

$$
D_{f s}=D_{f d} \cdot 1 S
$$

En la Figura 23, se observa la variación del índice asociada a los cambios de la disponibilidad y la digestibilidad de la pastura.

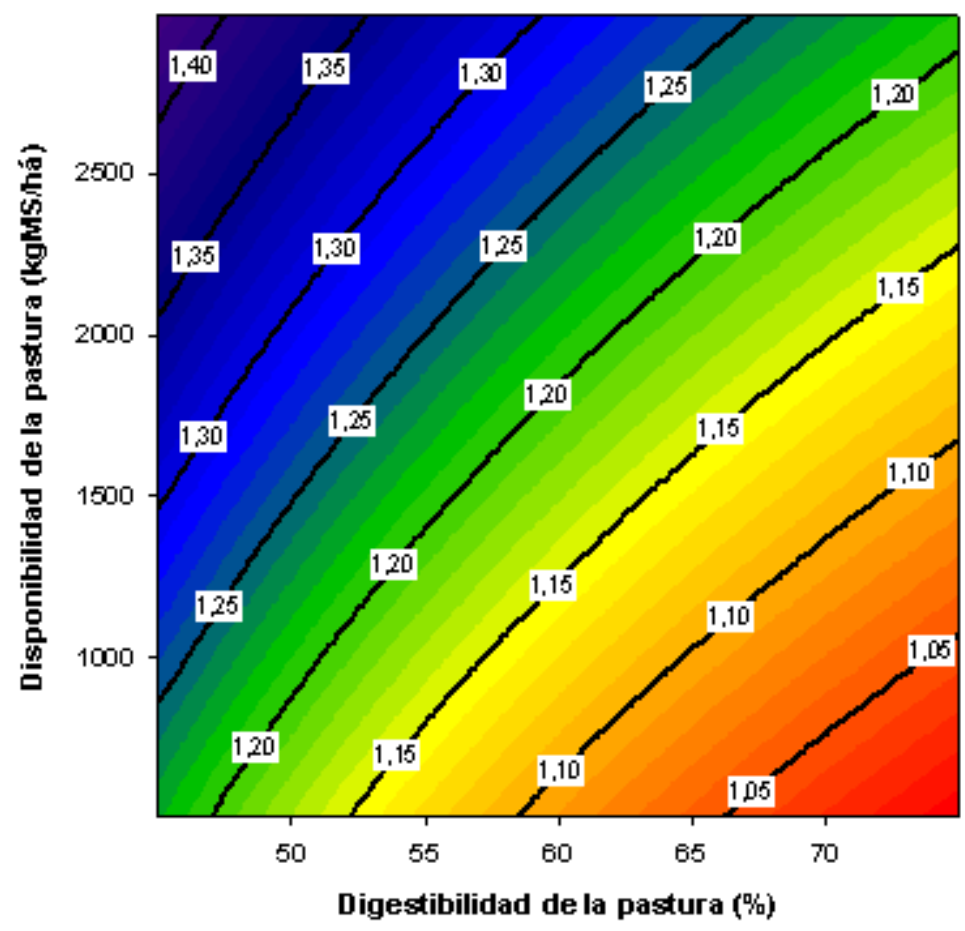

Figura 23. Valores calculados del índice de selectividad en función de la disponibilidad y digestibilidad de la pastura.

De forma similar a la descrita para la disponibilidad de forraje, para el caso de la calidad del mismo se plantea la utilización de la ecuación de calidad relativa $(R Q)$, 
desarrollada por Freer y Jones (1984) para pasturas templadas (C3) y leguminosas. Se aplica un término de ajuste $g$ si se trata de gramíneas C4 en base a información generada por diversos autores (CSIRO, 2007).

$R Q=1-1.7 \cdot\left(\max \left(\left(0.8-\left(1-P_{\text {legum }}\right) \cdot g\right)-D_{t s}\right), 0\right)$

donde:

$P_{\text {legum }}=$ leguminosas en la pastura, \%

$D_{f s}=$ digestibilidad del forraje seleccionado, \%

$g=0.00$ para gramíneas C3 y 0.16 para gramíneas C4

\subsubsection{Consumo real}

\subsubsection{Consumo de pastura}

Luego de calculado el consumo potencial de materia seca I (ecuación [2.6]), ajustado por la disponibilidad y calidad relativa de la pastura y corregido por el índice de selectividad, es posible estimar un consumo de pastura, definido por la ecuación:

$$
\operatorname{CON}_{\text {past }}=I{ }^{*} F{ }^{*} R Q * I S
$$

donde:

$I=$ consumo potencial $(\mathrm{kgMS})$

$F=$ disponibilidad relativa del forraje

$R Q=$ calidad relativa del forraje

$I S=$ índice de selectividad

\subsubsection{Consumo de suplementos}

El modelo asume que el consumo potencial de suplementos (CONPsup) está regulado principalmente por el peso del animal $(P)$ y la calidad del suplemento, medido a través de la metabolicidad (Qms) (Castellaro, 2007), utilizándose diferentes ecuaciones si el suplemento corresponde a silos y forrajes o a un concentrado energético. Las ecuaciones utilizadas son las propuestas por el Agricultural and Food Research Council (AFRC, 1994; Poppi, 1996):

$$
\begin{aligned}
& C O N P_{\text {sup }}=0.001 \cdot 116.8-46.6 \cdot Q m s \cdot P^{0.75}, \\
& \text { para concentrados, o } \\
& C O N P_{\text {sup }}=0.001 \cdot 106.5-24.1 \cdot Q m s \cdot P^{0.75}, \\
& \text { para silajes, henilajes, etc. }
\end{aligned}
$$


La definición de estos dos tipos se efectúa según el porcentaje de materia seca y la concentración de energía metabolizable (EM) presente en la MS del suplemento, definiendo como concentrado a aquellos suplementos que presentan un porcentaje de MS superior o igual a $88 \%$ y un valor de EM superior o igual a $11 \mathrm{MJ} \mathrm{kg}-1$. El consumo de suplemento se define como el mínimo entre la cantidad de suplemento ofrecido $(O f)$ y el consumo potencial de suplemento:

$$
C O N_{\text {supl }}=\min \left(C O N P_{\text {supl }}, \text { Of }\right)
$$

\subsubsection{Tasa de Sustitución}

Como ocurre en la mayoría de los casos, cuando la digestibilidad del suplemento es superior a la del forraje se da un efecto de sustitución, definido como la cantidad de MS de forraje proveniente del pastoreo que el animal deja de consumir por unidad de suplemento consumido (CSIRO, 2007). Las magnitud de esta tasa de sustitución (TS) está determinada por la digestibilidad del forraje seleccionado $\left(D_{\mathrm{fs}}\right)$, la del suplemento $\left(D_{\text {supl }}\right)$ y la disponibilidad de MS de la pastura $(B)($ Castellaro, 2007) según la siguiente expresión:

$$
\begin{aligned}
& \text { si } D_{f s} \geq D_{\text {supl }} \Rightarrow T S=0 \\
& \text { si } D_{f s}<D_{\text {supl }} \Rightarrow T S=\frac{D_{f s}}{D_{\text {supl }}} \cdot 1-e^{-0.0017287 \cdot B}
\end{aligned}
$$

donde:

$D_{t s}=$ digestibilidad del forraje seleccionado, \%

$D_{\text {sup }}=$ digestibilidad del suplemento, \%

$B=$ disponibilidad de pastura, $\mathrm{kgMS} / \mathrm{ha}$

Calculada TS se procede a corregir el consumo de MS proveniente de la pastura $\left(C O N_{\text {past }}\right)$ (ecuación [2.14]), y el consumo de suplemento $\left(C O N_{\text {supll }}\right)$ estimándose el consumo real de pastura (CONR $\left.R_{\text {past }}\right)$, y el consumo real de suplemento (CONR $\left.R_{\text {supl }}\right)$, respectivamente. El cálculo de estos valores dependerá de que se se verifique una de las siguientes tres posibilidades:
a) si no hay suplemento $\Rightarrow C O N R_{\text {supl }}=C O N_{\text {supl }}=0 ; C O N R_{\text {past }}=C O N_{\text {past }}$
b) si $D_{\text {supl }}>D_{\text {fs }} \Rightarrow C O N R_{\text {supl }}=C O N_{\text {supl }} ; C O N R_{\text {past }}=C O N_{\text {past }}-T S \cdot C O N R_{\text {supl }}$
c) si $D_{\text {supl }} \leq D_{t s} \Rightarrow C O N R_{\text {supl }}=\min \left(C O N P_{\text {supl }}, I-C O N R_{\text {past }}\right) ; C O N R_{\text {past }}=C O N_{\text {past }}$ 
siendo / el consumo potencial (ecuación [2.6])

Finalmente, se calcula la cantidad total de MS ingerida diariamente, a través de la suma del consumo real de pastura y el consumo real de suplemento, cifra que es acotada a un máximo equivalente al consumo potencial (Castellaro, 2007).

\subsubsection{Energía aportada por la dieta}

El consumo de pastura estimado determina el consumo de energía metabolizable, a través de la ecuación propuesta por CSIRO (2007):

$E M_{\text {past }}=0.172 * D_{f s}-1.707$

donde:

$D_{f s}=$ digestibilidad de la materia seca del forraje seleccionado, \%

De igual forma, el aporte de energía proveniente del suplemento, es calculado:

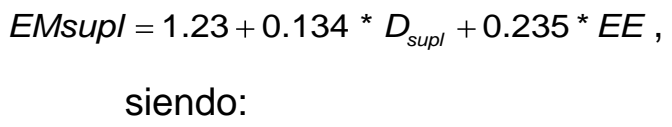

siendo:

$D_{\text {supl }}=$ digestibilidad del suplemento, $\%$ $E E=$ extracto etéreo, \%

para concentrados, 0

EMsupl $=-1.7754+0.1813 * D_{\text {supl }}$,

para silajes, henilajes, etc.

El consumo total de energía (CTE) queda definido como la suma de la energía aportada por la pastura más la energía proveniente del suplemento:

$$
C T E=E M_{\text {past }} \cdot C O N R_{\text {past }}+E M_{\text {supl }} \cdot C O N R_{\text {supl }}
$$

En el caso de terneros lactantes, se debe considerar el aporte de la leche, cuya producción es dependiente del tiempo transcurrido desde el parto, la condición corporal relativa de la madre al parto, el pico de producción de leche, el tiempo al pico de consumo potencial de la madre y el balance energético. 
Estimando la producción de leche y asumiendo un \% de grasa de la leche de entre 2.8 y 3.5\% (NRC, 1996; Melton et al.,1967) es posible estimar la energía aportada por la leche, según la ecuación:

$$
E_{\text {leche }}=0.0458 \cdot \% \text { grasa }+1.222
$$

\subsubsection{Requerimientos energéticos de mantenimiento}

Para realizar la estimación de los requerimientos de mantenimiento ( $R M)$, se adoptan las ecuaciones propuestas por CSIRO (2007). Los requerimientos energéticos de mantenimiento $\left(E M_{m}\right)$, se calculan como:

$$
E M_{m}=\frac{K \cdot S \cdot M \cdot\left(0.26 \cdot P^{0.75} \mathrm{e}^{-0.03 \cdot E}\right.}{k_{m}}+0.09 \cdot C E M+E M_{\text {pastoreo }}
$$

donde:

$K=$ constante que toma valor 1.4 para razas británicas

$S=$ constante dependiente del sexo, toma valor 1 para hembras y castrados y 1.15 para toros

$M=$ ajuste para terneros en lactancia $(1+(0.23$ * proporción de la energía proveniente de la leche $))$

$P=$ peso vivo excluyendo peso del feto en vacas gestantes

$E=$ edad en años, con máximo en 6

$K_{m}=$ eficiencia de uso de la EM para mantenimiento

$C E M=$ consumo total de energía metabolizable

$E M_{\text {past }}=$ gasto energético extra por pastoreo, relativo a un animal estabulado dividido por $K_{m}$

La estimación del costo energético extra debido al pastoreo se calcula:

$$
E M_{\text {pastoreo }}=\frac{C \cdot C E M \cdot\left(0.9-D_{f d}\right) \cdot P}{K_{m}}
$$

$C=0.0025$

$C E M=$ consumo energía proveniente de la pastura ( $\mathrm{kg} \mathrm{MS/día)}$

$D_{f d}=$ digestibilidad de la materia seca de la pastura (decimal)

$K_{m}=$ eficiencia de uso de la EM para mantenimiento

$P=$ peso vivo, excluyendo peso del feto en vacas gestantes

El cálculo de la eficiencia en la utilización de la energía $\left(k_{m}\right)$ se encuentra directamente relacionado al contenido de energía de la dieta, mediante la ecuación:

$$
k_{m}=0.02 \cdot E M_{\text {dieta }}+0.5
$$

donde:

$E M_{\text {dieta }}=$ energía metabolizable de la dieta, $\mathrm{MJ} / \mathrm{kg}=\frac{C T E}{\text { CONRpast }{ }^{+C O N R} \text { supl }}$ 


\subsubsection{Balance energético y estimación del cambio de peso vivo}

El cambio de peso es calculado a partir del balance energético $(B A L)$ resultado de la sustracción de los requerimientos energéticos de mantenimiento $(R M)$ al consumo total de energía (CTE), ponderado por la eficiencia de utilización de la energía para ganancia de peso $\left(k_{g}\right)$ :

$$
B A L=(C T E-R M) \cdot k_{g}
$$

El factor $k_{g}$ es estimado a partir de una ecuación sugerida por CSIRO, 2007, que toma en cuenta la concentración de energía de la dieta, la proporción de leguminosas en la pastura, la estación del año y la latitud, tal que:

$$
k_{g}=0.035 \cdot E M_{\text {dieta }} \cdot(1+0.33 \cdot \mathrm{Leg}) \cdot(1+0.12 \cdot(\lambda \cdot \operatorname{seno}(0.0172 \cdot T) / 40))
$$

donde:

Leg = proporción de leguminosas en la pastura, \%

$T=$ día desde el 1 de enero

$\lambda=$ Latitud, grados

En el caso de que los requerimientos sean mayores que el aporte de energía, se asume una eficiencia de movilización de las reservas corporales para el proceso de mantenimiento de peso de 0.80 .

El cambio de peso $(\triangle P)$, es calculado al dividir el balance energético $(B A L)$ entre el valor energético de un $\mathrm{kg}$ de peso vivo (VEPV), el cual es multiplicado por 0.92 para expresar ese peso como peso vivo vacío:

$\triangle P=\frac{B A L}{0.92 \cdot V E P V}$

El valor energético del $\mathrm{kg}$ de peso (VEPV) a su vez es estimado a partir de una ecuación que considera el tamaño relativo del animal $(Z)$, un parámetro de ajuste según el animal gane o pierda peso $(R)$ y otros parámetros asociados al biotipo del animal, utilizándose los correspondientes a razas británicas (Hereford, Angus, etc.):

$V E P V=(6.7+R)+\frac{(20.3-R)}{1+\mathrm{e}^{-6 \cdot(Z-0.4)}}$

En donde $R$ es calculado como:

$$
R=\frac{C T E}{R M}-2
$$




\subsection{Modelo poblacional}

En esta sección se presentan, en primer lugar, las variables que afectan la dinámica del rebaño, detallando a continuación los mecanismos mediante los cuales se simula la evolución de las categorías presentes, los nacimientos, el descarte de animales del sistema y las ventas de los productos del mismo.

Este modelo se compone de tres niveles o submodelos (Figura 24). El modelo central (M1) tiene como variables de entrada los coeficientes ingresados (tasas de preñez, mortalidad, descarte, etc.) y valores iniciales para la cantidad de animales de cada categoría presente en el rebaño.

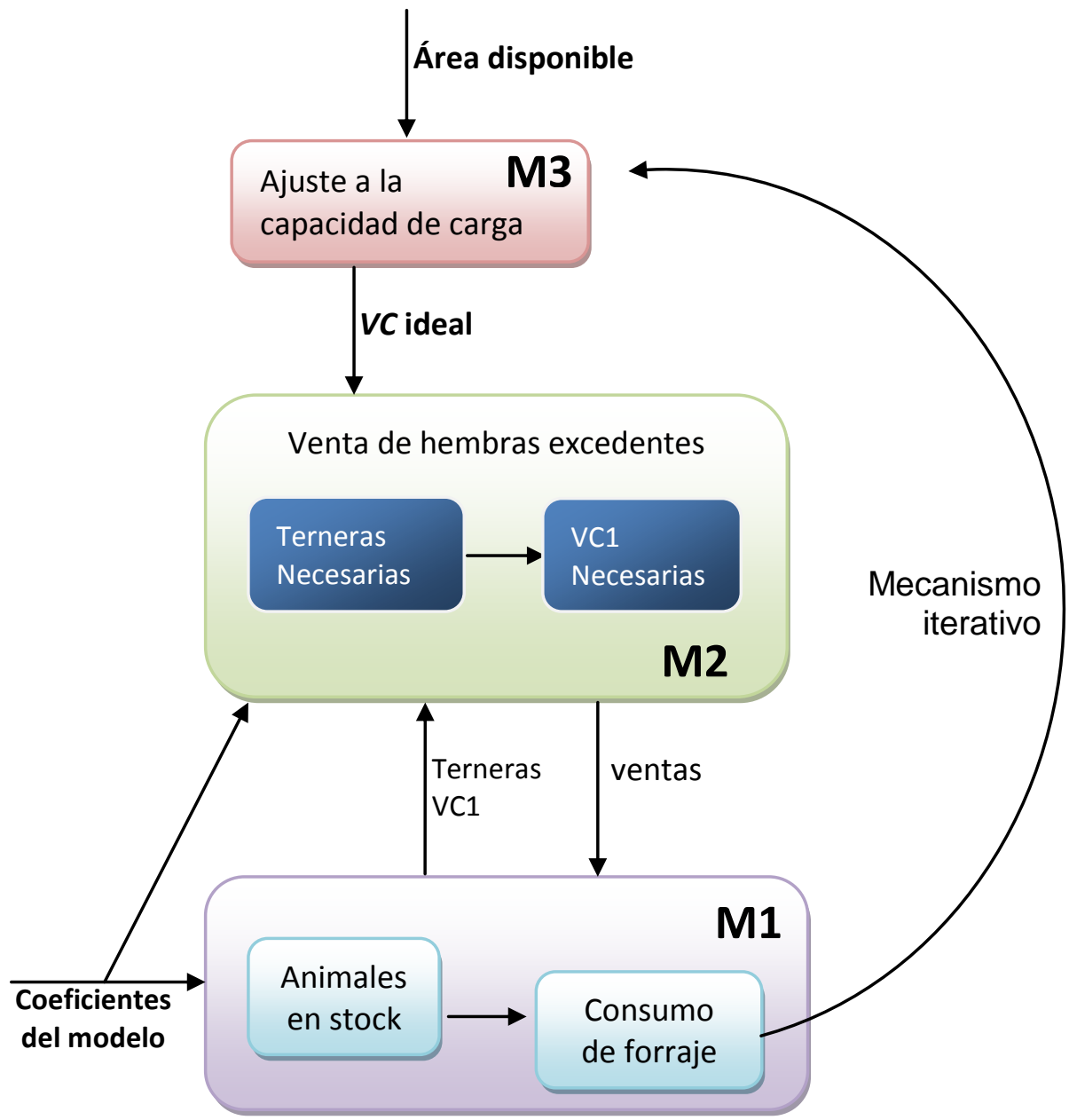

Figura 24. Estructura general del modelo y submodelos

Estas variables de entrada actúan sobre las variables de nivel representadas por las diferentes categorías animales, generando una evolución mensual y anual de las categorías del rebaño. Entre ellas, las terneras y las vacas que son servidas por primera vez revisten 
especial relevancia en la dinámica de este submodelo. El M1 es un submodelo dinámico teórico que, si no hubiera restricciones de área y/o alimento, tendería a crecer indefinidamente, considerando los coeficientes que se manejan habitualmente en estos sistemas (preñez $>60 \%$, mortalidad $<4 \%$ ). A modo de ejemplo, en la Figura 25 se presenta el número de vacas de cría generado, partiendo inicialmente de una población integrada únicamente por 100 vacas y tasas de preñez del 65 y $80 \%$.

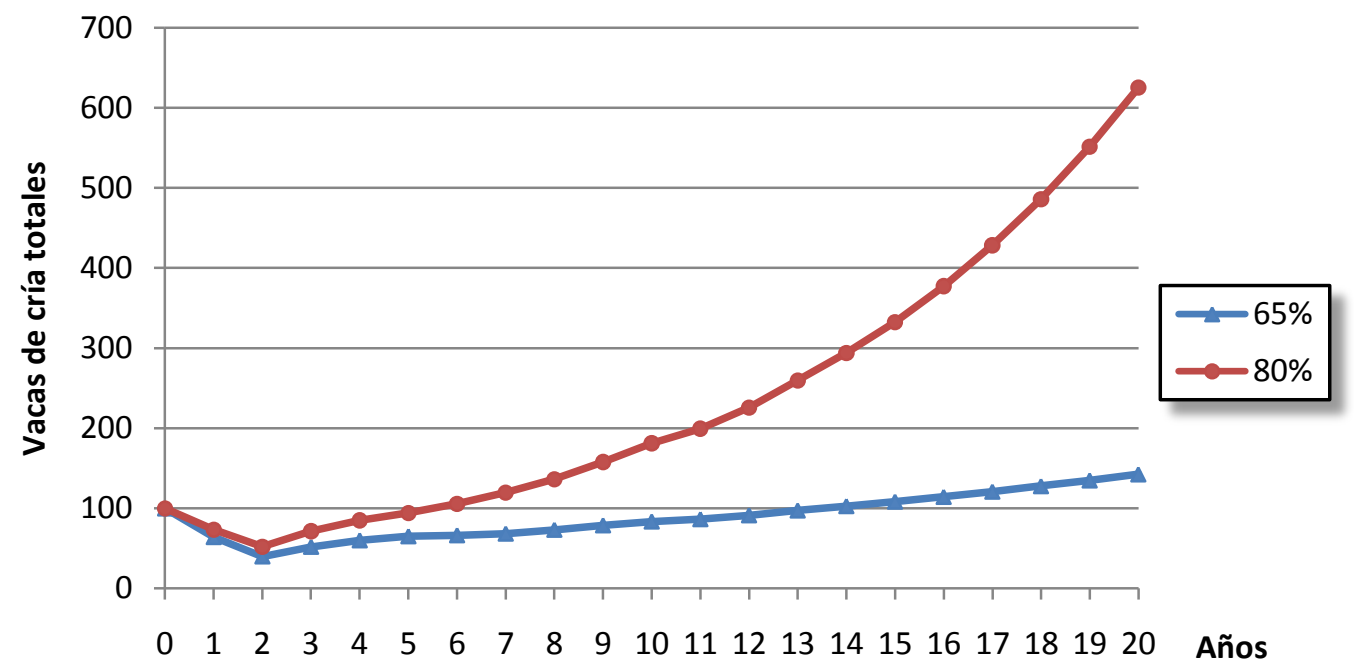

Figura 25. Evolución del número total de Vacas de cría sin control de stock en función de dos tasas de preñez (65 y 80\%)

Esta es una situación hipotética; la realidad es que éstos son sistemas comerciales y como tales, se ven restringidos a un área y/o volumen de alimento en mayor o menor medida definidos. Es por ello que existe un segundo submodelo (M2) encargado de regular el sistema a través de la venta de hembras que exceden las necesarias para la manutención de un número de $V C_{\text {ideal. }}$ Este número de vacas de cría "ideal" es el eje del modelo y conceptualmente puede ser definido como el valor de vacas de cría totales (sumatoria de las vacas de cría de cada categoría) que determina -en función de los parámentros del modelo-, un total de animales en el rebaño ajustado a los recursos alimenticios existentes.

La venta de hembras excedentes se convierte en lo que puede denominarse una regulación de segundo orden y la magnitud a vender estará en función de los coeficientes del modelo (preñez, mortalidad, descarte) y del valor de $\mathrm{VC}_{\text {ideal. }}$ A su vez, el modelo puede comercializar este excedente en tres momentos y estados diferentes de la vida del animal: como terneras al destete, como novillas para ser servidas o como novillas preñadas. En 
estos casos el destino de estos animales es el de otros productores que por diversas razones necesitan incrementar el número de vientres en su rebaño.

El valor de $\mathrm{VC}_{\text {ideal }}$ puede definirse arbitrariamente en cuyo caso el modelo estaría compuesto únicamente por los submodelos $\mathrm{M} 1$ y $\mathrm{M} 2$. En la realidad, el valor de $\mathrm{VC}_{\text {ideal }}$ suele estar definido por los recursos que limitan la producción del establecimiento (alimento, capital, mano de obra, tiempo, etc), siendo la limitante más usual el alimento, lo cual en estos sistemas pastoriles es equivalente al área de pastoreo disponible. Conceptualmente, el valor de vacas de cría ideal se corresponde al tamaño máximo de rebaño que es capaz de soportar el sistema, según la capacidad de carga que se le haya asignado.

En efecto, el número de vacas totales puede ser una medida de comparación aceptable si se contrastan opciones dentro de una misma orientación productiva o sistemas muy similares entre sí. En la medida que el modelo se hace más complejo y se involucran variables como el peso de las categorías, la retención de machos para cebo y la capacidad de aporte de alimentos de los esquemas productivos, se hace necesario recurrir a otros criterios que permitan contrastar las diferentes opciones productivas y de manejo en base a su utilización de recursos. Es evidente que un sistema de ciclo completo que mantiene el $100 \%$ de los machos en stock, no es comparable, en cuanto al número de vacas capaz de sostener, con un sistema exclusivamente de cría que vende la totalidad de los terneros al destete. De la misma forma, un sistema de uso extensivo de insumos (sin aporte de suplementos de fuera del predio, bajo porcentaje de praderas artificiales), puede generar un ingreso similar a uno intensivo con el mismo número de vacas, pero en un área significativamente mayor. Sin embargo, la superioridad del sistema intensivo, (aunque también tenga mejores indicadores de comportamiento individual), está determinada por la capacidad de mantener un mayor número de animales debido a un mayor nivel de intensificación en el uso de la tierra.

Por tal motivo se hace necesario un tercer submodelo (M3) el cual realiza una regulación de tercer orden en el que $V C_{\text {ideal }}$ pasa a ser una variable derivada 0 condicionada a la capacidad de producción de alimento del predio, estrechamente ligado al área disponible. Este procedimiento se realiza mediante el cálculo mensual de carga o dotación, definido por la ecuación [2.37]. El modelo posibilita distinguir, para cada mes, categorías que pastorean el campo natural $(\mathrm{CN})$, de otras que pastorean praderas artificiales (PRAD) por lo cual la capacidad de carga total del establecimiento estará definida por la proporción de área disponible de cada tipo de pastura.

$$
\text { KgStock }=\sum_{1}^{j} n C N_{j} \cdot p C N_{j}+\sum_{1}^{j} n P R A D_{j} \cdot p P R A D_{j}
$$


donde:

KgStock es el total de $\mathrm{kg}$ en stock en un determinado mes $n C N_{j y} n P R A D_{j}$ son el no de animales de la categoría jen CN y PRAD respectivamente $p C N_{j}$ y $p P R A D_{j}$ es el peso promedio de los animales de la categoría j en CN y PRAD respectivamente

Este valor se divide entre $400 \mathrm{~kg}$, peso que convencionalmente se utiliza en Uruguay para representar una unidad ganadera vacuna, obteniéndose el total de unidades ganaderas (TUG) soportado por el sistema:

$$
T U G=\frac{K g S t o c k}{400}
$$

El total de unidades ganaderas así calculado, se contrasta con la capacidad de carga total del sistema expresado en unidades forrajeras disponibles (TUF), mediante el cálculo del producto de la superficie de campo natural y praderas definidos, por un factor de carga dependiente del tipo de pastura. Por defecto se sugieren valores de $0.7 \mathrm{UG} / \mathrm{ha}$ para el campo natural y $1.20 \mathrm{UG} / \mathrm{ha}$ para el área de praderas, aunque estas magnitudes dependerán del tipo de campo y praderas, así como de otros factores.

$$
T U F=\frac{\text { CargaCN } \cdot \text { AreaCN }+ \text { CargaPrad } \cdot \text { AreaPrad }}{\text { AreaCN }+ \text { AreaPrad }}
$$

Este procedimiento no es más que una primera aproximación al control de stock. En efecto, la unidad ganadera asume un consumo de forraje relacionados en forma lineal con el peso, lo cual determina que un ternero consuma lo mismo (por $\mathrm{kg}$ de peso vivo) que un novillo o, lo que es más grave, que una vaca en lactancia tenga un consumo por kg similar al de una vaca vacía en mantenimiento. Las ecuaciones del modelo animal aquí planteadas se basan en premisas de mayor complejidad, por lo cual el procedimiento de ajuste a través de UG descrito constituye una aproximación inicial del número de animales a manejar en el punto de partida de una simulación, ya que se trata de unidades de uso generalizado en el país y por tanto de fácil interpretación. Habiendo definido el número de animales soportados por el sistema (cuando TUF-TUG=0), se establece el volumen de forraje consumido en esta situación y a partir de esta definición inicial, las simulaciones posteriores se realizarán manteniendo constante dicho volumen de forraje.

De esta forma, si el forraje consumido excede el volumen establecido inicialmente, el modelo disminuye iterativamente el valor de $V C_{\text {ideal }}$ en una magnitud proporcional al exceso hasta que la diferencia se aproxima a cero. Alternativamente, si el forraje consumido es menor al de referencia, el valor de $V C_{\text {ideal }}$ es incrementado hasta que la diferencia se 
minimiza. Así, al modificar iterativamente el valor de $V C_{\text {ideal, }}$ se ajustan en forma encadenada todas las categorías afectadas y todo el sistema al área definida.

El mismo procedimiento se aplica en el caso del sistema de Cebo, en cuyo caso se ajusta el valor de animales a comprar anualmente.

Con esta estructura se hace posible la comparación entre sistemas de diferente grado de intensificación, orientaciones productivas y combinaciones de éstos.

\subsection{1. $\underline{\text { Variables }}$}

En la Tabla 12 se presentan y describen las variables de nivel afectadas al sistema. Se nombran las variables con la abreviatura que se utilizará a lo largo de este trabajo, el significado de esta abreviatura y posteriormente una breve descripción de la misma para facilitar la mejor comprensión del modelo.

Tabla 12. Variables de nivel del modelo

\begin{tabular}{|c|c|c|}
\hline ID & Significado & Descripción \\
\hline$T$ & Toros & Toros \\
\hline$V C$ & Vacas de Cría & Representa el total de vientres en servicio en el rebaño \\
\hline VC1 & Vacas 1er cubrición & Vacas que se cubren por $1^{\underline{a}}$ vez \\
\hline VC2 & Vacas 2da cubrición & Vacas que se cubren por $2^{\mathrm{a}}$ vez \\
\hline VC3 & Vacas 3er cubrición & Vacas que se cubren por $3^{\mathrm{a}}$ vez \\
\hline VC4 & Vacas 4ta cubrición & Vacas que se cubren por $4^{\underline{a}}$ vez \\
\hline VC5 & Vacas 5ta cubrición & Vacas que se cubren por $5^{\mathrm{a}}$ vez \\
\hline VC6 & Vacas 6ta cubrición & Vacas que se cubren por $6^{\underline{a}}$ vez \\
\hline VC7 & Vacas 7ma cubrición & Vacas que se cubren por $7^{a}$ vez \\
\hline VC8 & Vacas 8va cubrición & Vacas que se cubren por $8^{\mathrm{a}}$ vez \\
\hline VC14m & $\begin{array}{l}\text { Vacas cubiertas con } 14 \\
\text { meses }\end{array}$ & $\begin{array}{l}\text { Subclase de VC1. Vacas que se cubren por primera vez con } 14 \\
\text { meses }\end{array}$ \\
\hline VC2a & Vacas cubiertas con 2 años & $\begin{array}{l}\text { Subclase de VC1. Vacas que se cubren por primera vez con } 2 \\
\text { años }\end{array}$ \\
\hline VC3a & Vacas cubiertas con 3 años & $\begin{array}{l}\text { Subclase de VC1. Vacas que se cubren por primera vez con } 3 \\
\text { años }\end{array}$ \\
\hline$U C$ & Vacas de ultima cría & $\begin{array}{l}\text { Vacas que aun están con el ternero al pie pero ya no son } \\
\text { cubiertas }\end{array}$ \\
\hline VI & Vacas de Invernada o Cebo & Vacas que se descartan del rebaño y se destinan a cebo \\
\hline VFall & $\begin{array}{l}\text { Vacas falladas (no } \\
\text { preñadas) }\end{array}$ & $\begin{array}{l}\text { Subcategoría de VI. Incluyen las vacas que se descartan del } \\
\text { rebaño por falladas más las vacas UC }\end{array}$ \\
\hline VDef & $\begin{array}{l}\text { Vacas descartadas por } \\
\text { defectos }\end{array}$ & $\begin{array}{l}\text { Subcategoría de VI. Vacas que se descartan a la cubrición por } \\
\text { defectos }\end{array}$ \\
\hline Terneros & Terneros & Total de terneros machos \\
\hline Terneras & Terneras & Total de terneras hembras \\
\hline Tm1 & Terneros de VC1 & $\begin{array}{l}\text { Subcat. de Terneros. Terneros hijos de vacas de primera } \\
\text { cubrición }\end{array}$ \\
\hline Th1 & Terneras de VC1 & $\begin{array}{l}\text { Subcat. de Terneras. Terneras hijas de vacas de primer } \\
\text { acubrición }\end{array}$ \\
\hline Tm2 & Terneros de VC2 & $\begin{array}{l}\text { Subcat. de Terneros. Terneros hijos de vacas de segunda } \\
\text { cubrición }\end{array}$ \\
\hline
\end{tabular}




\begin{tabular}{|c|c|c|}
\hline Th2 & Terneras de VC2 & $\begin{array}{l}\text { Subcat. de Terneras. Terneras hijas de vacas de segunda } \\
\text { cubrición }\end{array}$ \\
\hline TmUC & Terneros de UC & $\begin{array}{l}\text { Subcat. de Terneros. Terneros hijos de vacas de última } \\
\text { cubrición }\end{array}$ \\
\hline ThUC & Terneras de UC & $\begin{array}{l}\text { Subcat. de Terneras. Terneras hijas de vacas de última } \\
\text { cubrición }\end{array}$ \\
\hline TmResto & Terneros del resto de vacas & $\begin{array}{l}\text { Subcat. de Terneros. Terneros hijos de vacas del resto del } \\
\text { rebaño }\end{array}$ \\
\hline ThResto & Terneras del resto de vacas & $\begin{array}{l}\text { Subcat. de Terneras. Terneras hijas de vacas del resto del } \\
\text { rebaño }\end{array}$ \\
\hline Na12ss & $\begin{array}{l}\text { Novillas de } 1-2 \text { años sin } \\
\text { servir }\end{array}$ & Novillas que no se cubren con 14 meses \\
\hline Na23ss & $\begin{array}{l}\text { Novillas de } 2-3 \text { años sin } \\
\text { servir }\end{array}$ & Novillas que no se cubren con 14 meses ni con 2 años \\
\hline No12 & Novillos de 1-2 años & Novillos de 1 a 2 años de edad \\
\hline No23 & Novillos de 2-3 años & Novillos de 2 a 3 años de edad \\
\hline No34 & Novillos de 3-4 años & Novillos de 3 a 4 años de edad \\
\hline $\mathrm{No}+4$ & Novillos de +4 años & Novillos de más de 4 años de edad \\
\hline
\end{tabular}

A continuación se presentan las variables de entrada del modelo (Tabla 13).

Tabla 13. Variables de entrada del modelo

\begin{tabular}{|c|c|c|}
\hline ID & Significado & Descripción \\
\hline PropToro & Proporción de Toros & Proporción de toros respecto al total de vacas de cría \\
\hline estratos & Nro. categorías VC & Cantidad de estratos o grupos etarios de VC (4 y 8). \\
\hline Cub14 & Tasa cubrición a los 14 meses & Proporción de terneras que se cubren a los 14 meses \\
\hline Cub2 & Tasa cubrición a los 2 años & Proporción de terneras que se cubren a los 2 años \\
\hline par1 & Tasa parición VC1 & Tasa parición de vacas de primera cubrición \\
\hline par2 & Tasa parición VC2 & Tasa parición de vacas de segundo cubrición \\
\hline parresto & Tasa parición resto rebaño & Tasa parición del resto del rebaño de cría \\
\hline$s T$ & Sobrevivencia terneros/as & $\begin{array}{l}\text { Tasa de Sobrevivencia de terneros/as durante primer año de } \\
\text { vida }\end{array}$ \\
\hline sTpond & $\begin{array}{l}\text { Sobrevivencia terneros/as } \\
\text { ponderada }\end{array}$ & $\begin{array}{l}\text { Sobrevivencia de terneros/as considerando el uso del destete } \\
\text { precoz, ponderando por categoría que lo usa y duración del } \\
\text { mismo }\end{array}$ \\
\hline sNa12ss & Sobrevivencia $\mathrm{Na} 1-2 \mathrm{a}$ & Tasa de sobrevivencia novillas de 1 a 2 años sin servir \\
\hline sNa2ss & Sobrevivencia $\mathrm{Na} 2-3 \mathrm{a}$ & Tasa de sobrevivencia novillas de 2 a 3 años sin servir \\
\hline sVC14m & $\begin{array}{l}\text { Sobrevivencia Na cubiertas con } \\
14 \text { meses }\end{array}$ & $\begin{array}{l}\text { Tasa de Sobrevivencia de novillas que se cubren por primera } \\
\text { vez con } 14 \text { meses }\end{array}$ \\
\hline sVC2a & $\begin{array}{l}\text { Sobrevivencia Na cubiertas con } \\
2 \text { años }\end{array}$ & $\begin{array}{l}\text { Tasa de Sobrevivencia de novillas que se cubren por primera } \\
\text { vez con } 2 \text { años }\end{array}$ \\
\hline sVC3a & $\begin{array}{l}\text { Sobrevivencia Na cubiertas con } \\
3 \text { años }\end{array}$ & $\begin{array}{l}\text { Tasa de Sobrevivencia de novillas que se cubren por primera } \\
\text { vez con } 3 \text { años }\end{array}$ \\
\hline$s V C$ & Sobrevivencia VC & Tasa de sobrevivencia de resto vacas de cría \\
\hline sVI & Sobrevivencia VI & Tasa de sobrevivencia de vacas de cebo \\
\hline sNo12 & Sobrevivencia No12 & Tasa de sobrevivencia de novillos de 1-2 años \\
\hline sNo23 & Sobrevivencia No23 & Tasa de sobrevivencia de novillos de 2-3 años \\
\hline sNo34 & Sobrevivencia No34 & Tasa de sobrevivencia de novillos de 3-4 años \\
\hline$s \mathrm{No}+4$ & Sobrevivencia No+4 & Tasa de sobrevivencia de novillos de +4 años \\
\hline
\end{tabular}




\begin{tabular}{|c|c|c|}
\hline $\mathrm{DescNa}$ & Descarte novillas & $\begin{array}{l}\text { Variable binaria que toma el valor } 1 \text { si se descartan las vacas } \\
\text { de } 1^{\circ} \text { y } 2^{\circ} \text { cubrición al diagnosticarse vacías y } 0 \text { si se } \\
\text { mantienen en el rebaño }\end{array}$ \\
\hline DescDef & Descarte por defectos & Tasa de descarte de vacas de cría por defectos a la cubrición \\
\hline MesCubNa & Mes cubrición novillas & Mes de cubrición de novillas (Nov-Dic) \\
\hline DurCubNa & Duración Cubrición Novillas & Duración del cubrición de novillas (2-3 meses) \\
\hline MesDest1ra & Mes destete vacas 1er cría & Febrero - Mayo \\
\hline MesDestUlt & Mes destete vacas ultima cria & Febrero - Mayo \\
\hline MesDestResto & Mes destete resto rebaño & Febrero - Junio \\
\hline PAt & Peso Adulto toros & Peso Adulto toros \\
\hline PAn & Peso Adulto novillos & Peso Adulto novillos \\
\hline$P A v$ & Peso Adulto vacas & Peso Adulto vacas \\
\hline$P N m$ & Peso nacer machos & Peso nacer machos \\
\hline$P N h$ & Peso nacer hembras & Peso nacer hembras \\
\hline PVNovillito & Peso Venta Nov <2 años & $\begin{array}{l}\text { Peso mínimo para venta a matadero de novillos de hasta } 2 \\
\text { años de edad }\end{array}$ \\
\hline PVNovJov & Peso Venta Nov de 2 a 3 años & $\begin{array}{l}\text { Peso mínimo para venta a matadero de novillos de } 2 \text { a } 3 \text { años } \\
\text { de edad }\end{array}$ \\
\hline PVNovGde & Peso Venta Nov +3 años & $\begin{array}{l}\text { Peso mínimo para venta a matadero de novillos de más de } 3 \\
\text { años de edad }\end{array}$ \\
\hline$P V V G$ & Peso Venta Vacas Gordas & Peso mínimo de vacas de descarte para venta al matadero \\
\hline$z V T$ & Venta terneras & $\begin{array}{l}\text { Variable binaria que toma valor } 1 \text { ó } 0 \text { si la venta del excedente } \\
\text { de hembras se realiza como terneras }\end{array}$ \\
\hline$z V N a$ & $\begin{array}{l}\text { Venta novillas para ser } \\
\text { cubiertas }\end{array}$ & $\begin{array}{l}\text { Variable binaria que toma valor } 1 \text { ó } 0 \text { si la venta del excedente } \\
\text { de hembras se realiza como novillas para cubrición }\end{array}$ \\
\hline$z V V C 1$ & Venta novillas cubiertas & $\begin{array}{l}\text { Variable binaria que toma valor } 1 \text { ó } 0 \text { si la venta del excedente } \\
\text { de hembras se realiza como novillas cubiertas }\end{array}$ \\
\hline PRNa & Prioridad retención de Novillas & $\begin{array}{l}\text { Variable discreta que regula el orden de prioridad de retención } \\
\text { de las posibles categorías de novillas a vender }\end{array}$ \\
\hline
\end{tabular}

En la Tabla 14 se presentan las salidas del modelo. Para resumir, se omiten las variables asociadas a la muerte de animales, que es el producto de cada categoría por su correspondiente coeficiente de mortalidad (1-sobrevivencia).

Tabla 14. Variables de salida del modelo M2 (Ventas)

\begin{tabular}{|l|l|l|}
\hline ID & Significado & Descripción \\
\hline VtaTh & Venta Terneras & Excedente de terneras destinado a venta \\
\hline VtaTm & Venta Terneros & Terneros destinados a venta \\
\hline VtaNaCub & Venta novillas para cubrición & $\begin{array}{l}\text { Excedentes de hembras comercializado como novillas para ser } \\
\text { cubiertas }\end{array}$ \\
\hline VtaNaP & Venta novillas preñadas & Excedentes de hembras comercializado como novillas preñadas \\
\hline VtaNo12 & Venta Nov 1-2 años & Novillos de 1 a 2 años de edad destinados a venta \\
\hline VtaNo23 & Venta Nov 2-3 años & Novillos de 2 a 3 años de edad destinados a venta \\
\hline VtaNo34 & Venta Nov 3-4 años & Novillos de 3 a 4 años de edad destinados a venta \\
\hline VtaNo+4 & Venta Nov +4 años & Novillos de más de 4 años de edad destinados a venta \\
\hline VtaVG & Venta de vacas gordas & Vacas de cebo gordas a vender \\
\hline
\end{tabular}


Para facilitar el desarrollo de ecuaciones y la interpretación de las mismas se crean una serie de variables intermedias derivados de los coeficientes ingresados (Tabla 15).

Tabla 15. Variables intermedias calculadas

\begin{tabular}{|l|l|l|}
\hline ID & Significado & Descripción \\
\hline s1rapond & $\begin{array}{l}\text { Tasa cubrición a los 3 } \\
\text { años }\end{array}$ & $\begin{array}{l}\text { Proporción de terneras que se cubrirán a los 3 años. Se genera por } \\
\text { diferencia (1-Cub2) }\end{array}$ \\
\hline ponderado & Descarte por falladas & $\begin{array}{l}\text { Tasa de sobrevivencia de vacas de 1 ra cría, ponderado por la } \\
\text { composición de vacas cubiertas con 14 meses, 2 años ó 3 años y } \\
\text { su correspondiente sobrevivencia }\end{array}$ \\
\hline NoDescDef & Tasa de No Descarte & $\begin{array}{l}\text { Tasa de animales que no se descartan del rebaño por defectos (1- } \\
\text { DescDef) }\end{array}$ \\
\hline$z$ VC5 & Existencia de VC5 & Variable binaria que toma valor 1 ó 0 si existe o no la categoría VC5 \\
\hline$z$ VC6 & Existencia de VC6 & Variable binaria que toma valor 1 ó 0 si existe o no la categoría VC6 \\
\hline$z$ VC7 & Existencia de VC7 & Variable binaria que toma valor 1 ó 0 si existe o no la categoría VC7 \\
\hline$z V C 8$ & Existencia de VC8 & Variable binaria que toma valor 1 ó 0 si existe o no la categoría VC8 \\
\hline TerNec & Terneras Necesarias & $\begin{array}{l}\text { Número de terneras requerido para mantener valor objetivo de } \\
\text { vacas de cría (VC) }\end{array}$ \\
\hline VC1Nec & Vacas de cría necesarias & $\begin{array}{l}\text { Número de Vacas de cría requerido para mantener valor objetivo de } \\
\text { vacas de cría (VC) }\end{array}$ \\
\hline
\end{tabular}

El modelo opera sobre valores iniciales ingresados como punto de partida y posteriormente los valores se ajustan según las ecuaciones con la meta de que el total de vacas de cría ( $V C$; ecuación [2.40]) se iguale al de vacas de cría ideal ( $\left.V C_{\text {ideal }}\right)$.

El valor de $V C$, corresponde a la sumatoria de las vacas de cría de cada categoría según el valor que se le asigne a la variable estratos (4 a 8).

$$
V C=\sum_{i=1}^{\text {estratos }} V C_{\text {ideal }}
$$

A partir de este total se calcula para cada año el resto de las categorías en función de los valores de inicio y los coeficientes ingresados, según las siguientes funciones que se presentan seguidamente. El subíndice indica el valor temporal de la variable ( $\mathrm{a}=$ año actual; $\mathrm{a}-1=$ año anterior) . 


\subsubsection{Evolución de categorías en stock}

Novillas que se cubren con 14 meses

$\operatorname{VC14m}_{(\mathrm{a})}=\operatorname{terneras}_{(\mathrm{a}-1)}{ }^{*} s T^{*} \mathrm{Cub14}^{*}$ NoDescDef

Novillas 1-2 sin servir

$\operatorname{Na12ss}_{(\mathrm{a})}=$ terneras $_{(\mathrm{a}-1)}{ }^{*}$ sTpond $^{*}(1-$ Cub14 $)$

Novillas que se cubren con 2 años

$\operatorname{VC2a}_{(\mathrm{a})}=\operatorname{Na12ss}_{(\mathrm{a}-1)}{ }^{*} \mathrm{sNa12ss}$ *(Cub2 / (Cub2 +Cub3)) *NoDescDef

Novillas 2-3 sin servir

$\operatorname{Na2ss}_{(\mathrm{a})}=\operatorname{Na12ss}_{(\mathrm{a}-1)} * \mathrm{sNa12ss}^{*}(\mathrm{Cub3} /(\mathrm{Cub3}+\mathrm{Cub2}))$

Novillas que se cubren con 3 años

$V C 3 a_{(\mathrm{a})}=\operatorname{Na2ss}_{(\mathrm{a}-1)}$ * $s N a 2 s s^{*}$ NoDescDef

Vacas de primera cubrición

$V C 1_{(\mathrm{a})}=V C 14 m_{(\mathrm{a})}+V C 2 a_{(\mathrm{a})}+V C 3 a_{(\mathrm{a})}$

Vacas de segunda cubrición

$V C 2_{(\mathrm{a})}=\left(V C 14 m_{(\mathrm{a}-1)}{ }^{*} \operatorname{sVC14m}+V C 2 \mathrm{a}_{(\mathrm{a}-1)}{ }^{*} \mathrm{sVC2a}+V C 3 a_{(\mathrm{a}-1)}{ }^{*} \mathrm{sVC3a}\right){ }^{*}$ NoDescDef

equivalente a:

$\mathrm{VC}_{(\mathrm{a})}=\mathrm{VC}_{(\mathrm{a}-1)}{ }^{*} \mathrm{~s} 1 \mathrm{raPond}{ }^{*}$ NoDescDef

Vacas de tercera cubrición

$V C 3=V C 2{ }^{*} s V C *$ NoDescDef

Vacas de cuarta cubrición

$V C 4_{(\mathrm{a})}=V C 3_{(\mathrm{a}-1)}{ }^{*} \mathrm{sVC} *$ NoDescDef

Vacas de quinta cubrición

$V C 5_{(\mathrm{a})}=z V C 5^{*} V C 4_{(\mathrm{a}-1)}{ }^{*} \mathrm{sVC}$ * parresto $^{*}$ NoDescDef

Vacas de sexta cubrición

$V C 6_{(\mathrm{a})}=z v c 6^{*} V C 5_{(\mathrm{a}-1)}{ }^{*} \mathrm{sVC}$ * parresto * NoDescDef

Vacas de séptima cubrición

$V C 7_{(\mathrm{a})}=z v C 7^{*} V C 6_{(\mathrm{a}-1)}$ * $s V C$ * parresto * NoDescDef

Vacas de octava cubrición 
$V C 8_{(\text {a) }}=z V C 8^{*} V C 7_{(\text {a-1) }}{ }^{*} s V C *$ parresto * NoDescDef

\section{Toros}

$\mathrm{T}_{(\mathrm{a})}=\operatorname{PropToro} \cdot \sum_{i=1}^{\text {estratos }} V C_{i}$

En la Figura 26 se esquematiza el mecanismo de reposición de hembras. Las terneras pueden ingresan al rebaño de cría apenas cumplido el año de edad (VC14m) en una proporción Cub14 y las restantes pasan a la categoría Novillas 1-2 años sin servir (Na12ss). De esta categoría una proporción Cub2 se cubre con 2 años (VC2a) y las restantes pasan a la categoría Novillas 2-3 años sin servir (Na23ss). El 100\% de estos animales se cubre a los 3 años (VC3a). Estas tres categorías que pasan a integrar el rebaño de cría constituyen las vacas de primera cubrición (VC1) que conjuntamente con el resto de los estratos de cría componen el total de las vacas en producción (VC) cuyo valor "ideal" es definido en el submodelo M3. En función de este número de $V C$ y los coeficientes de preñez ingresados (par1, par2, parresto), se definirá el número de hembras (terneras) disponibles para la reposición del ciclo.

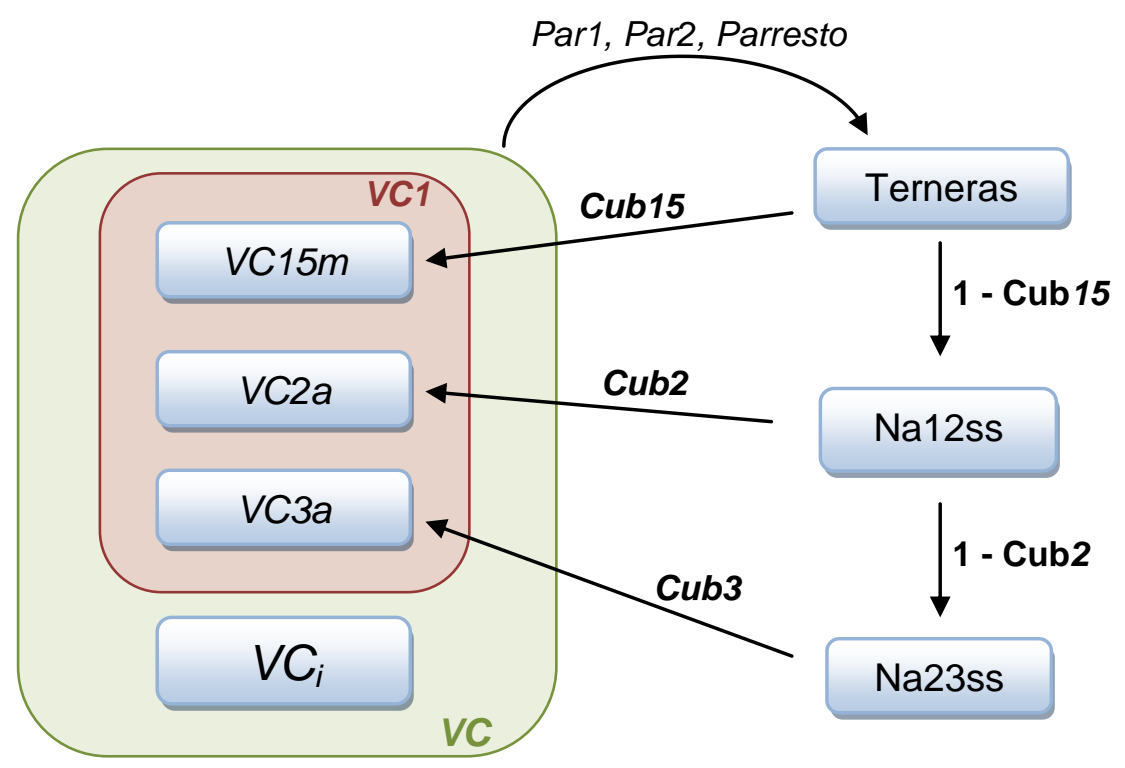

Figura 26. Esquema del mecanismo de generación de reemplazos del ciclo de cría 


\subsection{3. $\underline{\text { Nacimientos }}$}

Terneros hijos de vacas de primera cubrición

$T m 1_{(\mathrm{a})}=v c 1_{(\mathrm{a}-1)} * \operatorname{par1}^{*}$ s1rapond ${ }^{*} 0.5$

Terneras hijos de vacas de primera cubrición

$T h 1_{(\mathrm{a})}=\operatorname{vc}_{(\mathrm{a}-1)}{ }^{*} \operatorname{par1}^{*}{ }^{\text {s } 1 \text { rapond }}{ }^{*} 0.5$

Terneros hijos de vacas de segunda cubrición

$T m 2_{(\mathrm{a})}=v c 2_{(\mathrm{a}-1)}$ * par2 $^{*} \mathrm{sVC}$ * 0.5

Terneras hijos de vacas de segunda cubrición

$T h 2_{(\mathrm{a})}=v c 2_{(\mathrm{a}-1)}{ }^{*}$ par2 ${ }^{*} s V C{ }^{*} 0.5$

Terneros hijos de vacas multíparas (3a-ㄹㅗㅡ cubrición)

$\operatorname{TmResto}_{(\mathrm{a})}=\left(\sum_{i=3}^{\text {estratos }-1} V C_{i}\right)_{a-1}{ }^{*} s V C *$ parresto ${ }^{*} 0.5$

Terneras hijos de vacas multíparas (3ª-8aㅗ cubrición)

$\operatorname{ThResto}_{(\mathrm{a})}=\left(\sum_{i=3}^{\text {estratos }-1} V C_{i}\right)_{a-1}{ }^{*} s V C^{*}$ parresto * 0.5

Terneros hijos de vacas de última cubrición

$\operatorname{TmUC}(\mathrm{a})=\left(V C_{\text {estratos }}\right)_{(\mathrm{a}-1)}{ }^{*}$ sVC * parresto * 0.5

Terneras hijos de vacas de última cubrición

$\operatorname{ThUC}(a)=\left(V C_{\text {estratos }}\right)_{(\mathrm{a}-1)}{ }^{*}$ sVC *parresto * 0.5

Total terneros nacidos

$\operatorname{Terneros}_{(\mathrm{a})}=\operatorname{Tm} 1_{(\mathrm{a})}+\operatorname{Tm} 2_{(\mathrm{a})}+\operatorname{TmUC_{(\mathrm {a})}}+\operatorname{TmResto}_{(\mathrm{a})}$

$\operatorname{Terneras}_{(\mathrm{a})}=\operatorname{Th1_{(\mathrm {a})}}+\operatorname{Th} 2_{(\mathrm{a})}+\operatorname{ThUC_{(\mathrm {a})}}+\operatorname{ThResto}_{(\mathrm{a})}$

Esta división se realiza debido a la existencia de tres categorías bien definidas en el ciclo de cría en pastoreo en cuanto a su desempeño reproductivo y que determinan la necesidad de un tratamiento diferencial:

Novillas de primera cubrición: normalmente son animales que ingresan al rebaño de cría en buen estado corporal, puesto que su gasto energético ha sido únicamente el de 
mantenimiento y crecimiento. Este hecho determina índices reproductivos altos (normalmente par1 $\geq 90 \%$ ).

Vacas de segunda cubrición: esta categoría es la más problemática del ciclo de cría. Luego del gasto energético y la pérdida de reservas que significa la gestación y su primer parto, el animal que muchas veces no ha completado totalmente su desarrollo, debe dedicar energía al crecimiento, mantenimiento del estado corporal y a la producción de leche. Esto determina que al llegar a la segunda cubrición, el animal está en condiciones subóptimas de

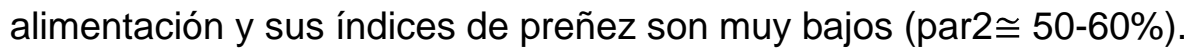

Resto del Rebaño: normalmente se da una situación intermedia a las dos categorías antes descritas. Son animales que ya no destinan energía al crecimiento, pero deben recuperarse del parto anterior. El porcentaje de preñez de esta categoría oscila entre 65 y $85 \%$.

Vacas de última Cría: son las vacas de mayor edad, están criando su último ternero pero ya no serán servidas nuevamente. A estos animales se busca destetarlos lo antes posible para acelerar su cebo y venta como vacas gordas.

\subsubsection{Estimación de la fecha de parto}

El modelo posibilita la opción de que las novillas que ingresan a su primer servicio, lo hagan en forma anticipada (noviembre). De esta forma se cuenta con un mes extra para permitir la recuperación de estado corporal de las vacas de primera cría. Si esta opción es seleccionada, los terneros hijos de las vacas de primera cría, tendrán aproximadamente un mes más de edad que el resto.

Paralelamente, existe una asociación positiva entre el peso a la cubrición como indicador del nivel nutricional de las vacas y la probabilidad de concepción de las hembras del rebaño en cada uno de los meses de duración del servicio. La ecuación logística que asocia estas variables para las tres categorías del rebaño de cría, fue estimada partir de la BDGL (INIA).

\section{Vacas de primera cría:}

$$
\begin{aligned}
& \text { PCM1 }=1-\frac{1}{1+e^{(-1.3265+0.00582 \text { PesoEnt })}} \\
& P C M 2=1-\frac{1}{1+e^{(0.9557-0.00576 \text { PesoEnt })}} \\
& \text { PCM3 }=1-(\text { PCM1 }+ \text { PCM2 })
\end{aligned}
$$




\section{Vacas de segunda cría:}

$P C M 1=1-\frac{1}{1+e^{(-5.9985+0.0156 \text { PesoEnt })}}$

$$
P C M 2=1-\frac{1}{1+e^{(2.723-0.00841 \text { PesoEnt })}}
$$

$P C M 3=1-(P C M 1+P C M 2)$

\section{Vacas multíparas:}

$$
\begin{aligned}
& \text { PCM1 }=1-\frac{1}{1+e^{(-3.274+0.00707 \text { PesoEnt })}} \\
& P C M 2=1-\frac{1}{1+e^{(1.4644-0.00461 \text { PesoEnt })}} \\
& P C M 3=1-(\text { PCM1 }+ \text { PCM2 })
\end{aligned}
$$

donde:

$P C M 1$ es la probabilidad de que una hembra que se preñe, conciba en el primer mes de cubrición $P C M 2$ es la probabilidad de que una hembra que se preñe, conciba en el segundo mes de cubrición $P C M 3$ es la probabilidad de que una hembra que se preñe, conciba en el tercer mes de cubrición

Las anteriores ecuaciones hacen referencia a una probabilidad condicional a animales que se preñan, habiéndose estimado otra ecuación para predecir la probabilidad de preñez global en todo el período de cubrición en función del peso de las vacas al inicio del mismo:

$$
\begin{aligned}
& \text { PPVC1 }=1-\frac{1}{1+e^{(-0.824+0.0097 \text { PesoEnt })}} \\
& \text { PPVC2 }=1-\frac{1}{1+e^{(-4.8897+0.0159 \text { PesoEnt })}} \\
& \text { PPVC3 }+=1-\frac{1}{1+e^{(-4.7825+0.0151 \text { PesoEnt })}}
\end{aligned}
$$

donde:

PPVC1 es la probabilidad de preñez de novillas de primera cubrición PPVC2 es la probabilidad de preñez de vacas de segunda cubrición $P P V C 3+$ es la probabilidad de preñez de vacas multíparas

A modo de ejemplo, el la Figura 27, se observa la probabilidad de concepción de una novilla en cada uno de los meses de servicio en función del peso al inicio de la cubrición. 


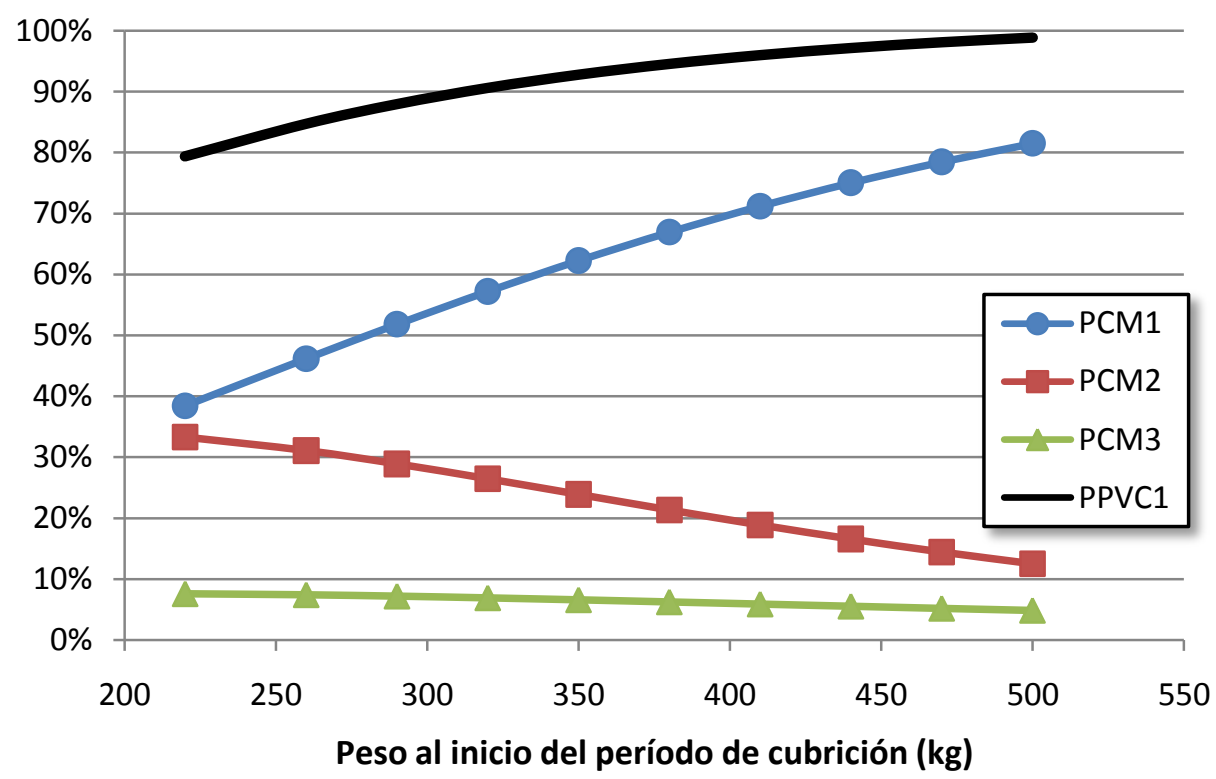

Figura 27. Probabilidad condicional de concepción en el $1^{\text {er }}$ (PCM1), $2^{\text {do }}$ (PCM2) y $3^{\text {er }}$ mes de cubrición (PCM3) y probabilidad de preñez global (PPVC1) en novillas de primer cubrición que ingresan al servicio con diferentes pesos

Otro factor que puede determinar un atraso en la fecha de parto es la ocurrencia de partos con distinto grado de dificultad, lo cual suele ser un problema relativamente frecuente en novillas (Colburn et al., 1997; Nix et al, 1997).

Analizando la base de datos existente (BDGL, INIA Uruguay) se encontró una incidencia del $10.6 \%$ de partos (ver sección 4.5.3.3) con algún grado de dificultad ( $n=320,5$ años), algo mayor a los valores encontrados por Nix et al. (1997), (7\%) pero menores a los reportados por Basarab et al. (1993), (26.5\%), aunque éstos últimos evaluaron novillas de diferentes razas. De los partos con algún grado de dificultad, se encontró un $24 \%$ con grado 2, un $74 \%$ con grado 3 y un $3 \%$ con grado 5 , similar a los valores reportados por Nix et al. (1997), (28, 69 y 3\% de los grados de asistencia leve, forzosa y cesárea respectivamente) o los encontrados por Basarab et al. (1993), (29, 65 y 6\% de los grados de asistencia leve, forzosa y cesárea respectivamente).

Para ajustar una ecuación predictiva de la probabilidad de ocurrencia de los distintos grados de dificultad al parto $(D P)$ a los datos observados, se utilizó una estimación logística multinomial (PROC LOGISTIC; SAS, 2007), utilizando como variables independientes el peso al nacer del ternero $(P n)$ y de la condición relativa $(R C)$ al parto de la novilla. Las ecuaciones estimadas fueron: 


\section{Probabilidad de ocurrencia de DP nivel 5 (Cesárea)}

$P(D P 5)=1-\left(1-\left(\frac{1}{1+e^{6.4877+1.82 \cdot R C^{2}-0.00137 \cdot P n^{2}}}\right)\right.$

Probabilidad de ocurrencia de DP de al menos nivel 3 (Asistencia forzada)

$P(D P 3)=1-\left(1-\left(\frac{1}{1+e^{3.235+1.82 \cdot R C^{2}-0.00137 \cdot P n^{2}}}\right)\right.$

Probabilidad de ocurrencia de DP de al menos nivel 2 (Asistencia leve)

$P(D P 5)=1-\left(1-\left(\frac{1}{1+e^{2.9149+1.82 \cdot R C^{2}-0.00137 \cdot P n^{2}}}\right)\right.$

Se debe tener en cuenta que las ecuaciones modelan la probabilidad acumulada de cada nivel respecto a los siguientes en orden decreciente por lo cual las probabilidades de que se verifique distocia de un determinado nivel (supuestos determinados valores de $R C$ y de $P n)$ son:

$$
\begin{aligned}
& p(D P 5)=P(D P 5) \\
& p(D P 3)=P(D P 3)-p(D P 5)=P(D P 3)-P(D P 5) \\
& p(D P 2)=P(D P 2)-p(D P 5)-p(D P 3)=P(D P 2)-P(D P 3)
\end{aligned}
$$

Éstas son las probabilidades condicionales de distocia de determinado nivel $j$ respecto a unos valores dados de $R c$ y $P n, p\left(D P_{j} \mid P n, R C\right)$; según el teorema de Bayes, asumiendo independencia entre $R C$ y $P n$, se cumple que:

$$
\begin{aligned}
& p(P n, R C)=p(P n) p(R C) \\
& p\left(D P_{j} \mid P n, R C\right) p(P n)=\frac{p\left(D P_{j}, P n, R C\right)}{p(R C)} \\
& \int p\left(D P_{j} \mid P n, R C\right) p(P n) d P n=\frac{p\left(D P_{j}, R C\right)}{p(R C)}=p\left(D P_{j} \mid R C\right),
\end{aligned}
$$

resultando que la probabilidad de distocia de un cierto nivel para un valor dado de $R C$, supuesta una determinada distribución de las probabilidades de los pesos al nacer $P n$, será:

$p\left(D P_{j} \mid R C\right)=\sum_{P n} p\left(D P_{j} \mid P n, R C\right) \cdot p(P n) \cdot \Delta P n$

Siendo $j$ (niveles distocia) $=2,3,5$ 
De esta forma, se estimó mediante simulación la probabilidad de ocurrencia de cada clase de dificultad al parto en función de la probabilidad de cada valor de peso al nacer de los terneros, asumiendo una distribución normal para esta variable. Esto es ejemplificado en la Figura 28, donde se grafican las funciones de densidad para cada nivel de distocia, asumiendo $R C=1$ y $P n \sim N(37.5,5)$ (línea segmentada).

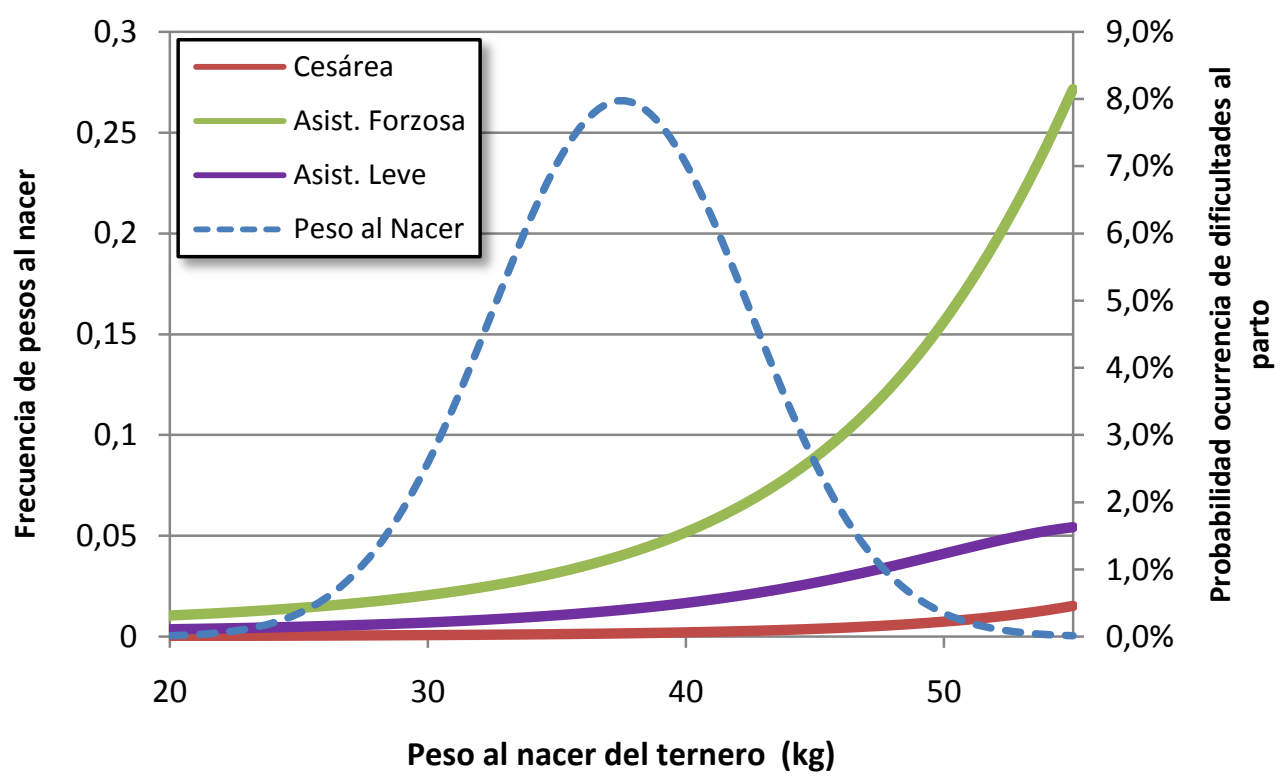

Figura 28. Funciones de densidad de probabilidad de diferentes niveles de distocia asociada a los diferentes peso de los terneros al nacer para $R C=1$ y $P n \sim N(37.5,5)$

A falta de información nacional acerca de la magnitud del efecto de la dificultad al parto sobre el atraso en el reinicio de la actividad reproductiva y consecuentemente, en la fecha de concepción, se utilizaron valores de literatura internacional, aunque es de esperar que en las condiciones de los sistemas productivos de Uruguay, este retraso sea sensiblemente mayor en virtud de las condiciones extensivas de producción. Se adoptan los valores hallados por Colburn et al. (1997) quienes obtuvieron retrasos de 3, 5, 11 y 2 días en novillas que presentaron escores de dificultad al parto de 2, 3, 4 y 5 respectivamente, en relación a las que tuvieron un parto sin asistencia (score 1). 


\subsubsection{Mortalidad}

La mortalidad de las diferentes categorías es ingresada en el modelo por el usuario, pero existen algunos casos en que el modelo estima un valor extra por encima del ingresado. Específicamente, la ocurrencia de dificultades al parto de distinto nivel en novillas, determina una tasa más alta de mortalidad tanto en las madres como los terneros. Para el caso de los terneros, se utilizaron los valores obtenidos por Nix et al. (1997), mientras que en el caso de las novillas, no se encontró información nacional ni internacional al respecto por lo cual se decidió incluirla como una variable de entrada del modelo. En la Tabla 16, se presentan las tasas de mortalidad sugeridas para novillas y las utilizadas para terneros.

Tabla 16. Tasas de mortalidad en novillas con distintos grados de dificultad al parto y sus terneros

\begin{tabular}{l|cc}
\hline Score de dificultad al parto & Mortalidad en novillas* & Mortalidad en terneros $^{* *}$ \\
\hline Asistencia Leve (2) & 0.07 & 0.21 \\
Asistencia forzada (3) & 0.15 & 0.30 \\
Asistencia mecánica forzada (4) & 0.20 & (no considera esta categoría) \\
Cesárea (5) & 0.20 & 0.50 \\
\hline
\end{tabular}

*Valores sugeridos

** Nix et al. (1997)

Estos valores de mortalidad son multiplicados por el número de novillas de primera cría existentes y por la probabilidad de ocurrencia de dificultad al parto correspondiente.

\subsubsection{Descarte de vacas del rebaño de cría}

\section{Vacas que se descartan por falladas}

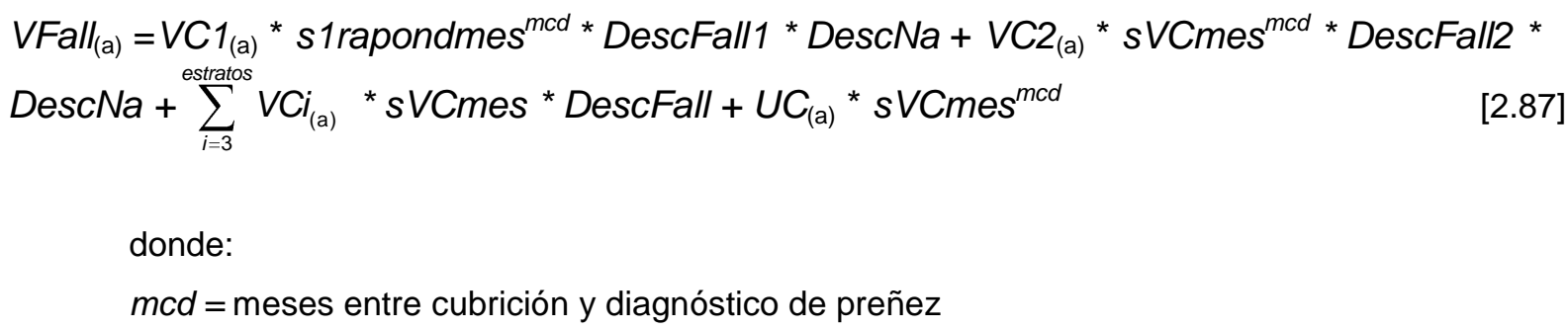


Las dos categorías más jóvenes (VC1 y VC2) no siempre se descartan aunque se diagnostiquen como vacías luego de la cubrición; el modelo permite especificarlo a través del valor de la variable binaria DescNa. Se trata de animales jóvenes, con una larga vida productiva por delante y que aún no alcanzan su tamaño adulto por lo cual su valor como vaca gorda es reducido. A partir de la tercera categoría ( $\mathrm{i}=3$ ), cada año, en el momento del diagnóstico de preñez se extraen del rebaño de cría aquellas vacas que no están preñadas (DescFall = $1-$ parresto) con destino a cebo y posterior venta. A este grupo se le suman las vacas de última cría (UC) que no han sido cubiertas y luego del destete se eliminan del rebaño de cría en su totalidad.

\section{Vacas que se descartan a la cubrición por defectos}

$\operatorname{VDef}_{(\mathrm{a})}=\operatorname{terneras}_{(\mathrm{a}-1)}{ }^{*} s T^{*}$ Cub14 $^{*} \operatorname{DescDef}_{+}$Na12ss $_{(\mathrm{a}-1)}{ }^{*} \mathrm{sNa12ss}^{*}($ Cub2 / (Cub2 + Cub3)) * DescDef +Na2ss (a-1) ${ }^{*}$ sNa2ss * DescDef + $\left(V^{*} 1_{(\mathrm{a}-1)}{ }^{*}\right.$ s1raPond * DescFall1 *

DescNa * DescDef) $+\mathrm{VC2}_{(\mathrm{a}-1)}{ }^{*} \mathrm{sVC}{ }^{*}$ DescFall $2{ }^{*} \operatorname{DescNa}{ }^{*} \operatorname{DescDef}+\sum_{i=3}^{\text {estratos }} V C_{i(\mathrm{a}-1)}{ }^{*} s V C^{*}$ DescFall * DescDef

Al inicio de la cubrición se realiza una selección y se descartan animales que presentan algún defecto. Esta práctica se aplica en todas las categorías que ingresan al rebaño de cría. Normalmente la tasa de descarte en esta instancia es de una magnitud muy

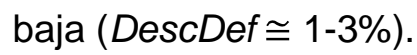

\section{Total de vacas de cebo}

$\mathrm{VI}_{(\mathrm{a})}=\mathrm{VFall}_{(\mathrm{a})}+\operatorname{VDef}_{(\mathrm{a})}$

\subsubsection{Venta}

\subsubsection{Venta de hembras excedentes}

Dependiendo de la estructura del rebaño y políticas de descarte, valores de preñez que se encuentren por encima de valores de 50-80\%, determinan que existan hembras excedentes a las necesarias para mantener el número de $\mathrm{VC}_{\text {ideal. }}$. Esto hace posible que un determinado número de hembras pueda ser destinado a la venta, de manera de mantener en el predio únicamente el número de animales necesario para la reposición, evitando retener animales improductivos. Como se ha mencionado, una de las variables de entrada del modelo es la categoría de venta de hembras de reemplazo, que pueden ser terneras, novillas para servir o novillas servidas. 
Para calcular el número de hembras excedentes se realiza el cálculo de las terneras necesarias ( $T e r N e c)$ para mantener el número de vacas de cría ideal ( $\left.V C_{\text {ideal }}\right)$, en función de los coeficientes actuales (sobrevivencia, preñez, descartes, etc). Esto se realiza sustituyendo en la ecuación general de las vacas de cría (ecuación [2.40]), cada una de las categorías por su expresión, en función de la categoría terneras. A continuación se presenta el método aplicado ejemplificado hasta la $4^{\text {ta }}$ categoría, a partir de la cual el método es idéntico para las categorías 5 a 8 si las hubiera.

\section{Cat 2 a 4:}

$$
\begin{aligned}
& \text { vc4 }=v c 3^{*} \mathrm{sVC}^{*} \text { parresto*norefdef } \\
& \mathrm{vc} 3=\mathrm{vc2}{ }^{*} \mathrm{sVC}{ }^{*} \text { norefdef } \\
& \mathrm{vc} 2=\mathrm{vc} 1^{*} \mathrm{~s} V C 1 \text { pond }{ }^{*} \text { norefdef }
\end{aligned}
$$

\section{Cat VC1:}

$$
\mathrm{vc} 1=\mathrm{VC} 14 \mathrm{~m}+\mathrm{vc} 2 \mathrm{a}+\mathrm{vc} 3 \mathrm{a}
$$

Cuyos componentes son:

VC14m=terneras*sobrT*Cub14*norefdef

vc2a $=\mathrm{Na12ss}{ }^{*} \mathrm{sNa} 12^{*}(\mathrm{Cub2} /(\mathrm{Cub} 2+\mathrm{Cub3}))^{*}$ norefdef

$v c 3 a=N a 2 s s^{*}$ sNa2ss ${ }^{*}$ norefdef

\section{Novillas sin servir:}

$$
\begin{aligned}
& \text { Na12ss=terneras }{ }^{*} \text { sobrT }^{*}(1-\text {-ent14 }) \\
& \text { Na2ss=Na12ss }{ }^{*} \text { sa12* }(\text { Cub3/(Cub3+Cub2) })
\end{aligned}
$$

Únicamente las expresiones $\mathrm{E}$ y $\mathrm{H}$ están referidas a terneras, pero las demás hacen referencia a ellas en forma escalonada, por lo cual al comenzar a sustituir:

(E) se mantiene tal cual

$$
(E)=\text { terneras }{ }^{*} \text { SobrT*Cub14*norefdef }
$$

En $(F)$ se sustituye Na12ss por su expresión:

$(F)=(H){ }^{*}$ sNa12*(Cub2/(Cub2+Cub3))*norefdef

En (G) se sustituye Na2ss por su expresión, donde a su vez se sustituyó Na12ss por su ecuación, resultando:

$$
(\mathrm{G})=(\mathrm{H}){ }^{*} \mathrm{sNa} 1{ }^{*}(\mathrm{Cub3} /(\mathrm{Cub3}+\mathrm{Cub} 2)){ }^{*} \mathrm{sNa2ss}{ }^{*} \text { norefdef }
$$

De donde VC1 queda:

$$
\begin{aligned}
\text { VC1 }= & \text { terneras }{ }^{*} \text { sobrT*Cub14*norefdef }+ \\
& \left.\left((\mathrm{H}){ }^{*} \text { sNa12*(Cub2/(Cub2+Cub3) }\right){ }^{*} \text { norefdef }\right)+ \\
& (\mathrm{H}){ }^{*} \text { sNa12*}\left(\text { Cub3/(Cub3+Cub2) }{ }^{*} \text { sNa2ss }{ }^{*}\right. \text { norefdef } \\
\text { VC2 }= & (\mathrm{J}){ }^{*} \text { sVC1pond*norefdef }
\end{aligned}
$$




$$
\begin{aligned}
& \text { VC3 }=(\mathrm{K}){ }^{*} \text { sVC*norefdef } \\
& \text { VC4 }=(L){ }^{*} \text { sVC* parresto*norefdef }
\end{aligned}
$$

Se realiza el mismo procedimiento para todas las categorías, concluyendo con una expresión:

$$
V C_{i}=V C 15 m_{t}+V C 2 a_{t}+V C 3 a_{t}+V C 2_{t}+V C 3_{t}+V C 4_{t} \cdots V C n_{t}
$$

donde cada categoría está expresada en función de la categoría terneras.

Esto genera una expresión muy extensa, que posteriormente se resuelve para la variable terneras, obteniendo la ecuación que se presenta en la tabla 1 del anexo. La variable obtenida (TerNec) representa el número mínimo de terneras a retener para mantener la estructura de hembras del rebaño. El número de terneras nacidas en cada año de simulación (ajustado por la mortalidad) y al que se resta este valor calculado (TerNec), determina el número de terneras excedentes que pueden ser comercializadas. Luego de calculado TerNec, se procede a calcular $\mathrm{VC} 1 \mathrm{Nec}$, variable que identifica el número de vacas requeridas par ingresar anualmente al rebaño. De esta forma, si en vez de comercializarze el excedente de hembras como terneras se las vende como novillas para cubrir (pre cubrición) o novillas servidas (pos cubrición), se efectúa el cálculo de las hembras excedentes y por tanto, factibles de venderse en el momento correspondiente.

Si se venden novillas para cubrición $(z \mathrm{VNa}=1)$ y hay más de una categoría, se definen como $\mathbf{a}=$ novillas aptas para cubrición de 14 meses; $\mathbf{b}=$ novillas aptas para cubrición de 2 años y $\mathbf{c}=$ novillas aptas para cubrición de 3 años. Paralelamente, la variable $P R N a$ (Prioridad Retención Novillas) toma un valor dentro de las 6 posibles combinaciones (abc, acb, bac, bca, cab, cba) que representa la prioridad que se le da a estas categorías para ser retenidas. Si por ejemplo, el orden definido es cba (máxima prioridad de cubrición a la novillas de 3 años y mínima a las de 14 meses) se venderá en primera instancia las novillas de 14 meses, luego las de 2 años, y solamente si aún existiera un excedente se venderían novillas de 3 años (Figura 29). 


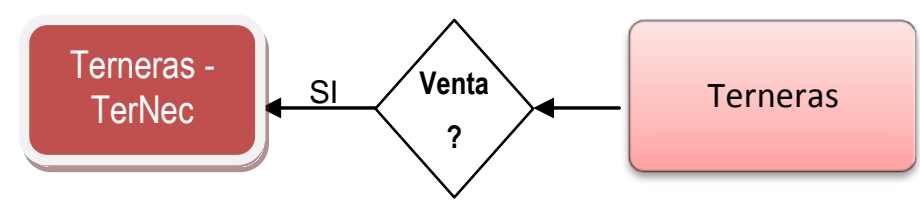

Cub14

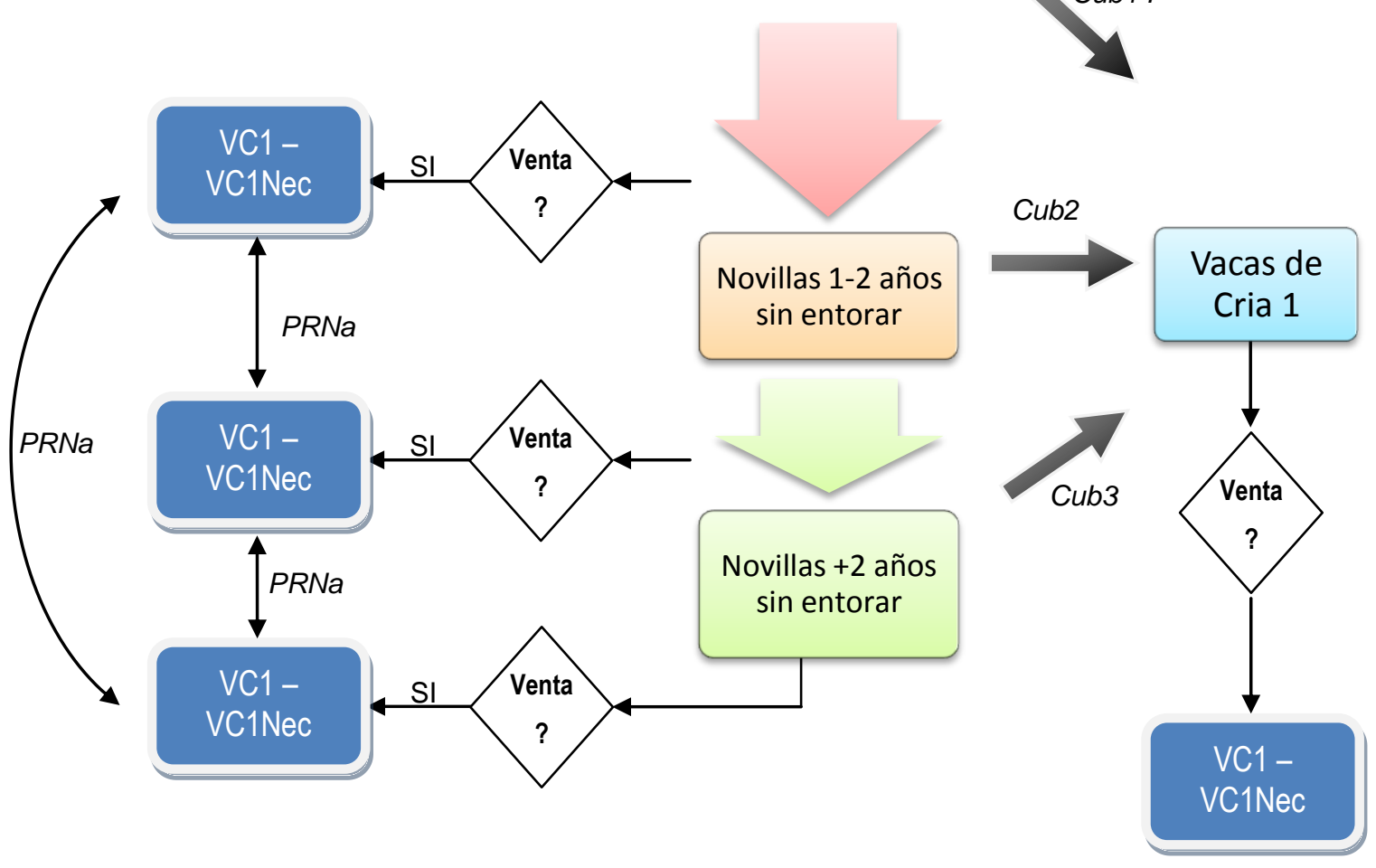

Figura 29. Esquema de venta de excedente de hembras

\subsubsection{Venta de vacas de descarte y novillos}

Las vacas que se descartan del rebaño de cría, tanto por defectos (a la cubrición) como por vacías (al destete), se destinan a cebo. La venta a matadero se da cuando un determinado número mínimo previamente establecido ha alcanzado el peso umbral definido como variable de entrada. Un proceso similar se verifica para los novillos en cebo, si los hubiera. A continuación se describe el proceso probabilístico mediante el cual se estima el número de animales disponibles para venta y su peso, así como el de los animales remanentes que permanecen en el establecimiento.

- Criterios de venta de animales a faena

Usualmente se acepta que la distribución que mejor se ajusta para describir el peso de los animales es la distribución normal. Bajo este supuesto, el mecanismo de destino a venta que se utiliza es el cálculo del número de animales que supera un determinado peso mínimo 
asumiendo una distribución normal de los mismos. Para ello se calcula la probabilidad $Z$ de una normal tipificada, de que la variable tome un valor superior al peso mínimo que ha sido fijado (pmin).

$P\left(X_{(\bar{x}, s)} \geq p \min \right)=P\left(\frac{X_{(\bar{x}, s)}-\mu}{\sigma} \geq \frac{p \min -\mu}{\sigma}\right)=P\left(Z_{(0,1)} \geq \frac{p m i n-\bar{x}}{s}\right)$

El software MS Excel dispone de una función integrada para realizar este cálculo. El valor así obtenido, es multiplicado por el número de animales existentes obteniéndose la cantidad que potencialmente puede destinarse a faena. El término "potencialmente" es utilizado porque en teoría sería posible disponer de un animal apto para faena cada día, si el número de animales es lo suficientemente elevado. En la práctica, las ventas se realizan en camiones que transportan un mínimo de aproximadamente 20 novillos o vacas gordas. Puesto que el costo de transporte de un camión tiene un valor fijo, no sería rentable su contratación para el transporte de un menor número de animales. Por otra parte, existen a nivel nacional, reglamentaciones relativas tanto a densidades de carga máximas como mínimas. En un predio de ciclo completo, puede ocurrir que se solicite el transporte para una categoría de animales y de esa forma se pueda completar el transporte con un número menor de animales de otra u otras categorías.

Así planteado, en el modelo se ingresa el valor mínimo de animales posibles de transportar y no se podrán vender animales aunque superen el peso de sacrificio si el número de ellos o de la sumatoria de animales disponibles para venta de otras categorías, no supera dicho valor mínimo.

Además, se deben especificar los umbrales de peso de venta, para novillos de menos de 2 años (PVNovillito), para novillos de entre 2 y 3 años ( $P$ VNovJov), para novillos de +3 años ( $P V N o v G d e)$ y para vacas cebadas o gordas ( $P V V G)$.

\section{- Cálculo del peso en animales remanentes}

Al vender animales de una población cuyos pesos se distribuyen en forma normal, se obtiene una población resultante (la que se mantiene en el predio) con una media inferior a la original, puesto que se están retirando lo animales más pesados (Figura 30). De igual forma, la desviación en los pesos restantes también se reduce. Para la estimación de los nuevos parámetros $\left(\overline{x^{\prime}} y s^{\prime}\right)$ de la distribución truncada, es necesario recurrir a la simulación puesto que no es posible realizarlo mediante cálculo directo. 


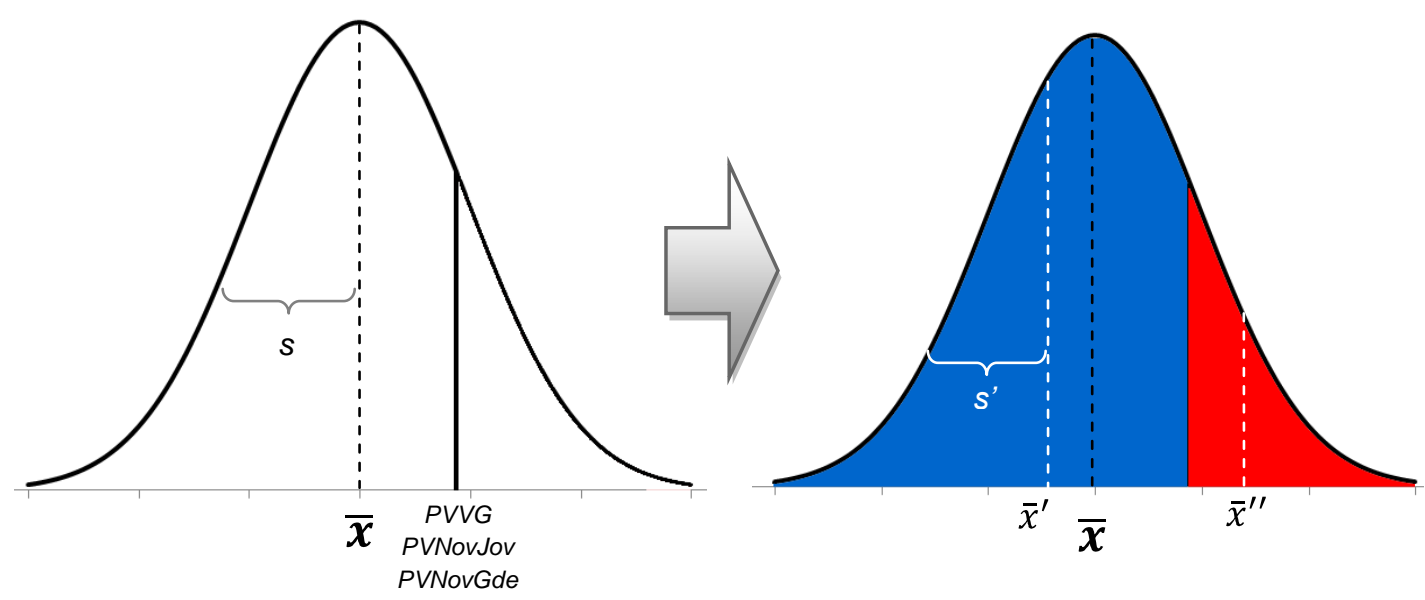

Figura 30. Esquema del efecto de la venta sobre un grupo de animales

La estimación se realiza simulando 100 valores de esa distribución, tomando como extremos la media \pm 3 desvíos estándar. Partiendo desde el valor inferior ( $\min$ ) y a intervalos $i$, siendo

$i=\frac{(\bar{x}+(3 * s))-(\bar{x}-(3 * s))}{100}$

se calcula la probabilidad $\left(p_{i}\right)$ de cada valor $\left(x_{i}\right)$ desde min hasta PVenta (PVVG, PVNovJov ó PVNovGde según el caso) a intervalos i de una distribución normal de media $\bar{x}$ y desvío s:

$p_{i}=P\left[x_{i}, N(\bar{x}, s)\right]$

se acumulan estas probabilidades:

$\sum_{\min }^{P V \operatorname{enta}} p_{i}$

Y se acumula el producto de la probabilidad por el peso:

$\sum_{\min }^{P \operatorname{Vin}}{ }^{2} p_{i} * x_{i}$

Finalmente la nueva media $x^{\prime}$, resulta del cociente:

$\boldsymbol{x}^{\prime}=\frac{\sum_{\min }^{\text {PVenta }} p_{i} * x_{i}}{\sum_{\min }^{\text {PVenta }} p_{i}}$

El código en VBA utilizado para esta simulación puede ser consultado en la Tabla A1 del anexo.

- Desviación en el peso de animales remanentes 
El desvío estándar en el peso de los animales es calculado inicialmente mediante la ecuación que surge del análisis de las bases de datos disponibles:

$$
\sigma=5.3+0.149 \bar{X}-0.000111 \bar{X}^{2}
$$

De la misma manera como se ve afectado el peso promedio de los animales remanentes posterior a una venta, se ve afectada la desviación. El nuevo desvío (s') es calculado a partir de la media truncada $\left(\bar{x}^{\prime}\right)$ mediante un procedimiento similar al descrito para el cálculo de ésta. Se utilizan también 100 valores y se corta la distribución en $\bar{x} \pm 3 s$.

Para cada valor $x_{i}$ se calcula su $p_{i}$ y se realiza la sumatoria,

$\sum_{\min }^{P \text { inta }} p_{i}$

Para cada valor $x_{i}$ se calcula su desvío parcial respecto a la media truncada, se lo multiplica por la $P$ hallada y se acumulan los resultados,

$\sum_{\min }^{P \operatorname{enta}}\left[\left(x_{i}-\bar{x}^{\prime}\right)^{2}\right] \cdot p_{i}$

Finalmente el desvío de la normal truncada resulta:

$S^{\prime}=\frac{\sum_{\min }^{P V e n t a}\left[\left(x_{i}-\bar{x} \prime\right)^{2}\right] \cdot p_{i}}{\sum_{\min }^{\text {PVenta }} p_{i}}$

De esta forma se estima la media y desvío del grupo restante de los animales vendidos. El código en VBA utilizado puede ser consultado en la tabla A-3 del anexo. De forma análoga al procedimiento descrito para el cálculo de la media de los animales remanentes en el predio, se calcula la media de los animales que se venden $\left(\bar{x}^{\prime \prime}\right)$, la cual corresponde a la media de una distribución normal truncada por la izquierda (Figura 30) y cuyo código VBA se presenta en la tabla A-2 del anexo.

Debe entenderse que este procedimiento es simplemente un método para tratar de reflejar el hecho de que la población presenta una menor dispersión luego de destinar un grupo de animales para faena. Se asume que la aplicación de parámetros asociados a una distribución normal no es exacta cuando ya no se está tratando con una distribución normal definida. Sin embargo, el grado de error dependerá del tamaño de la población existente y de la proporción retirada. Análisis realizados con datos experimentales indican que con un número mínimo de animales, la normalidad de la distribución se recompone en forma bastante consistente en el transcurso de un mes. En la Figura 31, se analizaron datos 
provenientes de la BDLE, (INIA) de novillos en cebo; se tomó un grupo de 86 animales de un año de edad, cuya distribución de pesos se presenta en el recuadro A1M1Original de la figura, correspondiente al mes 1 del año 1 . Se retiraron los animales con pesos iguales o superiores a la media $(232 \mathrm{~kg})$, resultando la distribución presentada en el recuadro A1M1Truncada, la cual como se observa tiene un fuerte sesgo hacia la derecha. El número de animales se reduce casi a la mitad y la nueva media y desvío toman valores de 218.2 y $9.4 \mathrm{~kg}$ respectivamente. Los valores estimados por el modelo para esta nueva población truncada son de $\bar{x}=219.2$ y $\sigma=11.8$. Puede observarse como al siguiente mes (A1M2Truncada), la distribución ya tiende a recuperar su forma original. Para el año 2, donde los pesos de los animales son mayores, se verifica una situación similar. Los valores para la media y desvío de la distribución truncada (A2M1Truncada), se ubican en 439.5 y $16.2 \mathrm{~kg}$ respectivamente, siendo los estimados $\bar{x}=440.8$ y $\sigma=19.2$.
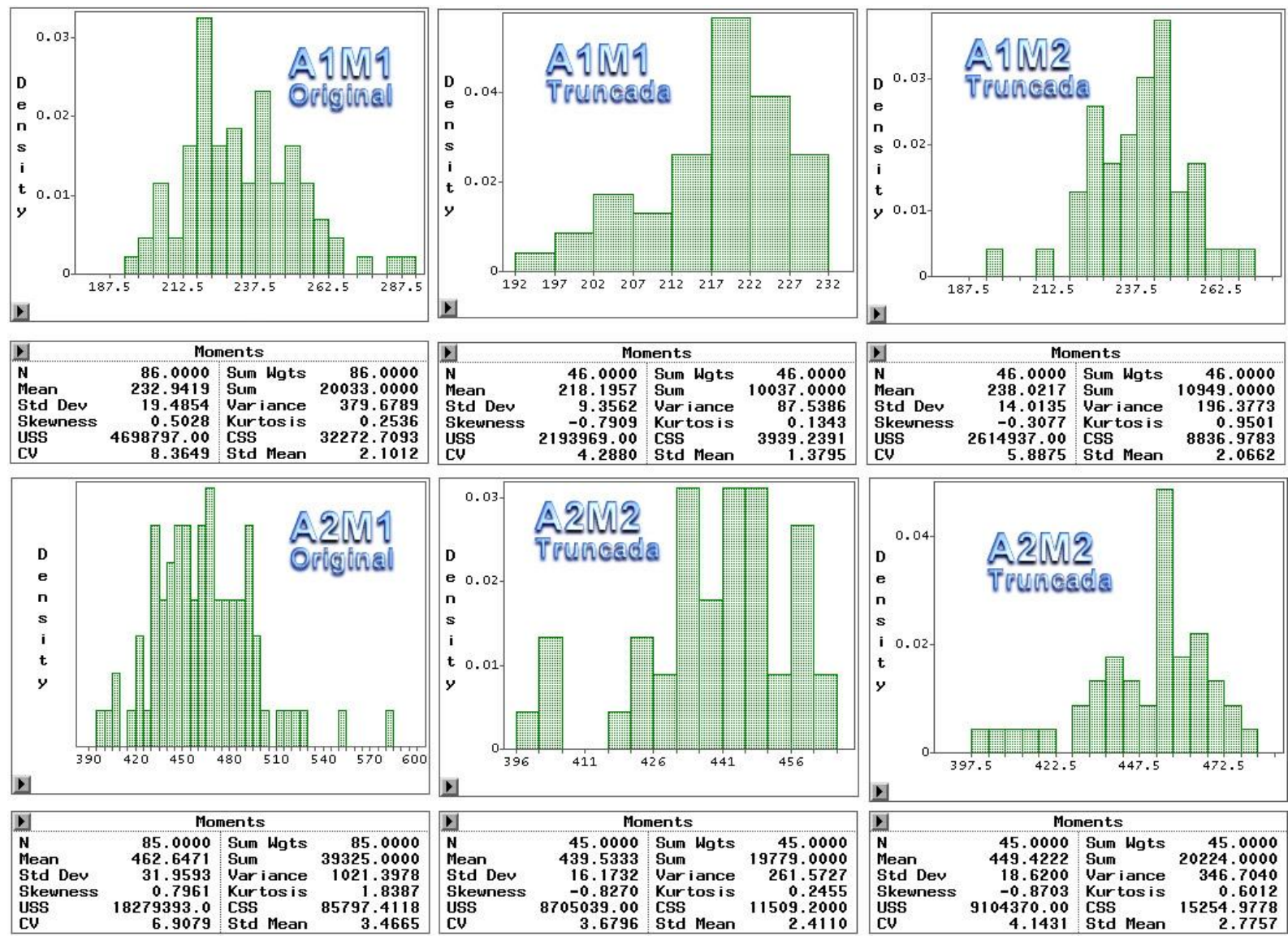

Figura 31. Efecto de la remoción de animales sobre la distribución resultante de un grupo de novillos, en dos años (A1 y A2) y dos meses consecutivos (M1 y M2) 


\subsubsection{Rendimiento de canal}

Actualmente en Uruguay, el principal sistema de comercialización de carne vacuna desde el productor a la industria frigorífica, se basa en el pago por peso de la canal caliente $(P C C)$ o peso en $2^{\underline{a}}$ balanza. Este es el peso resultante de la res luego de extraídos el cuero, la cabeza, las vísceras y una cierta proporción de grasa en exceso.

Por esta razón, el rendimiento en $2^{\text {a }}$ balanza (REND2) definido como el peso de la canal antes mencionado partido por el peso vivo del animal $(P V)$, es el principal determinante del valor comercial de la res, luego del propio peso vivo del animal.

En INIA se dispone de una base de datos de experimentos de campo culminando con el sacrificio de los animales, por lo cual es posible analizar los factores del animal que explican la variación en los diferentes indicadores de calidad de canal y carne.

La utilización de la ultrasonografía, efectuada en el animal in vivo, permite medir características antes del sacrificio o faena del animal (Faulkner et al., 1990). Las principales medidas que se toman con esta técnica son el área del ojo del bife ( $A O B$, definida como la sección transversal del músculo longissimus dorsi) y el espesor de grasa subcutánea (EGS) como indicador del grado de terminación alcanzado por el animal. Cabe mencionar que la componente genética de ambos parámetros es estimada en la evaluación genética de las principales razas carniceras de Uruguay.

Analizando la base de datos mencionada ( $n=650$ novillos), se ajustó una ecuación de regresión lineal que relaciona el $\mathrm{PV}$ del animal, la componente cuadrática del $A O B$ y el EGS con el rendimiento en $2^{\mathrm{a}}$ balanza. Esto es muy importante, puesto que implica que la selección genética por esta característica $(A O B)$ es capaz de afectar directamente el peso de la canal y por lo tanto el ingreso económico del productor. El efecto del espesor de grasa es menos relevante desde el punto de vista del mejoramiento genético, ya que su magnitud es posible de manejar mediante la alimentación. La ecuación ajustada $\left(r^{2}=0.41\right)$ es la siguiente:

$$
R E N D 2=55.82-0.01665 \cdot P V+0.00126 \cdot A O B^{2}+0.1245 \cdot E G S,
$$

Su representación gráfica para valores de $P V=500 \mathrm{~kg}$ y $E G S=5 \mathrm{~mm}$ se observa en la Figura 32. 


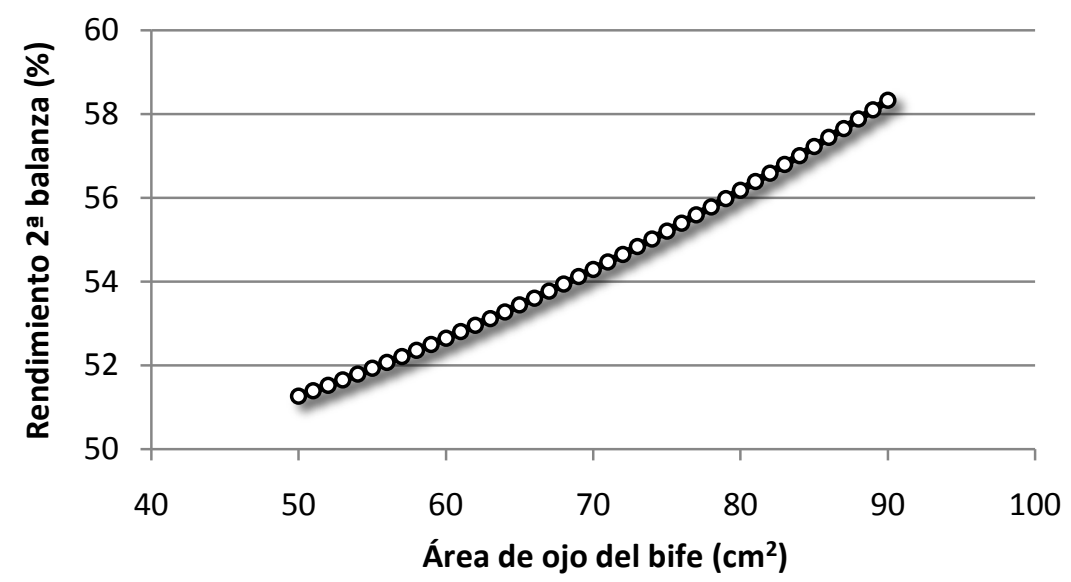

Figura 32. Rendimiento en $2^{a}$ balanza estimado en función del área de ojo del bife. Novillo de $500 \mathrm{~kg} P V$ y EGS de $5 \mathrm{~mm}$

El $A O B$ y el peso vivo no son independientes. Si bien la relación encontrada entre ellos es relativamente baja $(R=0.29)$, la misma es estadísticamente significativa, lo cual tiene dos connotaciones: en primer lugar esta baja asociación implica que la selección genética es posible, ya que existe una importante variación en el $A O B$ independiente del peso del animal. En segundo lugar, a los efectos del desarrollo del modelo, la significancia estadística de esta relación $(p<0.0001)$, justifica su utilización para la estimación del AOB, mediante la ecuación:

$A O B=35.16+0.05658 \cdot P V$

Esta ecuación es introducida en el modelo, permitiendo variar el valor del intercepto, de tal forma que es posible estimar el impacto económico derivado de su cambio, bajo el supuesto que la pendiente de dicha ecuación se mantiene constante.

Cuando en el modelo un grupo de novillos alcanza el peso de faena, el rendimiento es estimado mediante la ecuación [2.101] a partir de dicho peso, del AOB calculado en [2.102] y de un valor de EGS variable según la edad de faena y el sistema de terminación en el que han sido cebados los animales, con valores sugeridos que se presentan en la Tabla 17.

Tabla 17. Espesores de grasa subcutánea $(\mathrm{mm})$ sugeridos según edad y sistema de terminación de los novillos

\begin{tabular}{r|cccc}
\hline Edad & Campo Natural & Pradera & Suplemento & $\begin{array}{c}\text { Pradera + } \\
\text { Suplemento }\end{array}$ \\
\hline 1 a 2 años & - & 5 & 4 & 8 \\
2 a 3 años & 2 & 6 & 5 & 10 \\
3 a 4 años & 3 & 7 & 6 & 12 \\
+ 4 años & 4 & 8 & 7 & 14 \\
\hline
\end{tabular}


En la Figura 33 se presenta el rendimiento estimado de un novillo de 2-3 años de edad y $P V=500 \mathrm{~kg}$, en los 4 sistemas de terminación y dos valores de AOB.

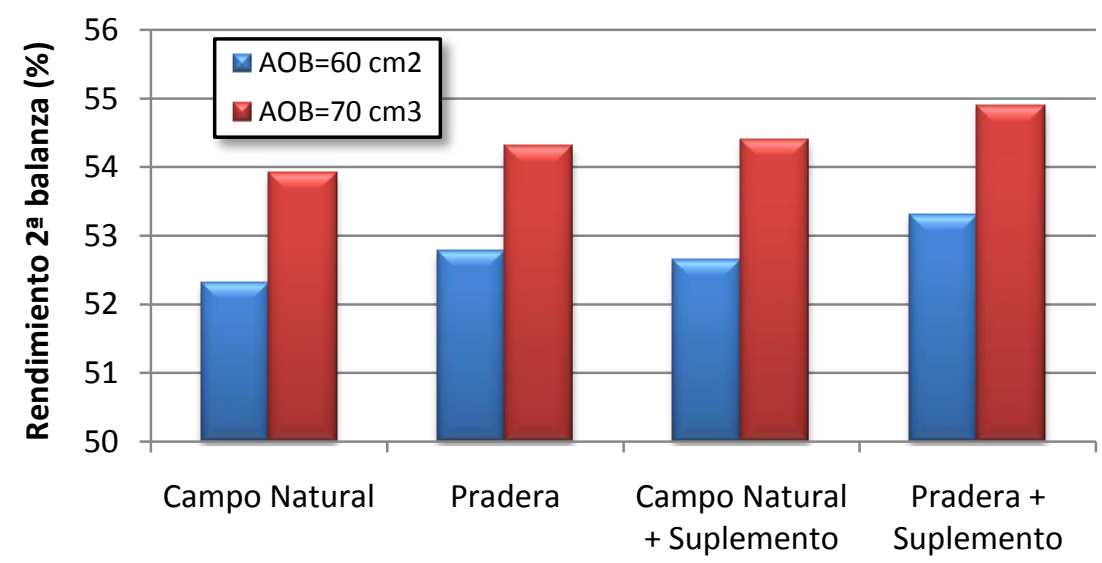

Figura 33. Valores estimados de rendimiento en $2^{a}$ balanza para un novillo de $P V=500 \mathrm{~kg}$, 23 años de edad según sistema de cebo y $A O B$

\subsubsection{Compras}

En el caso del sistema de cebo, se estima un número de animales que ajuste la carga definida por el recurso forrajero existente.

Además de la cantidad de animales, es posible seleccionar la categoría (ternero, novillo 1-2 años, novillo 2-3 años), el número de compras anuales y los meses en que se realizan estas compras.

\subsection{Variables de manejo consideradas}

Ciertas estrategias de manejo han sido incluidas en este trabajo por considerarse de importancia tanto en los resultados físicos como económicos de una explotación agropecuaria.

En primer lugar, la decisión/capacidad de cubrir las novillas a una edad lo más temprana posible, determina un aumento muy importante en la eficiencia de todo el sistema y consecuentemente, en el beneficio productivo y económico de la empresa.

Otra práctica de manejo de alto impacto en el rebaño de cría y cada vez más utilizada es el destete precoz (DP). El mismo consiste en retirar el ternero del pie de la madre a edad muy temprana (60-100 días), pasando a ser alimentado en confinamiento, con un alimento 
balanceado, agua y heno. Este retiro precoz determina una rápida y temprana recuperación corporal de la madre y un inicio casi inmediato de la actividad reproductiva. En Uruguay, Quintans (2008) reporta incrementos de entre 20 y 80 puntos porcentuales en la tasa de preñez, dándose los mayores valores cuando las vacas se encuentran en condición corporal más baja.

Como se ha mencionado, esta técnica es especialmente recomendada para las vacas de primera cría, cuyos requerimientos nutricionales son usualmente superiores al aporte que reciben. De esta manera, el retiro del ternero determina el corte de la lactancia y por lo tanto de uno de los destinos más importantes de nutrientes en esa etapa.

Otra categoría en la que se suele aplicar la técnica del DP son las vacas de última cría. Estos animales, que ya no van a ser servidos y cuyo destino es el cebo y posterior venta, ven muy acelerado este proceso cuando se practica un destete anticipado.

El modelo contempla 5 posibilidades respecto a la utilización de esta técnica:

1) No se realiza

2) Primera cría

3) Ultima cría

4) Ambas (2 y 3)

5) Todo el rebaño

En virtud de la elección de una de estas opciones y de otras dos variables asociadas (mes de destete y duración del mismo), los terneros de las categorías involucradas se ven afectados por una tasa de mortalidad más alta, menores ganancias de peso y un costo de alimentación mayor.

\subsection{Variables de resultado}

En lo que respecta a lo productivo, es relevante la estimación del volumen de ventas que genera el sistema, tanto en cantidad de animales como en peso vivo. Cuando el sistema se ha estabilizado, es decir no hay diferencias de inventario en los $\mathrm{kg}$ en stock, los $\mathrm{kg}$ vendidos anualmente por unidad de superficie ( $\mathrm{Kg}$ venta/área total) determinan la producción de peso vivo del sistema (PPV). Además de su valor absoluto, la tasa de extracción ( $T E$ ) es un coeficiente muy utilizado en Uruguay como indicador de la eficiencia del proceso productivo y se calcula dividiendo el total de $\mathrm{kg}$ vendidos en el año entre los $\mathrm{kg}$ en stock promedio. Las variables de resultado de índole económico más relevantes, como el ingreso bruto $(I B)$, el costo directo total $(C D T)$ y el margen bruto $(M B)$ se detallan en la sección siguiente. 


\subsection{Análisis económico}

Si bien el nivel de producción suele estar muy asociado al resultado económico, el fin de todo sistema productivo comercial es el de lograr un resultado lo más favorable posible desde el punto de vista económico. La función de beneficio utilizada estima el margen bruto anual $(\mathrm{MB}, €)$, resultante de restar a los ingresos por ventas, los costos directos involucrados en el proceso productivo, ya que los costos fijos no son dependientes del nivel de producción:

$$
\begin{aligned}
M B=\sum_{m=1}^{12} & I_{m}-C D_{m} \\
& \text { donde: } \\
& I_{m}=\text { Ingresos del mes } m \\
& C D_{m}=\text { Costos directos derivados del proceso de producción en el mes } m
\end{aligned}
$$

\subsubsection{Ingresos}

Los ingresos que contempla el modelo son aquellos generados a partir de las ventas de animales tanto de las categorías que se destinan a sacrificio, como de las categorías que se venden como reposición para otros productores (hembras excedentes). El ingreso procedente de la venta de estas últimas (IngRep) se estima en base al peso vivo (peso en pie) multiplicado por el precio del $\mathrm{kg}$ en pie $(€ / \mathrm{kg})$ :

$$
\text { IngRep }=\sum_{m=1}^{12} n_{c} \cdot \text { PesoVivo }_{c} \cdot \text { PrecioPie }_{c},
$$

donde:

$m$ es el mes

$n_{c}$ es el número de animales de la categoría $c$

En el caso de los animales destinados a faena, se estima el peso de la res en matadero, mediante el producto del peso en pie por la tasa de rendimiento estimada (ecuación [2.101]).

El peso estimado de la res es multiplicado por un precio por $\mathrm{kg}$ de canal o precio en 2da balanza (PrecioRes, $€ / \mathrm{kg}$ ). El ingreso proveniente de la venta de estos animales (IngSacrif) es entonces calculado: 
IngSacrif $=\sum_{m=1}^{12} n_{c} \cdot$ Peso Vivo $_{c} \cdot$ Rend $\cdot$ PrecioRes $_{c}$

El ingreso bruto total anual $(I B)$ es calculado mediante la suma de los ingresos de ambas categorías de venta.

\subsubsection{Egresos}

\subsubsection{Compra de animales}

Para el sistema de cebo se computan los costos de compra de los animales, expresados en $€ / \mathrm{kg}$ en pie, según valores aportados por la Cámara Mercantil de productos del país (www.camaramercantil.com.uy), los cuales se detallan más adelante.

\subsection{3. $\underline{\text { Costos }}$}

Los costos en el modelo son tratados como variables de entrada modificables por el usuario. Los costos directos considerados, son diferenciados en 4 categorías:

a) Costos de alimentación (CA)

b) Costos de sanidad (CS)

c) Mano de Obra $(C M O)$

d) Costos de comercialización (CCom)

El costo directo total $(C D T)$ es la resultante de la sumatoria de los costos mencionados:

$C D T=C A+C S+C M O+C C O m$

\subsubsection{Costos de alimentación}

En esta categoría se incluyen los costos de las praderas artificiales y de los suplementos, ambos expresados en $€ / \mathrm{kgMS}$. El forraje proveniente del campo natural no es considerado como un costo monetario en la ecuación de beneficio, aunque sí se lo valoriza al estimar el valor económico del peso adulto de los animales, asociado al potencial de consumo. Esta estimación se realiza asumiendo el valor de la renta de una hectárea (40€) dividido por la producción promedio de la misma unidad de superficie (4000 kgMS ha ${ }^{-1}$ ). Los costos de las praderas se estiman asumiendo una duración de las mismas de 4 años: se estima un costo total de realización de 1 hectárea más el mantenimiento de los 3 años 
siguientes. En este trabajo se utilizan valores de: $(300+100 * 3=600 €)$ lo cual determina un costo anual de $600 € / 4$ años $=150 €^{*}$ año ${ }^{-1}$, el cual se divide entre la producción anual estimada (aprox $8000 \mathrm{~kg} \mathrm{MS}$ ) para obtener el costo del kg de MS de forraje (Molina, 2008).

\subsubsection{Costos de sanidad}

Los costos de sanidad (CS) son estimados por cabeza y su valor disminuye al incrementarse la edad de los animales. Se propone una ecuación de la forma:

$C S=C_{\text {base }}+E_{d a d} d^{-0.301}$

donde:

$C_{\text {base }}=$ Costo base

$E d a d=$ edad de los animales en meses

Este costo base es ingresado por el usuario. Se sugiere un valor de $1.2 €$. Además de este costo general para cada categoría, existen casos especiales, a saber:

a) Terneros de destete precoz - se asume un costo extra por cabeza de magnitud variable (sugerido $2.2 €$ /animal $^{*}$ mes $^{-1}$ )

b) Novillas de primer cría afectadas por dificultad al parto 5 (Cesárea) - se asume un costo por la intervención quirúrgica (sugerido $150 €$ /animal)

c) Toros - costo de sanidad y aptitud reproductiva (sugerido 18.7€/animal*año ${ }^{-1}$ )

d) Rebaño de cría - costo de diagnóstico de gestación (sugerido $1.12 €$ /animal*año $^{-1}$ )

e) Rebaño de cría - a la ecuación de costo de sanidad base se suma un valor sugerido de $0.35 €$ al costo base

\subsubsection{Mano de Obra}

El costo de mano de obra se encuentra asociado al nivel de intensificación del establecimiento. Un indicador de este grado de intensificación es el área de pasturas artificiales o mejoradas, por lo cual se ajusta una ecuación de regresión lineal simple dependiente del \% área mejorada a partir de la información proveniente de Molina (2008) y Pereira (2000). 
La pendiente para los datos aportados por estos autores es estimada en $0.18 € /$ unidad porcentual de pasturas mejoradas y se asume un intercepto variable, con un valor sugerido de $10.5 €$.

\subsubsection{Costos de comercialización}

En este ítem se incluyen aquellos costos asociados directamente a la compra y venta de animales, incluyendo impuestos, inspección veterinaria y costos de transporte.

Se estima como un porcentaje del valor de compra-venta, sugiriéndose un $4 \%$.

\subsubsection{Precios de venta}

Los precios son variables a criterio del usuario, puesto que los mismos en Uruguay tienen fluctuaciones muy importantes asociadas a categorías, meses y coyunturas de mercado nacional e internacional (Figura 34).

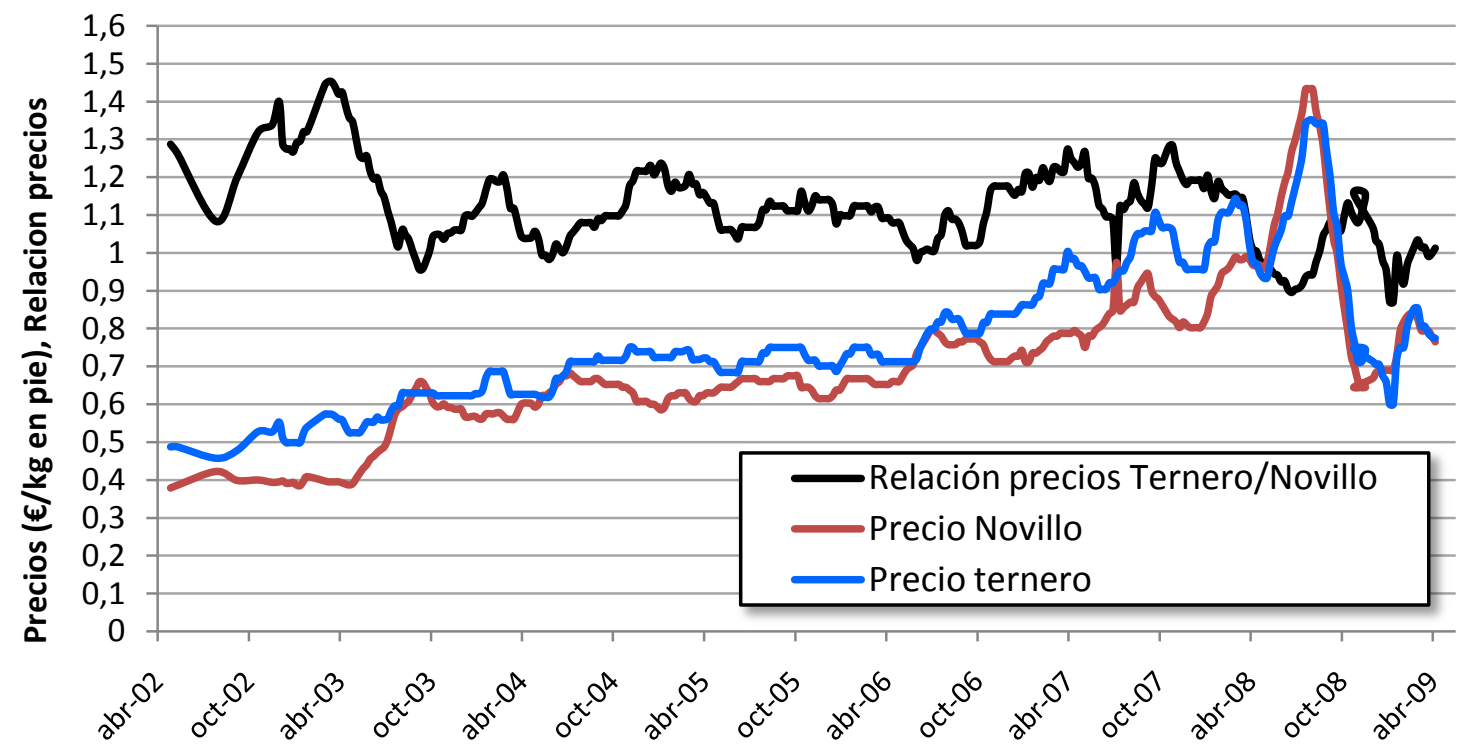

Figura 34. Evolución reciente de los precios de terneros y novillos expresada en $€ / k g$ en pie y relación entre ambos valores

Los precios sugeridos en primera instancia son los correspondientes a la semana del 07/01/2009 al 15/01/2009 publicados por la Cámara Mercantil de productos del país (Tabla 18). El precio por kg de venta de los terneros presenta una relación lineal negativa con el 
peso vivo (Lanfranco et al., 2006), por lo cual se adaptó la regresión reportada por estos autores a los precios actuales tanto para machos como para hembras. Para facilitar su modificación, en el modelo se ingresa el precio promedio para cada categoría, luego de lo cual la pendiente es ajustada.

Tabla 18. Precios utilizados para el cálculo del ingreso bruto $(€ / \mathrm{kg})$

\begin{tabular}{r|c}
\hline Categorías para reposición & Precio $€$ / $\mathbf{k g}$ de peso vivo \\
\hline Terneros & $0.9118-0.001156^{*} \mathrm{PV}$ \\
Terneras & $0.8631-0.001094{ }^{*} \mathrm{PV}$ \\
Novillas a servir & 0.452 \\
Novillas servidas & 0.414 \\
Categorías para faena & Precio $€ / \mathbf{k g}$ de peso de res \\
Vacas gordas & 1.159 \\
Novillos & 1.415 \\
\hline
\end{tabular}

Fuente: Cámara Mercantil de productos del país (www.camaramercantil.com.uy)

Además del precio en valor absoluto, es de gran relevancia el análisis de las relaciones de precios Ternero/Novillo o Ternero/Vaca. Estas relaciones definen en forma directa o indirecta, el margen bruto a obtener dependiendo de la orientación productiva planteada.

En el caso de un sistema de cebo, definirá directamente el ingreso al vender los novillos, respecto a los costos al comprar los terneros (reposición). Si se trata de sistemas de cría o ciclo completo su efecto es algo más complejo, al interaccionar con otras variables.

Para el análisis de este factor, se establece la relación de precios ternero/novillo (RTN) correspondiente a la segunda semana de enero de 2009 proveniente de la fuente mencionada, cuyo valor es:

$R T N=\frac{\text { PrecioTernero }}{\text { PrecioNovillo }}=\frac{0.692}{0.734}=0.943$

y el precio promedio ( $P M)$ de estas 2 categorías:

$P M=\frac{\text { PrecioTernero }+ \text { PrecioNovillo }}{2}=\frac{0.692+0.734}{2}=0.713$

Despejando el precio del ternero $(P T)$ y del novillo $(P M)$ se obtiene: 


$$
P T=\frac{1,426 * R T N}{R T N+1} \text { y } P N=\frac{1,426}{R T N+1}
$$

De esta forma, es posible analizar las diferentes relaciones de precios sin afectar el valor medio de los mismos.

Para realizar simulaciones explorando diferentes escenarios, tanto de producción como de condiciones de mercado, se utiliza el valor promedio del RTN de los últimos 7 años ( $R T N=1.12$; Figura 34), al cual se le suma y resta uno y dos desvíos estándar, con lo cual la serie se conforma con los valores $0.91,1.01,1.12,1.22$ y 1.33 .

El precio de las vacas gordas se estableció en un $80 \%$ del precio del novillo (0.8PN), según series históricas de precios (INAC, 2008).

\subsection{Validación del modelo}

El modelo es validado a tres niveles:

A. Nivel nacional. Se escala el modelo a nivel del país, tomando como base el número de vacas de cría promedio de los últimos 5 años registrados por el organismo estatal de contralor de semovientes de Uruguay (DICOSE) dependiente del Ministerio de Ganadería, Agricultura y Pesca (MGAP). Se contrastan los valores del resto de categorías. Paralelamente se compara la información que surge del modelo en lo referente a ventas de animales a matadero, con los valores promedio de sacrificio nacional de los últimos 5 años proporcionados por el Instituto Nacional de Carnes (INAC), organismo para-estatal encargado del contralor y la generación de registros y estadísticas de faena.

B. Nivel predial. Se comparan los resultados del modelo con los registros de distintos grupos de productores de ciclo completo y cría. Dichos productores provienen del proyecto "Monitoreo de empresas ganaderas" llevado adelante desde el año 2001 por el Instituto Plan Agropecuario (IPA), principal organismo de extensión en ganadería de Uruguay (http://www.planagro.com.uy) y de productores de FUCREA (Federación Uruguaya de Grupos CREA; www.fucrea.org).

C. Nivel individual. A este nivel el modelo fue validado contrastando sus resultados con un ensayo de cebo de novillos realizado en INIA durante los años 2006 y 2007, en el cual se evaluaron diferentes niveles de oferta de forraje, con o sin la adición de un concentrado energético a la dieta. 


\subsection{Análisis de variables que afectan los resultados económico-productivos}

Sin duda el principal producto del modelo y el centro de los resultados de este trabajo lo constituye la cuantificación del impacto de las variables consideradas clave en el resultado de los sistemas ganaderos de Uruguay.

En el capítulo II y en el ítem 5.2 de este capítulo se describen las referidas variables. La actividad de cría, con una mayor cantidad de procesos biológicos involucrados (crecimiento y desarrollo, concepción, gestación, lactancia), presenta una mayor complejidad respecto al cebo, en el cual se dan exclusivamente procesos de crecimiento y deposición de grasa; en la medida que existe un número importante de variables con considerables niveles cada una, y debido a la imposibilidad de considerar todas las combinaciones existentes, en la Tabla 19 se plantean las variables y niveles a ser analizados.

Tabla 19. Variables y niveles utilizados para la generación de resultados

\begin{tabular}{l|cc}
\hline Variable & Tipo de variación & Niveles \\
\hline Tasa preñez & Continua & $0.60-1$ \\
$\begin{array}{l}\text { Edad 1 } 1^{\text {er }} \text { Cubrición (\% hembras } \\
\text { cubiertas con 1, 2 y 3 años de edad) }\end{array}$ & Discreta & 0, 25, 50, 75 y $100 \%$ en cada edad \\
№ Estratos VC & Discreta & $4,5,6,7,8$ \\
Categoría de venta en hembras & Discreta & $\begin{array}{c}\text { Terneras ; Novillas para servir; } \\
\text { Novillas Servidas }\end{array}$ \\
$\begin{array}{l}\text { Venta Terneros (\%) } \\
\text { Categoría que ingresa a Praderas y } \\
\text { tiempo de permanencia }\end{array}$ & Discreta & 0,100 \\
$\begin{array}{l}\text { Categoría y duración de la } \\
\text { suplementacion }\end{array}$ & Discreta & Múltiples combinaciones \\
Relación precios Ternero/Novillo & Discreta & Múltiples combinaciones \\
\hline
\end{tabular}

Se analizarán interacciones entre algunas variables de mayor interés, principalmente en aquellas en que se detecten efectos de índole no-lineal, a fin de identificar óptimos (máximos o mínimos). 


\subsection{Estimación de pesos económicos (índice de selección)}

El mejoramiento genético en las principales razas de carne en Uruguay, a través del esfuerzo conjunto de organismos de investigación y sociedades de productores, se apresta a dar un importante paso en lo que se refiere a implementación de herramientas de mejora genética. Luego de la utilización durante muchos años de las DEP's (diferencias esperadas en la progenie) obtenidas en el marco de las evaluaciones genéticas, se plantea la implementación de un índice de selección complementario a la información con que hoy se dispone. El objetivo es obtener un valor único en el cual condensar el mérito genético de un reproductor habiendo definido el ambiente o sistema de producción para el cual el índice fue desarrollado y bajo el supuesto de que dicho reproductor se desenvolverá en un ambiente similar.

Si bien este trabajo no pretende desarrollar dicho índice de selección, se plantea la utilización del modelo desarrollado para la estimación de los valores económicos que servirán a posteriori para la definición del referido índice.

Para lograr este objetivo, se sigue el método descrito por Ponzoni y Newman (1989) que consta de cuatro fases: a) especificación del sistema de cría, producción y comercialización; b) identificación de las fuentes de ingresos y de costos en rebaños comerciales; c) determinación de los rasgos biológicos que contribuyen a cada fuente de ingreso y de costos; d) cálculo del valor económico de cada rasgo.

\subsubsection{Especificación del sistema de producción}

Se plantea el análisis en base a 4 sistemas de producción; dos de cría y dos de ciclo completo. Se asume que los objetivos económicos planteados en el sistema de ciclo completo serán coincidentes con los sistemas especializados en cebo, por lo cual no se consideran en forma particular.

1. Sistema extensivo de cría (CRIAEXT): definido como un sistema de producción de terneros exclusivamente en base al forraje proveniente del campo natural. Esta base forrajera, determina la existencia de un déficit de alimento invernal, por lo cual sólo es posible cubrir el $50 \%$ de las novillas a los 2 años de edad, ingresando el resto al servicio con 3 años. El porcentaje de preñez global es 70\%. Las fuentes de ingreso del sistema son la venta de terneros machos y terneras excedentes al destete (mayo), y la venta de vacas gordas con un peso mínimo de $420 \mathrm{~kg}$ las cuales se comercializan en forma 
escalonada a partir del diagnóstico de gestación. Los principales costos los constituyen la sanidad, los gastos de comercialización y la mano de obra.

2. Sistema intensivo de cría (CRIAINT): sistema de producción de terneros similar a CRIAEXT que incorpora un $20 \%$ del área con pasturas sembradas, las cuales son utilizadas en diferentes categorías según necesidades y momento del año. La mejora en la base alimenticia permite servir un $50 \%$ de las novillas a los 14 meses, mientras el resto se sirven con 2 años. El índice de preñez global se eleva a 85\%. Las fuentes de ingresos no cambian. A los costos se agrega el correspondiente a las pasturas implantadas.

3. Sistema extensivo de ciclo completo (CCEXT): se trata de un sistema de cría con posterior recría y cebo de los machos, actividades que se realizan exclusivamente sobre campo natural. Los indicadores productivos del componente cría son iguales que en CRIAEXT. Las fuentes de ingreso del sistema son la venta de terneras excedentes al destete (mayo), vacas y novillos gordos para matadero. En función de la oferta limitada de forraje, los novillos se venden con una edad promedio de 38 meses, aunque las variaciones individuales asociadas a leves diferencias en edad, determinan ventas escalonadas a partir de los 2.5 años que se prolongan hasta los 4.5 años de edad. Las fuentes de costos del sistema son las mismas que en CRIAEXT.

4. Sistema intensivo de ciclo completo (CCINT): se plantea un sistema similar al anterior respecto a su orientación productiva, pero al igual que en CRIAINT, el $20 \%$ del área de campo natural es remplazado por praderas sembradas. Esto determina un aumento de la eficiencia del sistema de cría que logra indicadores productivos comparables a CRIAINT y adicionalmente es incentivado el cebo. De esta manera, se logra la venta de novillos a una edad promedio de 23 meses, con un $70 \%$ de ellos comercializados antes de los 2 años de edad. Al igual que en el sistema anterior, las fuentes de ingreso del sistema son la venta de terneras excedentes al destete (mayo), vacas y novillos gordos para matadero y a los costos se le agrega la implantación y mantenimiento de las pasturas.

Habiendo caracterizado los cuatros sistemas, se presentan una serie de supuestos que aplican a todos ellos, conformando el escenario general de la simulación.

i. Carga: la carga promedio anual sostenida por el campo natural es de $0.70 \mathrm{UG} / \mathrm{ha}$ y la del área de praderas es de $1.20 \mathrm{UG} / \mathrm{ha}$, por lo cual en CRIAEXT y CCEXT la carga promedio del sistema es de $0.70 \mathrm{UG} /$ ha y en CRIAINT y CCINT es de 0.80 UG/ha. Se asume una carga fija, para cada situación, por lo cual si la modificación en las variables a estudiar determina una perturbación en la carga, ésta es ajustada a través del cambio en el total de vacas de cría del sistema. 
ii. Estratos de edad en VC: se asume la existencia de 8 estratos de edad en vacas de cría.

iii. Precios: se manejan los precios definidos en la Tabla 18, ajustados para definir una relación precio ternero/precio novillo de 1.12, la cual correspondiente al promedio del período 2002-2009.

En función de los sistemas definidos y las fuentes de ingresos y costos detectadas, el siguiente paso consiste en definir aquellos rasgos (ej, crecimiento, reproducción) y posteriormente aquellas características (ej, peso al destete, tasa de preñez), que definen directamente los ingresos y/o los costos así como otras que puedan ser de interés, aunque no intervengan en forma directa en la estructura de ingresos y costos (Madalena, 2003). En la Tabla 20 se presentan los rasgos biológicos que afectan el beneficio económico y las características asociadas a éstos que se evalúan en el presente trabajo.

Tabla 20. Rasgos biológicos determinantes del ingreso y características derivadas a evaluar

\begin{tabular}{|c|c|c|}
\hline Rasgo & $\begin{array}{l}\text { Característica económicamente } \\
\text { relevante }\end{array}$ & $\begin{array}{l}\text { Parámetros determinantes a } \\
\text { evaluar }\end{array}$ \\
\hline Crecimiento & $\begin{array}{l}\text { Peso de venta novillos } \\
\text { Peso de venta vacas } \\
\text { Peso al destete machos y hembras }\end{array}$ & $\begin{array}{l}\text { Tasa de ganancia machos } \\
\text { Tasa de ganancia hembras } \\
\text { Peso al nacer }{ }^{\mathrm{a}} \\
\text { Peso adulto machos } \\
\text { Peso adulto hembras } \\
\text { Producción de leche } \\
\text { Consumo }^{b} \\
\text { Tasa de conversión }^{c}\end{array}$ \\
\hline Consumo & Forraje consumido & $\begin{array}{l}\text { Consumo }{ }^{\mathrm{b}} \\
\text { Tasa de conversión }{ }^{\mathrm{c}}\end{array}$ \\
\hline Reproducción & $\begin{array}{l}\text { № de terneros/as destetados } \\
\text { Mortalidad neonatal }\end{array}$ & $\begin{array}{l}\text { Tasa de parición } \\
\text { Dificultad al parto } \\
\text { Peso al nacer } \\
\end{array}$ \\
\hline $\begin{array}{l}\text { Rendimiento } \\
\text { Carnicero }\end{array}$ & Peso $2^{2}$ balanza & $\begin{array}{l}\text { Rendimiento res } \\
\text { Área del ojo del bife }\end{array}$ \\
\hline
\end{tabular}

${ }^{a, b, c}$ Caracteres con incidencia en más de un rasgo de interés

El procedimiento utilizado para la ponderación económica de las variables de interés está basado en el concepto Hazel (1943) consistente en evaluar el resultado económico resultante de la variación en una unidad de la característica en cuestión, manteniendo las demás constantes. En este caso, se analiza el efecto de incrementar en 1\% dichas características, a fin de poder realizar un análisis comparativo entre variables con diferentes unidades. La variación en el margen bruto resultante es expresado en $€$ cada 1000 hectáreas. 


\subsection{Análisis de sensibilidad y escenarios}

Mediante el software @Risk (Palisade Corporation, www.palisade.com) es posible obtener resultados probabilísticos con un modelo inicialmente determinístico como el desarrollado en este trabajo. Esto se logra especificando una distribución y los parámetros que la definen para cada variable independiente (input) que se considere relevante. Paralelamente, se define la o las variables resultado (output) que interese analizar y se determina un número de simulaciones a realizar. Al efectuar un número suficientemente alto de simulaciones, se obtiene una base de datos que puede ser analizada con diversos objetivos:

I. Identificar las variables que inciden sobre cierta variable resultado

II. Cuantificar la magnitud relativa de de los cambios en la variable respuesta frente a cambios de las variables de entrada (análisis de sensibilidad)

III. Realizar análisis de escenarios

IV. Estimar la probabilidad de que cierta variable resultado supere o alcance determinado valor previamente definido

V. Obtener intervalos de confianza para determinadas variables resultado

Según los diferentes objetivos, los análisis estocásticos se aplican a las variables presentadas en la Tabla 19.

En el caso del análisis de sensibilidad a los precios, en lugar de analizar la relación de precios ternero/novillo se utilizan los precios de ambas categorías y se agregan las distribuciones de precios del maíz como indicador del precio del suplemento y el fosfato de amonio, como valor indicativo de los precios de fertilizantes para pasturas.

Se utilizaron series históricas recogidas en diversos organismos de información estatales de Uruguay en lo que respecta a precios de res (precio en gancho o $2^{\underline{a}}$ balanza) de novillo y vaca (INAC; www.inac.gub.uy), de terneros en pie (DIEA; www.mgap.gub.uy/diea/), de fosfato de amonio (DIEA; www.mgap.gub.uy/diea/) y maíz (Secretaría de Agricultura, Ganadería, Pesca y Alimentos (Argentina); http://www.sagpya.mecon.gov.ar). Se realizaron estimaciones para escoger las distribuciones que mejor se ajustaran a los datos, obteniéndose los resultados que se presentan en la Tabla 21. 
Tabla 21. Medianas, distribuciones ajustadas y parámetros estimados para las series de precios utilizadas en el análisis de sensibilidad

\begin{tabular}{c|cccc}
\hline Variable & Mediana & $\begin{array}{c}\text { Distribución } \\
\text { ajustada }\end{array}$ & Parámetros & $\begin{array}{c}\text { Años } \\
\text { evaluados }\end{array}$ \\
\hline $\begin{array}{c}\text { Novillo } \\
(€ / \text { kg de res })\end{array}$ & 1.251 & LogNormal & $\mathrm{E}(\mathrm{X})=0.807 ; \operatorname{Var}(\mathrm{X})=0.41584$ & $2000-2009$ \\
$\begin{array}{c}\text { Vaca gorda } \\
(€ / \text { kg de res })\end{array}$ & 1.157 & LogNormal & $\mathrm{E}(\mathrm{X})=0.831 ; \operatorname{Var}(\mathrm{X})=0.359$ & $2000-2009$ \\
$\begin{array}{c}\text { Ternero } \\
(€ / \text { kg en pie }) \\
\text { Fosfato de } \\
\text { amonio }(€ / \mathrm{tt})\end{array}$ & 0.878 & Logistica & $\mathrm{E}(\mathrm{X})=0.867 ; \operatorname{Var}(\mathrm{X})=0.099$ & $2000-2008$ \\
Maíz $(€ / \mathrm{tt})$ & 757 & LogNormal & $\mathrm{E}(\mathrm{X})=226 ; \operatorname{Var}(\mathrm{X})=910$ & $2000-2009$ \\
\hline
\end{tabular}

En los casos en que se simula un establecimiento con praderas, se asume que éstas persisten 4 años, por lo cual se renueva $1 / 4$ del área anualmente, a un costo fijo de $200 €$ correspondiente a semilla, inoculante, maquinaria más el costo variable del fosfato de amonio, estimado en una magnitud correspondiente a $200 \mathrm{~kg} / \mathrm{ha}$. Paralelamente a esta área nueva, en las $3 / 4$ partes restantes de la superficie con praderas, se aplican $100 \mathrm{~kg} / \mathrm{ha}$ por concepto de refertilización. Se asume una producción de las praderas de $8000 \mathrm{kgMS} / \mathrm{ha}$ por lo cual el costo del Kg MS de las praderas (CPrad) queda definido por:

CPrad $=\frac{200+0.2 \cdot \text { PrecioFosfAmon }}{4}+3 \cdot 0.1 \cdot$ PrecioFosfAmon

Donde:

PrecioFosfAmon es el precio del fosfato de amonio ( $€ /$ tonelada)

Los sistemas productivos simulados son:

1) Sistema de cría extensivo definido como CRIAEXT en el apartado anterior, con una producción de peso vivo (PPV) de $80 \mathrm{~kg} / \mathrm{ha}$ )

2) Ciclo completo intensivo, como el ya descrito en el ítem anterior (CCINT; $P P V=130 \mathrm{~kg} / \mathrm{ha})$

3) Sistema de Invernada o cebo intensivo con 30\% praderas y suplementación otoñal con maíz al $100 \%$ de los novillos de un año de edad al $0.8 \%$ de su peso vivo $(P P V=264 \mathrm{~kg} / \mathrm{ha})$

Finalmente, se realizaron 1000 simulaciones para cada combinación de orientación productiva y nivel de intensificación, incorporando todas las variables de interés y los precios 
de los productos e insumos mencionados. De esta forma es posible visualizar el efecto relativo de las variables controlables (en cierta medida) por el productor y la variables exógenas al sistema, en este caso los precios.

\subsection{Análisis estadístico de resultados}

Como se ha mencionado, el software @Risk puede ser utilizado para generar un elevado número de simulaciones al especificar un rango de valores para las variables de entrada que se desea analizar. Estos valores se generan en algunos casos a partir de una distribución uniforme a la que se le definen el mínimo y máximo, o bien se puede especificar una distribución discreta con una serie de valores y una probabilidad asociada a ellos. De esta forma, se exploran todas las combinaciones posibles generando un alto número de resultados que pueden después analizarse en forma conjunta o dentro de una selección. Esto permite, por ejemplo, analizar el efecto global de la tasa de parición sobre el margen bruto para toda la población de datos recogida, o bien analizar el efecto de la edad de cubrición sobre la productividad para una determinada relación de precios, estrato de vacas y nivel de preñez.

La información recogida fue analizada utilizando métodos multivariantes (componentes principales) y univariantes (regresión lineal múltiple, regresión lineal y regresión cuadrática simple), correlaciones de Pearson, análisis de la varianza e indicadores estadísticos básicos.

La información fue procesada mediante los paquetes estadísticos SAS ${ }^{\circledR}$ y Minitab ${ }^{\circledR}$. 
CAPITULO VI - RLESULADOS Y DISCUSIÓN 



\section{CAPÍTULO VI - RESULTADOS Y DISCUSIÓN}

\subsection{Validación del modelo}

El procedimiento de validación involucra la comparación del desempeño del modelo respecto a registros reales del sistema modelado o a la apreciación subjetiva de las salidas que el modelo debería proporcionar, si se tiene un conocimiento suficientemente amplio de dicho sistema (Dent y Blackie, 1979). Habiendo constatado la coherencia global en los resultados obtenidos con el modelo, se procede a contrastarlo con registros de producción y de esta manera verificar el ajuste de sus resultados a situaciones reales.

\subsubsection{Validación a escala país}

El modelo es llevado a una escala que permite simular el stock vacuno existente en el país y de esa manera comparar sus salidas con los volúmenes de faena registrados actualmente. Es evidente que el modelo simulará un único gran sistema, cuando en el país la producción ganadera se compone de muchos sistemas heterogéneos, por lo cual de antemano se asume la imposibilidad de un ajuste perfecto.

Como se describe en los métodos utilizados, se toma como punto de partida de la simulación el promedio de vacas de cría del período 2004-2008, registrado por DICOSE. Se ajustan los parámetros del modelo para lograr coincidencia con los valores del resto de las categorías. Logrado esto, se compara la información que surge del modelo en lo referente a ventas de animales a matadero, con la información de faena nacional proporcionada por el Instituto Nacional de Carnes (INAC). Por otra parte se contrastan los parámetros utilizados para ajustar las cantidades de las diferentes categorías del stock, con los indicadores productivos nacionales. En la Tabla 22 se presentan los resultados obtenidos al comparar los registros nacionales (real) con los obtenidos con el modelo (estimado). 
Tabla 22. Existencias de vacunos en Uruguay a julio de 2007, total de animales faenados ese año y estimaciones del modelo para ambos registros

\begin{tabular}{l|cc|cc}
\hline & \multicolumn{2}{|c|}{ Existencias(miles) } & \multicolumn{2}{c}{ Faena (miles de cabezas) } \\
\hline Categoría / Año & Real (04-08) & Estimado & Real (03-07) & Estimado \\
Toros & 173 & 171 & & \\
Vacas de cría & 4120 & 3407 & & \\
Vacas de cebo & 421 & 1134 & $\mathbf{8 5 8}$ & $\mathbf{8 7 4}$ \\
Total Vacas & $\mathbf{4 5 4 1}$ & $\mathbf{4 5 4 1}$ & & \\
Novillos de 1 a 2 años & 1182 & 1208 & $559(1-3$ años) & 201 \\
Novillos de 2 a 3 años & 893 & 800 & 239 & 362 \\
Novillos de 3 a 4 años & $534(+3$ años) & 453 & 394 & 407 \\
Novillos de + 4 años & $\mathbf{2 6 0 9}$ & $\mathbf{2 8 0 1}$ & $\mathbf{1 1 9 2}$ & $\mathbf{1 2 7 3}$ \\
Total Novillos & 1239 & 1238 & & \\
Novillas de 1 a 2 años & 562 & 564 & & \\
Novillas + 2 años & $\mathbf{1 8 0 1}$ & $\mathbf{1 8 0 2}$ & $\mathbf{1 9 9}$ & $\mathbf{3 0 0}$ \\
Total Novillas & 2664 & 2664 & 18 & $18^{*}$ \\
Terneros/as & $\mathbf{1 1 7 8 8}$ & $\mathbf{1 1 9 7 9}$ & $\mathbf{2 1 4 4}$ & $\mathbf{2 4 6 5}$ \\
TotAL &
\end{tabular}

* En base a registros; el modelo no considera faena de terneros

El modelo permitió ajustar los registros de stock con relativa precisión. Se debe tener en cuenta que el stock ganadero en Uruguay ha tenido una evolución creciente en los últimos años. Se destacan algunas inconsistencias, como por ejemplo el número de vacas de cría. Es notorio que una alta proporción de productores no realiza diagnóstico de gestación en el rebaño de cría, por lo cual en julio, cuando se realiza la declaración anual de existencias, las vacas que no están preñadas (que deberían estar en la categoría de vacas para cebo) permanecen en el rebaño de cría, siendo computadas como vacas de cría. Por esta razón el modelo se ajusta por el total de vacas (vacas de cría + vacas de cebo).

Otras diferencias se observan en los registros totales de sacrificio. Parte de las diferencias observadas se deben a la existencia de un volumen de exportación en pie de aproximadamente 70 mil cabezas anuales en promedio y al consumo en los establecimientos (64 mil cabezas) (Frugoni y Oyhantçabal, 2008). De cualquier manera, no fue posible ajustar totalmente las categorías de novillos de más edad, encontrándose ciertas inconsistencias de los datos nacionales en lo que respecta a las categorías de 3 a 4 años y más de 4 años. En efecto, los valores relativamente bajos en stock no condicen con los valores de sacrificio, que resultan menores de lo que se esperaría. La agrupación de las categorías de 1 a 2 años y de 2 a 3 años en una sola que provee INAC y la consideración de novillos de 3 a 4 años y más de 4 años en forma agrupada que considera DICOSE, dificultan el seguimiento preciso de las relaciones numéricas en estas categorías. De cualquier manera, el crecimiento en el volumen de animales sacrificados registrado en los últimos 
años determina que un promedio en ese período no sea representativo de una situación en condiciones de estabilidad.

Habiendo ajustado estas estimaciones, los parámetros resultantes de las mismas se presentan en la Tabla 23.

Tabla 23. Coeficientes técnicos de la ganadería uruguaya y parámetros ajustados en el modelo

\begin{tabular}{l|ccc}
\hline & $\begin{array}{c}\text { Parámetros } \\
\text { reales }^{1}\end{array}$ & $\begin{array}{c}\text { Parámetros } \\
\text { Modelo }\end{array}$ & Diferencia \\
\hline Producción Carne/ha & 67.9 & 67.0 & $-1.3 \%$ \\
Peso promedio novillos sacrificados & 486.3 & 484.4 & $-0.4 \%$ \\
Tasa extracción (\%) & 20.0 & 20.6 & $+3.0 \%$ \\
$\%$ destete & 64.7 & 64.7 & $+0.0 \%$ \\
$\%$ Novillas cubiertas $\leq 2$ años & 54.8 & 56.0 & $+2.2 \%$ \\
\hline
\end{tabular}

${ }^{1}$ Fuente: DIEA, 2008; Frugoni y Oyhantçabal, 2008; INAC, 2009

Se destaca el buen ajuste del modelo a los coeficientes nacionales, máxime si se tiene en cuenta que se intentan ajustar los datos de un país, conformado por múltiples unidades de producción, a los resultados de un modelo que estima un único gran sistema productivo.

\subsubsection{Validación a nivel predial}

En Uruguay no existe un sistema de recolección de información productiva y/o económica generalizada a nivel agropecuario, más allá de la declaración jurada de DICOSE, que únicamente aporta información sobre las existencias de animales por categoría. Sin embargo, existen algunas agrupaciones o gremiales de productores con un nivel mayor de registros productivos y fundamentalmente económicos. Estos productores usualmente establecidos en una misma zona, vuelcan la información productiva y/o económica al grupo, propiciando de esa manera un ambiente de discusión e intercambio de ideas bajo el asesoramiento de un técnico. Generalmente estos grupos siguen la metodología CREA (Consorcios Regionales de Experimentación Agrícola) de origen francés.

En este contexto, para la validación del modelo a escala predial se utilizaron los registros provenientes del "cierre" anual de resultados o resumen del ejercicio 2007-2008 de los grupos CREA ganaderos de todo el país. El documento con el resumen de estos resultados se encuentra a disposición de los integrantes de los grupos CREA y fue aportado para este trabajo (Llanes, F., com pers.). 
Por otra parte, el Instituto Plan Agropecuario (IPA) viene llevando a cabo desde el ejercicio agrícola 2001-2002 un seguimiento productivo y económico de un conjunto de productores agrupados en el "Programa de Monitoreo de Empresas Ganaderas. Este programa es definido como "un programa de trabajo mediante el cual un conjunto de productores ganaderos registra y analiza la información productiva y económica de sus establecimientos, en un formato homogéneo y con el apoyo de un técnico del IPA. Esta información individual es integrada a una base de datos general, anónima, que permite generar valores de referencia para comparar los valores de cada empresa" (http://www.planagropecuario.org.uy/ docs/herramienas_gestion/10.pdf). Los datos del ejercicio 2007-2008 de este programa constituyen la segunda fuente de información, los cuales se encuentran a disposición pública en la página del mencionado instituto de extensión.

El objetivo de esta validación es comprobar el grado de aproximación del modelo a determinados resultados productivos y económicos promedio de un conjunto de empresas cuando se le aportan indicadores básicos.

Se utiliza la información referente al sistema productivo, área total de pastoreo, porcentaje de pasturas mejoradas, niveles de preñez del rebaño y precios promedio obtenidos en el ejercicio. Con estos datos el modelo estima la producción de carne, la tasa de extracción y el ingreso bruto. En la Tabla 24 se presentan las variables ingresadas al modelo y los resultados del mismo comparados con los valores reales.

Tabla 24. Indicadores productivos y económicos promedio según orientación de distintos grupos de productores en Uruguay. Valores reales y estimados por el modelo.

\begin{tabular}{|c|c|c|c|c|c|c|c|c|c|c|}
\hline & \multicolumn{4}{|c|}{$\begin{array}{l}\text { Instituto Plan Agropecuario } \\
\text { Monitoreo de Empresas } \\
\text { Ganaderas } 2007 \text { - } 2008\end{array}$} & \multicolumn{6}{|c|}{$\begin{array}{c}\text { Federación Uruguaya de grupos CREA } \\
\text { Resultados de empresas ganaderas } 2007 \text { - } 2008\end{array}$} \\
\hline & \multicolumn{2}{|c|}{ Cría } & \multicolumn{2}{|c|}{ Ciclo completo } & \multicolumn{2}{|c|}{ Cría } & \multicolumn{2}{|c|}{ Ciclo completo } & \multicolumn{2}{|c|}{ Cebo } \\
\hline & Real & Estim. & Real & Estim. & Real & Estim. & Real & Estim. & Real & Estim. \\
\hline Área (ha) & \multicolumn{2}{|c|}{690} & \multicolumn{2}{|c|}{1440} & \multicolumn{2}{|c|}{1896} & \multicolumn{2}{|c|}{2459} & \multicolumn{2}{|c|}{1391} \\
\hline$\%$ mejorado (\%) & \multicolumn{2}{|c|}{19} & \multicolumn{2}{|c|}{23} & \multicolumn{2}{|c|}{20} & \multicolumn{2}{|c|}{30} & \multicolumn{2}{|c|}{55} \\
\hline $\begin{array}{l}\text { Dotación } \\
\text { vacuna (UG/ha) }\end{array}$ & \multicolumn{2}{|c|}{0.62} & \multicolumn{2}{|c|}{0.69} & \multicolumn{2}{|c|}{0.60} & \multicolumn{2}{|c|}{0.70} & \multicolumn{2}{|c|}{0.82} \\
\hline$\%$ destete & \multicolumn{2}{|c|}{75} & \multicolumn{2}{|c|}{78} & \multicolumn{2}{|c|}{84} & \multicolumn{2}{|c|}{80} & \multicolumn{2}{|c|}{-} \\
\hline $\begin{array}{l}\text { Prod. de Peso } \\
\text { Vivo (kg/ha) }\end{array}$ & 77 & 72 & 98 & 96 & 75 & 72 & 97 & 107 & 163 & 194 \\
\hline Extracción (\%) & 33 & 30 & 39 & 35 & - & 35 & - & 38 & - & 60 \\
\hline $\begin{array}{c}\text { Ingreso Bruto } \\
(€ / \mathrm{ha})\end{array}$ & 82 & 82 & 114 & 110 & 79 & 79 & 113 & 123 & 194 & 238 \\
\hline
\end{tabular}


En la tabla no figura el margen bruto, debido a que en la situación real la producción se realiza conjuntamente con ovinos. Si bien se tiene información de dotación, producción y precios en forma diferencial para vacunos y ovinos, los costos se manejan en forma conjunta por lo cual es imposible estimar la fracción de dichos costos que procede del rubro vacuno.

Se verifica una buena aproximación de los valores generados por el modelo a los valores reales. Igualmente, para ser utilizado con fines predictivos será necesario realizar chequeos del modelo con situaciones donde haya un mayor grado de información registrada.

\subsubsection{Validación a nivel de comportamiento individual}

Para validar el modelo a escala individual, se utilizaron datos generados en INIA, en un ensayo de pastoreo en praderas, con o sin aporte de granos a la dieta. Fue escogido dicho experimento por contar con un grado importante de registración a distintos niveles. Los tratamientos consistieron en diferentes combinaciones entre niveles de oferta de forraje (NOF) expresado como \% del peso vivo (PV) de los novillos y niveles de grano en la dieta, (G) también expresado como \% del PV.

En la Tabla 25 se describen en detalle los tratamientos en los 2 años en que fue realizado.

Tabla 25. Descripción del ensayo de cebo de novillos utilizado en la validación del modelo

\begin{tabular}{c|c|c|c|c|c|c|c}
\hline \multirow{2}{*}{ Año } & \multicolumn{3}{|c|}{ Tratamientos } & \multicolumn{2}{c|}{ Animales } & \multicolumn{2}{c}{ Fecha } \\
& Nombre & NOF & G & No & Edad & Inicio & Fin \\
\hline \multirow{4}{*}{2006} & T1 & $4 \%$ & - & & & & \\
& T2 & $2 \%$ & - & \multirow{2}{*}{24} & 2.5 años & 22 ago & 15 dic \\
& T3 & $2 \%$ & $0.8 \%$ & & & & 2006 \\
& T4 & $2 \%$ & $1.6 \%$ & & & & \\
\hline \multirow{3}{*}{2007} & T1 & $4 \%$ & - & & & \multirow{2}{*}{12 jun } & 10 dic \\
& T2 & $2 \%$ & - & 24 & 1.5 años & 2007 & 2007 \\
\hline
\end{tabular}


En la Figura 35 y la se presentan las curvas de pesos observados y estimados por el modelo para los años 2006 y $2007^{5}$.

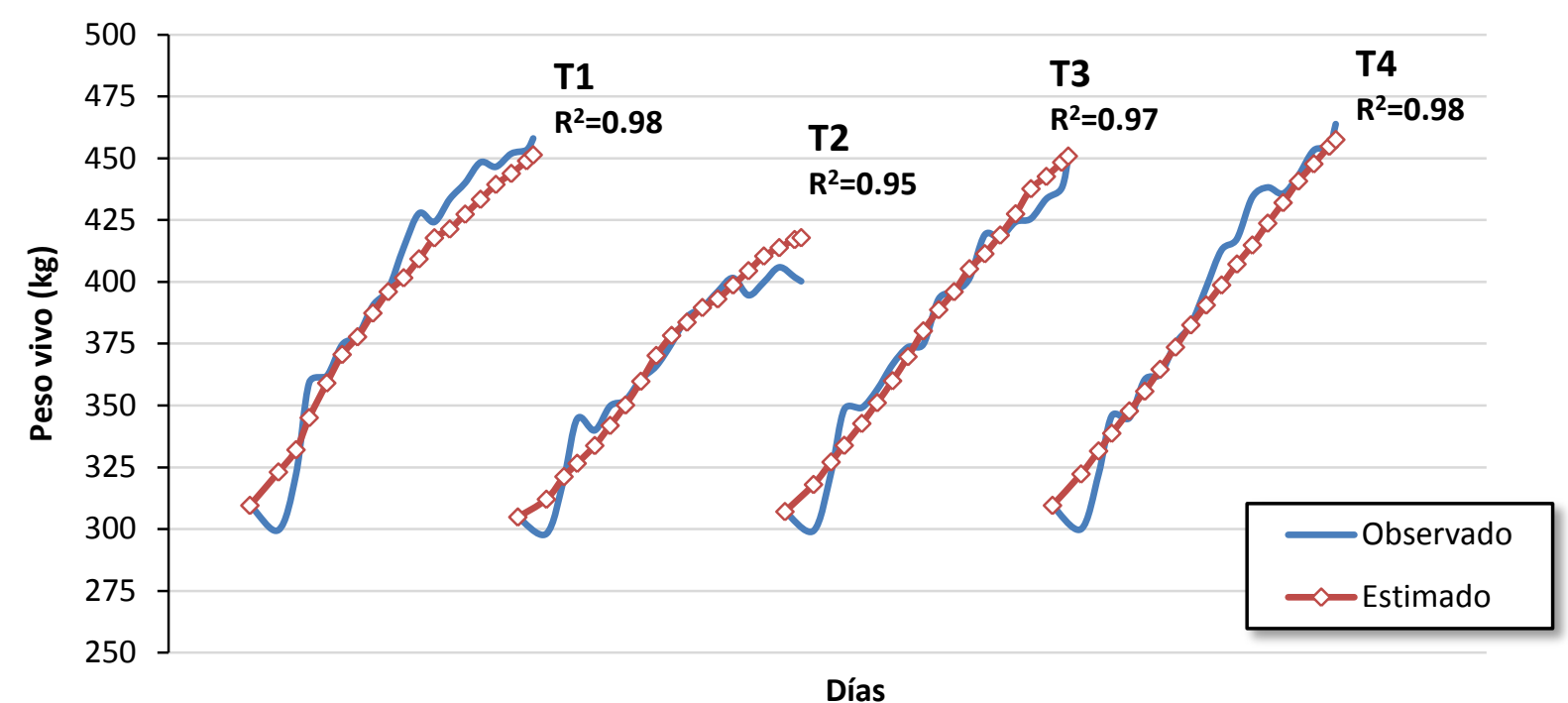

Figura 35. Evolución de peso real (observado) y estimado por el modelo para el experimento realizado en el año 2006.

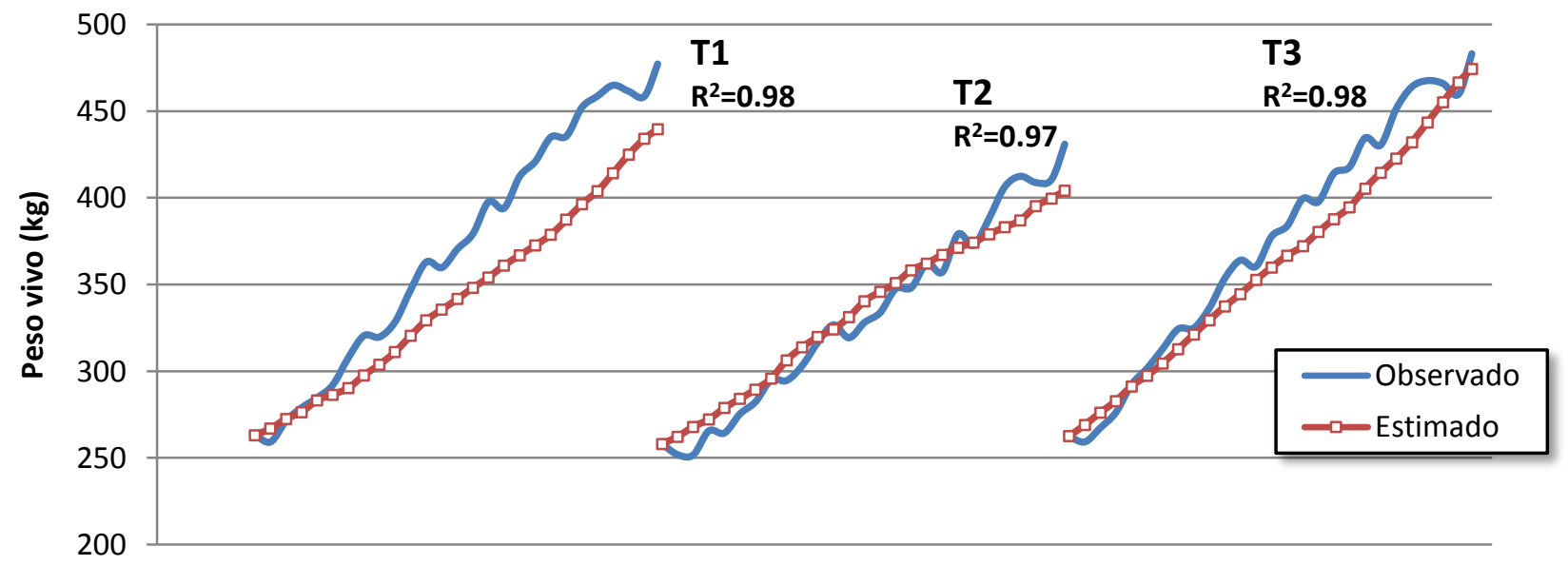

Figura 36. Evolución de peso real (observado) y estimado por el modelo para el experimento realizado en el año 2007.

5 En ambos gráficos el eje de las abscisas se ha desfasado entre tratamientos para facilitar la visualización de las curvas, pero todos ellos comienzan y terminan en el mismo momento como se describe en la Tabla 25 y la escala es proporcional entre ellos. 
Se verifica un buen ajuste del modelo a los pesos reales del experimento en ambos años. El tratamiento 1 del año 2007 es el que presenta una mayor diferencia, seguido por el tratamiento 2 en el primer año, donde al final del ensayo los animales reducen su tasa de ganancia sin razón aparente. En el primer año, se observa un desajuste inicial en los 4 tratamientos, con un descenso importante de los pesos al iniciarse el ensayo y una recuperación posterior. Esto pudo deberse a una situación real de pérdida inicial de peso por adaptación a la nueva dieta o bien pudo haber sido un efecto del peso del contenido ruminal. En este tipo de ensayos con rumiantes a cielo abierto, donde los hábitos de pastoreo pueden variar en función de diferentes motivos (principalmente de orden climático), la estimación de las ganancias diarias está muy afectada por las variaciones del contenido ruminal de los animales, de tal forma que si el peso no es registrado luego de un período de entre 12 y 24 horas de ayuno (Meyer et al., 1960) los resultados pueden ser muy imprecisos. Por esta razón, es usual que en muchos ensayos de campo no se logre un ajuste entre la disponibilidad y calidad del forraje consumido y las ganancias posteriores.

Como complemento a la representación de los valores promedios observados y estimados por el modelo, se presenta en la Tabla 26 el porcentaje de puntos estimados por el modelo cuya desviación respecto a los valores reales es igual o inferior al $5 \%$, según la metodología descrita por Mitchell y Sheehy (1997).

Tabla 26. Ajuste del modelo expresado como porcentaje de las estimaciones que se desvían $5 \%$ o menos del valor real

\begin{tabular}{c|cccc|ccc}
\hline & \multicolumn{4}{|c|}{ Año 2006 } & \multicolumn{4}{c}{ Año 2007 } \\
\hline $\begin{array}{c}\text { Tratamiento } \\
\text { Estimaciones con }\end{array}$ & T1 & T2 & T3 & T4 & T1 & T2 & T3 \\
$\leq 5 \%$ de desviación & $95 \%$ & $95 \%$ & $95 \%$ & $95 \%$ & $26 \%$ & $81 \%$ & $70 \%$ \\
\hline
\end{tabular}

El modelo determinó errores de baja magnitud, excepto en el tratamiento 1 del segundo año del experimento, donde los animales tuvieron una ganancia superior a la esperada,

Si bien existió un buen ajuste excepto situaciones puntuales, para poder concluir respecto a la bondad de ajuste del modelo es necesario contar con mayores frecuencias de muestreo de disponibilidad y fundamentalmente de digestibilidad del forraje (en estos ensayos se tomaron una o dos muestras por estación), a fin captar las causas que estarían explicando las variaciones en el comportamiento productivo de los animales. No obstante, 
se debe tener presente que en experimentos de pastoreo a cielo abierto, el alto número de factores que inciden sobre este desempeño (nutricionales, genéticos, climáticos, etc.) hacen que sea muy difícil obtener estimaciones precisas. Existen modelos más específicos para procesos de cebo en pastoreo desarrollados en Uruguay (Cardozo y Ferreira, 1994) que toman en cuenta áreas reducidas de pastoreo, especies forrajeras y categorías animales definidas y períodos de tiempo más acotados, todo lo cual contribuye a disminuir las fuentes de incertidumbre mencionadas.

El modelo que se desarrolla en este trabajo apunta a una visión más amplia de los sistemas productivos ganaderos por lo cual, tal como se menciona en los objetivos del trabajo, su principal función es la de evaluar diferentes opciones tanto productivas como de manejo y mercado, no centrándose en la estimación de desempeño a nivel individual per se.

\subsection{Variables determinantes de los resultados económico-productivos}

Se presentan los resultados a nivel de productividad física y económica obtenidos a través de la modificación de las variables descritas en el ítem 5.10. Éstas son consideradas las de mayor relevancia sobre la dinámica del rebaño, los resultados productivos y los resultados económicos de los sistemas ganaderos de Uruguay (Rovira, 1996; Pereira y Soca, 1999; Feldkamp, 2004; Jorge, 2006; Ponssa et al., 2007).

Como se ha mencionado, la mayor complejidad de la cría, en cuanto a la multiplicidad de procesos biológicos involucrados, determina que la mayoría de las variables analizadas provengan de esa orientación productiva.

En primera instancia, se intenta analizar el efecto individual de estas variables sobre el sistema, aislando en lo posible su efecto. El objetivo es lograr una primera aproximación de la forma en que la variable actúa sobre el sistema analizado. Posteriormente, se realizarán simulaciones en contextos más complejos, a fin de interpretar las interacciones entre variables, intentando modelar los procesos con la complejidad que se dan en la realidad y de esa forma explotar las fortalezas del enfoque sistémico.

\subsubsection{Tasa de preñez}

Tanto en el caso de un sistema exclusivamente de cría como en un ciclo completo, la tasa de preñez constituye una variable crítica en la dinámica y productividad del proceso. Varios autores señalan su grado de importancia en la determinación de la eficiencia física y 
económica del sistema de cría bovina (Rovira, 1996; Monje, 1997; Feldkamp, 2004; Ponssa et al, 2007).

\subsubsection{Efecto sobre la estabilización del sistema}

Se presenta la evolución de las vacas de cría a lo largo de los años, a efectos de visualizar la incidencia de la tasa reproductiva sobre el tiempo necesario para la estabilización del sistema. Para simplificar la interpretación, se parte de una situación inicial con el número de $V C_{\text {ideal }}(1000)$ pero sin animales de las demás categorías de reposición.

En la Figura 37 y la Figura 38, se presentan la evolución de $V C$ en los 20 años, en función de tres índices de preñez propuestos (60, 75 y 90\%).

Supuestos: cubrición con 2 años de edad; a partir de la categoría 3 (multíparas) se descarta el $100 \%$ de las vacas que no se preñan

Cuando al final del año 1 se descartan las vacas de la última categoría más las vacas multíparas que no se preñan (falladas), la falta de reemplazos determina una caída en el número de vacas de cría. Esta caída continúa hasta el segundo año, donde recién ingresan al rebaño de cría las hembras hijas de las vacas cubiertas en el año 0.

En la Figura 37 se observa el resultado en un rebaño con 4 estratos de vacas, mientras que en la Figura 38 se analiza la misma variable en un rebaño con 8 estratos de edad de $V C$. 


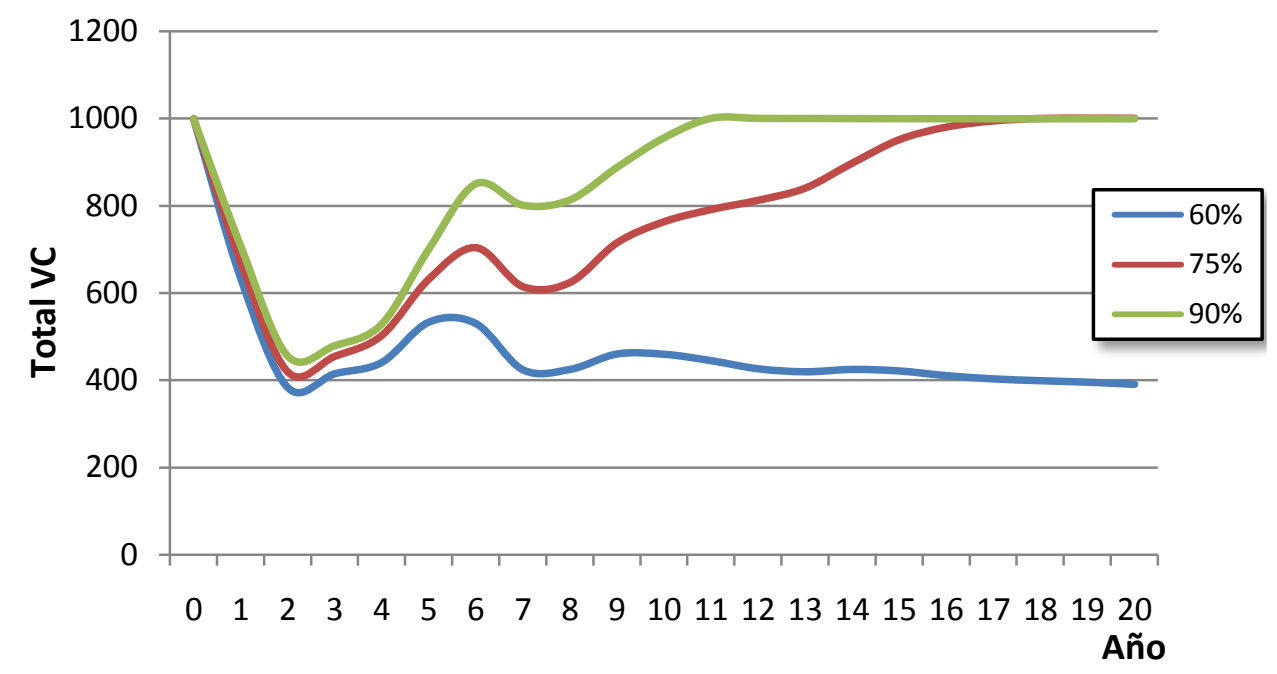

Figura 37. Evolución del número de VC en función del porcentaje de preñez con 4 estratos de edades

Como se observa en la Figura 37, en el caso del $60 \%$ de parición, no sólo no se vuelve a alcanzar el valor de $V C_{\text {ideal, }}$, sino que la evolución se hace descendente. Con $75 \%$ de preñez se llega a las 1000 vacas en el año 16, y con el $90 \%$ de preñez la meta se alcanza en el año 11. Se observa un patrón similar en las oscilaciones anuales de los tres casos.

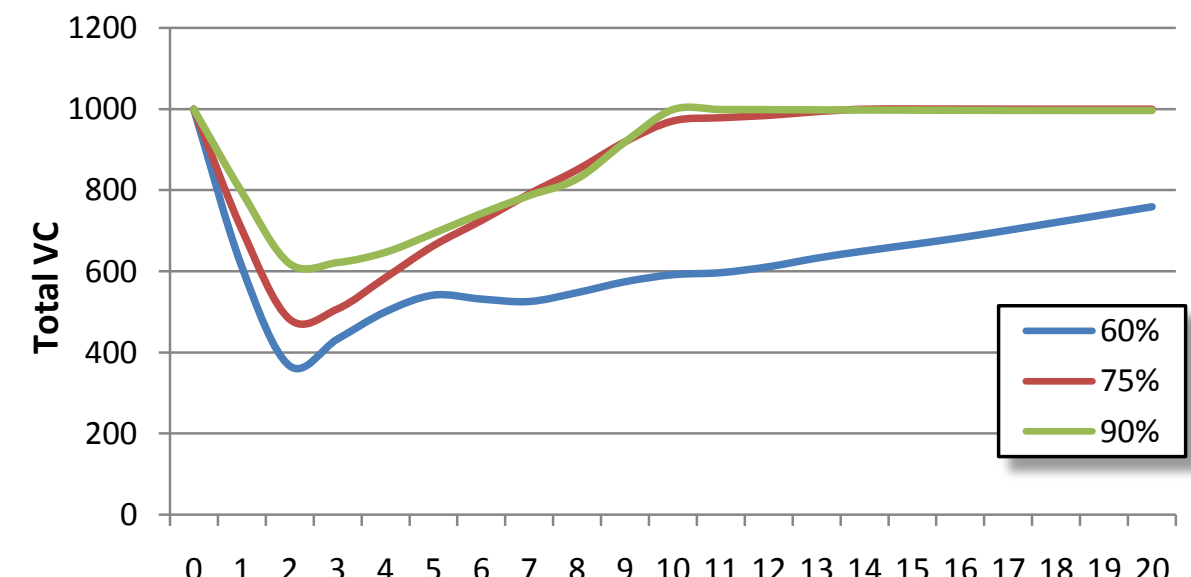

Año

Figura 38. Evolución del número de VC en función del porcentaje de preñez con 8 estratos de edades 
En el caso de contar con más estratos de edades, el recambio de animales se hace en forma menos drástica, debido a que la cantidad de vacas de última cría (categoría que se descarta anualmente) es sensiblemente menor que cuando existen 4 estratos (Figura 19). Por esta razón, incluso con el porcentaje más bajo de preñez, la curva es ascendente, aunque no llegue a la meta antes de los 20 años. Las curvas correspondientes a 75 y $90 \%$ de preñez evolucionan en forma bastante similar a partir del 6ำ año, momento hasta el cual las diferencias debidas a la mayor recuperación de la curva del 90\%, se hacen evidentes.

En el caso de que el descarte de hembras falladas fuera selectivo, es decir se eliminara sólo las hembras excedentes en función del logro de vacas objetivo al año siguiente, la recuperación del stock se haría mucho más rápidamente, tal y como se observa en las figuras 1 y 2 del anexo para 4 y 8 estratos de edad respectivamente.

\subsubsection{Efecto sobre la productividad del sistema}

Diversos autores coinciden en que la tasa reproductiva es uno de los principales factores determinantes del resultado productivo y económico de los sistemas de cría, tanto en la región (Rovira, 1996; Monje, 1997; Feldkamp, 2004; Ponssa et al., 2007) como fuera de ella (Bourdon, 1987b; Ritchie, 1995; Mathews y Short, 2001; Arnade y Jones, 2003; Cook et al., 2007).

La tasa de procreo o de destete determina directamente el número de terneros logrados, lo que constituye el principal producto de los sistemas de cría. Por otra parte, estos animales serán cebados para constituir el producto comercializable, si es el caso de un sistema de ciclo completo. A partir de cierta tasa reproductiva, se generan hembras excedentes a las necesarias para mantener la estructura de hembras del rebaño, las cuales también se destinan a venta. Como contraparte, el incremento en los índices reproductivos disminuye la cantidad de vacas falladas (vacías) las cuales, previo cebo, son una importante componente de la producción y de los ingresos económicos en estos sistemas. El resultado de este balance responde a múltiples factores que se analizarán a lo largo de este capítulo.

En la Figura 39 se presenta la producción expresada en $\mathrm{kg}$ peso vivo.ha ${ }^{-1}$ en función de la tasa reproductiva global del sistema. Los resultados se presentan para un sistema de cría (Cria) y uno de ciclo completo (CiCo), combinados con dos niveles de intensividad: a) un sistema exclusivamente basado en el forraje proveniente del campo natural (CN) con uso extensivo de insumos y b) un sistema con un $20 \%$ del área con pasturas implantadas (PAST). 
Mediante el software @Risk, se realizan 500 simulaciones para cada una de las cuatro combinaciones orientación productiva/nivel de intensividad explorando todas las combinaciones posibles con igual nivel de probabilidad, excepto para la variable edad de cubrición, para la cual se presentan valores en el rango entre 2 y 3 años en el caso de CN y entre 1 y 2 años en el caso de PAST.

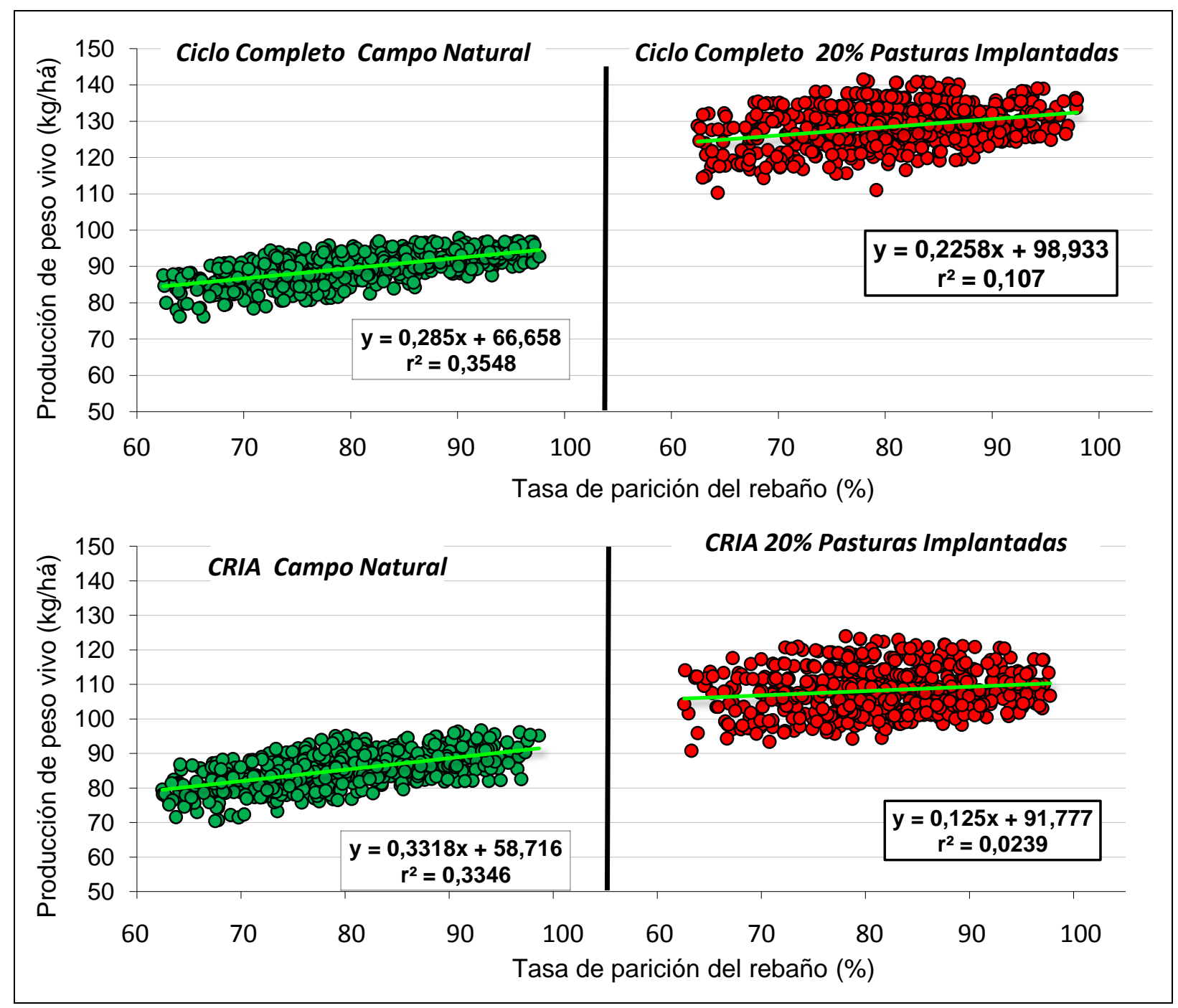

Figura 39. Productividad de 2 sistemas de cría y 2 de ciclo completo de diferente intensividad en el uso de insumos en función de la tasa de parición global del rebaño

Comparando dentro de la actividad de cría, el CN exhibe un mayor grado de asociación entre la tasa reproductiva y la productividad del sistema, determinado por un coeficiente de regresión $\left(r^{2}\right)$ más elevado respecto a PAST. En segundo lugar, la pendiente de la recta de regresión ajustada es más alta, indicando un efecto mayor de dicha variable sobre la productividad de este sistema. 
La explicación a estos resultados estaría basada en la diferente eficiencia de los procesos involucrados. Como se ha mencionado, en un sistema de cría se combina un proceso reproductivo que finaliza con la producción de terneros vendidos al destete y un proceso de cebo de vacas de descarte. Diversos autores coinciden en afirmar que el primero es un proceso biológica y energéticamente más ineficiente que el segundo (Monje, 1987; Pigurina y Berreta, 2002; Ponssa et al., 2003, 2007). Esta menor eficiencia determina que el proceso de cría sea relativamente menos sensible a la intensificación que el proceso de cebo, donde ha sido comprobado que la frontera productiva puede alcanzar valores que multiplican por diez la productividad de un sistema de cebo con mínimo aporte de insumos (Vaz Martins et al., 2003a, 2003b; Beretta et al., 2006). De esta forma, en un sistema con aporte forrajero extra, se incrementa sustancialmente la productividad a través del cebo de vacas reduciéndose, por tanto, el aporte relativo de la producción de terneros (tasa reproductiva) sobre el sistema.

En el caso del ciclo completo intensivo, al componente cría se agrega el cebo de los terneros que se producen. De esta forma, al incrementar la tasa de parición, si bien se reducen las hembras a cebar, se potencia el cebo de los machos, lo cual constituye el principal ingreso del sistema. Por esta razón, el efecto de la tasa reproduciva en el ciclo completo se encuentra más correlacionado con el nivel productivo que en el sistema de cría.

En el sistema de ciclo completo extensivo, el peso de la preñez sobre la producción se mantiene en valores similares a lo observado en la cría extensiva.

\subsubsection{Efecto sobre el retorno económico del sistema}

En la Figura 40 se presenta el margen bruto obtenido en las simulaciones descritas. En el caso de los sistemas de cría, el retorno económico presenta un comportamiento similar al observado desde el punto de vista productivo, con una mayor pendiente en el caso extensivo, denotando un efecto importante de la tasa reproductiva sobre el margen bruto, así como un mejor ajuste (mayor $\mathrm{r}^{2}$ ), poniendo de manifiesto que en estos sistemas el resultado económico resulta muy afectado por esta variable. En sistemas más intensivos el mayor peso relativo del cebo determina que el beneficio por unidad porcentual de preñez (pendiente) sea menor y el bajo ajuste de la recta de regresión sugiere un limitado aporte de esta variable como factor explicativo del retorno económico.

Si bien el margen bruto promedio es menor en el sistema con pasturas mejoradas, no debe olvidarse que en estas simulaciones se generan todas las combinaciones de valores sin consideraciones probabilísticas. En otras palabras, en ambos niveles de intensividad se 
da un número similar de simulaciones con altos niveles de preñez, mientras que en la realidad es esperable que estos casos se verifiquen con mayor frecuencia en el sistema intensivo, cuyos animales tienen un mejor nivel nutricional. Es lógico que un sistema con un costo de producción menor logre mejores resultados económicos si obtiene altos niveles de productividad.

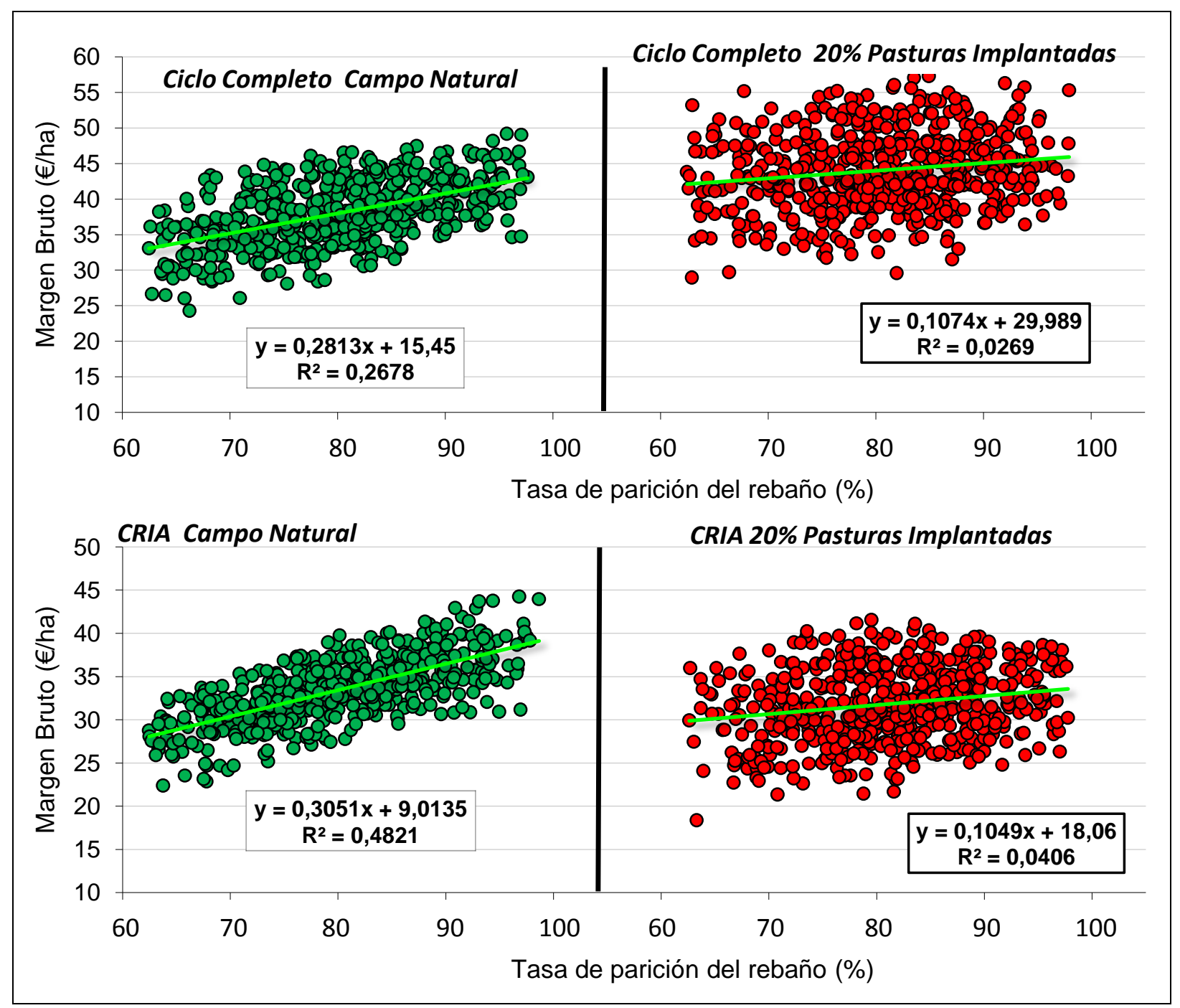

Figura 40. Retorno económico de 2 sistemas de cría y 2 de ciclo completo de diferente intensividad en el uso de insumos en función de la tasa de parición global del rebaño

En el sistema de ciclo completo sucede algo similar. En la medida que el componente cebo comienza a pesar más, se reduce la importancia relativa de la tasa reproductiva sobre el retorno económico.

Asimismo, se observa una mayor dispersión en los puntos en relación a los gráficos de productividad, ya que al añadir la relación precio ternero/precio novillo como variable explicativa se incrementa la variabilidad observada en los resultados. 
En la medida que se examine el efecto de otras variables sobre los indicadores físicoproductivos y económicos, se contará con información que facilite el análisis del efecto de la tasa reproductiva sobre los sistemas de producción, ya que su análisis en forma aislada es una sobresimplificación en el análisis de una variable cuya influencia sobre el beneficio económico es relativamente compleja.

\subsubsection{Edad de cubrición de novillas}

El momento de cubrición de las novillas constituye una de las decisiones más importantes en el manejo de cría. A menor edad de primera cubrición se acorta el período improductivo, pero aumentan los riesgos de fracasos ya que la gestación, el parto y la lactancia ocurrirán en un animal que debe completar su crecimiento (Berger et al., 2003). A continuación se verán algunos de los efectos de esta variable sobre distintos componentes del sistema.

\subsubsection{Efecto sobre la recuperación de stock}

La cubrición de novillas con 14 meses de edad determina un adelanto importante en el comienzo del ciclo reproductivo del rebaño de cría. Esto permite, entre otros factores, la recuperación anticipada del stock cuando éste se ha reducido por alguna razón o, como en este caso hipotético del ejemplo, cuando se parte de un establecimiento sin animales de reposición (sólo vacas de cría).

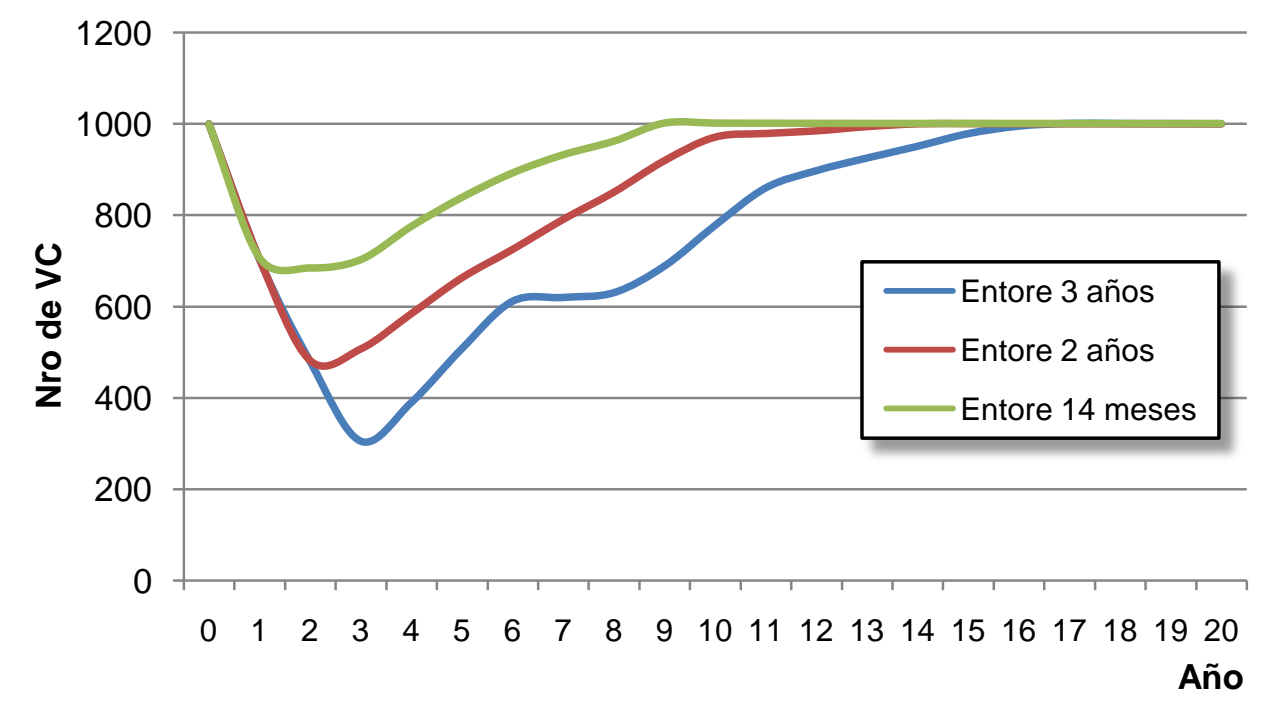

Figura 41. Evolución de stock de vacas de cría según política de cubrición 
Como se observa en la Figura 41, sirviendo las novillas a la edad más temprana se llega al objetivo de $V C$ cuatro años antes que si se cubre a los 2 años y siete años antes que si la cubrición es a los 3 años de edad. Igualmente, la caída inicial que se verifica como consecuencia de la inexistencia de reemplazos, es atenuada en forma muy importante si la cubrición se realiza a los 14 meses. Cuando se debe esperar hasta los 3 años para que un animal ingrese a su actividad reproductiva, el número de $V C$ al tercer año cae hasta las 300 vacas de cría.

\subsubsection{Efecto sobre la productividad y el retorno económico del sistema}

El adelanto en la edad de cubrición no sólo tiene consecuencias sobre el tiempo en que se verifican los procesos sino que afecta a la eficiencia global del mismo a través de la reducción del número de animales improductivos mantenidos en el establecimiento. En la Figura 42 se presenta el promedio de producción de peso vivo y margen bruto de las simulaciones realizadas en los cuatro sistemas descritos en el ítem anterior.

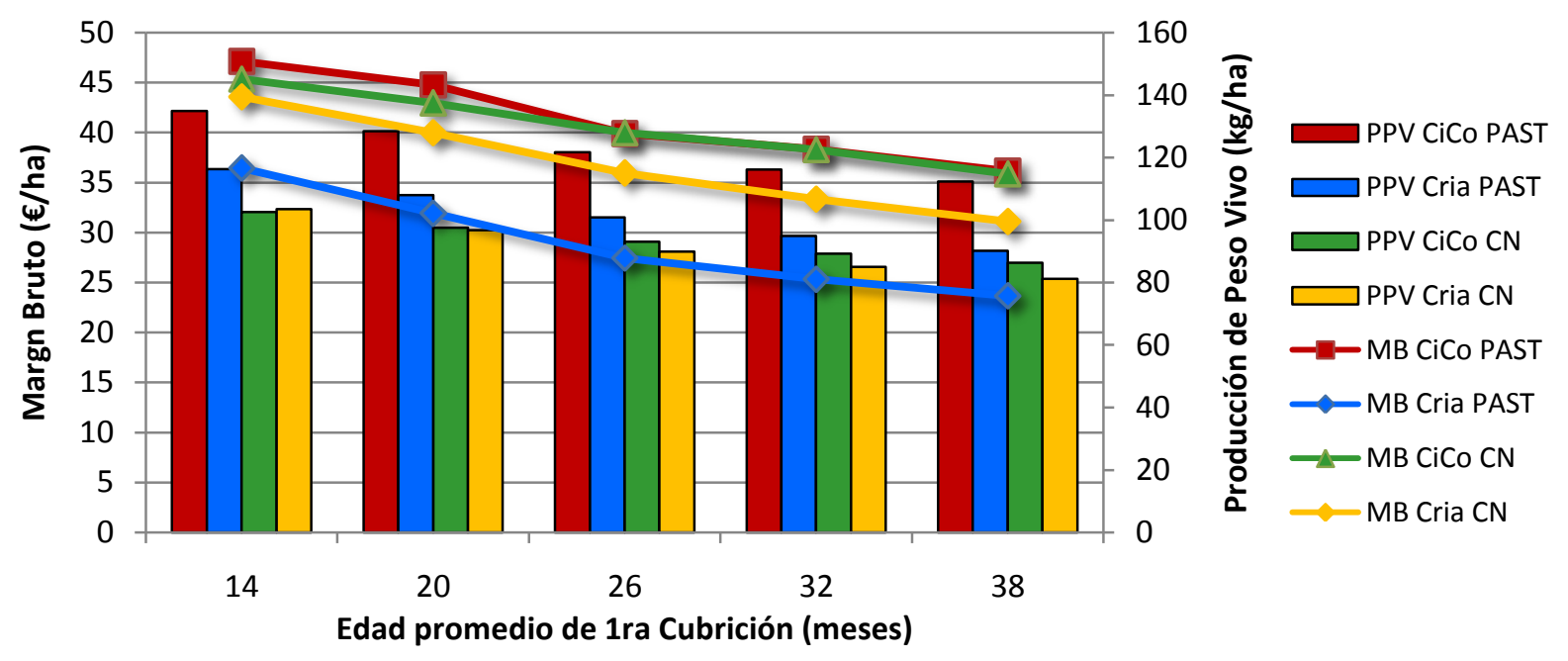

Figura 42. Productividad (PPV; kg PV/ha) y Margen Bruto (MB; $€ /$ ha) de 2 sistemas de cría y 2 de ciclo completo de diferente intensividad en el uso de insumos en función de la edad de primera cubrición de las novillas

Tanto la productividad como el retorno económico de los sistemas, decrecen consistentemente al incrementarse la edad de cubrición. El atraso en la edad de la primera cubrición determina una drástica reducción en el número de vacas de cría en producción, al requerirse de una importante área para el mantenimiento de las categorías de reemplazo (novillas de 1-2 años y novillas de +2 años sin servir). 
En el siguiente ejemplo se plantea un establecimiento de 1000 hectáreas con un sistema exclusivamente de cría, que vende el 100\% de los machos y las hembras excedentes al destete. Se simula un sistema de producción extensivo, sin mejoramientos forrajeros, con $65 \%$ de destete y en una situación de partida en la cual se cubren las novillas con 3 años de edad. Estos indicadores representan una situación muy usual en muchas regiones de Uruguay; se contrasta dicha situación con un sistema en el cual se reduce la edad de primera cubrición a los 2 años y con otra en la cual se logra la primera cubrición a los 14 meses de edad de las novillas. En la Tabla 27 se presentan los resultados físicos y económicos de los tres sistemas.

Supuestos: las vacas de $1^{\mathrm{a}}$ y $2^{\mathrm{a}}$ cría que fallan se mantienen en el rebaño, descartándose las de más de 2 crías que se detecten falladas; porcentaje de parición $=65 \%$ en los tres sistemas; relación precios kgTernero $/ \mathrm{kgNovillo}=1.12$.

Tabla 27. Efecto de la edad de primera cubrición sobre los resultados productivos y económicos de un sistema de cría

\begin{tabular}{|c|c|c|c|c|c|c|}
\hline \multirow{2}{*}{$\begin{array}{l}\text { Edad } 1^{e r} \\
\text { Cubrición }\end{array}$} & \multirow{2}{*}{$v C$} & \multicolumn{3}{|c|}{ Ventas (cabezas) } & \multirow{2}{*}{$P P V(\mathrm{~kg} / \mathrm{ha})$} & \multirow{2}{*}{$M B$ (€/ha) } \\
\hline & & Terneras & Terneros & $\begin{array}{l}\text { Vacas } \\
\text { gordas }\end{array}$ & & \\
\hline 3 años & 464 & 33 & 144 & 93 & 65 & 20 \\
\hline 2 años & $525(+13 \%)$ & 38 & 163 & 105 & $72(+11 \%)$ & $23(+15 \%)$ \\
\hline 14 meses & $615(+33 \%)$ & 47 & 190 & 122 & $83(+28 \%)$ & $29(+45 \%)$ \\
\hline
\end{tabular}

Comparado con la situación más extensiva donde las novillas se cubren con 3 años, la cubrición con 14 meses determina la posibilidad de contar con un 33\% más de vacas de cría que se encuentran produciendo en el establecimiento, consumiendo los recursos forrajeros que de otra manera serían utilizados por las novillas de 1-2 y 2-3 años sin servir, es decir improductivas. En forma proporcional se incrementan las ventas de terneros (32\%) y vacas gordas $(31 \%)$, mientras que las de terneras aumentan en forma más que proporcional (42\%), en virtud de que además de que la mayor tasa de preñez determina un mayor número de terneras producidas, también se reducen las necesidades de reposición de hembras. De esta forma, se verifica un incremento en la producción de peso vivo (PPV) del $28 \%$ y un incremento del margen bruto del $45 \%$. Estos resultados coinciden con los reportados por Berger et al. (2003) y Ponssa et al. (2007), en Argentina.

Es evidente que la reducción en la edad de cubrición necesariamente traerá aparejado una mejora en la alimentación y un consiguiente incremento en los costos para alcanzar el 
desarrollo adecuado de las novillas a una edad más temprana. Esta simulación intenta mostrar el impacto sobre la estructura del rebaño y la consiguiente productividad del sistema, para lo cual se hace necesario comparar las opciones asumiendo una misma base forrajera y dotación global. En simulaciones posteriores se analizará el efecto de la reducción en la edad de cubrición tomando en consideración las necesidades forrajeras y los costos asociados a cada esquema productivo.

\subsubsection{Categoría de hembras a vender}

La categoría de hembras de reemplazo a ser comercializadas tiene una importante incidencia en la carga y la productividad del sistema y por ende en el margen bruto obtenido. De forma similar al efecto del adelanto en la edad de cubrición, la venta de hembras como terneras (al destete), determina una reducción de la carga durante el invierno, el cual constituye un período crítico en cuanto a disponibilidad de forraje. Al retener las hembras hasta la cubrición o posterior a la misma (si se cubren y venden preñadas), se ocupa un área y recursos forrajeros que podrían ser utilizados por las categorías de cría, incrementando su número (Figura 43).

Supuestos: establecimiento de 1000 ha; porcentaje de preñez del 75\%; cubrición a los 2 años; ausencia de mejoramientos forrajeros; relación precios $\mathrm{kgTernero} / \mathrm{kgNovillo}=1.12$

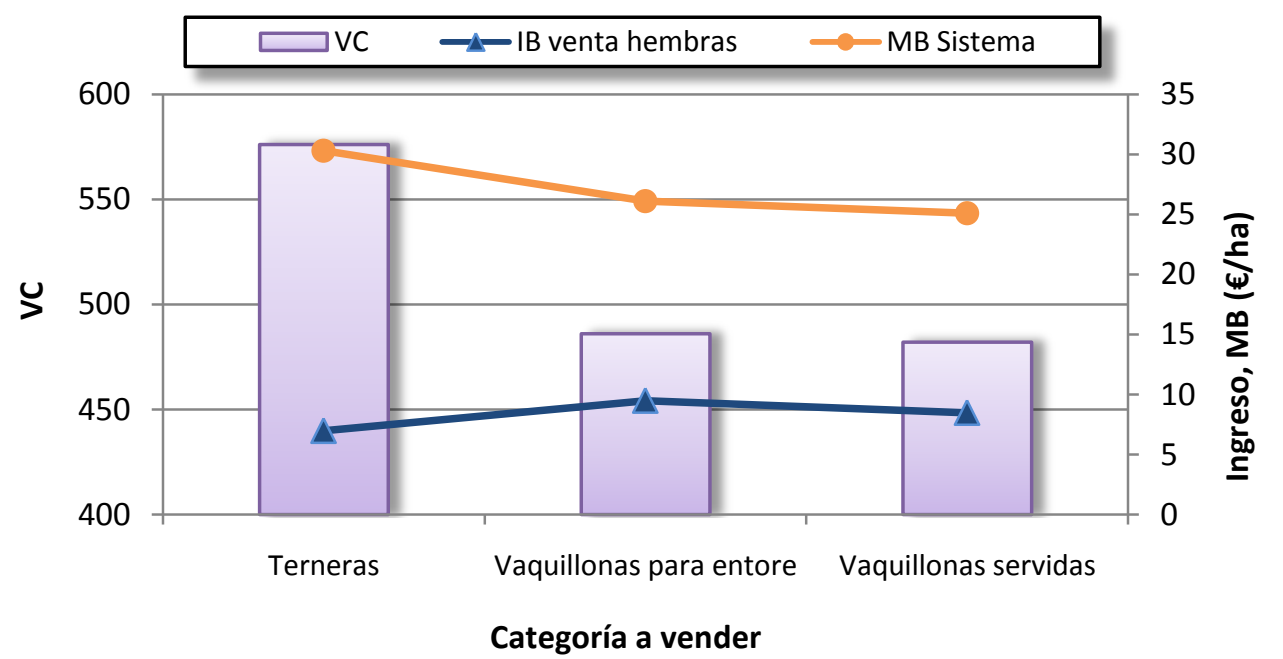

Figura 43. Efecto de la categoría de hembras destinada a venta sobre la estructura del rebaño y el Margen Bruto del sistema 
Como se observa en la Figura 43, si bien hay un incremento en el Ingreso por venta de novillas en lugar de terneras, éste no compensa la drástica reducción en el total de vacas de cría que es capaz de soportar el sistema y en consecuencia el margen bruto desciende. La venta de las terneras previo al invierno, determina un incremento importante en la capacidad de carga del sistema, lo que permite el mantenimiento de un mayor número de vacas en producción.

Deben acotarse estas consideraciones a las relaciones de precios manejadas entre las distintas categorías, puesto que el margen bruto es muy dependiente de éstas.

\subsubsection{Diagnóstico de gestación y políticas de descarte}

En Uruguay la actividad de cría se lleva a cabo en el contexto de una amplia gama de situaciones en materia de escala y calidad de los recursos naturales y se realiza fundamentalmente en base al pastoreo de campo natural. La base forrajera que sirve de soporte al proceso productivo tiene por consiguiente un límite, establecido en buena medida por la aptitud pastoril de los suelos y por eventos climáticos, dos factores sobre los que los productores tienen escasas posibilidades de incidir.

Esto determina que la tecnología aplicada por los productores en sus rebaños en cuanto al manejo del balance forrajero (la correspondencia entre los requerimientos del rebaño y la oferta forrajera) tenga un rol fundamental en el resultado productivo de dichas explotaciones (DIEA, 2003). En este contexto, tiene fundamental importancia la eliminación de animales improductivos del establecimiento, permitiendo que el forraje (principalmente en el período invernal) sea utilizado por categorías en producción y determinando una mayor carga del sistema en su conjunto.

El diagnóstico de gestación permite identificar los animales preñados, eliminando en forma temprana las vacas vacías del rebaño de cría. Permite la asignación de recursos forrajeros en función de los requerimientos animales, y debe ser realizado en el otoño temprano para poder aplicar un manejo diferencial a las categorías preñadas y falladas (Quintans, 2004).

Sin embargo esta técnica no es utilizada por todos los productores del país. Si bien se carece de información actualizada sobre la magnitud de su aplicación, en el año 2003 fue determinado que solamente el $40 \%$ de las explotaciones del país utilizaban esta técnica (DIEA, 2003). 
En la Tabla 28 se presentan resultados obtenidos con el modelo sobre el efecto productivo y económico de la realización de diagnóstico de gestación en el otoño y la consiguiente destinación de las vacas vacías a la venta. Se intenta visualizar la importancia de esta técnica como medida de incremento de la eficiencia de los rebaños de cría más extensivos del país, por lo cual se evalúa este efecto bajo dos situaciones: a) el cebo de las vacas vacías que se descartan del rebaño con posterior venta a matadero y b) la venta inmediata al mercado intraganadero, a otros productores que las cebarán para ser comercializadas luego al matadero.

Supuestos: establecimiento de 1000 ha; cubrición con 2 años de edad; se retienen las novillas de $1^{\text {er }}$ cubrición y las vacas de segunda cubrición aunque sean diagnosticadas vacías; 8 estratos de edad de vacas; relación precios $\mathrm{kgTernero} / \mathrm{kgNovillo}=1.12$; dotación=0.7 UG/ha

Tabla 28. Efecto de la utilización del diagnóstico de gestación y la eliminación de vacas multíparas de rebaño de cría sobre la productividad y el margen bruto económico de un sistema de cría extensivo y uno de ciclo completo de similares características

\begin{tabular}{c|cc|cc|cc|cr}
\hline & \multicolumn{4}{|c|}{ Sistema de Cría } & \multicolumn{3}{c}{ Sistema de Ciclo Completo } \\
\hline & \multicolumn{2}{|c|}{$\begin{array}{c}\text { Con cebo vacas } \\
\text { PPV }\end{array}$} & \multicolumn{2}{|c|}{ MB cebo vacas } & \multicolumn{2}{c}{ Con cebo vacas } & \multicolumn{2}{|c}{ Sin cebo vacas } \\
MPV & PPV & MB & PPV & MB & PPV & MB \\
\cline { 2 - 9 } $\begin{array}{c}\text { Sin Diagnóstico ni } \\
\text { descarte (inicial) }\end{array}$ & 70 & 24.8 & 71 & 21.8 & 80 & 36.7 & 80 & 34.7 \\
\hline $\begin{array}{c}\text { Diagnóstico + } \\
\text { descarte }\end{array}$ & 83 & 31.0 & 85 & 25.4 & 88 & 40.6 & 89 & 37.2 \\
Diferencia (\%) & $\mathbf{+ 1 9}$ & $\mathbf{+ 2 5}$ & $\mathbf{+ 2 0}$ & $\mathbf{+ 1 6}$ & $\mathbf{+ 1 0}$ & $\mathbf{+ 1 0}$ & $\mathbf{+ 1 1}$ & $\mathbf{+ 7}$ \\
\hline
\end{tabular}

Un establecimiento de cría con capacidad para cebar las vacas descartadas lograría un incremento de su productividad del 19\%, asociado a un incremento del retorno económico del orden del $25 \%$. En el caso de no contar con la posibilidad de realizar el cebo, se logra igualmente un beneficio económico extra del $20 \%$ respecto a la situación en que no se realiza diagnóstico de gestación y las vacas falladas se mantienen en el establecimiento.

El cambio en esta política de manejo determina una reducción en la venta de terneras para reposición, pero esta reducción es compensada por la venta de hembras falladas, categoría que de otra manera sería mantenida en el establecimiento, improductiva y consumiendo recursos.

En el caso del sistema de ciclo completo, al constituirse el cebo de los machos en la actividad preponderante desde el punto de vista de la productividad y el ingreso, se reduce 
el aporte relativo de la técnica analizada sobre el sistema en su conjunto. Igualmente posibilita aumentar el MB entre un 7 y un $10 \%$.

Otro aspecto importante, en lo que respecta a las políticas de reemplazo de hembras del rebaño, es el descarte de novillas y vacas de segunda cubrición que no se preñan. Por lo general, excepto en sistemas muy intensivos, a estas categorías se les proporciona una "segunda oportunidad" por varios motivos: en primer lugar es un animal joven, con una vida productiva recién iniciada y en el cual se han invertido tiempo y recursos forrajeros para su recría. En segundo lugar, son animales que muchas veces no han completado su desarrollo, por lo cual no son un buen producto para cebo, siendo necesario un largo período de alimentación para que logren la terminación adecuada. Por el contrario, si se cuenta con los recursos forrajeros o de piensos necesarios para un cebo eficiente de estas categorías, su eliminación del rebaño de cría determina ventajas que ya han sido comentadas para las categorías adultas, particularmente en lo que respecta a la eficiencia de mantener en el establecimiento sólo aquellas categorías que se encuentren en producción.

Estas dos alternativas tienen otras connotaciones además de las ya comentadas, La primera de ellas (que se encuentra muy asociada con el número de estratos de vacas de cría presentes en el rebaño) se refiere a la tasa mínima de preñez para asegurar la estructura de vientres del rebaño. En la Tabla 29 se presenta el valor de esta tasa mínima para las opciones de estratos de edades manejadas por el modelo y para las dos posibilidades de descarte de hembras jóvenes.

Supuestos: Cubrición con 26 meses de edad; se descartan las vacas multíparas que se diagnostican vacías

Tabla 29. Tasa mínima de preñez general del rebaño para asegurar la reposición de hembras según estratos de edades de vacas y política de descarte de vacas jóvenes

\begin{tabular}{l|ccccc}
\hline & \multicolumn{5}{c}{ Número de estratos de edades de vacas } \\
\cline { 2 - 6 } & $\mathbf{4}$ & $\mathbf{5}$ & $\mathbf{6}$ & $\mathbf{7}$ & $\mathbf{8}$ \\
\hline $\begin{array}{l}\text { Se descartan las hembras } \\
\text { jóvenes falladas } \\
\begin{array}{l}\text { Se retienen las hembras } \\
\text { jóvenes falladas }\end{array}\end{array}$ & 79 & 75 & 73 & 72 & 71 \\
\hline
\end{tabular}

El descarte de vacas jóvenes determina un aumento muy importante en la tasa mínima de preñez para asegurar la reposición de vientres del rebaño de cría. Por otra parte, en la medida que se reduce el número de grupos de vacas, se incrementa el número de hembras 
de primera cubrición que ingresan cada año (Figura 19) por lo cual la preñez global debe incrementarse para asegurar este número de hembras. Ponssa et al. (2007), mediante simulación, estiman esta tasa mínima en $77.8 \%$, asumiendo que se descartan todas las vacas vacías. En dicho trabajo no se especifica claramente el número de grupos etarios manejado.

La clara diferenciación existente entre estos grupos de vacas ( $\leq 1$ parto y $>1$ parto), en lo que respecta a sus políticas de descarte y potencial de cebo descritos, merece un tratamiento discriminado. En un escenario productivo como el de Uruguay, donde el componente cebo tiene un gran peso en la ecuación económica y una vaca de "descarte" tiene un valor por kg muy superior al de una vaca en plena producción, no es suficiente con manejar una sola tasa de procreo o destete. En virtud de las diferencias mencionadas entre estos grupos se hace necesario manejar tres o al menos dos tasas reproductivas distintas. Adicionalmente, al adentrarse en el análisis de situaciones con mayor grado de complejidad, como de hecho lo son los sistemas ganaderos del país, se torna necesario analizar interacciones entre variables. En particular, la política planteada de descarte de ambos grupos de hembras, interacciona fuertemente con las relaciones de precios ternero/vaca gorda y la tasa de preñez en la definición del retorno económico de los sistemas. Para ejemplificar estos conceptos se plantean dos situaciones productivas contrastantes sobre las cuales se analizará la forma en que la combinación de las variables mencionadas afecta el resultado productivo y económico. Se compara un sistema intensivo de cría, con $30 \%$ de pasturas artificiales e indicadores acordes al nivel alimenticio, con un sistema extensivo exclusivamente basado en el campo natural como base forrajera. Asumiendo un valor preestablecido para la tasa de procreos de las hembras jóvenes, se estima el efecto de las tasas de preñez en vacas adultas, en combinación con tres relaciones de precios ternero/novillo y dos estructuras de rebaño: 4 y 8 estratos de edad de vacas de cría. En la Figura 44 se presentan los resultados para el sistema de cría con $30 \%$ de pasturas mejoradas (intensivo).

\section{Supuestos Cría Intensiva}

30\% pasturas implantadas;

cubrición con 14 meses;

preñez: 95\% novillas, $85 \%$ vacas $1^{\text {a }}$ cría;

rel. precios ternero/novillo, 0.91, 1.12, 1.33;

descarte de vacas multíparas vacías

\section{Supuestos Cría Extensiva}

100\% Campo natural;

cubrición con 32 meses (50\% 2 años y 50\% 3

años);

preñez: $85 \%$ novillas, $65 \%$ vacas $1^{\text {a }}$ cría;

rel. precios ternero/novillo, 0.91, 1.12, 1.33;

descarte de vacas multíparas vacías 


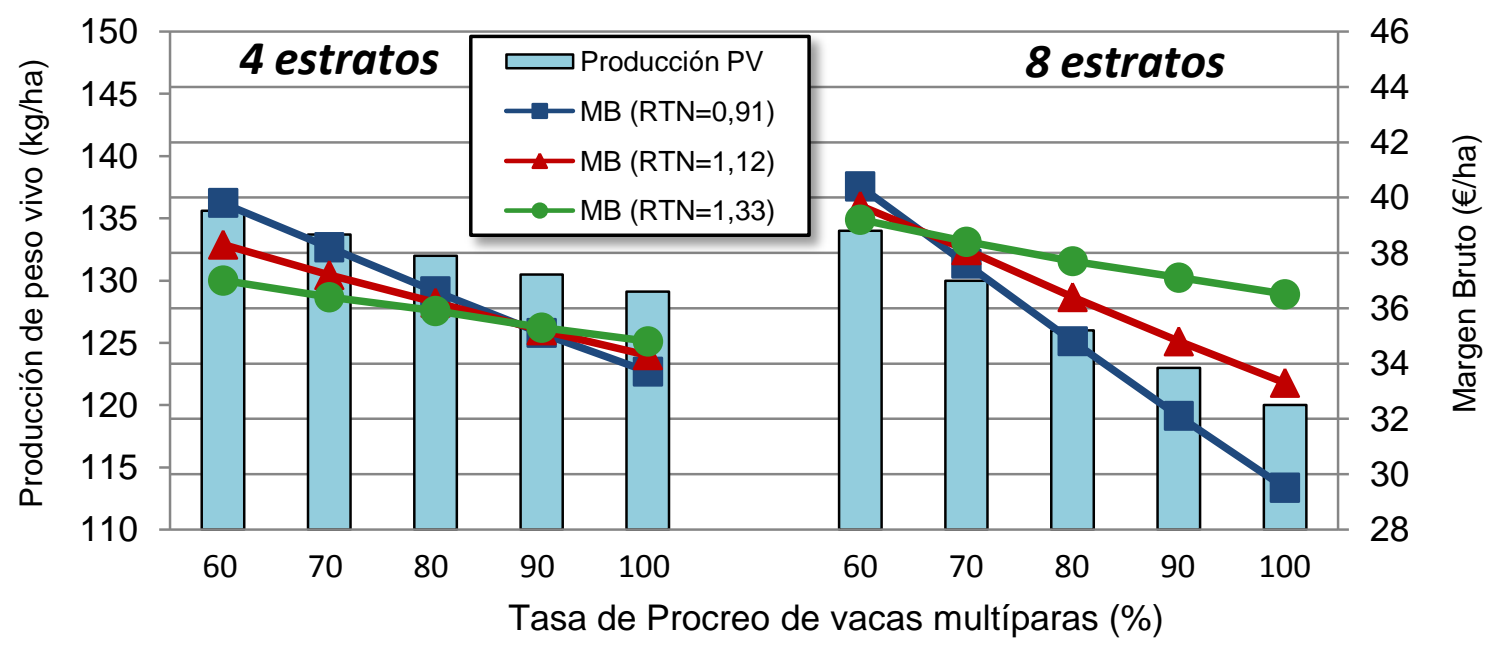

Figura 44. Efecto de la tasa de procreo de vacas de más de 2 partos sobre la productividad y el margen bruto de un sistema de cría intensiva según el número de estratos de edad y la relación de precios ternero/novillo (RTN)

El primer punto a destacar es la relación negativa entre la productividad expresada en $\mathrm{kg}$ de peso vivo producidos por hectárea y la tasa reproductiva de las vacas de más de 2 partos. Efectivamente, superando un valor mínimo de procreo para mantener la estructura de hembras del rebaño, una baja tasa de preñez determina una mayor producción de peso vivo. Una vaca vacía es un animal con un potencial de producción de $\mathrm{kg}$ de carne muy superior al de producción de $\mathrm{kg}$ de ternero, considerando la eficiencia biológica y el tiempo necesario para lograr uno y otro producto. De esta forma, si se cuenta con suficiente disponibilidad de forraje, una vaca que es diagnosticada vacía en otoño podrá ser cebada y comercializada habiendo consumido menos recursos energéticos de los que consumiría hasta destetar un ternero (si se preñara) a través de un proceso de gestación y lactancia energéticamente costoso. A su vez, cuando el cebo de las vacas es realizado eficientemente, una baja tasa reproductiva permite mantener un mayor número de vacas de cría totales y en consecuencia la producción absoluta de terneros no cae proporcionalmente a la reducción de la preñez (Tabla 30 ).

Tabla 30. Tasa de preñez en vacas multíparas y valores resultantes en cuanto a vacas de cría totales y terneros vendidos según intensificación del sistema de cría. Valores expresados en cabezas e índice entre paréntesis (Indice $100=60 \%$ de procreo)

\begin{tabular}{c|cc|cc}
\hline & \multicolumn{3}{|c|}{ Cría intensiva } & \multicolumn{2}{c}{ Cría extensiva } \\
\% de procreo & Venta de terneros & Total de vacas de cría & Venta de terneros & Total de vacas de cría \\
\hline 60 & $243(100)$ & $685(100)$ & $164(100)$ & $512(100)$ \\
80 & $256(105)$ & $640(93)$ & $190(116)$ & $542(106)$ \\
100 & $270(111)$ & $580(85)$ & $217(132)$ & $560(109)$ \\
\hline
\end{tabular}


La reducción en el total de vacas de cría al incrementarse la preñez contrasta con los resultados obtenidos por Bourdon y Brinks (1987b), quienes reportan una relación positiva entre estas variables.

Las tres relaciones de precios manejadas determinan una asociación negativa entre la tasa reproductiva y el margen bruto, si bien la pendiente se reduce al disminuir la RTN o, lo que es lo mismo, al incrementarse proporcinalmente más el precio del ternero respecto al de la vaca gorda. En el caso de contarse con 8 estratos de vacas y bajo los supuestos considerados, un valor de preñez de $66 \%$ permitiría independizarse de las relaciones de precios. Conceptualmente, este valor puede definirse como la tasa de preñez en la cual el nivel de productividad ( $\mathrm{kg}$ de vaca gorda $+\mathrm{kg}$ de terneros y terneras) es tal que la variación de la relación de precios no afecta al margen bruto obtenido. En el caso de que la estructura del rebaño sea de 4 grupos de vacas se hace necesario elevar la tasa de partos al $88 \%$ para que el mercado no afecte al margen obtenido (isoingreso). Se postula que la alta proporción de novillas y vacas de segunda cubrición en este sistema, determina que a igual porcentaje de fallos en estas categorías el número de vacas vacías sea mayor, por lo cual para llegar al punto de isoingreso en el grupo de vacas multíparas podrían descartarse menos animales (mayor preñez).

Como corolario de lo que se ha discutido, en la Figura 44 puede comprobarse gráficamente la asociación existente entre la productividad y el margen bruto a bajas relaciones ternero/vaca en los sistemas de cría intensivos simulados. En otras palabras, la productividad está fuertemente determinada por el proceso de cebo de hembras de descarte, por lo cual si la relación de precios es favorable, el retorno económico acompasará dicha tendencia. 


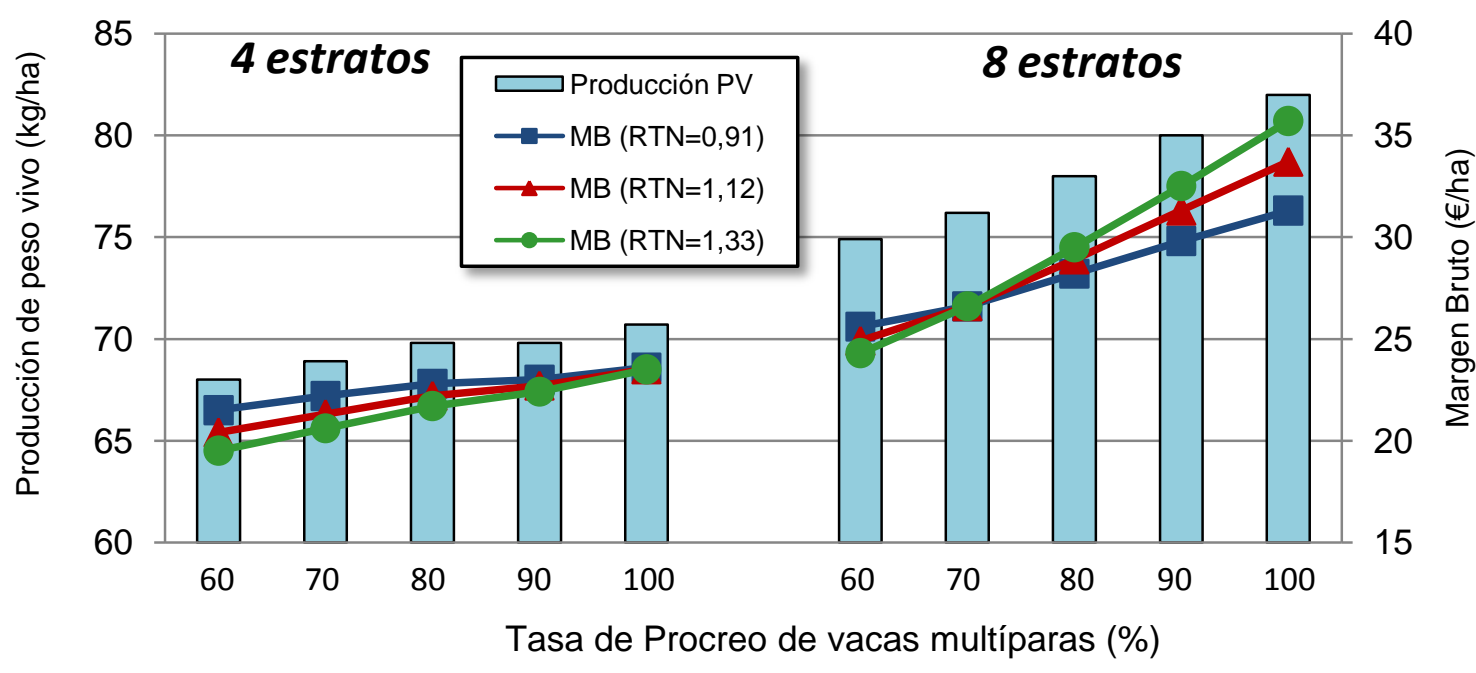

Figura 45. Efecto de la tasa de procreo de vacas de más de 2 partos sobre la productividad y el margen bruto de un sistema de cría extensivo según el número de estratos de edad y la relación de precios ternero/novillo (RTN)

En el caso de los sistemas de cría extensivos (Figura 45) la situación se revierte, existiendo una asociación positiva entre la tasa de preñez de estas vacas con el margen bruto obtenido en todas las situaciones simuladas. La explicación de estos resultados puede extraerse de la Tabla 30 donde se observa que una mayor tasa de procreo determina un leve incremento en las vacas de cría totales, en contraposición a la situación intensiva donde este valor se reduce fuertemente. De esta manera, con mayor tasa de preñez y mayor número de vacas, el incremento de la tasa reproductiva aumenta la cantidad de terneros obtenidos hasta en un $32 \%$ respecto a la situación base. A diferencia de la situación intensiva, aquí el cebo es un proceso ineficiente que requiere más tiempo y por lo tanto mayor consumo de forraje.

Por otra parte, esta relación positiva es consistente en las tres relaciones de precios evaluadas. Debe recordarse que las relaciones de precios extremas utilizadas corresponden a los valores promedio registrados en los últimos 7 años \pm 2 desvíos estándar, por lo cual la probabilidad de que se verifique un valor inferior es muy baja, indicando que en las condiciones planteadas es altamente improbable que se pierda dinero por incrementar la preñez en esta categoría.

En lo que respecta al efecto del número de estratos de vacas, al igual que en la situación intensiva, al aumentar este valor se incrementa la proporción de hembras multíparas del rebaño, por lo cual las variaciones estudiadas tienen un impacto mayor. Además, en esta situación donde las novillas se cubren con 2.5 años, la opción de 4 estratos de edad determina la existencia de un mayor volumen de hembras de 1-2 años y de 
2-3 años sin entrar en producción, respecto a la situación de 8 estratos, ya que en este último caso la proporción anual de hembras a reponer es sensiblemente menor (Figura 19).

Existe otra interacción no visible en los gráficos anteriores y que afecta en mayor medida a la productividad y en menor grado al retorno económico. Se trata del efecto de la preñez en vacas multíparas y la edad de primera cubrición. Se manifiesta como un efecto negativo de la tasa de preñez mencionada a baja edad de cubrición que se transforma en positivo al incrementarse dicha edad. Esta interacción se ha detectado, aunque con diferente intensidad, para todas las combinaciones entre orientaciones productivas y niveles manejados. En la Figura 46 se presenta el efecto de dicha interacción en dos situaciones: un sistema de ciclo completo extensivo, donde no se descartan las vacas de $1^{\underline{a}}$ y $2^{\underline{a}}$ cría (A) y un sistema de cría intensivo con descarte de todas las hembras que se diagnostican vacías (B).

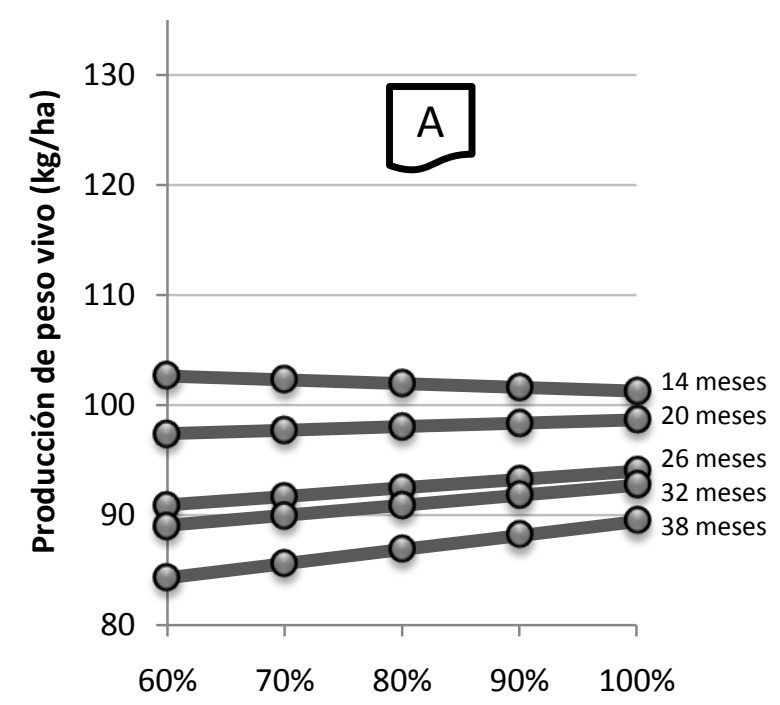

Tasa de procreos en vacas multíparas

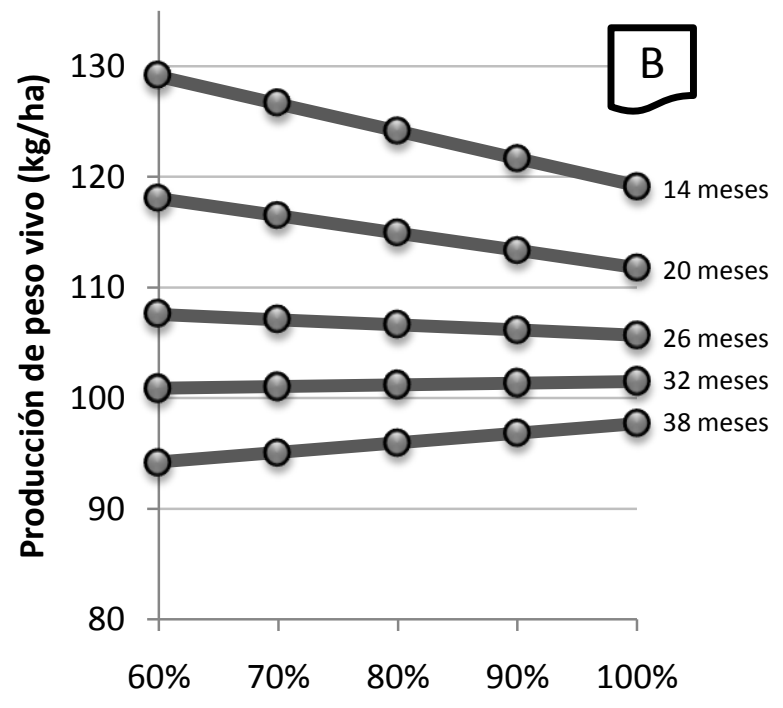

Tasa de procreos en vacas multíparas

Figura 46. Efecto de la interacción entre la edad de cubrición de novillas y la tasa de partos de vacas multíparas sobre la productividad de: A) un sistema de ciclo completo extensivo y, B) un sistema de cría intensivo

En el sistema de ciclo completo, donde el aporte fundamental a la producción lo hace el cebo de novillos, la edad de cubrición para la que hay indiferencia a la tasa de preñez se encuentra alrededor de 18 meses. En el sistema de cría con descarte de todas las hembras vacías, por debajo de 30 meses de edad de cubrición, desde el punto de vista productivo es conveniente minimizar la tasa de partos en las vacas multíparas.

Detrás de estos resultados, subyace el concepto de la mayor eficiencia del proceso de cebo frente al de cría. Por esta razón, si se logran los reemplazos necesarios con las categorías de $1^{\underline{a}}$ y $2^{\underline{a}}$ cría (de menor potencial de cebo por tener un menor desarrollo) a nivel 
general no es biológicamente conveniente tener altos valores de preñez en las vacas multíparas. Pero como se ha visto ya, este concepto biológico es muy dependiente de otros factores. Particularmente para el caso de la edad de cubrición de novillas, en los gráficos se observa que la superioridad en eficiencia del cebo se desvanece si, al descartar una vaca, ésta es reemplazada por una ternera que debe ser recriada durante tres años para lograr su cubrición. Ese es el caso de la curva de 38 meses de edad promedio de cubrición, donde una baja preñez (o alta tasa de descarte) determina una menor productividad por hectárea. En contrapartida, la mayor eficiencia del proceso de cebo sí es capitalizada cuando la edad de cubrición es de 14 meses, de tal forma que productivamente es preferible obtener tasas de preñez más bajas 0 , en otras palabras, una mayor cantidad de vacas para cebar, puesto que el reemplazo de estas vacas descartadas del rebaño se hace efectivo en mucho menos tiempo.

Habiendo detectado un importante grado de complejidad en la situación intensiva en lo que respecta a la interacción entre el desempeño reproductivo, las relaciones de precios y las políticas de descarte en vacas jóvenes y multíparas, se analizan algunas otras posibilidades asumiendo el descarte de todas las hembras que no se preñan.

En primer lugar se plantea el análisis de la preñez como un único indicador aplicado a todas las categorías de hembras del rebaño. En la Figura 47 se presenta el margen bruto por hectárea según preñez del rebaño en un sistema de cía intensiva, con una relación de precios igual a la que se verifica actualmente (0.94). Para facilitar la comprensión de las causas que determinan la relación presentada, se muestra además el ingreso por ventas de terneros, terneras y vacas de cebo para cada valor de preñez.

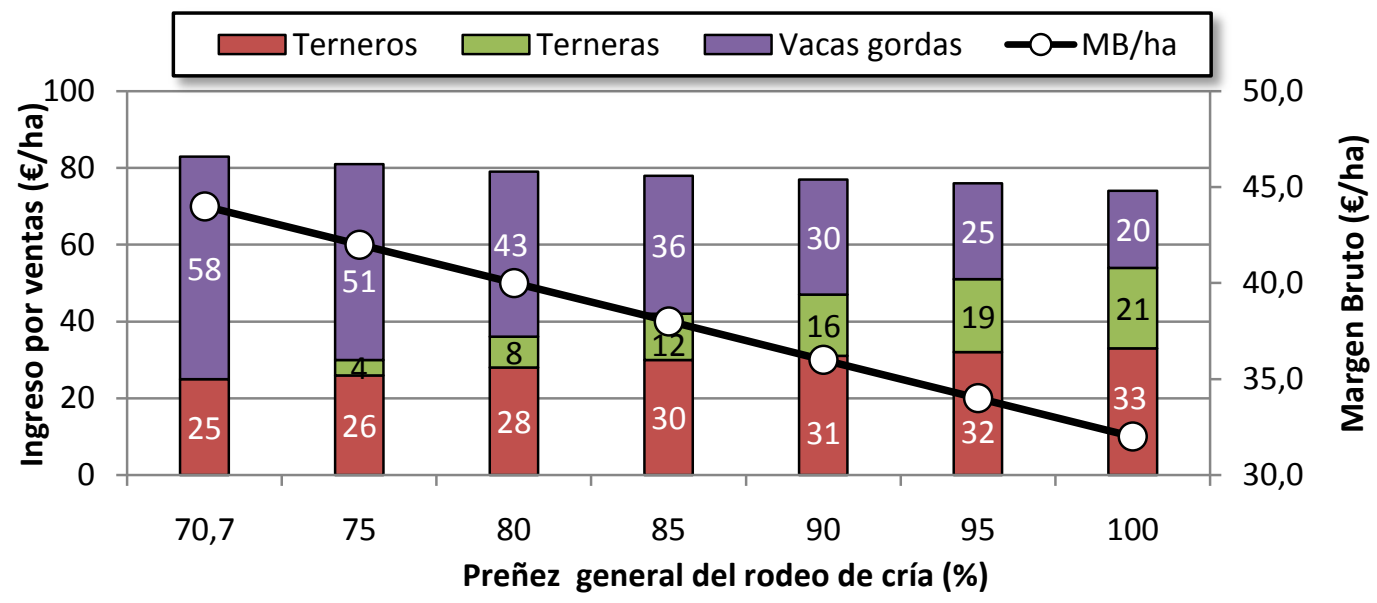

Figura 47. Ingresos por venta de diferentes categorías y margen bruto de un sistema de cría intensiva según \% de preñez global 
Al incrementarse la preñez, el total de vacas de cría se reduce, puesto que hay más animales que deben ser mantenidos en el rebaño. En consecuencia la venta de terneros se incrementa muy levemente (mayor tasa de preñez pero menos vacas totales). La situación con $70.7 \%$ de procreos representa el mínimo valor para mantener la estructura del rebaño (no hay venta de terneras) y es donde se verifica el máximo ingreso por venta de vacas gordas; casi un $30 \%$ de vacas se descartan por falladas y el número de vacas totales es el más alto. También en este punto es donde se maximiza el margen bruto por unidad de superficie del sistema. Para los supuestos considerados en este ejercicio, se ha estimado en 1.33 la relación de precios con la cual no se afecta el margen bruto al variar la tasa de procreo.

En el escenario productivo y de precios definido, la reducción del período de cubrición (45 días) constituye una medida de manejo sin costo y que permite una mejora en la eficiencia del sistema. Si bien este acortamiento reduce en parte la probabilidad de concepción (especialmente en vacas de baja condición corporal), en este caso este efecto no sería desfavorable. Por otra parte, con esta medida se logra: 1) la reducción de la temporada de partos con lo cual se logra una mayor homogeneidad en la edad y consiguiente peso de los terneros al destete, característica que es valorada positivamente en el mercado (Lanfranco et al., 2006) y 2) se puede adelantar el diagnóstico de gestación y detectar en forma temprana las hembras vacías, destinándolas antes a cebo, con el consiguiente aumento en la productividad del sistema.

Anteriormente se ha expresado la importancia de anlizar en forma diferencial la tasa reproductiva de hembras jóvenes respecto a las vacas de tercer cubrición en delante. En este sentido, se realizaron 3000 simulaciones combinando tasas de preñez entre 0.73 y 1 tanto para hembras jóvenes como para vacas multíparas, con 3 relaciones de precios ternero/novillo $(0.91,1.12$ y 1.33$)$. En la Figura 48 se presenta un gráfico para cada una de estas relaciones de precios, representándose en cada uno de ellos el margen bruto obtenido según la tasa reproductiva de vacas jóvenes y vacas multíparas. 


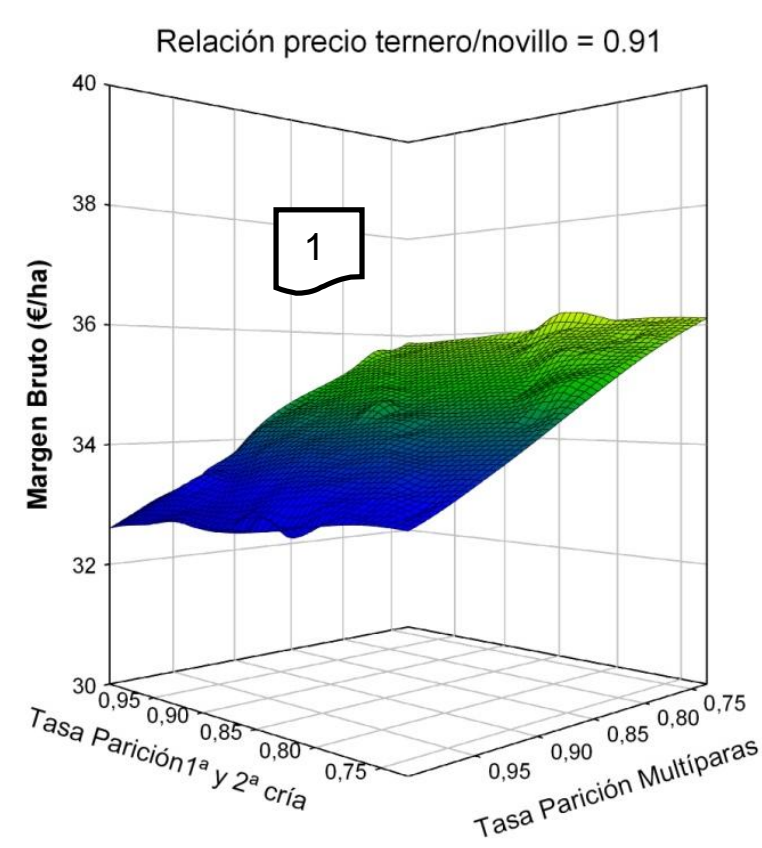

Relación precio ternero/novillo $=1.12$
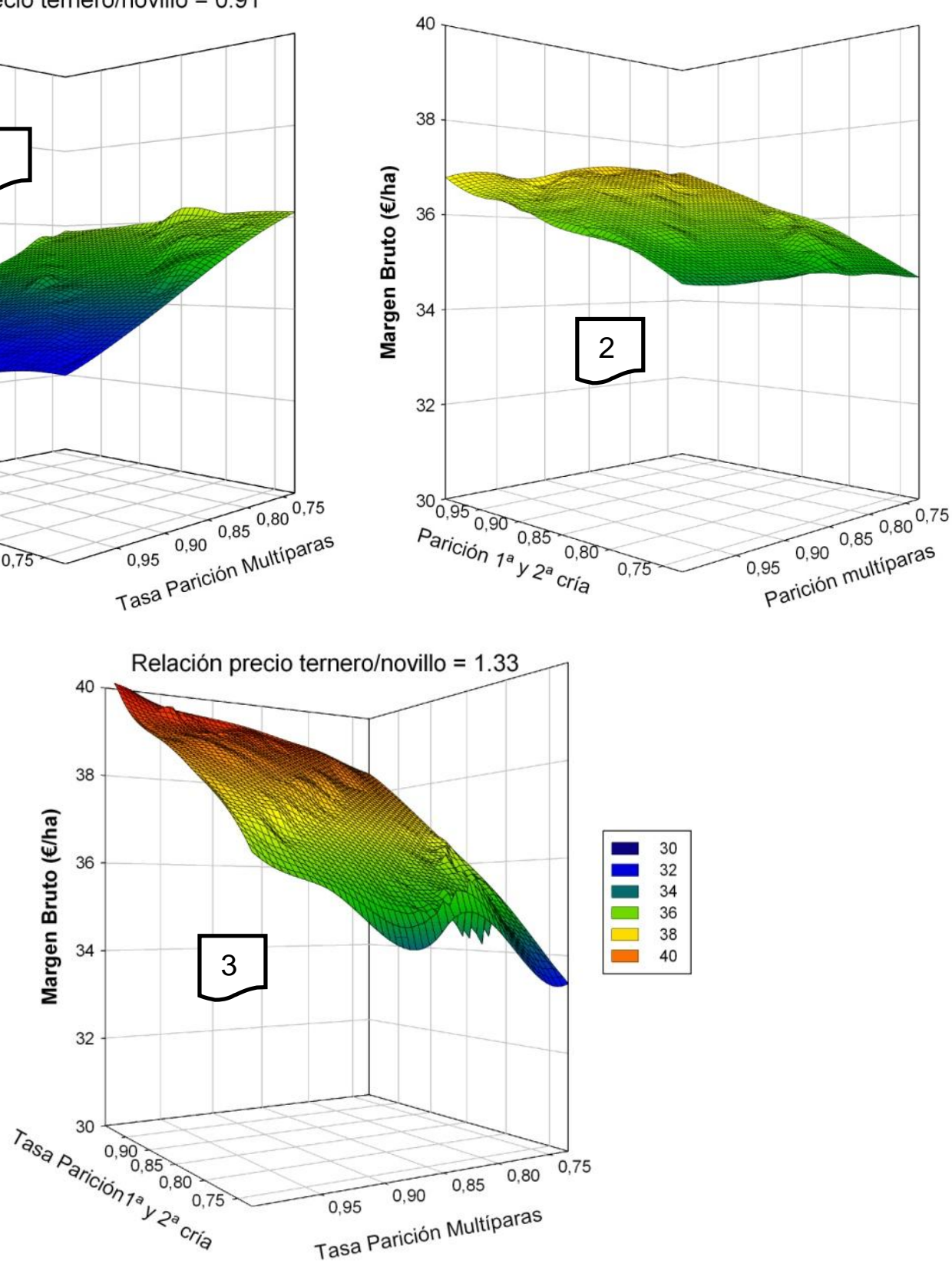

Figura 48. Relación entre la tasa de procreos de vacas jóvenes y multíparas sobre el margen bruto en diferentes escenarios de precios

Cuando la relación de precios favorece los procesos de cebo (1), resulta antieconómico producir terneros a través de las vacas multíparas, ya que es más rentable cebarlas, y generar la reposición con la progenie de las vacas de $1^{\underline{a}}$ y $2^{\underline{a}}$ cría. En esta categoría, también es preferible preñar el mínimo necesario de animales aunque la pendiente de esta relación (preñez/margen bruto) es casi nula en este escenario y para este grupo. A una relación de precios promedio de los últimos 7 años (2), el óptimo económico se 
obtiene maximizando la preñez de hembras jóvenes, mientras que en el caso de las hembras adultas este indicador prácticamente no afecta al resultado económico. Si los precios favorecen la producción de terneros (3), el óptimo económico se logra maximizando ambas tasas de procreo. De cualquier manera, observando los valores absolutos en los tres escenarios de precios, debe notarse que los mayores beneficios se obtienen cuando se logran altas tasas de procreo en escenarios de precio favorables (situación 3; 40€/ha), mientras que con bajos índices reproductivos, aunque los precios favorezcan la producción de carne, los ingresos no logran superar los $36 € /$ ha.

Es clave entonces, que no prevalezca la idea de que un aumento de la productividad expresada en el incremento del índice reproductivo, resulta antieconómico. De hecho esta situación se verifica sólo si se dan determinadas condiciones en forma conjunta:

a) Relación de precios. La relación de precios ternero/vaca gorda debe ser menor a cierto valor para que comparativamente resulte ventajoso vender una vaca fallada respecto a producir un ternero extra.

b) Sistemas de cría intensivos. Caracterizados por un alto costo de producción, lo que determina que en situaciones de precio desfavorables a la actividad de cría, el retorno de la inversión en pasturas sea más fácilmente viabilizado a través del cebo de hembras de descarte.

c) Edad al primer servicio. Cuando una vaca adulta es diagnosticada como vacía, se descarta del rebaño, por lo cual para mantener la estructura del mismo, es necesario retener una ternera para sustituir dicho animal eliminado. La eficiencia económico-productiva de este reemplazo está en gran medida determinada por el tiempo en el cual una ternera improductiva se transforme en una hembra en producción. En el caso de sistemas donde las novillas entran en servicio a los 14 meses, la alta eficiencia de este proceso (pasaje de ternera a vaca en producción) puede determinar la conveniencia de descartar un mayor porcentaje de vacas adultas, transformarlas rápidamente en producto comercializable (vaca gorda) en lugar de esperar un año para lograr un ternero, con el alto costo energético asociado a la gestación y lactancia involucrado. En contraposición, resulta evidente que si para obtener una hembra productora se necesitan tres años como en algunos sistemas extensivos, la ventaja comparativa de este reemplazo desaparece.

d) Descarte de novillas y vacas de segunda cubrición. Interactuando con la variable anterior se encuentra la política de reemplazo de novillas y vacas de segunda cubrición. En forma similar a la edad al primer servicio, el descarte de esas 
hembras que no se preñan, incrementa la eficiencia del sistema, lo cual asociado a una edad temprana de primera cubrición, determina la conveniencia de tener niveles de preñez no mayores a los requeridos para mantener la estructura del stock. De esta manera se descarta y vende un alto número de vacas adultas falladas, manteniendo en el establecimiento un rebaño joven donde todas las hembras existentes (excepto las terneras) se encuentran produciendo (gestando o lactando). Por el contrario, si no se descartan estos animales, ya no resulta tan eficiente reemplazar una vaca adulta por una ternera si ésta, en el caso de no quedar preñada en su primer y/o segunda cubrición, es mantenida sin producir en el rebaño de cría (figura 3 del anexo).

\subsubsection{Orientación productiva y grado de intensificación}

Un tema de debate constante en Uruguay es el estancamiento de la cría vacuna, cuyos indicadores, principalmente la tasa de destete no han experimentado una mejora sustancial en los últimos años (Pereira y Soca, 1999; Blasina, 2005; Caputi, 2005;). Las causas de este estancamiento suelen atribuirse a razones técnico-productivas básicamente asociadas al nivel nutricional de las vacas y a condiciones de mercado donde los precios no valorizan apropiadamente un proceso productivamente más costoso (Monje, 1987; Pigurina y Berreta, 2002; Ponsse, 2003, 2007). Éstas últimas condicionan a su vez la inversión en tecnología capaz de superar las limitaciones productivas existentes, por lo cual se genera un ciclo continuo.

En establecimientos donde existen los recursos forrajeros necesarios para realizar el cebo de los machos o al menos de una parte de ellos, es usual que se escoja esta opción antes de destinar esos recursos a mejorar la eficiencia del sistema de cría en aspectos como la nutrición de la vaca, el adelanto de la edad de cubrición, etc. A este respecto, existen diferentes opiniones en cuanto a si la especialización en la cría puede ser económicamente ventajosa, o si es preferible diversificar rubros y capitalizar la mayor eficiencia del cebo realizando el ciclo completo. En general se concluye que no es posible arribar a una conclusión definitiva, a menos que se restrinja el escenario, definiendo los precios, la escala productiva, los recursos disponibles, la eficiencia de producción de cada una de las opciones, la capacidad financiera de la empresa, etc., evaluando incluso la afinidad del productor a desarrollar una u otra actividad. 
A continuación se presentan resultados de simulaciones en donde se contrastan tres niveles de intensificación, asociados a la cantidad y calidad de la dieta ofrecida a los animales a lo largo del año:

CN (Campo Natural). La oferta de forraje proviene exclusivamente del campo natural durante todo el año, por lo cual la dotación promedio anual es de $0.7 \mathrm{UG} / \mathrm{ha}$

PAST (Pastura). Se incluye un área de pasturas artificiales, correspondiente a un $15 \%$ del área total, por lo cual la carga se eleva a $0.78 \mathrm{UG} / \mathrm{ha}$

PAST+G (Pastura+Grano). El área de praderas se eleva a $30 \%$ del área total y se incluye el aporte de grano en forma estratégica a determinadas categorías durante el invierno. La dotación se incrementa debido al incremento de pasturas hasta un valor de 0.85 y se asume que el aporte de grano permite aumentar la carga en 0.10 UG/ha. La dotación total es de $0.95 \mathrm{UG} / \mathrm{ha}$

Supuestos: establecimiento de 1000 ha; 8 estratos de edades en vacas; relación precios $\mathrm{kgTernero} / \mathrm{kgNovillo}$, actual (0.94); tasa de preñez: $\mathrm{CN}=0.70, \mathrm{PAST}=0.78, \mathrm{PAST}+\mathrm{G}=0.95$; edad a la $1^{\mathrm{er}}$ cubrición $=2$ años

Se comparan los niveles descritos (CN, PAST y PAST+G) sobre los resultados productivos y económicos de tres orientaciones productivas: a) sistema de cría (Cria) con venta de terneros machos y hembras al destete, b) Ciclo Completo (CiCo) con venta del terneras al destete y machos como novillos para faena y, c) Sistema de Cebo (Cebo), con compra de terneros, cebo y posterior venta de novillos a matadero.

En la Tabla 31 se presentan algunos indicadores productivos de las combinaciones entre los sistemas descritos: VC representa el número de vacas de cría en los sistemas de cría y ciclo completo o TC la cantidad de terneros comprados si el sistema es de Cebo. PPV ( $\mathrm{kg} / \mathrm{ha}$ ), indica la producción de peso vivo, es decir los kilos totales producidos por unidad de área cuando el sistema se estabiliza, con lo cual ya no es necesario computar diferencias de stock y todo lo producido es vendido. TE (\%), es la tasa de extracción, que se calcula dividiendo los $\mathrm{kg}$ producidos (vendidos, si el stock está estabilizado) por los $\mathrm{kg}$ en stock promedio del año y constituye un indicador de la eficiencia productiva del sistema. 
Tabla 31. Indicadores productivos resultantes de las combinaciones entre Orientación Productiva y Nivel de Intensificación

\begin{tabular}{l|rrr|rrr|rrr} 
& \multicolumn{3}{|c|}{ Cría } & \multicolumn{3}{c|}{ Ciclo Completo } & \multicolumn{3}{c}{ Cebo } \\
& CN & PAST & PAST+G & CN & PAST & PAST+G & CN & PAST PAST+G \\
\hline VC/TC & 566 & 549 & 589 & 314 & 408 & 470 & 239 & 462 & 760 \\
PPV (kg/ha) & 80 & 95 & 120 & 80 & 114 & 149 & 79 & 150 & 243 \\
TE (\%) & 29 & 31 & 32 & 29 & 37 & 39 & 28 & 48 & 64 \\
$\begin{array}{l}\text { Edad venta } \\
\text { novillos (meses) }\end{array}$ & - & - & - & 47 & 26 & 20 & 46 & 33 & 27 \\
\hline
\end{tabular}

Como se observa en la Tabla 31, el ciclo completo y especialmente la cría se muestran menos sensibles al grado de intensificación respecto al cebo, tanto en niveles de productividad como de eficiencia (medido a través de la tasa de extracción). Esto es coincidente con otros autores, quienes atribuyen esta menor eficiencia al proceso de producción de terneros, donde el pasto es transformado en leche por la madre, para luego ser transformado en carne por el ternero, con la consiguiente pérdida energética en cada etapa del proceso (Monje, 1987; Pigurina y Berreta, 2002).

En el otro extremo, el cebo es capaz de capitalizar en toda su magnitud el incremento en el aporte de insumos. En forma casi lineal, el aporte de mejoramientos y luego la complementación del cebo con granos, permite aumentar en forma sostenida los indicadores, triplicar la cantidad de animales comprados y la producción por hectárea, alcanzando tasas de extracción muy elevadas.

Abarcando ambos procesos (cría y cebo), el CiCo se encuentra en una situación intermedia, tanto en producción como en eficiencia.

Al plantear estos resultados a nivel de país, resulta evidente que aunque la eficiencia productiva y económica del cebo sea superior a la de la cría, la primera no puede subsistir sin la segunda. Desde este punto de vista es esperable que en una situación de libre mercado, el incremento en la tasa de extracción de novillos determinado por el aumento en la velocidad de cebo y la disminución de la edad de faena que se verifica actualmente, determine un incremento en la demanda de terneros con la consecuente alza en los precios de esta categoría, estímulo que permitirá rentabilizar la actividad haciendo más atractivo el negocio. 
Respecto a la componente económica, en la Figura 49 se observan los resultados obtenidos respecto al margen bruto y al ingreso por ventas de las diferentes categorías.

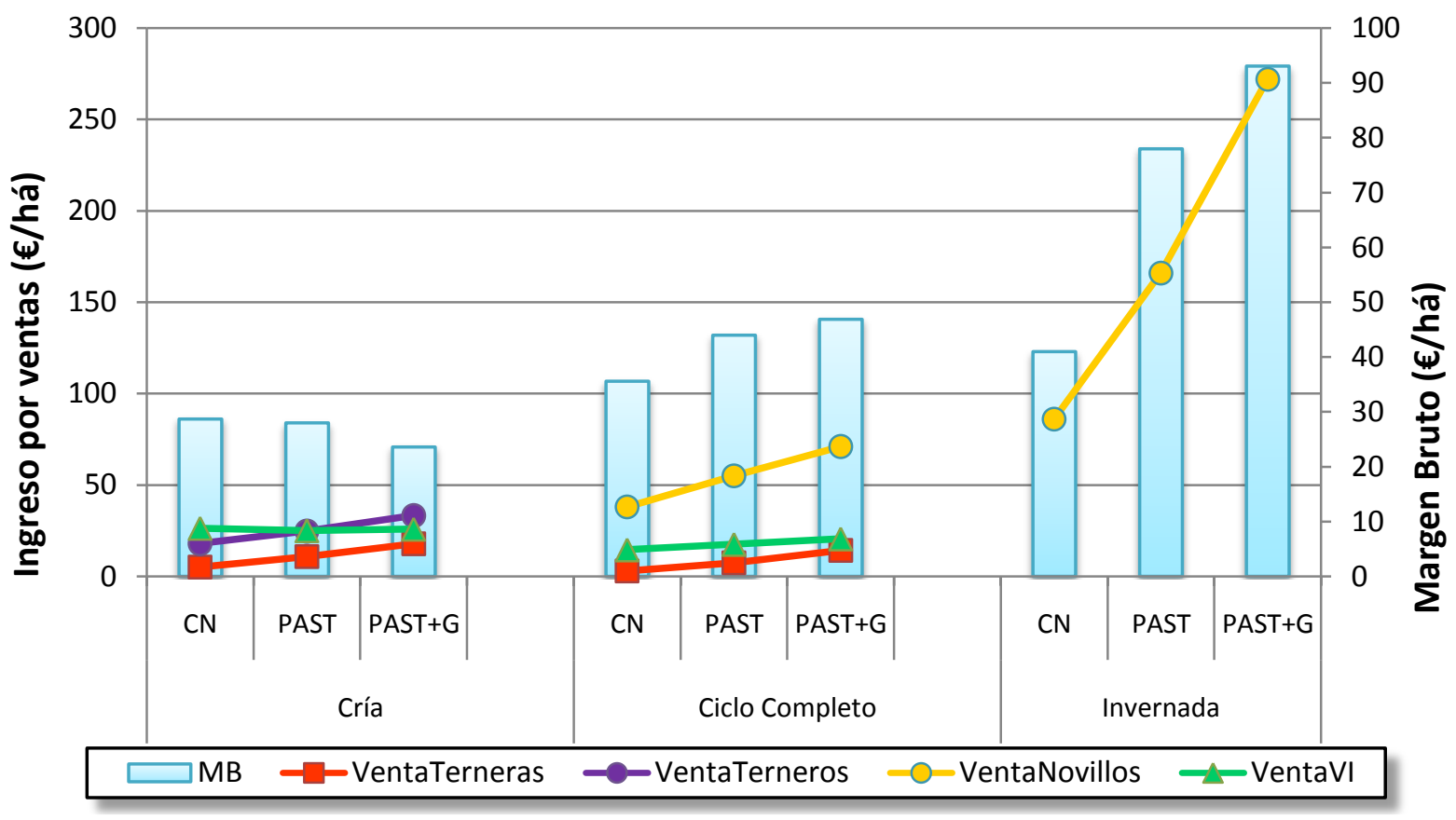

Figura 49. Margen bruto (MB) e ingreso por ventas de cada categoría según orientación productiva y nivel de intensificación

Para los supuestos considerados (especialmente la relación de precios), el incremento productivo asociado a la intensificación en la cría, no determina un incremento sustancial en el ingreso, aunque mejora la preñez y determina un aumento importante en la carga del sistema, en coincidencia con los reportes de numerosos autores (Taylor et al., 1985; Bourdon y Brinks, 1987b,1987c). En una situación intermedia, el MB en el CiCo se incrementa con el aporte de pasturas, como consecuencia de una mayor productividad a través del cebo de novillos. El sistema de cebo ve elevada notoriamente su productividad, respondiendo en forma sostenida al aporte creciente de insumos. La incorporación de grano en la dieta, actualmente con altos precios, determina un incremento de costes compensados en un sistema de muy alta productividad como lo es el de cebo y en menor medida, en el ciclo completo.

En el caso de la cría, puede considerarse una sobre simplificación asumir que al intensificarse el sistema de producción, solamente se incrementa el porcentaje de parición. La edad a la primera cubrición debería descender al existir mayor aporte de forraje en cantidad y calidad. Por esta razón, se realizó otra simulación asumiendo que en el CN se 
cubre a los tres años de edad, en PAST a los dos años y en PAST+G, las hembras entran en servicio a los 14 meses. En la Tabla 32 se presenta el efecto de esta variable asociada a la mayor tasa de preñez.

Tabla 32. Indicadores reproductivos, producción de peso vivo, extracción y margen bruto obtenido con 2 relaciones de precios, de un sistema de cría difiriendo en el grado de intensividad.

\begin{tabular}{|c|c|c|c|c|}
\hline & \multicolumn{3}{|c|}{ Nivel de Intensificación } \\
\hline & & $\mathrm{CN}$ & PAST & PAST+G \\
\hline \multicolumn{2}{|c|}{ \% preñez del rebaño } & 70 & 80 & 90 \\
\hline \multicolumn{2}{|c|}{ Edad $1^{\text {er }}$ cubrición } & 3 años & 2 años & 14 meses \\
\hline \multicolumn{2}{|c|}{ Total VC } & 472 & $549(+16 \%)$ & $649(+38 \%)$ \\
\hline \multicolumn{2}{|c|}{ Prod. peso vivo (kg/ha) } & 68 & $95(+40 \%)$ & $136(+100 \%)$ \\
\hline \multicolumn{2}{|c|}{ Extracción (\%) } & 24 & $31(+29 \%)$ & $36(+50 \%)$ \\
\hline \multirow{2}{*}{$\begin{array}{l}\text { Margen } \\
\text { Bruto } \\
(€ / \text { ha) }\end{array}$} & $\begin{array}{l}\text { Relación precios } \\
\text { ternero/novillo } 0.94 \text { (actual) }\end{array}$ & 23 & $28(+22 \%)$ & $32(+39 \%)$ \\
\hline & $\begin{array}{l}\text { Relación precios } \\
\text { ternero/novillo } 1.2\end{array}$ & 23 & $29(+26 \%)$ & $35(+52 \%)$ \\
\hline
\end{tabular}

La intensificación en la cría determina un aumento muy importante en la productividad, en gran medida explicado por la reducción en la edad de cubrición, variable que permite incrementar notoriamente el número de vacas de cría que el sistema puede soportar. En efecto, la eliminación de las dos categorías de novillas en proceso de crecimiento (novillas 1-2 años y +2 años), desde la situación de primera cubrición a los tres años hasta la situación de cubrición con 14 meses, posibilita incrementar el total de vacas de cría en casi un $40 \%$, con un aumento en la productividad del sistema del $100 \%$. Dependiendo de las relaciones de precios existentes, este aumento en producción es acompañado (en grado variable) por un incremento en el margen bruto del sistema.

La intensificación del sistema también determina un cambio radical en la edad de los novillos que se destinan a la venta (Figura 50). En el CiCo, el sistema mas extensivo (CN) faena una mayor proporción de animales de +4 años, mientras en el nivel de mayor intensificación sólo el 15\% de los novillos vendidos son mayores a 2 años (Tabla 31).

El sistema de cebo muestra una tendencia similar, aunque en el nivel PAST+G la proporción de novillos de más edad es mayor, debido a que los terneros que se compran 
tienen menor peso que los producidos en el $\mathrm{CiCo}^{6}$, lo que retrasa el tiempo de cebo. La ausencia de animales de cría con su reposición determina la posibilidad de contar con un número de animales mucho mayor que en el CiCo.

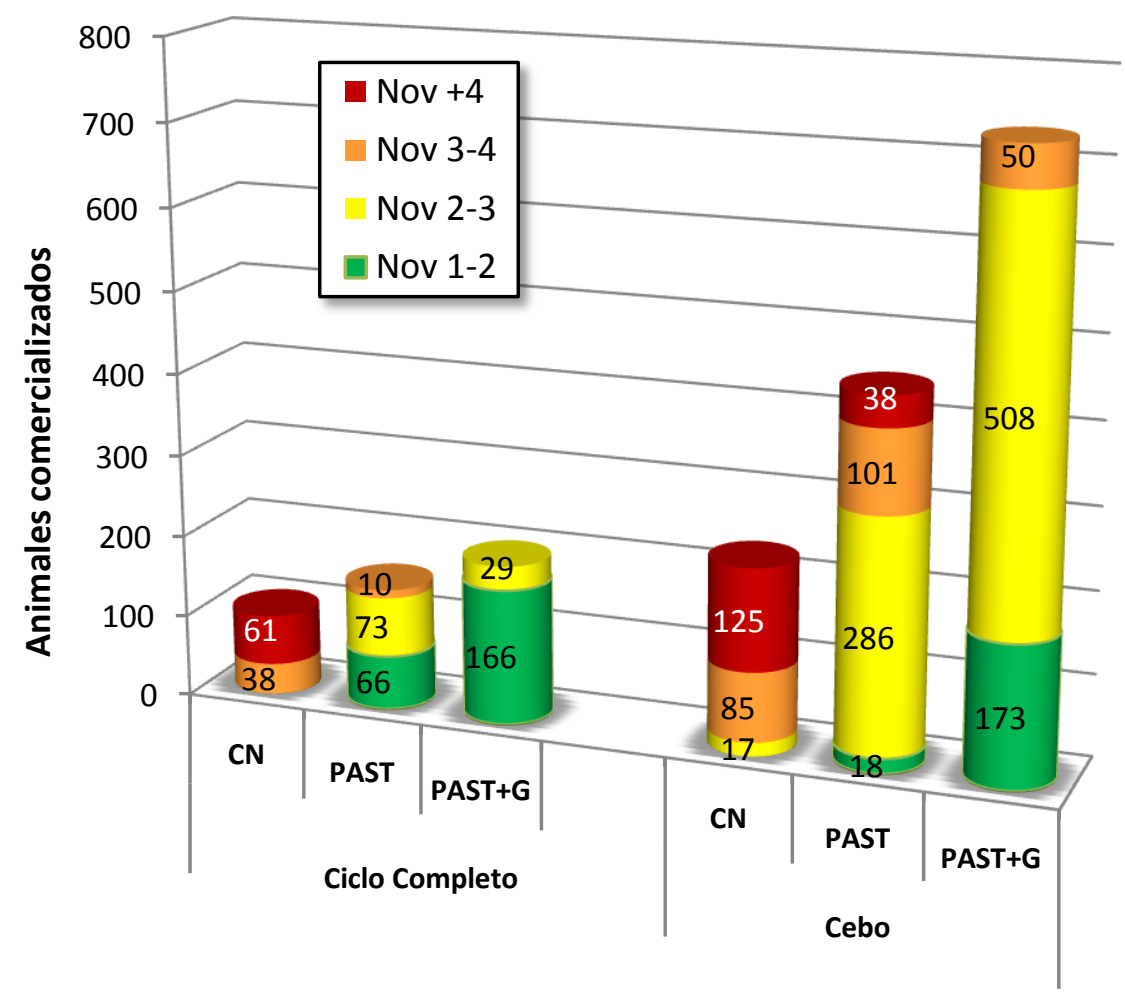

Figura 50. Composición de edades de novillos vendidos según sistema

Beretta, et al. (2002) reportan resultados similares cuando analizan mediante un modelo determinístico la eficiencia y productividad de sistemas de cebo del sur de Brasil con diferentes niveles de intensificación del proceso. Cuando los animales son faenados con 18 meses de edad, se logra una productividad de $343 \mathrm{Kg} / \mathrm{ha}$ y una extracción de $88.5 \%$. El sistema que determina la faena a los 30 meses, logra una producción de $155 \mathrm{~kg} / \mathrm{ha}$ y una extracción de $53.9 \%$ y el cebo extensivo con venta a los 42 meses produce $84 \mathrm{~kg} / \mathrm{ha}$ con una extracción de 33.9\%.

\footnotetext{
${ }^{6}$ Los sistemas de cría que producen terneros para venta, suelen ser ambientes relativamente restrictivos desde el punto de vista nutricional, por lo cual es esperable que los terneros volcados al mercado tengan un peso menor que los producidos en sistemas más intensivos para cebo propio.
} 


\subsubsection{Categoría a comprar en sistemas de cebo}

Como ha sido comentado en diferentes secciones de este trabajo, los animales más jóvenes presentan una mayor eficiencia en la utilización de la energía consumida, lo que determina un mayor crecimiento relativo. Con el objetivo de analizar posibles variaciones en la eficiencia biológica y el retorno económico de un establecimiento de cebo, se realiza una simulación donde se contrastan tres opciones de compra: terneros, novillos de 1 a 2 años y novillos de 2 a 3 años.

Para ello se asume que, independientemente de la edad de compra, los animales siguen la curva de crecimiento descrita por la ecuación [2.2] del capítulo $V$ de este trabajo, considerando que los animales a comprar se encuentran en una condición corporal inferior a la de la curva "normal", es decir que dicha curva no discurre por el centro de la escala $(R C=1)$, sino por una valor de condición relativa de 0.70 . Se asume que los animales se compran en 2 momentos del año (abril y julio).

Los resultados evidencian una mayor producción física ( $P P V, \mathrm{Kg}$ peso vivo/hectárea), una mayor tasa de extracción (TE, \%) y un mayor retorno económico expresado como margen bruto $(M B, € / h a)$ en los sistemas que realizan compras de animales más jóvenes (Tabla 33).

Tabla 33. Productividad física y económica de sistemas de cebo con animales comprados a diferentes edades

\begin{tabular}{|c|c|c|c|c|c|c|}
\hline & \multicolumn{3}{|c|}{ Compra } & \multicolumn{3}{|c|}{ Resultados } \\
\hline Categoría & $\begin{array}{l}\text { Mes de } \\
\text { compra }\end{array}$ & $\begin{array}{c}\text { Edad } \\
\text { (meses) }\end{array}$ & $\begin{array}{l}\text { Peso vivo } \\
(\mathrm{kg})\end{array}$ & $\begin{array}{c}P P V \\
(\mathrm{~kg} / \mathrm{ha})\end{array}$ & $\begin{array}{l}T E \\
(\%)\end{array}$ & $\begin{array}{c}M B \\
(€ / \text { ha })\end{array}$ \\
\hline Terneros & $\begin{array}{l}\text { Abril } \\
\text { Julio }\end{array}$ & $\begin{array}{l}6 \\
9\end{array}$ & $\begin{array}{l}140 \\
163\end{array}$ & 243 & 64 & 93 \\
\hline $\begin{array}{c}\text { Novillos } 1 \text { a } 2 \\
\text { años }\end{array}$ & $\begin{array}{l}\text { Abril } \\
\text { Julio }\end{array}$ & $\begin{array}{l}18 \\
21\end{array}$ & $\begin{array}{l}260 \\
280\end{array}$ & 192 & 51 & 82 \\
\hline $\begin{array}{c}\text { Novillos } 2 \text { a } 3 \\
\text { años }\end{array}$ & $\begin{array}{l}\text { Abril } \\
\text { Julio }\end{array}$ & $\begin{array}{l}30 \\
33\end{array}$ & $\begin{array}{l}320 \\
330\end{array}$ & 169 & 43 & 77 \\
\hline
\end{tabular}

El cebo de animales más jóvenes estuvo caracterizado por una mayor eficiencia expresada como:

a) la proporción de energía metabolizable destinada a mantenimiento respecto a la energía total consumida $\left(\mathrm{EM}_{\mathrm{m}} / \mathrm{CTE}, \%\right)$ 
b) los $\mathrm{kg}$ de forraje consumidos para producir $1 \mathrm{~kg}$ de peso vivo (kgMS/kgPV, $\mathrm{kg}$ )

c) la energía necesaria para producir un $1 \mathrm{~kg}$ de peso vivo (EM/kgPV, kg)

Los resultados se presentan en la Figura 51.

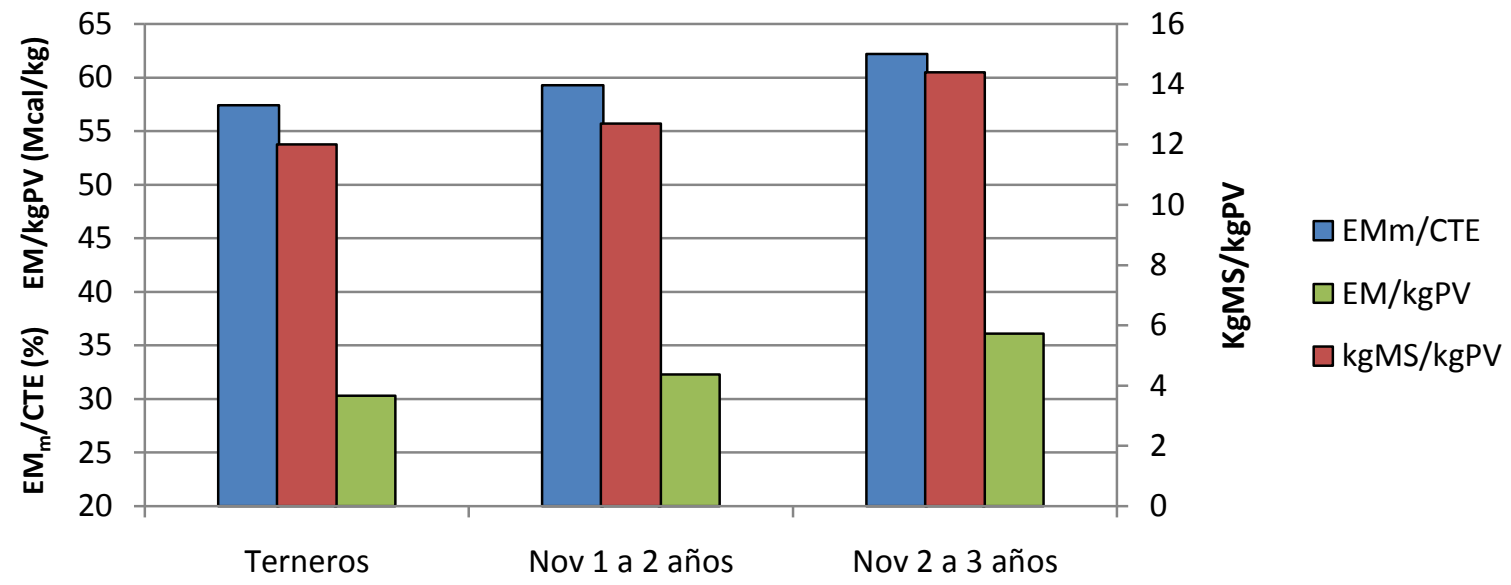

Figura 51. Indicadores de eficiencia biológica en los sistemas contrastados

Estos resultados son coincidentes con los obtenidos por Beretta, et al. (2002), en tanto que Cundiff et al. $(1981,1984)$ y Gregory et al. (1994) obtienen menores valores de EM por unidad de peso, posiblemente por tratarse de cebo en confinamiento con dietas de alta energía. Se debe considerar que estos indicadores están referidos al sistema en forma global, es decir que aunque se compren terneros, las ventas se realizan como novillos por lo cual la eficiencia de todo el sistema decrece en el proceso. La eficiencia de conversión de forraje en producto a distintas edades manejada en este modelo, puede observarse en la Figura 52. En la misma se presentan los $\mathrm{kg}$ de materia seca de forraje necesarios para posibilitar una ganancia de peso vivo de $500 \mathrm{gr} / \mathrm{día}$, asumiendo que no hay restricciones en cuanto a disponibilidad y calidad del forraje. 


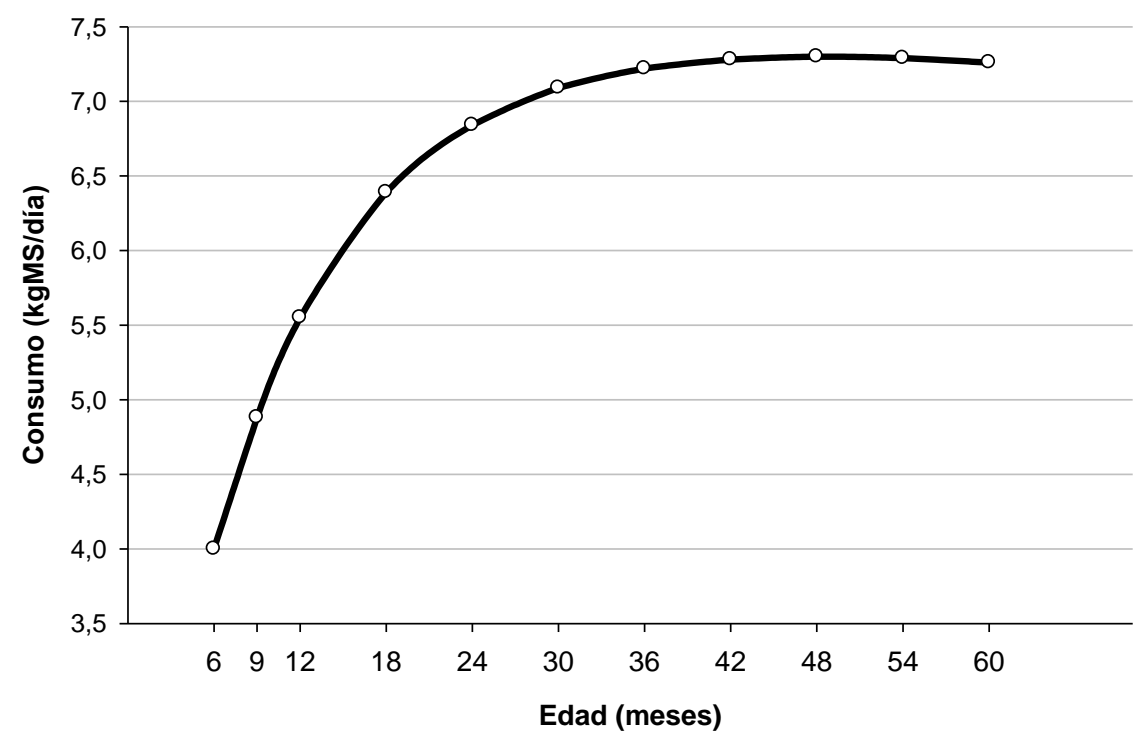

Figura 52. Eficiencia de conversión de forraje en peso vivo, expresada como Kg MS de forraje necesarios para lograr una ganancia diaria de 500 grs. de peso vivo

Del análisis de la figura se desprende que es posible tener 1.83 terneros de 6 meses ganando 500 gr. diarios cada uno con el mismo consumo total que realiza un animal de 4 años de edad a igual ganancia diaria.

\subsection{7. $\underline{\text { Relaciones de precios }}$}

Los precios de los productos agrícolas en Uruguay son altamente dependientes de las fluctuaciones del mercado internacional, así como también de las condiciones de oferta y demanda del mercado interno. Este también es el caso de la ganadería, donde los precios internos dependen de las señales de los mercados, fundamentalmente los de exportación, reflejándose en la capacidad de las empresas del sector agroindustrial nacional de colocar su producción en dichos mercados. El coeficiente de variación de los precios del ganado es del orden del 8-12\% (Helguera y Lanfranco, 2006). Si se considera que la producción de $1 \mathrm{~kg}$ de ternero es biológica/energéticamente más costosa que la producción de $1 \mathrm{~kg}$ de novillo gordo, sería lógico esperar que el valor de mercado del ternero acompañara esa tendencia con precios para el ternero sustancialmente superiores. En Uruguay, la relación de precios ternero/novillo en los últimos años fue levemente favorable al precio del ternero (promedio 1.12), determinando que el cebo sea una opción relativamente más atractiva. Más allá del valor promedio de este indicador, los precios no están regulados a nivel estatal como en otros países, por lo cual sufren importantes oscilaciones tanto dentro del año como entre 
años, asociadas a condiciones de mercado (nacional e internacional), situación climática, oferta de animales, expectativas a futuro, etc. (Figura 34).

Como se mencionó en la sección anterior, estas relaciones tienen un efecto directo en el caso de productores de cebo, donde el beneficio económico se encuentra directamente vinculado (en forma inversa) a esta relación. Esto se observa en la Figura 53, para el caso de un sistema de cebo sobre campo natural.

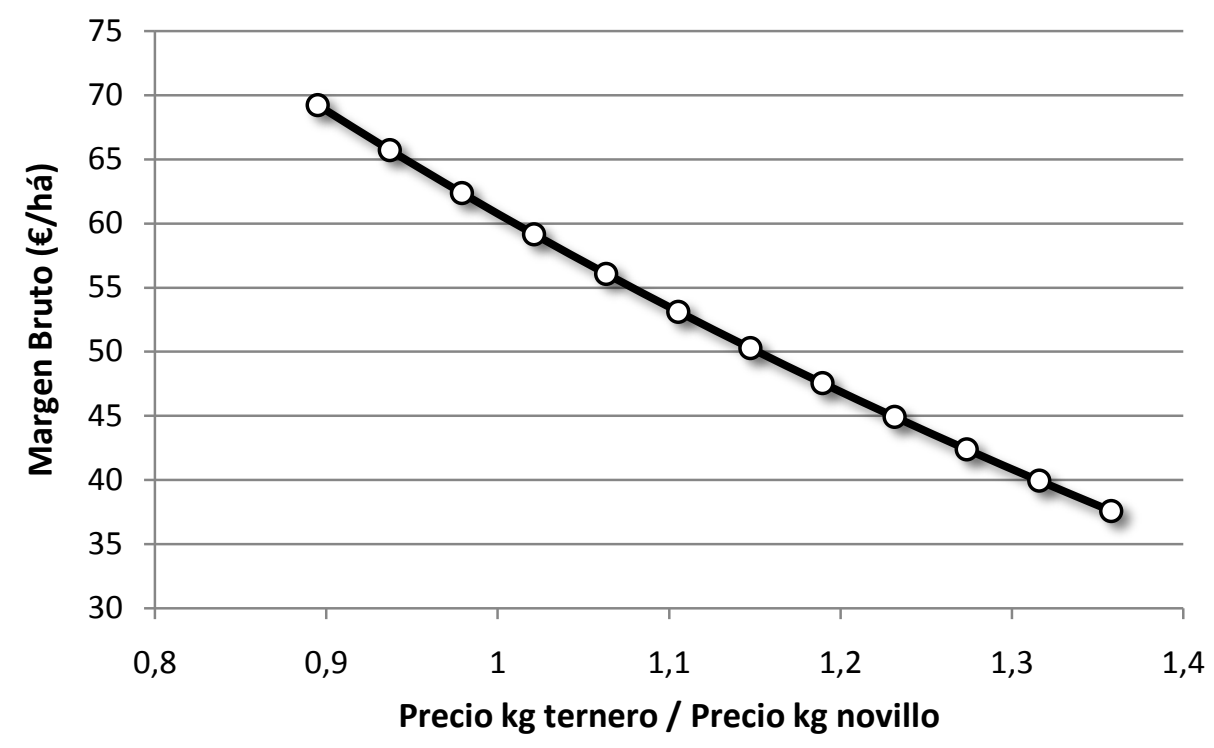

Figura 53. Efecto de la relación de precios de compra (ternero) y venta (novillo) sobre el margen bruto de un establecimiento de cebo

En lo que respecta a la cría, como se ha visto, la relación entre el margen bruto y las relaciones de precios no es tan directa. Se debe recordar que si bien en esta orientación productiva la principal fuente de ingresos es la venta de terneros, la venta de vacas de descarte representa un ingreso económico de alta incidencia en la economía de la empresa, por lo cual la relación de precios ternero/vaca gorda, reviste gran importancia como determinante del ingreso. Aunque el efecto de las relaciones de precios asociadas a la tasas de preñez, ya ha sido incluido en análisis anteriores, en la Figura 54 se presentan algunos resultados de simulaciones enfocados desde otra perspectiva.

Supuestos: establecimiento de 1000 ha; nivel intensificación = CN; 8 estratos de edades en vacas; edad a 1 er cubrición $=50 \%$ a los 2 años, $50 \%$ a los 3 años. 


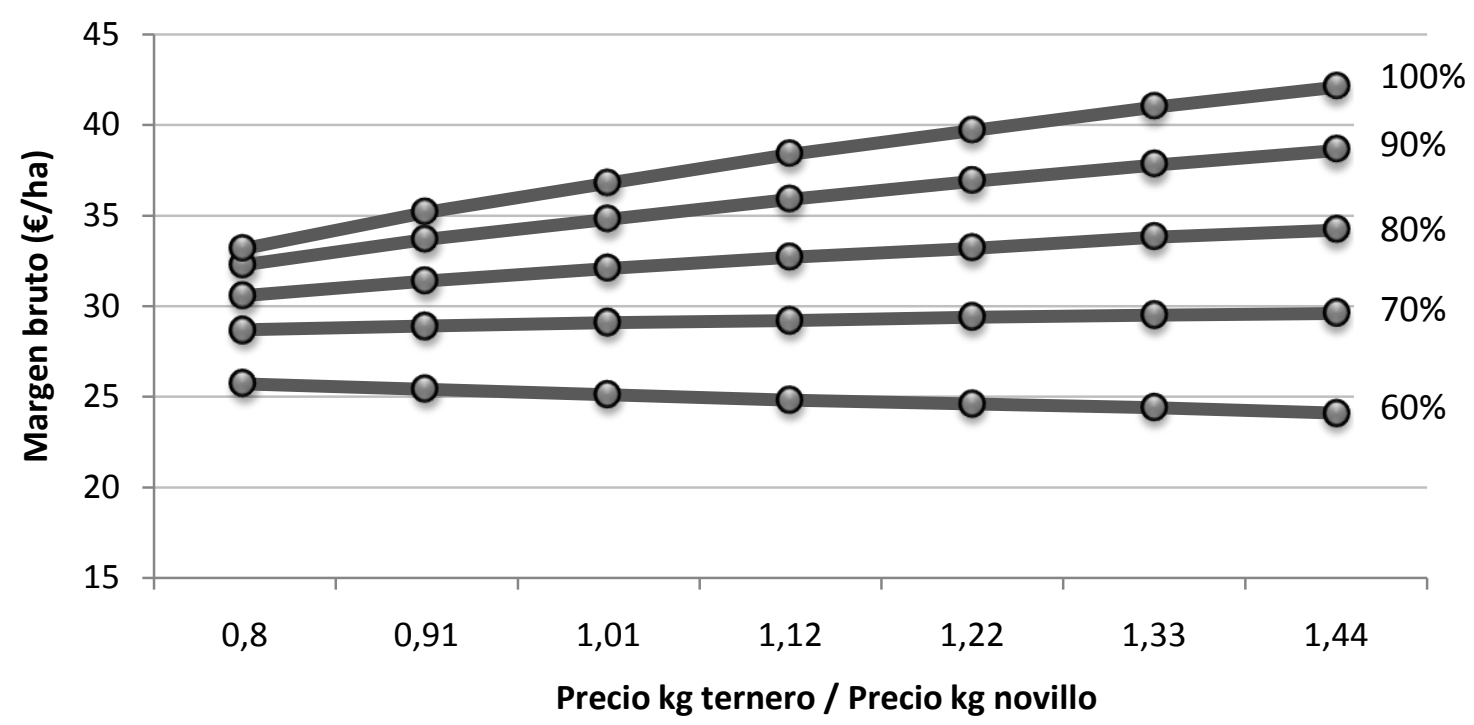

Figura 54. Margen bruto de un sistema extensivo de cría en función de relaciones de precios Ternero/Novillo y niveles de preñez

En un escenario de altas relaciones de precios (favorables al ternero), el incremento en los índices reproductivos determina importantes diferencias en el margen bruto obtenido. Por el contrario, bajas relaciones de precios ternero/vaca no permiten capitalizar significativamente un superior desempeño reproductivo. En este escenario, el sistema de $60 \%$ de preñez es capaz de compensar la baja productividad con el ingreso por concepto de vacas de descarte, las cuales se comercializan a un alto precio relativo. Así, hasta aproximadamente un $66 \%$ de procreos, una alta relación de precios es desfavorable, ya que el aporte importante a la productividad del sistema lo hace la venta de vacas de descarte gordas. A partir de este $66 \%$ de parición, valor de indiferencia a la relación de precios, el mayor aporte productivo lo realizan los $\mathrm{kg}$ de terneros destetados por lo cual el incremento en la relación de precios beneficia el retorno económico. Analizando el gráfico desde otra perspectiva, un sistema ineficiente desde el punto de vista reproductivo no es capaz de capitalizar situaciones ventajosas, como en este caso una relación de precio favorable. Efectivamente, con $66 \%$ de preñez, la respuesta a este factor de precios es nula, mientras que en un sistema de alta eficiencia reproductiva como el que logra un 100\% de preñez, entre la situación más desfavorable y la más favorable el sistema es capaz de incrementar su margen bruto en un $27 \%$ (33 a $42 € / h a)$.

En el escenario planteado, vale la pena destacar que aún en situaciones de precios muy desfavorables a la cría como la representada por la relación de precios de 0.8 , el incremento de la tasa reproductiva determina un aumento del margen bruto obtenido. Por 
otra parte, esta relación de precios corresponde a un valor de -3 desvíos respecto a la media, siendo altamente improbable su existencia en situaciones normales.

Como se ha mencionado en varias instancias, los indicadores de destete vacuno en Uruguay se sitúan en el orden del 64\% desde hace muchos años (DIEA, 2007; Peyrou e Ilundain, 2006), por lo cual una situación productiva con $60 \%$ de preñez, representa una situación relativamente común en años de situaciones climáticas adversas (sequías, exceso de heladas), principalmente en las zonas marginales desde el punto de vista de producción de forraje. En la Figura 55 se analizan las causas que determinan esta reducción en el margen bruto asociado al incremento de la relación de precios para una situación de cría extensiva con $60 \%$ de preñez en el rebaño.

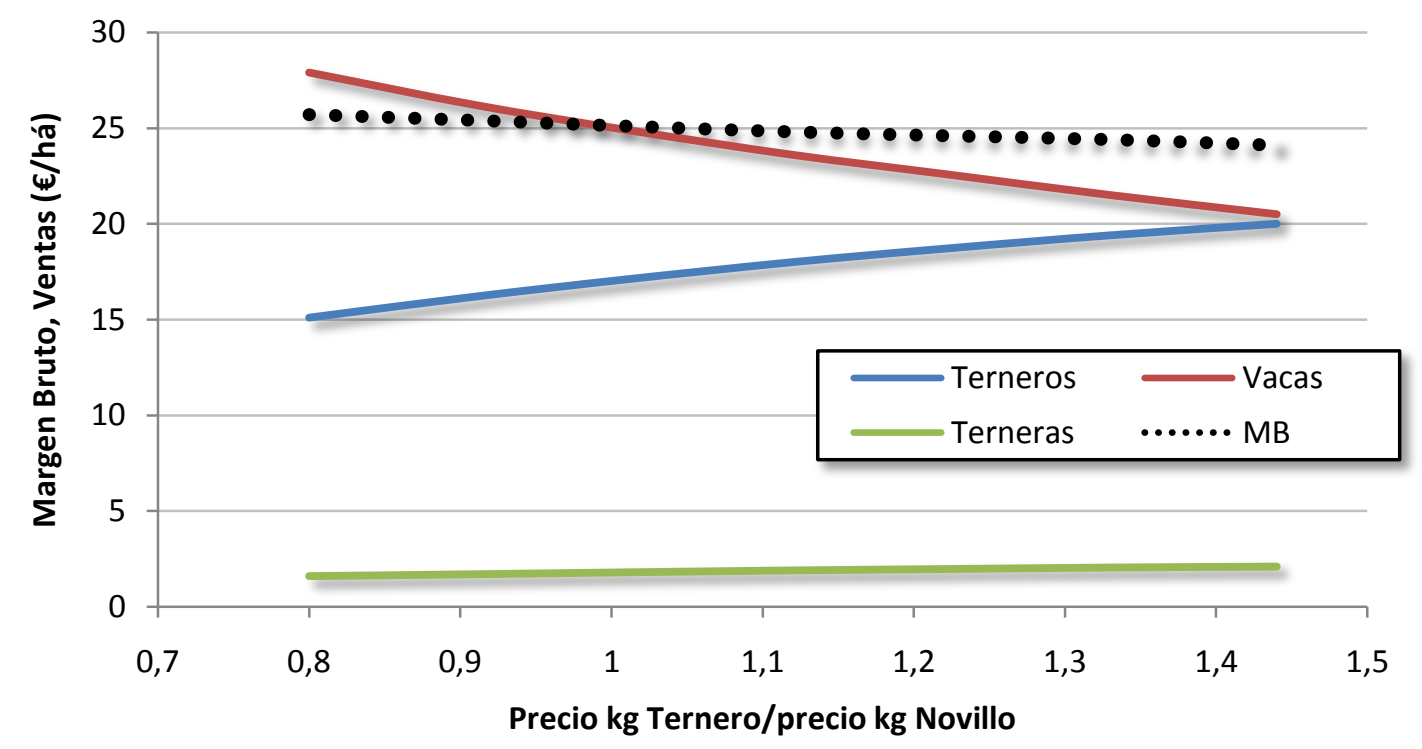

Figura 55. Ingreso por ventas de distintas categorías y margen bruto, en función de relaciones de precios Ternero/Novillo, para una siituación de preñez $=60 \%$

En este escenario reproductivo deficiente, un incremento en la relación de precios ternero/novillo determina un aumento en el ingreso por ventas de terneros, pero no es capaz de compensar la disminución que se verifica en el ingreso por venta de vacas gordas, las cuales representan un volumen muy importante asociado a las tasas de descarte (1- tasa preñez), también muy elevadas.

En el caso de un sistema de ciclo completo, ya ha sido comentado el mayor peso económico que representa el rubro cebo respecto al componente cría (Figura 49). Por esta razón, estos sistemas productivos se ven favorecidos cuando la relación de precios referida es baja, o lo que es lo mismo, el valor del novillo es comparativamente mayor. En lo que 
respecta al nivel de intensificación (Figura 56), sistemas más extensivos ( $C M$ ) presentan comparativamente un menor peso del cebo, actividad que como se ha comentado, es capaz de capitalizar el mayor aporte de insumos al sistema. Por esta razón los sistemas extensivos son menos sensibles a las relaciones de precios.

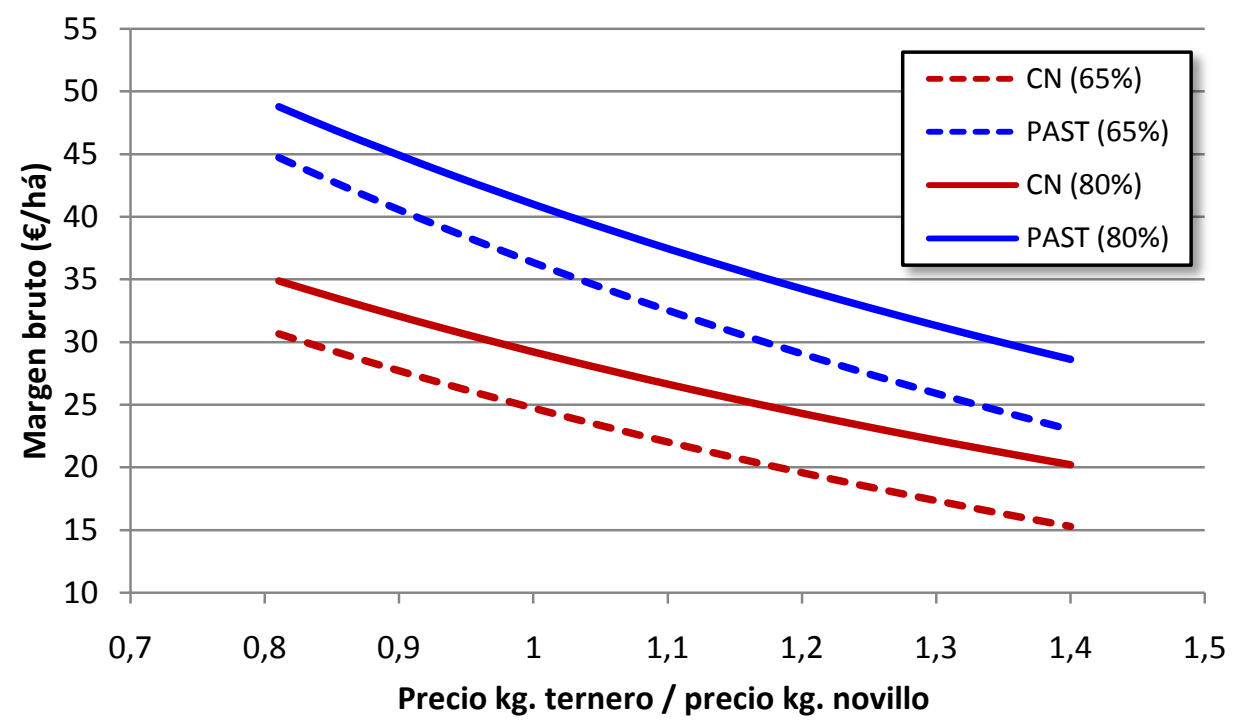

Figura 56. Efecto de la relación de precios ternero/novillo sobre el margen bruto en sistemas de ciclo completo con dos niveles de intensificación y dos niveles reproductivos.

En el nivel más intensivo (PAST), un mayor volumen de producción de novillos gordos determina un efecto mayor del precio relativo sobre el ingreso y en consecuencia, sobre el margen bruto.

\subsection{Importancia relativa de las variables analizadas sobre el sistema}

Para lograr una visión conjunta de las variables analizadas y su grado de asociación con la productividad y el retorno económico de los sistemas, se presenta un análisis de componentes principales, efectuado sobre los resultados de 1000 simulaciones realizadas para cada orientación productiva (cría, ciclo completo) y nivel de intensificación (extensivo, intensivo) tal y como fueran definidos en el ítem 6.2.1.2 de este capítulo. Las variables incluidas fueron la edad a la $1^{\text {era }}$ cubrición (EdadCubr), el número de estratos de edad de vacas de cría (estratos), la tasa de parición de vacas multíparas (ParMulti), la tasa de parición de vacas de $1^{\text {era }}$ y $2^{\text {da }}$ cubrición (Par1y2) y la relación de precios ternero/novillo (Rel_T/N). Como variables resultado se presentan el margen bruto (MB), la producción de 
peso vivo por hectárea (PPV), el ingreso por venta de vacas gordas (VtaVG), el ingreso por venta de terneros (VtaTerneros) y terneras (VtaTerneras) y el total de vacas de cría soportadas por el sistema (Total_VC). Complementariamente, en cada gráfico se incluyen las variables que presentan un mayor coeficiente de correlación de Pearson con el margen bruto y su valor.

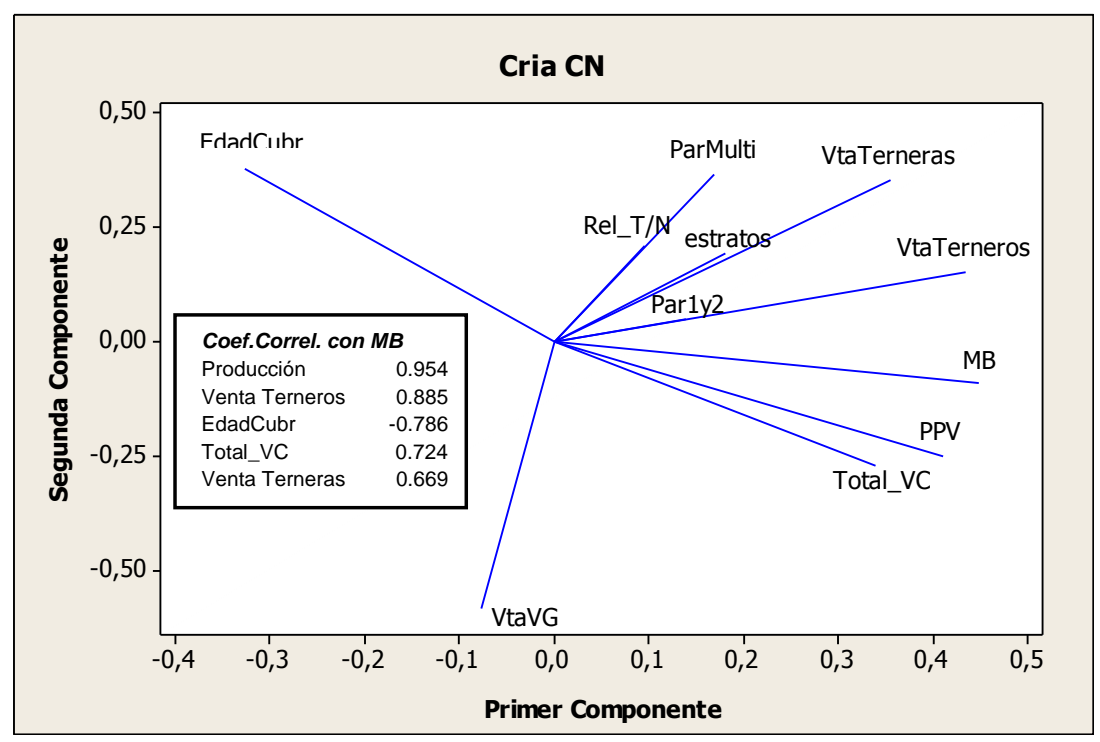

Figura 57. Análisis de componentes principales. Representación de las principales variables asociadas al resultado económico-productivo de sistemas de cría extensiva

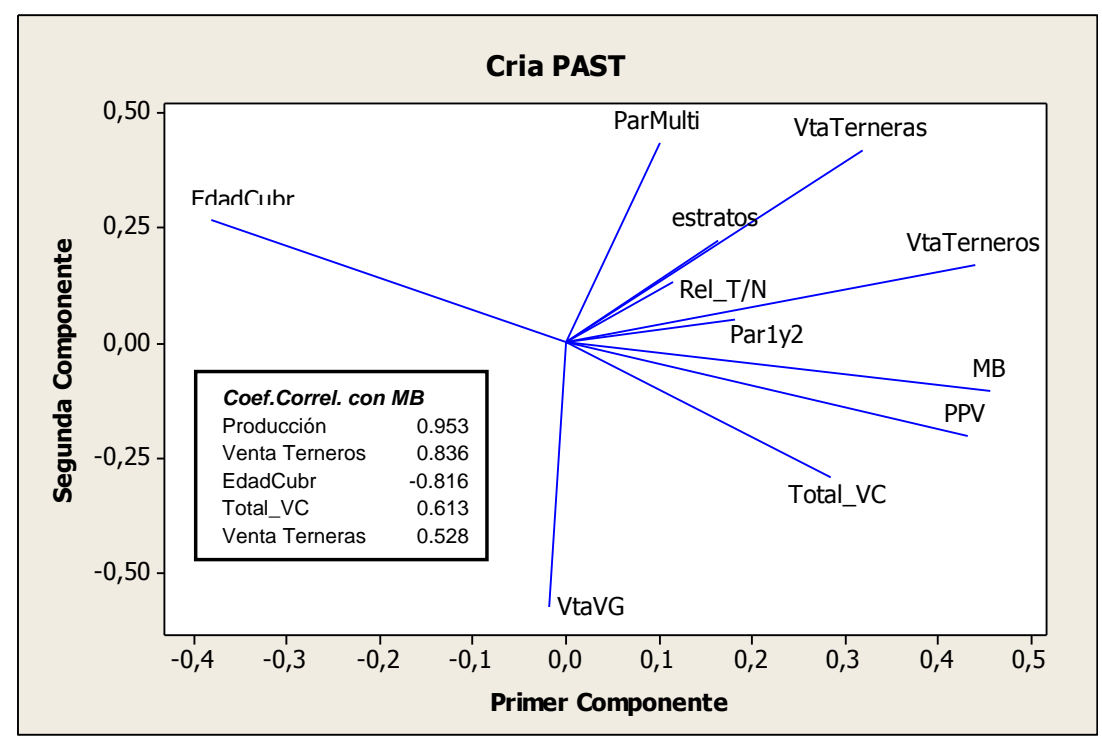

Figura 58. Análisis de componentes principales. Representación de las principales variables asociadas al resultado económico-productivo de sistemas de cría intensiva 
Tanto en el gráfico como en el coeficiente de correlación se pone de manifiesto la estrecha asociación entre la producción (PPV) y el margen bruto logrado (MB) para ambos sistemas de cría, mientras que la relación precio ternero/precio novillo (Rel_T/N) tiene un efecto comparativamente menor aunque igualmente positivo. El margen bruto logrado está fuertemente explicado por el ingreso proveniente de la venta de terneros y en menor medida de terneras. El ingreso por venta de vacas gordas (VtaVG) tiene poco aporte al MB en ambos sistemas, seguramente porque las relaciones de precios analizadas (0.91-1.33; $\bar{x}=1.12$ ) favorecen la producción de terneros frente a la de animales cebados.

La edad de cubrición tiene una incidencia muy alta y negativa en ambos sistemas, lo cual es consistente con lo visto anteriormente, siendo una variable que independientemente de que el escenario favorezca la producción de terneros o vacas gordas, incide a través de la eficiencia del sistema en su conjunto. Dicha variable afecta directamente el número de vacas de cría totales (Total_VC) soportadas por el sistema productivo, la cual a su vez presenta una estrecha vinculación tanto con la productividad (PPV) como con el margen bruto.

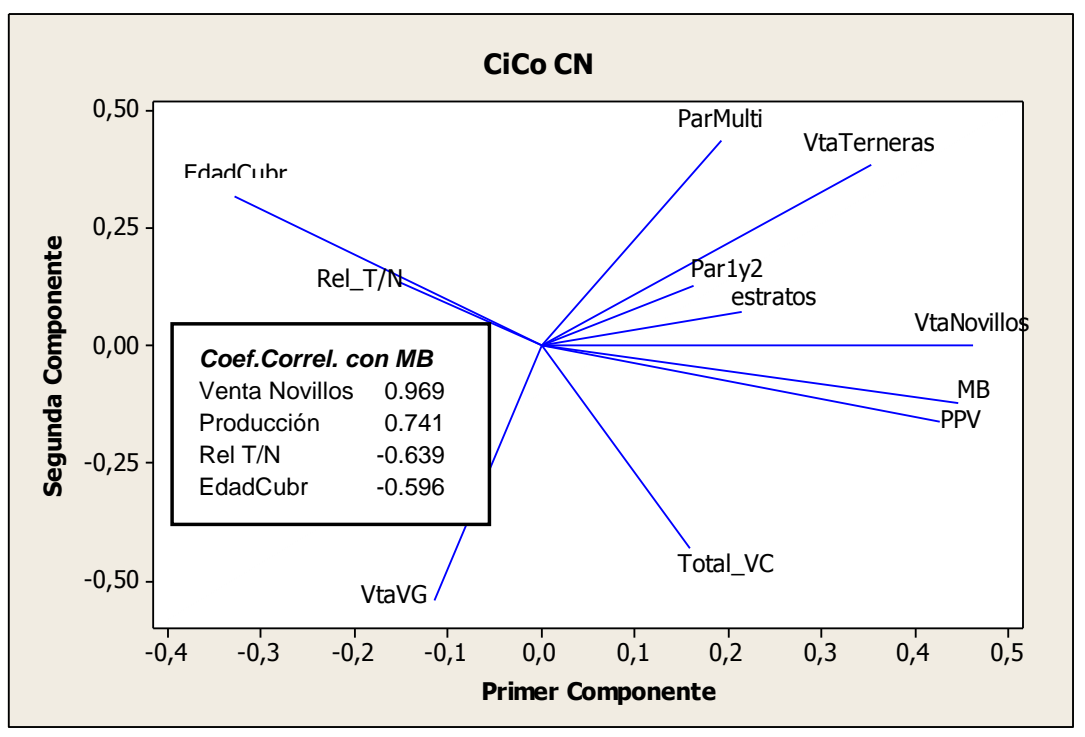

Figura 59. Análisis de componentes principales. Representación de las principales variables asociadas al resultado económico-productivo de sistemas de ciclo completo extensivo 


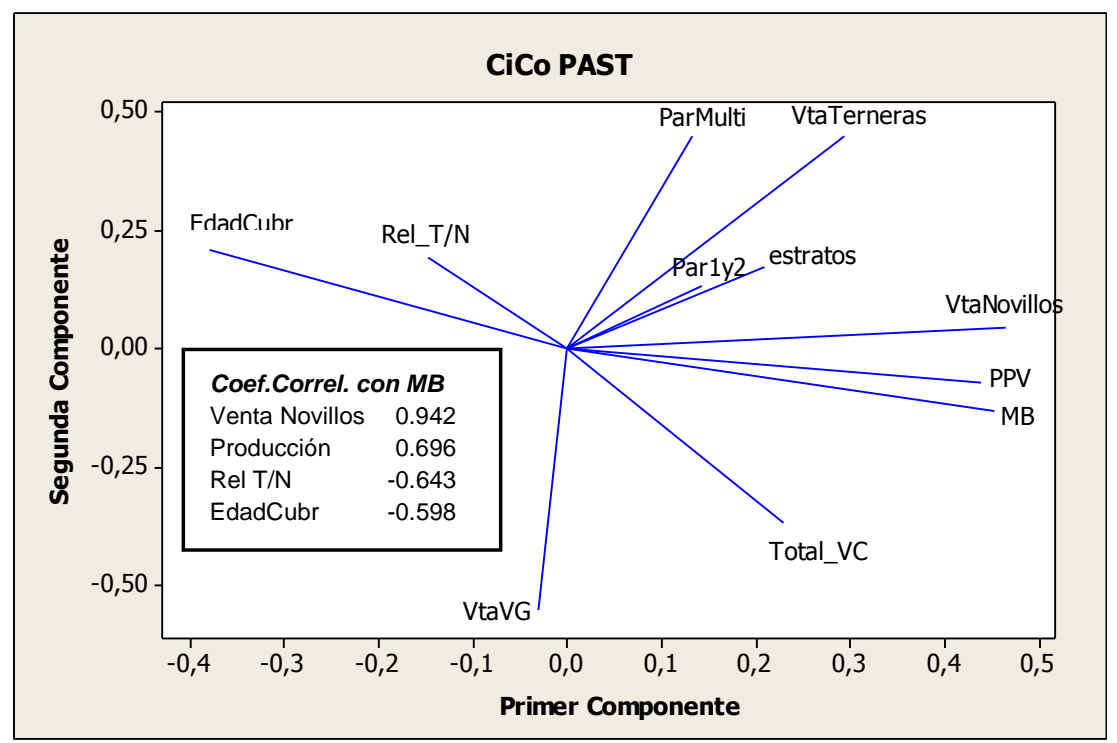

Figura 60. Análisis de componentes principales. Representación de las principales variables asociadas al resultado económico-productivo de sistemas de ciclo completo intensiva

En los sistemas de ciclo completo, el margen bruto se encuentra comparativamente menos asociado a la productividad y más a las relaciones de precios.

En ambos niveles de intensificación, el resultado económico (MB) se encuentra definido netamente por el ingreso proveniente de la venta de novillos, con valores de correlación de 0.969 para el sistema extensivo y 0.942 para el intensivo. A su vez este ingreso por ventas depende de una componente productiva (correlaciones VtaNovillos-PPV de 0.702 y 0.673 para CiCoCN y CiCoPAST respectivamente) y de la relación de precios (correlaciones VtaNovillos-Rel_T/N de -0.584 y -0.559 para CiCoCN y CiCoPAST respectivamente).

La edad de cubrición determina, nuevamente, buena parte de la variación en el margen bruto, tanto en el sistema extensivo (-0.596) como intensivo (-0.598), definiendo la capacidad de carga productiva (Total_VC) que condiciona, a su vez, el potencial de producción de terneros y por ende de novillos a ser cebados. 


\subsection{Valor económico de caracteres genéticamente mejorables}

En la Tabla 34 se presentan los resultados generados con el modelo en lo que respecta a aquellas características con incidencia económica en los sistemas productivos definidos en el ítem 5.11. La simulación se realiza en un establecimiento de 1000 ha, donde se aplica un incremento de $1 \%$ en la característica, expresándose el resultado en variación de margen bruto $(€)$.

Tabla 34. Ponderación económica de características relevantes para los sistemas definidos expresado en variación de MB (€) para un establecimiento de 1000 ha.

\begin{tabular}{|c|c|c|c|c|c|}
\hline Rasgo & Variables evaluadas & CRIAEXT & CRIAINT & CCEXT & CCINT \\
\hline \multirow{5}{*}{ Crecimiento } & Tasa de ganancia de peso machos ${ }^{a}$ & 149 & 232 & 283 & 338 \\
\hline & Tasa de ganancia de peso hembras ${ }^{a}$ & 134 & 147 & 66 & 103 \\
\hline & Peso adulto machos & 92 & 133 & 290 & 163 \\
\hline & Peso adulto hembras & 243 & 178 & -157 & -18 \\
\hline & Producción de leche & 98 & 12 & -7 & -38 \\
\hline Consumo & Consumo & 328 & 239 & 340 & 106 \\
\hline \multirow{5}{*}{ Reproducción } & Tasa parición novillas & 152 & 42 & 47 & 65 \\
\hline & Tasa parición vacas 1aㅗ cría & 85 & 82 & 53 & 77 \\
\hline & Tasa parición vacas +2 crías & 165 & -26 & 127 & 66 \\
\hline & Tasa parición global & 356 & 97 & 226 & 205 \\
\hline & Dificultad al parto & -14 & -1 & -16 & -2 \\
\hline \multirow{2}{*}{$\begin{array}{l}\text { Rendimiento } \\
\text { Carnicero }\end{array}$} & Rendimiento res & 224 & 242 & 517 & 813 \\
\hline & AOB en novillos & - & - & 39 & 63 \\
\hline
\end{tabular}

${ }^{a}$ Estimada como el incremento de la tasa de ganancia que permite lograr $+1 \%$ de peso vivo al destete

Todos los cálculos fueron realizados a carga fija, la cual es ajustada luego de cada iteración del modelo.

En primera instancia se debe aclarar que esta simulación es una primera aproximación a la estimación de los valores económicos definitivos. Los valores de la tabla son los resultados obtenidos al incrementar en $1 \%$ cada característica, lo cual si bien es un indicativo del potencial efecto de las variables, no permite comparar con precisión entre ellas. Un resultado más concluyente requiere la expresión de la variación económica en unidades de desvío estándar genético (Ponzoni, 1992), lo cual es una forma de expresar el impacto económico en función de las posibilidades potenciales de mejoramiento genético. La aproximación realizada en este trabajo, permite analizar la importancia relativa de los caracteres en los distintos escenarios productivos.

De la Tabla 34 se destaca la importancia de la tasa de preñez, lo cual coincide con numerosos autores (Phocas et al., 1998; Urioste et al., 1998; Kluyts et al., 2003; Jorge et al., 
2006) quienes los mayores pesos económicos a características asociadas con fertilidad, tasa de preñez, parición y/o tasa de destete.

Observando la Tabla 34 se evidencia que al pasar de una situación de bajos procreos y cubrición a los 2.5 años, a otra de mayor preñez y cubrición temprana, el incremento de preñez en vacas de más de 2 crías resulta en un valor económico negativo. Debe recordarse que en este escenario las hembras de $1^{\underline{a}}$ y $2^{\underline{a}}$ cría no se descartan por falladas por lo cual resulta más rentable mantener una hembra en producción (preñada) que improductiva. Por el contrario, una vaca adulta que no se preña es vendida como vaca gorda, y en un escenario donde la reposición de hembras no es un problema $(85 \%$ de preñez en $1^{\text {a }}$ y $2^{a}$ cría, cubrición a 1.5 años, 8 estratos de vacas), superar determinado índice de procreo en las vacas adultas no es económicamente rentable.

Si bien se ha constatado la importancia de la tasa de procreos, se debe tener presente la complejidad del efecto de este rasgo sobre el valor económico en los diferentes escenarios, como se ha comprobado en los múltiples ejercicios de simulación efectuados en lo que respecta a la interacción de la preñez con las políticas de descarte de vacas adultas y jóvenes, la edad de cubrición, estratos de edades, relaciones de precios ternero/vaca y orientaciones productivas. Todas ellas han demostrado afectar sustancialmente a la magnitud y la vía a través de la cual la tasa reproductiva afecta al ingreso económico, por lo cual se recomienda un exhaustivo análisis y una delimitación precisa de la situación productiva antes de efectuar recomendaciones al respecto. A priori, resulta difícil pensar en la estimación de un valor económico único para este carácter, en virtud de la variabilidad de resultados encontrados.

En la Tabla 34 se observa que la tasa de preñez sí determina un beneficio en el sistema intensivo de ciclo completo, donde los terneros se convierten en novillos cuyo valor es sustancialmente superior al que se obtiene por un ternero. Esto refuerza el concepto de que en los sistemas de cría de Uruguay, una porción muy importante del ingreso es obtenido con la venta de vacas de descarte, especialmente en sistemas de bajos porcentajes de procreo (Figura 55, Figura 61), donde el ingreso por venta de vacas tiene un peso en ocasiones mayor que el obtenido por la venta de terneros. A su vez esto es consistente con el alto impacto económico observado para el rendimiento carnicero en los sistemas de cría. 


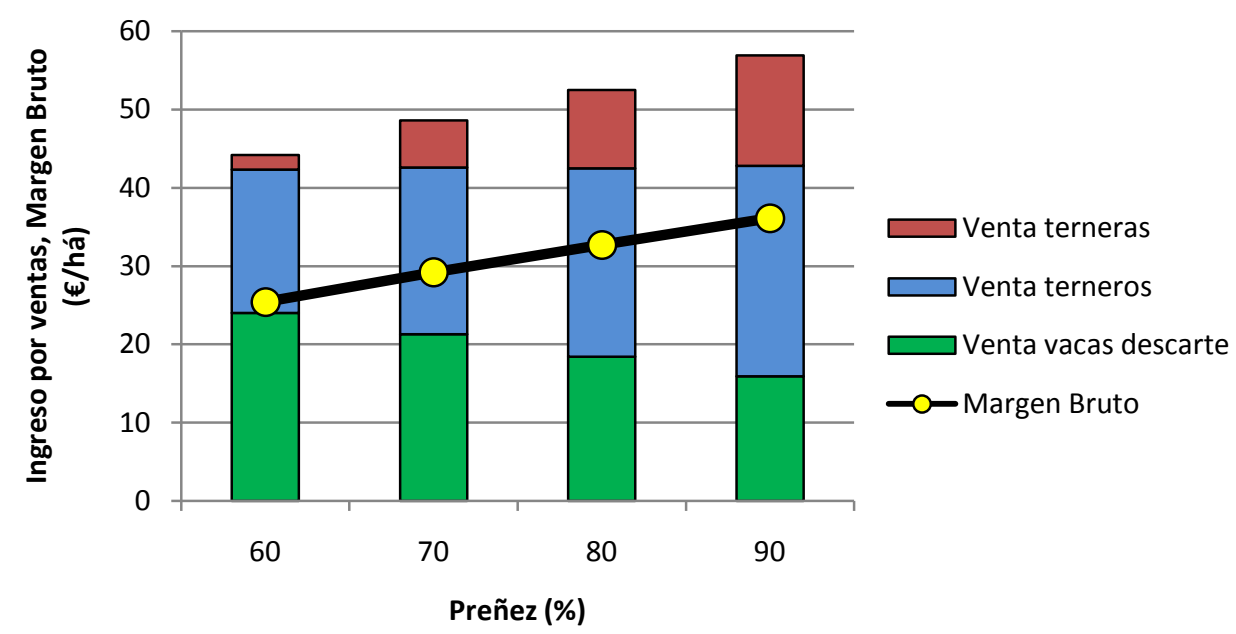

Figura 61. Ingresos por ventas de las diferentes categorías y margen bruto en un sistema extensivo de cría con diferentes niveles de preñez

En la Tabla 34 no se presenta el valor económico de la característica peso al nacer, el cual requiere de una consideración especial. Es esperable que esta característica demuestre una variación no lineal, puesto que su incremento puede ser beneficioso para el crecimiento posterior del ternero, pero perjudicial en el caso de novillas por su incidencia en problemas al parto asociados al tamaño del ternero.

En la Figura 62 se presenta el margen bruto asociado a la variación del peso al nacer en un sistema de cría y un sistema de ciclo completo.

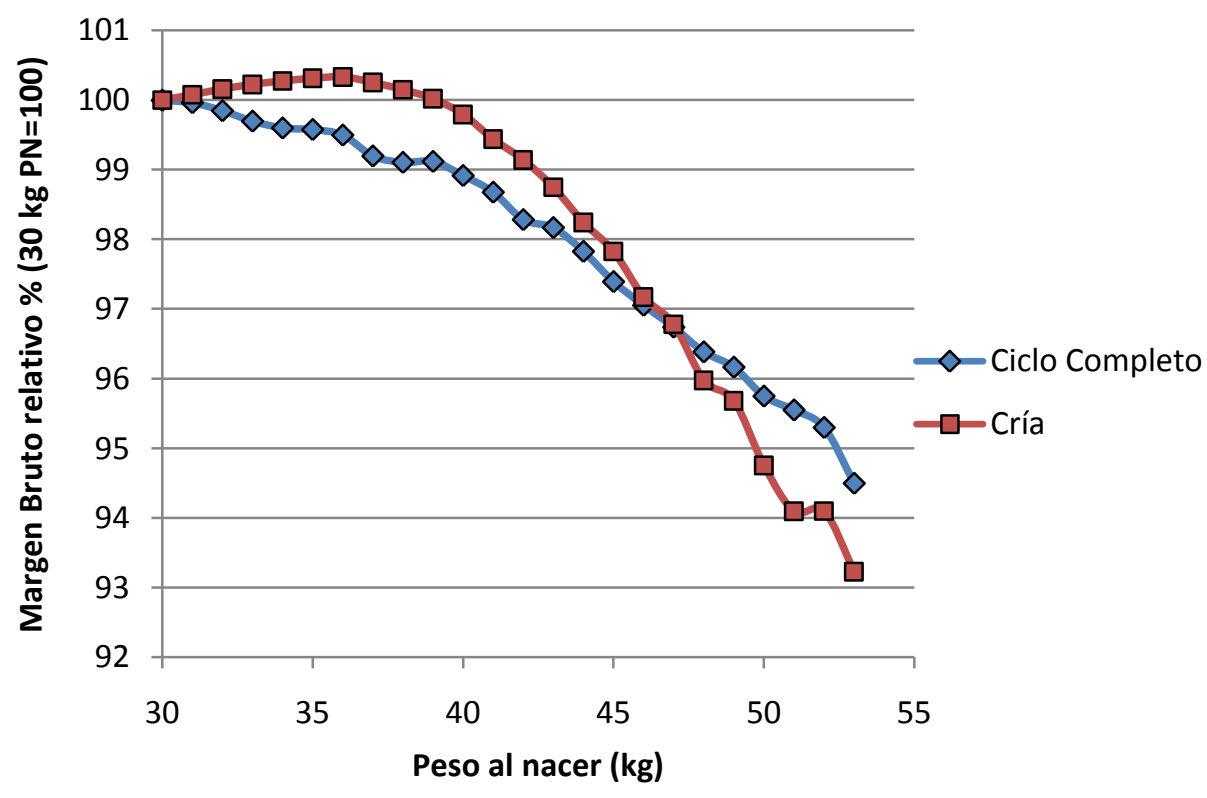

Figura 62. Efecto del peso al nacer sobre el margen bruto relativo en sistemas de cría y ciclo completo 
Como se observa en la Figura 62, en el sistema de cría el incremento del peso al nacer a bajos niveles tiene un efecto positivo, mientras que luego de los $36 \mathrm{~kg}$, comienza a tener un beneficio marginal negativo. Es de suponer que en un sistema donde los terneros se venden al destete con 130-160 kg PV, el peso al nacimiento aún pueda determinar en parte este peso de venta, por lo cual mientras no se compromete seriamente la proporción de novillas con problemas al parto, su incremento es beneficioso. Resultados coincidentes reportan Burfening et al. (1978) y Spitzer et al. (1995) (Tabla 6). En el caso del ciclo completo, el peso de venta de los animales a los 3-4 años de edad no es prácticamente afectado por el peso al nacer, lo cual coincide con los resultados de Spitzer et al. (1995), quienes lo atribuyen al crecimiento cpompensatorio.

Las variables de crecimiento tienen mayor impacto en los sistemas de ciclo completo, donde los procesos de crecimiento y cebo permiten aprovechar la potencialidad de esta mejora. Se destaca el efecto negativo del peso adulto en hembras en los sistemas de ciclo completo, donde proporcionalmente el peso de venta de las vacas afecta menos el resultado global de la empresa. En el caso de las vacas, la relevancia del cebo de las vacas de descarte en los sistemas de cría asociado a los bajos costos del forraje proveniente del campo nativo, determina un valor económico positivo del peso adulto. En este aspecto, los resultados coinciden con los reportados por Jorge et al. (2006) trabajando en condiciones extensivas similares.

Un resultado aparentemente contradictorio se observa en el valor económico del peso adulto de machos, el cual es más alto en CCEXT respecto a CCINT. Al observar en detalle el origen de este efecto, se observa una reducción considerable en la edad de faena en CCEXT, donde la mayoría de los animales se venden inicialmente entre 3 y 4 y +4 años. Este efecto influye menos sobre CCINT, donde las ventas se realizan en animales muy jóvenes, por lo cual el incremento del peso adulto, si bien acelera el proceso de cebo, no modifica en forma importante la estructura de edades de novillos ni la carga global del sistema.

En lo que respecta a la producción de leche de las vacas, los valores negativos que se verifican en los sistemas de ciclo completo estarían dando la pauta de que los altos niveles de alimentación en CCINT y/o el mayor tiempo necesario para el cebo de un novillo respecto a un ternero, no permite que el elevado gasto energético de las madres asociado a un mayor consumo, sea compensado por el mayor peso de los terneros. La producción de leche es un proceso energéticamente costoso, si se tiene en cuenta que una vaca de cría requiere de 4500 Mcal EM para mantenimiento, 300 para gestación y 1200 para lactancia (Di Marco, 2007). Se debe tener presente que las ecuaciones desarrolladas por CSIRO 
incluidas en el modelo, tienen en cuenta el crecimiento compensatorio (véase consumo potencial, sección 4.5.2.2).

\subsection{Análisis de sensibilidad}

\subsubsection{Sensibilidad a variables analizadas en el modelo}

La sensibilidad del margen bruto a la variación en los principales efectos analizados, se ha determinado mediante análisis de regresión de los datos de salida de las simulaciones. Se presentan los coeficientes $b$ (pendiente) estandarizados para cada variable, los cuales miden el grado de respuesta del margen bruto a la modificación de la variable independiente. Específicamente, este valor $b$ indica que por cada fracción $k$ que se incrementa la variable de entrada, el margen bruto se modificará en bk desvíos estándar. De esta manera es posible comparar entre variables que tienen diferentes unidades.

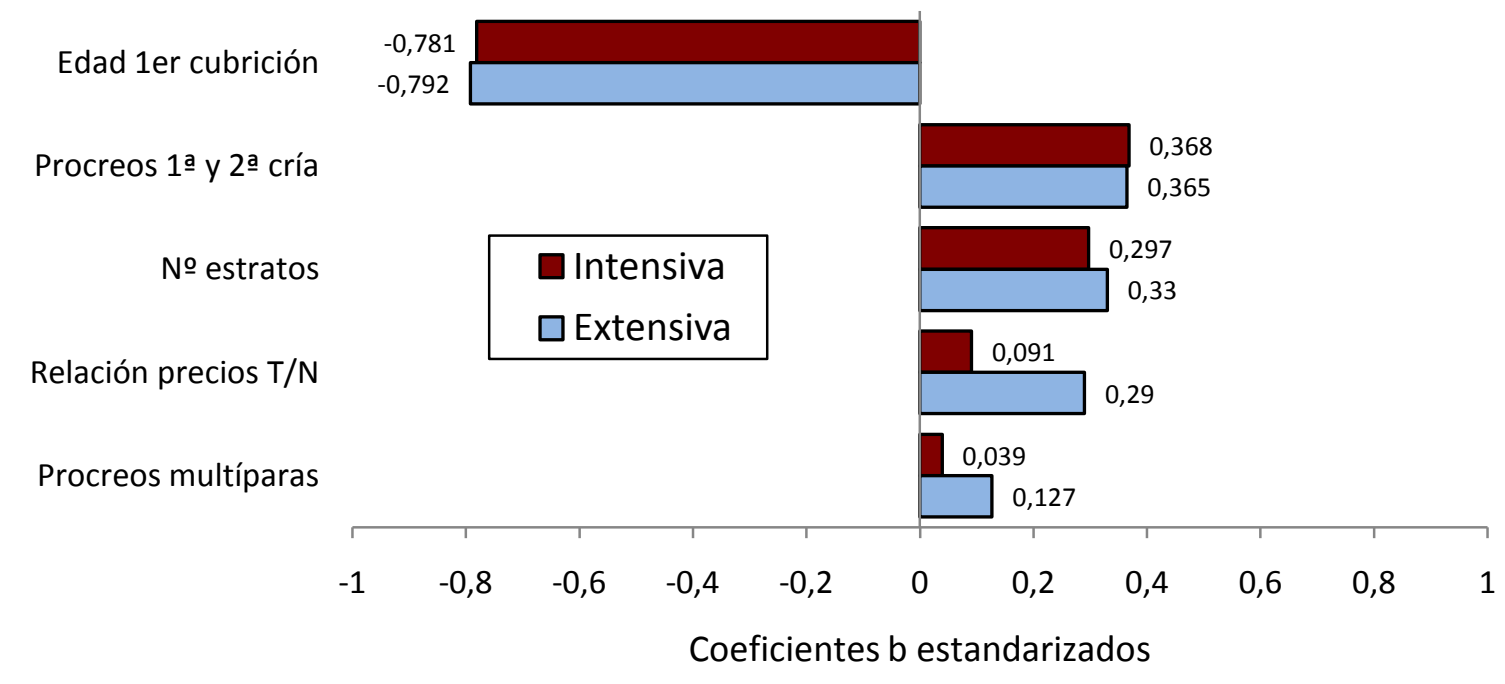

Figura 63. Sensibilidad del margen bruto a las principales variables analizadas en sistemas de cría intensivos y extensivos

En cualquiera de los dos sistemas, la variable a la cual el margen bruto demuestra mayor sensibilidad es la edad de cubrición, cuya reducción determina un impacto muy importante sobre el retorno económico a través del incremento de la eficiencia productiva global del sistema.

Bajo los supuestos de la simulación, en donde se descartan solamente las vacas multíparas que se detectan vacías, la tasa de partos de las hembras jóvenes es también una 
variable de alta incidencia, puesto que si esos animales se van a mantener en el establecimiento, es altamente conveniente que lo hagan estando preñadas (en producción).

De igual forma, al retenerse las vacas jóvenes vacías, el número de estratos de edad afecta a la proporción de hembras improductivas que se mantienen en el establecimiento, por lo cual esta variable (№ estratos) manifiesta un efecto positivo.

La relación de precios ternero/novillo afecta comparativamente más a los sistemas extensivos, cuya eficiencia en el proceso de cebo es muy baja. Es por ello que, ante situaciones de precios desfavorables al ternero, estos sistemas no tienen la capacidad de adaptarse a dicho escenario. En sistemas intensivos en cambio, la capacidad de cebar las vacas descartadas del rebaño rápida y eficientemente permite compensar un escenario de precios desfavorable a la producción de terneros en base a la producción de kg de vacas cebadas.

La tasa de parición de vacas adultas afecta positivamente el retorno económico en sistemas extensivos, al tener baja capacidad de cebo. En este caso, el incremento de vacas de descarte no compensa la disminución en la venta de terneros y terneras. En sistemas intensivos, el coeficiente cercano a cero de esta variable oculta el efecto real de una interacción con la relación de precios (Figura 48), donde según la magnitud de esta última, la tasa de partos en esta categoría puede resultar positiva o negativa.

El ajuste del modelo analizado estimado a través del coeficiente de regresión $\left(r^{2}\right)$ toma un valor de 0.94 en el caso del sistema de cría extensivo y de 0.88 en el sistema intensivo.

En sistemas de ciclo completo (Figura 64), el margen bruto logrado es altamente sensible a la relación de precios. En estos sistemas, la productividad lograda está fuertemente determinada por el cebo de machos, por lo cual bajas relaciones de precios ternero/novillo permitirán capitalizar dicha producción.

Nuevamente, entre un sistema intensivo y uno extensivo, varía consistentemente el efecto de la tasa de procreo de vacas adultas, por las mismas razones expuestas en el caso de cría. 


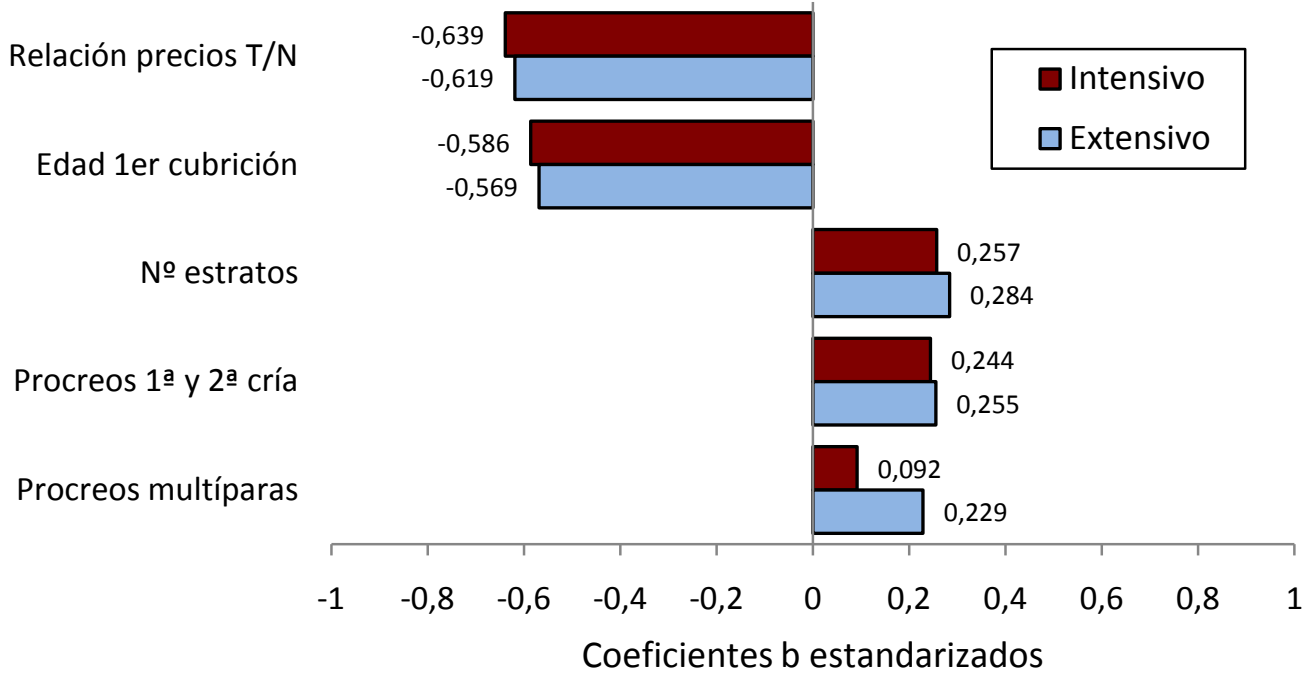

Figura 64. Sensibilidad del margen bruto a las principales variables analizadas en sistemas de ciclo completo intensivos y extensivos

\subsubsection{Sensibilidad a los precios de productos e insumos}

Como fue presentado en la Figura 34, en Uruguay existe una alta volatilidad de los precios del ganado, tanto dentro como entre años.

Es evidente que estas oscilaciones pueden definir el resultado económico de una empresa agropecuaria, máxime si se considera que el precio de insumos como el fertilizante han registrado fluctuaciones muy importantes en los últimos años y en el caso de los granos, utilizados para alimentación animal, se ha verificado una tendencia similar (maíz y soja, variación 2004-2008=150 y 100\% respectivamente) (Frugoni y Oyhantçabal, 2008).

Se plantea la realización de una serie de simulaciones con el objetivo de explorar la sensibilidad de los diferentes sistemas ganaderos de Uruguay, a los precios de los principales determinantes del ingreso (ternero, novillo y vaca gorda) y a los precios de algunos insumos que revisten un alto peso en la estructura de costos (fertilizantes, granos). A su vez, en cierta forma éstos últimos son indicadores de adopción tecnológica en la ganadería uruguaya.

En la Figura 65 se presentan los resultados obtenidos a partir de la realización de 10.000 simulaciones sobre los sistemas de cría extensiva, ciclo completo intensivo y cebo intensivo, tal como fueron definidos en el ítem 5.12. 

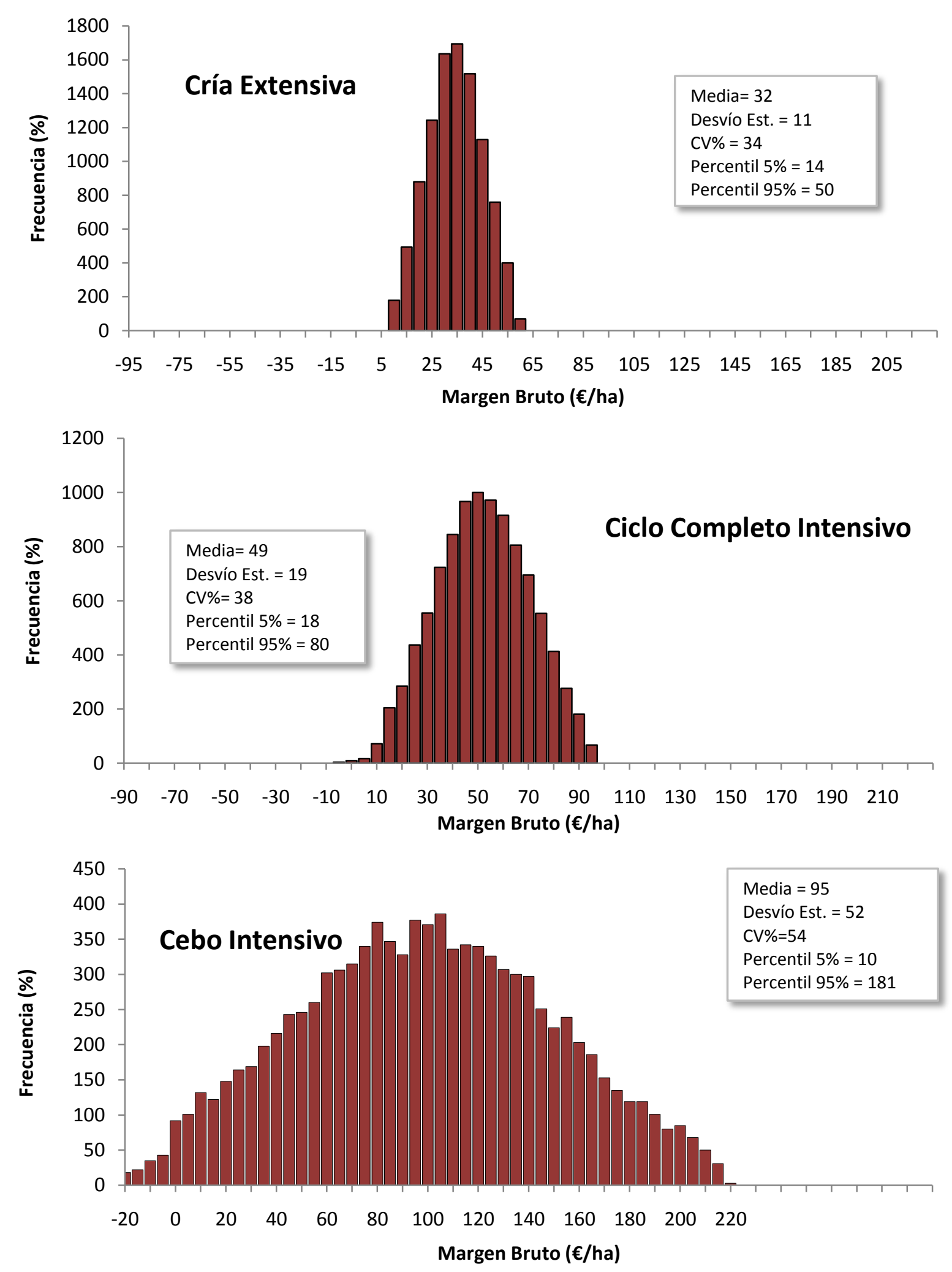

Figura 65. Variabilidad de los resultados económicos expresados como Margen Bruto en función de los precios de productos y principales insumos 
En el sistema de cría, el ingreso está determinado por los precios de venta ya que no utiliza forraje de praderas ni suplementos. De esta manera, tiene un ingreso relativamente estable al mercado. Con estos niveles de preñez (70\%), el precio de la vaca de descarte tiene un mayor peso en la definición del margen bruto que el precio del ternero. Efectivamente, el coeficiente $b$ de la regresión del precio de la vaca sobre el MB tiene un valor de 0.54 frente al 0.48 del precio del ternero. En contraste, en el caso de un sistema de cría intensivo el margen bruto es más sensible al precio del ternero $\left(r^{2}=0.62\right)$ que al de la vaca gorda $\left(r^{2}=0.27\right)$. Esto es coherente con el hecho de que en un sistema intensivo, con altos niveles de preñez y baja edad de cubrición como éste, la producción de terneros pesa proporcionalmente más que la de vacas gordas. Concretamente, en el sistema definido como CRIAINT en simulaciones anteriores, la venta (en kilos) de terneros y terneras representa un $63 \%$ del total comercializado, mientras que en el caso de CRIAEXT el mismo indicador es del $48 \%$.

El sistema de cebo intensivo si bien obtiene los mayores ingresos promedio gracias a una alta productividad (264 kg PV/ha), es altamente sensible a los precios ya que es afectado por precios de insumos (praderas, suplementos), de compra (ternero) y de venta (novillo). Es relevante aclarar que en este análisis se toma en cuenta la alta correlación existente entre los precios del novillo y el ternero (0.9, en base a INAC y DIEA), por lo cual es altamente improbable que se verifiquen situaciones de altos precios del novillo y bajos precios del ternero. De esta manera, descensos en el precio del novillo (principal producto) se encuentran asociados a descensos en el precio del ternero (principal insumo del sistema). En lo que respecta a la sensibilidad relativa a los precios considerados, el precio del novillo es el que manifiesta un efecto mayor sobre el margen bruto $(b=1.2)$, mientras que el precio del ternero y el precio del suplemento afectan en magnitud similar, con valores de pendiente estandarizados $(b)$ de -0.38 y -0.37 respectivamente. El precio del fosfato de amonio es la variable con menor efecto de las analizadas $(b=-0.19)$.

En el caso del sistema de Ciclo Completo, si bien es dependiente de precios de insumos como en el caso del sistema de cebo, los animales que se ceban son propios, lo que determina la independencia a las variaciones en los precios de compra, resultando menos sensible a las condiciones de mercado. En este sistema, el precio del novillo es la variable que más afecta al margen bruto obtenido, con una pendiente de 0.96 , mientras con el precio del fertilizante ostenta un valor $b=-0.27$.

Se debe recalcar que en esta simulación se mantiene fija la productividad física del sistema, cuyas variaciones afectan sensiblemente al retorno económico y además pueden hacerlo en forma diferencial según la orientación productiva, intensificación, etc. A este respecto, es esperable que un sistema de cría, cuya productividad depende de un número 
mayor de variables, aporte relativamente más a la variabilidad económica total del sistema en comparación con un sistema de cebo intensivo.

De cualquier manera, a los efectos de este modelo, donde se considera un número restringido de variables y sobre todo se asume estabilidad en la producción de forraje a lo largo de los años, la principal fuente de variación del ingreso económico de los sistemas manejados son los precios, fundamentalmente de novillo, vaca de descarte y terneros.

\subsubsection{Análisis de sensibilidad conjunto}

En la Figura 66 y la Figura 67 se presentan los coeficientes $b$ de la regresión de la productividad expresada como peso vivo y del margen bruto, en las cuales además de las variables ya analizadas, se incluyen los precios del ternero (PTern) y del novillo (PNov) e insumos según corresponda a cada simulación. Al igual que para el ejercicio anterior, se asumen las distribuciones definidas en la Tabla 21 y una correlación entre el precio del novillo y el ternero de 0.90 . 


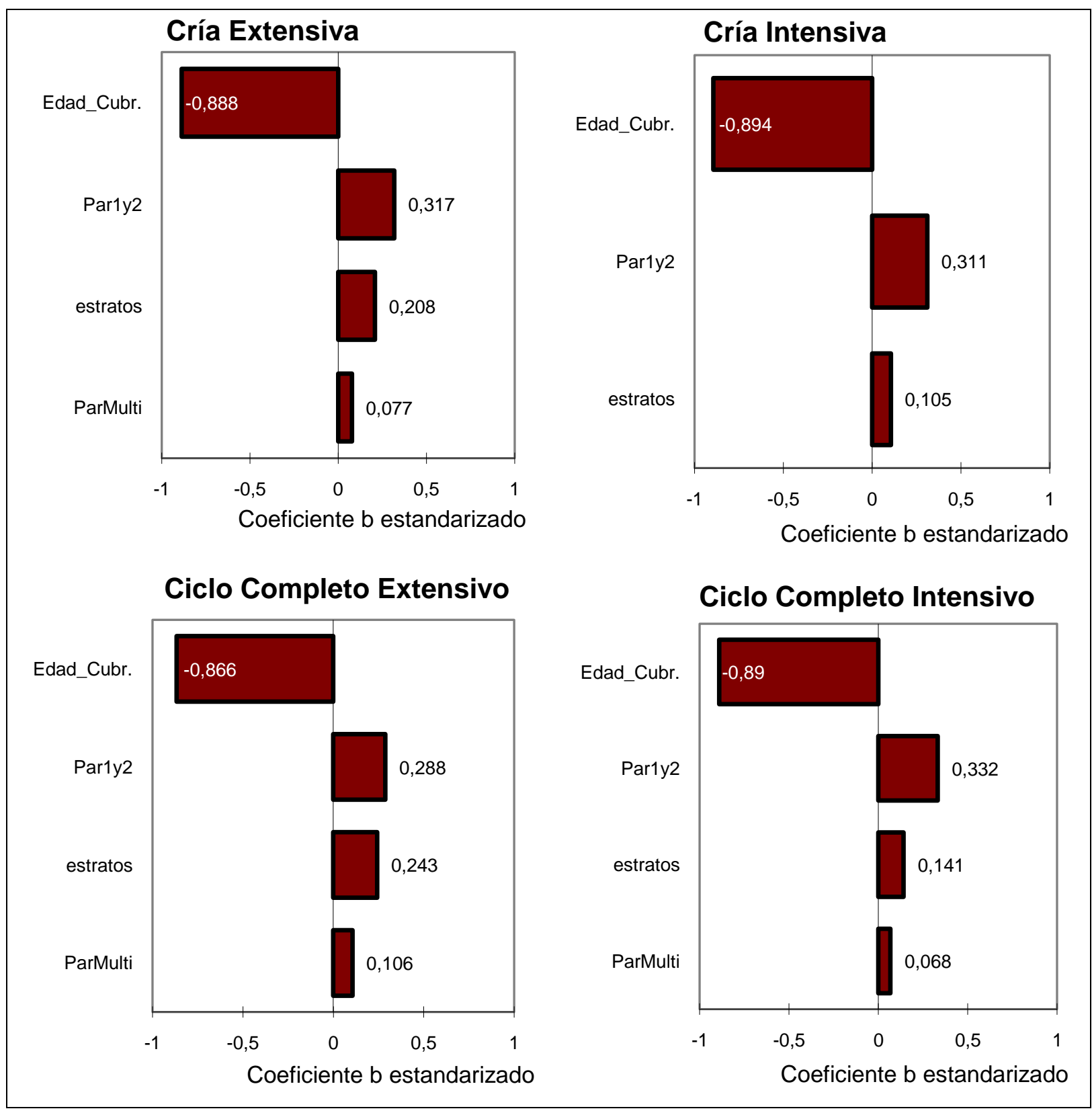

Figura 66. Análisis de sensibilidad de la producción de peso vivo a diferentes variables según orientación productiva y nivel de intensificación

Como está planteado el modelo, los precios de productos e insumos no tienen incidencia directa sobre la productividad de los sistemas.

En forma similar a como fue visto para el caso del margen bruto, la edad de cubrición es el principal determinante de la productividad en los cuatro sistemas simulados. En segundo lugar, la tasa de preñez de vacas jóvenes aparece con un efecto notorio sobre dicha variable. Debe recordarse que en los cuatro sistemas se asume que esta categoría se retiene aunque se diagnostiquen vacías, por lo cual resulta evidente el beneficio de obtener la mayor tasa de preñez posible en ella. El número de estratos de vacas también tiene un 
efecto positivo aunque más bajo y con mayor incidencia en el caso de sistemas extensivos. En estas condiciones, un menor número de categorías determina una alta proporción de vacas de descarte por edad, en sistemas que no cuentan con los recursos suficientes para hacer del cebo un proceso eficiente. Respecto a la preñez de vacas multíparas, sólo se verifica un efecto en sistemas extensivos como ya fuera visto en simulaciones anteriores, aunque de cualquier manera éste es significativamente menor al observado para vacas de primera y segunda cría.

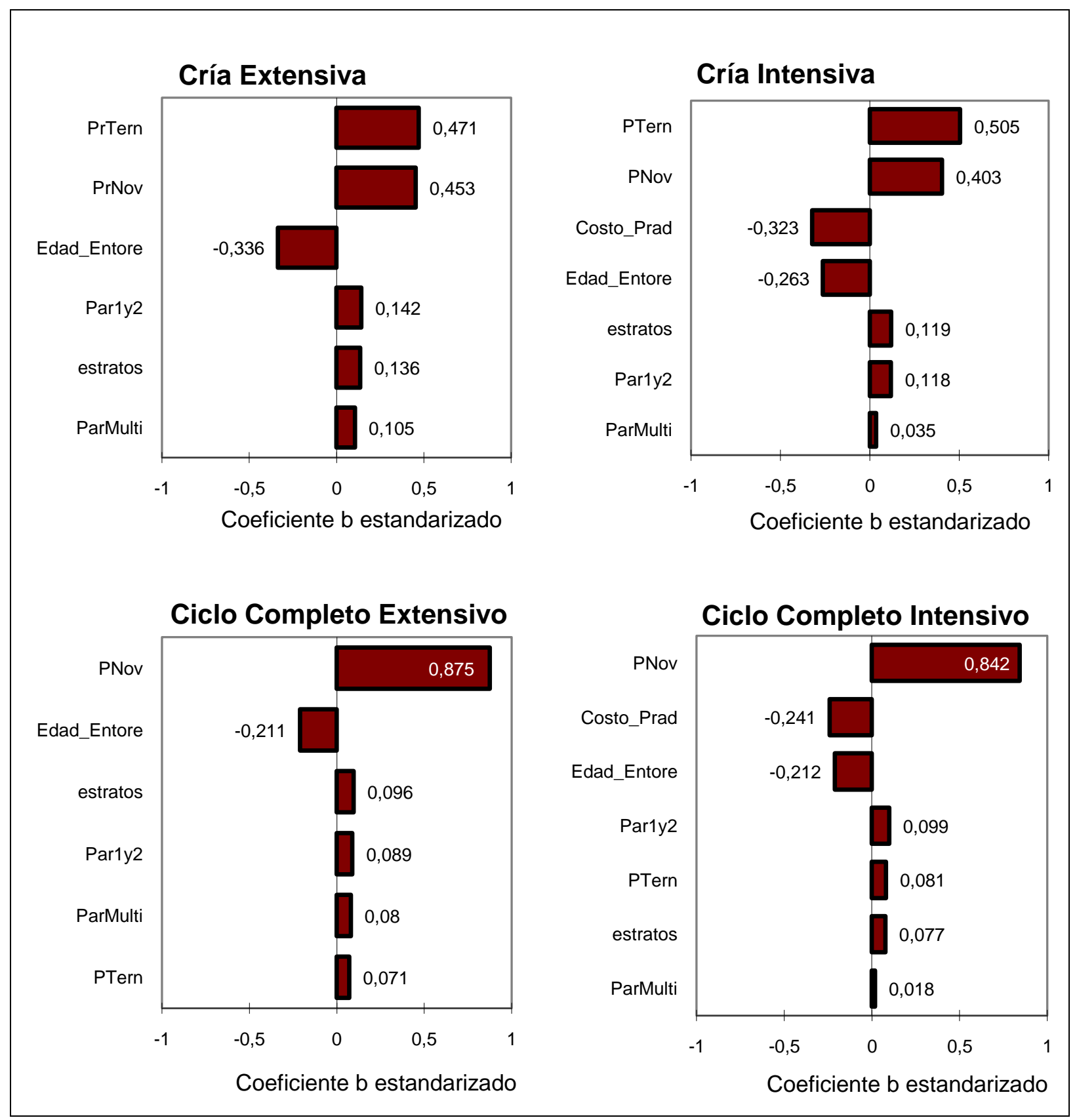

Figura 67. Análisis de sensibilidad del margen bruto a diferentes variables según orientación productiva y nivel de intensificación 
En lo que respecta la sensibilidad sobre el margen bruto, se observa que los principales determinantes del mismo son los precios de los productos de venta, especialmente en los sistemas de ciclo completo. En el caso de la cría, el precio del ternero y el del novillo (referido al precio de la vaca gorda) son las variables más influyentes, ejerciendo un efecto de similar magnitud. En sistemas intensivos, el costo de las praderas aparece en tercer orden. Respecto a las variables productivas, como ya fue comentado y presentado en la figura 59, la reducción en la edad de cubrición es la variable que demuestra un mayor impacto sobre el margen bruto, independientemente del sistema.

En el caso de los sistemas de ciclo completo, se destaca el efecto notable del precio del novillo, al ser el principal producto de venta de estos sistemas. Exceptuando la edad de cubrición, las demás variables productivas presentan comparativamente una baja incidencia.

\subsection{Análisis de escenarios}

Del análisis de las 1000 simulaciones realizadas para cada combinación orientación productiva/nivel de intensificación, se propone analizar los valores que toman las variables dependientes en 2 escenarios: uno de alta productividad, representado por el $5 \%$ de los registros superiores en esta variable (PPV) y un escenario de alto ingreso caracterizado por el $5 \%$ de los valores superiores de margen bruto. Se incluyen únicamente las variables cuyas medianas calculadas para el percentil definido (95\%) difieren al menos en 0.5 desvíos estándar de la mediana de todos los datos. En la Tabla 35 se presentan para cada caso los valores que toma la variable expresada en sus respectivas unidades y entre paréntesis expresado como percentil. 
Tabla 35. Determinación de variables asociadas a escenarios de alta productividad y alto margen bruto

\begin{tabular}{|c|c|c|c|c|}
\hline \multicolumn{5}{|c|}{ Escenario Alta productividad ( $5 \%$ superior PPV) } \\
\hline & CriaExt & Crialnt & CiCoExt & CiColnt \\
\hline $\begin{array}{l}\text { Edad de } \\
\text { cubrición }\end{array}$ & $14(11)$ & $14(11)$ & $14(11)$ & $14(11)$ \\
\hline $\begin{array}{c}\text { Tasa Parición } 1^{\underline{a}} \\
\text { y } 2^{\mathrm{a}} \text { cría }\end{array}$ & $0.89(83)$ & $0.90(87)$ & $89(80)$ & $88(79)$ \\
\hline $\begin{array}{l}\text { Tasa Parición } \\
\text { multíparas }\end{array}$ & - & - & $73(32)$ & $71(31)$ \\
\hline Estratos & $7(80)$ & - & & \\
\hline \multicolumn{5}{|c|}{ Escenario Alto ingreso (5\% superior MB) } \\
\hline & CriaExt & Crialnt & CiCoExt & CiColnt \\
\hline $\begin{array}{c}\text { Precio } \\
\text { Novillo/Vaca }\end{array}$ & $1.87(95)$ & $1.06(95.9)$ & $1.9(96.4)$ & $1.89(95.6)$ \\
\hline Precio ternero/a & $1.05(94.8)$ & $1.89(95.8)$ & $1.05(95)$ & $1.05(95.3)$ \\
\hline Precio Praderas & & & & \\
\hline $\begin{array}{l}\text { Edad de } \\
\text { cubrición }\end{array}$ & $17(22)$ & $17(22)$ & $20(33)$ & $20(33)$ \\
\hline $\begin{array}{c}\text { Tasa Parición } 1^{\underline{a}} \\
\text { y } 2^{\underline{a}} \text { cría }\end{array}$ & $0.83(66.7)$ & $0.83(66)$ & $0.85(69)$ & $0.83(65)$ \\
\hline $\begin{array}{l}\text { Tasa Parición } \\
\text { multíparas }\end{array}$ & - & - & - & - \\
\hline Estratos & $7(80)$ & - & - & - \\
\hline
\end{tabular}

En todas las situaciones evaluadas, una alta productividad se encuentra asociada con baja edad de cubrición de novillas y altas tasas de procreo en hembras jóvenes.

A primera vista, parece incoherente que la tasa de parición de vacas adultas resulte significativa y con un valor inferior al promedio general (percentil 32 y 31 ) en los sistemas de ciclo completo. Como fue visto en la Figura 66, esta variable tiene una pendiente baja pero positiva (0.106) en este sistema y nivel de intensificación. Sin embargo, como se observa en el gráfico A de la Figura 46, si bien en el promedio de los resultados la pendiente es positiva, en el grupo de menor edad de cubrición (variable fuertemente asociada con la productividad) la preñez en vacas multíparas esta correlacionada negativamente con la productividad. En el caso de los sistemas de cría, la pendiente de esta variable respecto a la producción de peso, si bien es negativa en el percentil superior de productividad, tiene una pendiente menor y por tanto no se diferencia significativamente del promedio general. 
El margen bruto se encuentra fuertemente asociado a los precios de venta. La edad de cubrición toma el primer lugar en importancia dentro de las variables productivas, seguida por la tasa de procreo de las hembras jóvenes. No aparecen otras variables cuya mediana en el grupo de alto MB supere en 0.5 desvíos estándar la mediana del promedio general.

\subsection{Algunas consideraciones a nivel de la cadena cárnica uruguaya}

Uruguay ha sufrido en los últimos años un proceso de dinamización del sector si consideramos a la ganadería globalmente. Si se diferencian sectores dentro de la actividad, se verifica una mejora sostenida en el volumen de animales sacrificados con una reducción de la edad de los novillos al sacrificio (Figura 2). En primer lugar, debe tenerse en cuenta que el stock ganadero ha crecido en la última década como consecuencia de una drástica reducción del stock ovino nacional y en cierta medida de un incremento del área de mejoramientos forrajeros. El incremento en los volúmenes de sacrificio es en parte consecuencia de estos dos factores. Sin embargo, la reducción de la edad promedio de sacrificio sí puede considerarse una mejora en la eficiencia del proceso.

Al analizar los indicadores de la cría, actividad que provee de insumos (terneros básicamente) a los productores de cebo, esta mejora global de la ganadería no es tan evidente. Es posible detectar una reducción en la edad de cubrición de las novillas, pero la tasa de destete, indicador clave en lo que respecta a la producción de terneros (futuros novillos) no ha tenido un incremento significativo, más allá de oscilaciones anuales.

El Uruguay se encuentra ante un escenario de alta competencia por la tierra, con una agricultura de secano que en 2008 se expandió fuertemente y un sector forestal que, aunque en menor medida, también aumenta su área. Las perspectivas son de reducción del área de pastoreo, por lo cual, si se quiere aumentar o incluso mantener la producción, se debe necesariamente incrementar la productividad por hectárea.

Ante este escenario, surge la interrogante obvia respecto a cómo sostener este avance en el cebo si paralelamente no se incrementa la producción de terneros. En los últimos 5 años, aunque con altibajos, se han sacrificado 2.3 millones de cabezas vacunas en promedio. Estos valores se encuentran relativamente en equilibrio con la actual producción de terneros machos y hembras (2.66 millones) menos una tasa de mortandad promedio (10\%). Si asumimos que el sector de cebo es capaz de disponer en el corto plazo de los recursos de forraje o alimentos para intensificar el proceso, se presenta el gran desafío de incrementar la producción de terneros en el sector criador. 
Caputi (2007) señala a la posible existencia de dos grupos de productores. El primero apunta a un grupo de productores criadores especializados, con alto nivel de inversión, donde la producción de terneros tiene un impacto importante en la ecuación económica global de la empresa. El autor afirma que en este grupo, con precios de mercado acordes, es posible esperar una mayor intensificación tecnológica con efectos positivos sobre el sistema. Estos conceptos concuerdan con muchos resultados aquí obtenidos, aunque como se ha visto detalladamente, este resultado estará influenciado por muchas variables además de la tasa de preñez y los precios. Concretamente, la política de refugos de las hembras jóvenes puede determinar que, si se logran altas tasas de preñez en estas categorías, el beneficio marginal de esta tasa en vacas adultas sea negativo. La cuestión no es que estos productores pierdan dinero por incrementar la tasa de procreo en las vacas adultas, sino que, aún sin tener conciencia de ello, puedan estar dejando de percibir un beneficio mayor por destinar recursos a preñar esta categoría de vacas a una tasa que posiblemente exceda el óptimo económico. En segundo término, Caputi alude a un grupo de predios ganaderos con bajo nivel de inversión global (criadores y de ciclo completo), con valores de destete del orden de 10 puntos menos que el promedio (54\%), para los cuales una vaca fallada no necesariamente es un problema. Su respuesta al factor "precio del ternero" estará condicionada por otro factor: el precio de la vaca gorda. Mientras éste siga siendo relativamente alto no habrá mayores estímulos a "orientar" los insumos para mejorar significativamente el porcentaje de destete.

Las opiniones de este autor coinciden plenamente con los resultados aquí obtenidos. Podrían hacerse algunas puntualizaciones: en primer lugar, la diferenciación de los productores de cría y de ciclo completo de este último grupo no es trivial. Para un productor de ciclo completo es relativamente más difícil aumentar la producción de terneros, ya que estos animales deben ser cebados en el mismo predio. A diferencia de los productores criadores, donde los terneros extra son volcados al mercado intraganadero, en el caso del ciclo completo el aumento en la preñez determina un aumento en la dotación por la vía del incremento en el número de vacas preñadas y por la vía de los terneros y novillos extra en la escalera de cebo. Esto implica que el número de vacas deba reducirse notoriamente por cada punto extra de preñez logrado.

Con respecto al grupo de predios más extensivos que menciona este autor, se considera que si bien pueden ser productores con menor grado de receptividad a la tecnología, cualquier pequeño aumento en la productividad logrado tendría un impacto considerable a nivel ganadero global, en virtud de que representan un volumen muy importante, tanto en superficie ocupada como en número de animales. El mayor rezago tecnológico de este grupo de productores, puede estar determinando algunas 
oportunidades, ya que la implementación de técnicas o medidas de manejo de mínimo costo pueden determinar un impacto muy importante tanto a nivel productivo como económico. Por el contrario, en establecimientos con mayor nivel de tecnificación inicial, el avance necesariamente debe discurrir por alternativas de mayor inversión o mayor coste. En este sentido, en la Tabla 28 se analizó el efecto de la realización de diagnóstico de gestación y descarte de hembras adultas falladas del rebaño. Desde el punto de vista de la cadena cárnica uruguaya, la implementación de esta medida tendría un notorio impacto en cuando a la producción de carne. A modo de ejemplo, en el año 2003 existían 1400 mil vientres a los que no se les practicaba diagnóstico de gestación, equivalente a un $40 \%$ del total de vientres (DIEA, 2003). Asumiendo que en la actualidad existiera un millón de vientres en similar condición (24\%) y se aplicara diagnóstico de gestación a estas hembras con el consiguiente descarte del $36 \%$ de animales vacíos, se podrían comercializar 191 mil vacas gordas en lugar de las 110 mil actuales, las que son descartadas únicamente por edad. En contrapartida se reduciría de 182 a 90 mil las terneras comercializadas, manteniéndose los terneros, y en este balance se producirían 21.5 mil toneladas en pie más, en la misma área. En lo que refiere al ingreso, éste se incrementaría en $3 € /$ ha, lo que equivale a un beneficio para todo el sector de 9.2 millones de euros. En la Figura 68 se observa la evolución de indicadores a partir de la implementación de esta medida. A partir del año 12 dichos indicadores se estabilizan.

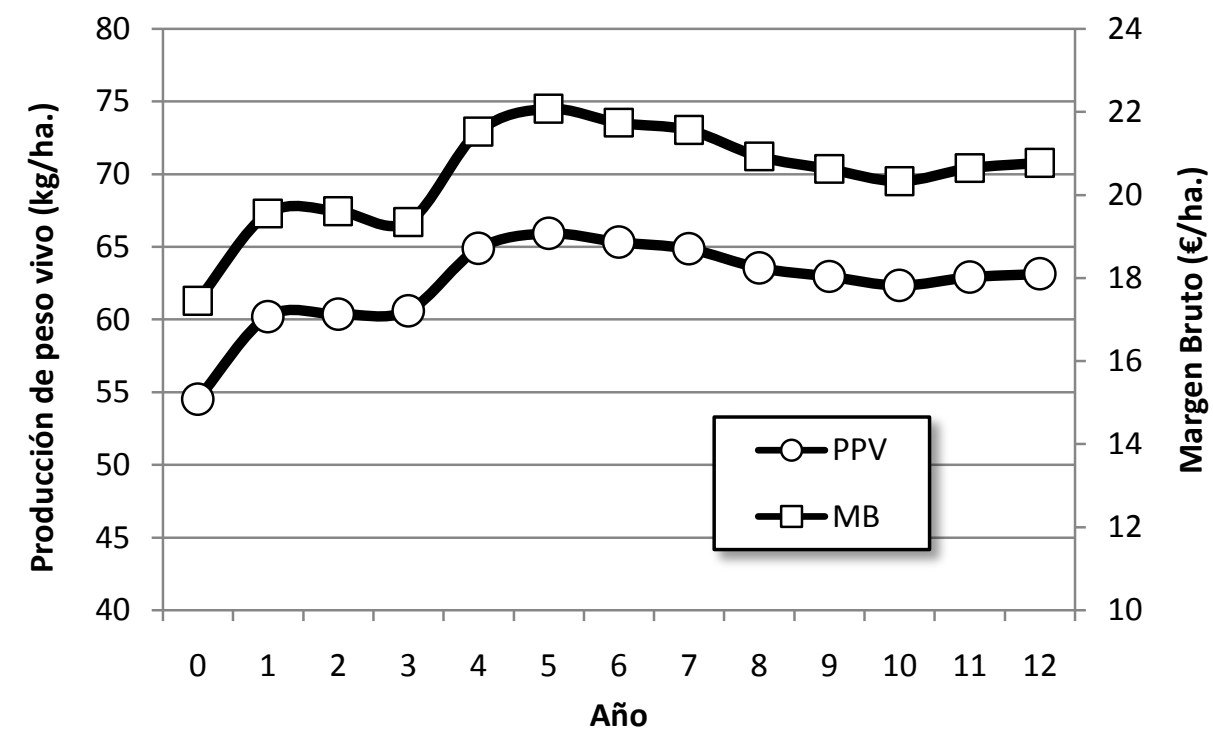

Figura 68. Evolución de la productividad (PPV) y el margen bruto (MB) a partir de la implementación del diagnóstico de gestación y posterior descarte y cebo de vacas adultas vacías 
En el caso de que estos productores no tuvieran las condiciones forrajeras para cebar estos animales, la venta de vacas para ser cebadas por otros productores, determinaría un incremento en 19.7 mil toneladas de peso en pie extra, y un ingreso asociado de $1.3 € /$ ha, equivalente a 4 millones de euros para el sector. En este caso, el beneficio que estos productores dejan de percibir respecto a la alternativa de cebar las vacas se transferiría a otros sectores de la cadena como productores de cebo, intermediarios y transportistas, con lo cual de una manera u otra el sector se beneficiaría. Estas estimaciones fueron realizadas utilizando los indicadores ajustados al promedio nacional para la validación del modelo a escala país (Tabla 23), donde el 59\% de las novillas se cubren con 2 años de edad. En el caso de que la edad de cubrición sea de 3 años, el margen económico se reduce; en efecto, las terneras que ingresan al sistema (en lugar de venderse) para reemplazar a las vacas que se descartan del rebaño al diagnosticarse falladas deben recriarse durante tres años en el predio antes de ser cubiertas. Igualmente, existe un beneficio económico hasta relaciones de precios ternero/ novillo de 1.22 y la productividad extra lograda se mantiene como en el caso anterior. Éste es un claro ejemplo de potencial generación de valor para la cadena cárnica.

Particularmente, en el enfoque de alternativas para este grupo de productores se debe tener presente la naturaleza del proceso de la producción en pastoreo, determinado por una alta incertidumbre asociada a la dependencia del clima y sus efectos. Esta incertidumbre trae aparejado un riesgo, tanto biológico como económico-financiero (Helguera y Lanfranco, 2006). El proceso de la cría presenta múltiples alternativas de mejoramiento o estabilización productiva, muchas veces dependiendo más de variables de manejo y gestión de la información (tecnologías de procesos) que de la aplicación estandarizada de insumos (tecnologías de insumos) (Ponssa et al., 2007). La natural aversión al riesgo de los productores agropecuarios, en gran medida justificada considerando las oscilaciones de precios y sobretodo la alta dependencia climática mencionada, determina que algunas alternativas productivas o tecnologías tengan un mayor grado de adopción. Un ejemplo puede ser la suplementación estratégica de ciertas categorías, donde su naturaleza de aplicación y verificación de resultados en el corto plazo puede ser más atractiva respecto a inversiones de mayor magnitud como la instalación de praderas artificiales y verdeos, donde la incertidumbre del éxito productivo y/o económico puede ser más elevada. En este sentido, se ha visto la importancia de la reducción en la edad de cubrición como dinamizadora de los sistemas ganaderos. En establecimientos extensivos de cría, es muy común encontrar situaciones donde la novilla es cubierta a los 3 años, con lo cual produce su primer ternero a los 4 años de edad. Se presentan los resultados de una simulación tomando como situación de partida en un establecimiento de 1000 ha., con una tasa de destete similar al promedio 
nacional $(65 \%)$ con venta de terneros y vacas gordas. Se plantea una suplementación con pienso a razón de $1.5 \%$ del peso vivo durante 3 meses (julio a setiembre) durante el segundo año en la vida de la novilla a efectos de lograr alcanzar un peso que posibilite su cubrición en noviembre, con 2 años de edad. La evolución de peso de las novillas con y sin pienso se presenta en la Figura 69.

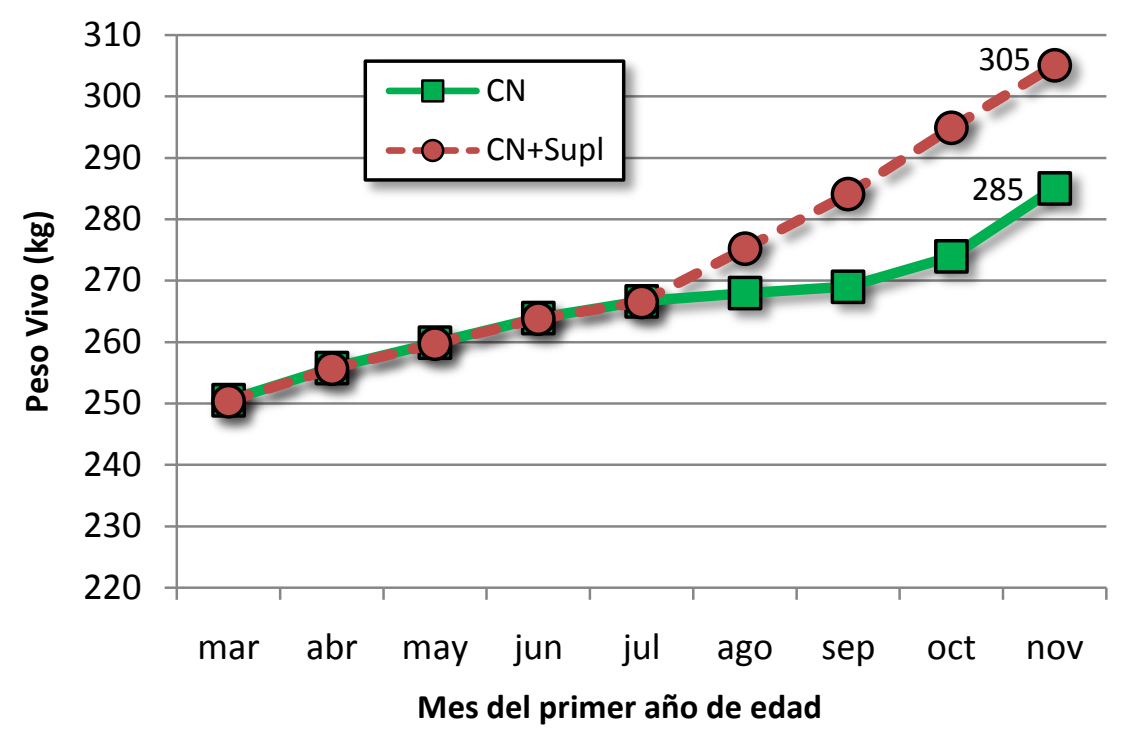

Figura 69. Efecto de la suplementación con pienso sobre la evolución de peso vivo en novillas durante su segundo invierno (julio-setiembre)

Los animales que se suplementan alcanzan el inicio de período de cubrición con $20 \mathrm{~kg}$ más de peso que los animales pastoreando campo natural exclusivamente. Puede notarse un efecto compensatorio en los animales no suplementados en el último período (oct-nov). Los resultados de la suplementación sobre el sistema se presentan en la Tabla 36.

Tabla 36. Efecto de la suplementación en novillas pre-cubrición sobre el sistema de cría

\begin{tabular}{c|ccc}
\hline & $\begin{array}{c}\text { Total de vacas } \\
\text { de cría }\end{array}$ & $\begin{array}{c}\text { Productividad } \\
(\mathrm{kg} / \mathrm{ha} \text {. })\end{array}$ & $\begin{array}{c}\text { Margen Bruto } \\
(€ / \mathrm{ha} .)\end{array}$ \\
\hline Campo natural & 477 & 71 & 21.1 \\
Campo natural + pienso & $545(+14 \%)$ & $81(+14 \%)$ & $24.7(+17 \%)$ \\
\hline
\end{tabular}

La suplementación permite servir las novillas un año antes, con lo cual se reduce la carga improductiva en el establecimiento, permitiendo soportar un $14 \%$ más de vacas en el 
predio, lo que incrementa la productividad en proporción similar y el margen bruto en un $17 \%$.

Se considera pertinente citar textualmente una frase de Caputi (2007), la cual resume la importancia de no reducir el análisis a un solo punto de vista, porque esto indefectiblemente conducirá a una visión sesgada y por lo tanto errónea de la cadena cárnica uruguaya: "Debemos analizar globalmente el problema de nuestra cadena ganadera y descubrir la racionalidad económica de las decisiones en el cebo y la cría, huyendo de las explicaciones simplistas sobre el comportamiento de los productores. Sólo entendiendo esa trama oculta podremos diseñar estrategias de estímulo que contribuyan a dar un nuevo salto en el desarrollo ganadero, con tasas de extracción significativamente más altas". 
CAPITULO VII - CONCLUSIONES 



\section{CAPÍTULO VII - CONCLUSIONES}

El modelo desarrollado en el presente trabajo ha logrado captar globalmente las principales fuentes de variación en los resultados productivos y económicos de los sistemas ganaderos del Uruguay, demostrando la suficiente versatilidad para ser utilizado a nivel de un establecimiento, así como a escala regional o nacional.

A través de la utilización del modelo, es posible cuantificar el impacto de variables de manejo, mejora genética y otras sobre la productividad y el retorno económico en distintos escenarios de producción y mercado.

Se destaca la importancia de la edad de cubrición de las novillas, cuya reducción determina una notoria mejora en la eficiencia del sistema, al reducir el número de animales en recría y en consecuencia incrementar el número de vacas en producción. Se debe destacar que esta variable no presenta interacciones con otras variables analizadas, por lo cual su efecto es consistente en todas las situaciones manejadas en este trabajo.

La tasa de destete, considerada clave en lo que respecta a la productividad de la ganadería en nuestro país, debe ser analizada en forma cuidadosa, ya que su efecto, principalmente sobre el ingreso económico, esconde complejas interacciones con otras variables, especialmente si se tratan en forma independiente ciertas categorías del rebaño de cría cuyas características ameritan una consideración diferencial.

La mejora en la competitividad de estos sistemas y de la ganadería en el país está fuertemente ligada al aumento de la productividad de los sistemas de cría, pero para que ello sea efectivo es necesario un incremento en la demanda del producto (terneros) con el consiguiente estímulo en el precio.

La estimación de los pesos económicos para caracteres mejorables por vía genética debe tener en cuenta las complejas respuestas de algunas de estas variables al ser evaluadas en diferentes escenarios. Una excesiva simplificación en su tratamiento, como puede ser asumir erróneamente un efecto lineal, puede llevar a un cambio de la característica en una dirección no deseada. La tasa de preñez, la tasa de crecimiento en machos y el rendimiento de res aparecen como las variables de mayor relevancia en este aspecto, aunque se debe profundizar en lo que respecta a la variación genética potencial de estas características. El bajo coste de la alimentación en sistemas extensivos y la importancia del cebo de las vacas de descarte evidenciada en los sistemas de cría, determinan un peso positivo de algunos caracteres como el consumo y el peso adulto, los cuales son usualmente reportados con pesos económicos muy bajos o negativos en la literatura internacional. En un escenario caracterizado por una alta complejidad y 
heterogeneidad de sistemas de producción, parece ineludible el desarrollo de más de un índice de selección, a la vez que se debería evitar que un exceso de éstos determine una menor credibilidad en esta herramienta de mejoramiento. El desafío futuro parece ser el logro de este balance.

El escenario de precios sigue siendo una de los factores que imprimen mayor nivel de incertidumbre al resultado económico ganadero. De cualquier manera, la investigación en Uruguay ha desarrollado tecnologías de diversa índole y grado de inversión para superar, salvo situaciones excepcionales, los altibajos en los precios de productos e insumos mediante el incremento en la productividad.

Se ha evidenciado la existencia de medidas de bajo coste que determinan un alto retorno económico y cuya aplicación se considera especialmente recomendadda en sistemas de productividad más limitada o donde las características tipológicas de los productores hagan menos factible la aplicación de tecnologías que requieran un alto grado de inversión, conocimiento técnico o habilidad empresarial.

En cualquier caso, es posible concluir que el análisis sistémico resulta fundamental si se quiere evitar malgastar esfuerzos en solucionar problemas puntuales que muchas veces no representan una limitante a nivel global. En algunas situaciones, la mejora de ciertos indicadores no determina un incremento en la productividad del sistema y en muchas otras situaciones una mayor productividad no necesariamente trae aparejado un ingreso mayor.

A nivel de toda la cadena cárnica, es relevante destacar situaciones en las que un sector, por carecer de recursos productivos, puede tomar acciones que restringen la productividad de todo el complejo ganadero. Tal es el caso del descarte de vacas falladas en establecimiento de cría extensiva. Se plantea la posibilidad de que el estado o alguna institución asuman un rol facilitador de algún tipo de asociación entre productores a fin de captar un beneficio que actualmente se deja de percibir.

Un sistema que modele la generación de valor en el sector productor de la cadena cárnica uruguaya constituye una excelente base para la identificación mediante simulación del impacto de la tecnología generada por la investigación en Uruguay. Paralelamente, posibilita la identificación de puntos críticos y de ineficiencias no sólo a nivel predial sino en forma agregada a nivel de la fase primaria o de la cadena cárnica uruguaya en su conjunto. 
CAPITULO VIII - REHELREINCIAS BIBLIOGRÁFICAS 



\section{CAPÍTULO VIII - REFERENCIAS BIBLIOGRÁFICAS}

AFRC. 1994. Necesidades energéticas y proteicas de los rumiantes. Acribia, Zaragoza, España.

Agabriel, J., Ingrand, S. 2004. Modelling the performance of the beef cow to build a herd functioning simulator. Animal Researche, 53:247-361.

Aguilar, C., Cortés, H., Allende, R. 2002. Los modelos de simulación. Una herramienta de apoyo a la gestión pecuaria. Archivos Latinoamericanos de Producción Animal 10(3): 226-231.

Aguirrezabala, M., Oficialdegui, R. 1993. Simulación del consumo bovino y ovino en condiciones de pastoreo. Producción Ovina 6: 89-110.

ARC. 1980. The nutrient requirements of ruminant livestock. Slough, UK : Commonwealth Agricultural Bureaux, 351p.

Arnade, C., Jones, K. 2003. Modeling the Cattle Replacement Decisions. In: Proceedings of the American Agricultural Economics Association Annual Meeting, July 27-30, Montreal, Canada

Arnold, M., Osorio, F. 1998. Introducción a los Conceptos Básicos de la Teoría General de los Sistemas. Revista Cinta de Moebio. Facultad de Ciencias Sociales. Universidad de Chile. № 3

Basarab, J.A., Rutter, L.M., Day, P.A. 1993. The efficacy of predicting dystocia in yearling beef heifers: I. Using ratios of pelvic area to birth weight or pelvic area to heifer weight. Journal of animal science 71(6): 1359-.

Beretta, V., Lobato, J.F.P., Mielitz, C.G.N. 2002. Produtividade e eficiência biológica de sistemas de recria e engorda de gado de corte no Rio Grande do Sul. Revista Brasileira de Zootecnia 31(2): 696-706

Beretta, V., Simeone, A., Elizalde, J.C., Baldi, F. 2006. Performance of growing cattle grazing moderate quality legume-grass temperate pastures when offered varying forage allowance with or without grain supplementation Australian Journal of Experimental Agriculture 47(6,7): 793-797. 
Berger, H., Machado, C., Copes, M., Ponssa, E., Auza, N. 2003. Impacto de la edad de entore de vaquillonas sobre el resultado global de un sistema de cría de alta producción. Revista de la Asociación Argentina de Producción Animal 23(1): 301 302.

Berger, P.J., Cubas, A.C., Koehler, K.J., Healey, M.H. 1992. Factors affecting dystocia and early calf mortality in Angus cows and heifers. Journal of animal science 70(6): 1775-.

Bernués, A., Herrero, M., Dent, J.B. 1995. El estudio de los sistemas ganaderos mediante simulación: una revisión de los modelos de ovino a nivel del animal individual, del rebaño y de la explotación. Investigación Agraria. Prod. y Sanidad Animales 10(3): 243-272.

Bernués, A., Riedel, J.L., Asensio, M.A., Blanco, M., Sanz, A., Revilla, R., Casasús, I. 2005. An integrated approach to studying the role of grazing livestock systems in the conservation of rangelands in a protected natural park (Sierra de Guara, Spain). Livestock Production Science 96: 75-85.

Bertalanffy, L.V. 1976. Teoría General de los Sistemas. México: F.C.E.

Blanc, F., Agabriel, J. 2008. Modelling the reproductive efficiency in a beef cow herd: effect of calving date, bull exposure and body condition at calving on the calving-conception interval and calving distribution. Journal of Agricultural Science 146: 143-161

Blasina, E. 2005. Situación de la cría vacuna en Uruguay. Una descripción posible [en línea]. Documento MS Powerpoint. Disponible en: www.caf.org.uy/IMG/ppt/E.Blasina.ppt Consultado: Enero 2009.

Bourdon, R.M., Brinks, J.S. 1987a. Simulated Efficiency of Range Beef Production. I. Growth and Milk Production. Journal of animal science 65(4): 943-

Bourdon, R.M. and Brinks, J.S. 1987b. Simulated Efficiency of Range Beef Production. II. Fertility Traits. Journal of animal science 65(4): 956-.

Brereton, A.J., Holden, N. M., McGilloway, D.A., Carton, O.T. 2005. A model describing the utilization of herbage by steers in a rotational grazing system. Grass and Forage Science 60 367-384

Brody, S. 1945. Bioenergetics and growth, with special reference to the efficiency complex in domestic animals. Reinhold, New York. 
Brockington, N.R. 1979. Computer modelling in Agriculture. New York. Oxford University press. $1 \mathrm{~V}$.

Brorsen, W.W., Walker, O.L., Horn, G.W., Nelson, T.R. 1983. A Stocker Cattle Growth Simulation Model. So. J. Agr. Econ. 15(1): 97-102.

Burfening, P.J., Kress, D.D., Friedrich, R.L., Vaniman, D.D. 1978. Phenotypic and Genetic Relationships between Calving Ease, Gestation Length, Birth Weight and Preweaning Growth. Journal of animal science 47(3): 595-.

Caputi, P. 2005. Evolución del sector agropecuario uruguayo 1984-2004: balance y perspectivas [en línea]. Revista Coyuntura agropecuaria. Disponible en: www.iica.org.uy. Consultado: enero 2009

Caputi, P., Murguia, J.M. 2003. Análisis del Crecimiento Ganadero a través de un Modelo de Equilibrio. Agrociencia 7(2): 79-90.

Cardozo, O., Ferreira, G. 1994. Engorde de novillos: un modelo bio-económico, INIA Tacuarembó, 26 p. (Serie Técnica 49)

Cartwright, T.C. 1979. The Use of Systems Analysis in Animal Science with Emphasis on Animal Breeding. Journal of animal science 49(3): 817-.

Castellaro, G.G. 2007. Crecimiento de praderas mesofíticas a largo plazo, en respuesta a factores edafoclimáticos y modalidades de defoliación. 132 p. Tesis Magíster en Ciencias Animales. Pontificia Universidad Católica de Chile, Facultad de Agronomía e Ingeniería Forestal, Santiago, Chile.

Colburn, D.J. Deutscher, G.H., Nielsen, M.K., Adams, D.C. 1997. Effects of sire, dam traits, calf traits, and environment on dystocia and subsequent reproduction of two-year-old heifers. Journal of animal science 75(6): 1452-.

Cook, B., Biermacher, J., Childs, D. 2007. The value of pregnancy testing spring-calving beef cows. In: Proceedings of the 16th international Farm Management Association Congress A Vibrant Rural Economy - The Challenge For Balance, Seamus O'Reilly, Michael Keane, Pat Enright (Eds.), ISBN: 978-92-990038-3-1, pp. 1-9.

CSIRO. 2007. Nutrient Requirements of Domesticated Ruminants. CSIRO Publishing, Collingwood, 270 págs. 
Cundiff, L.V., Koch, R.M., Gregory, K.E., Smith, G.M. 1981. Characterization of Biological Types of Cattle-Cycle II. IV. Postweaning Growth and Feed Efficiency of Steers. Journal of animal science 53(2): 332-.

Cundiff, L.V., Koch, R.M., Gregory, K.E. 1984. Characterization of Biological Types of Cattle (Cycle III) IV. Postweaning Growth and Feed Efficiency. Journal of animal science 58(2): 312-.

Dent, J.B., Blackie, M. 1979. Systems simulation in Agriculture. L.T.D. London. Applied Science Publisher, 180 pp.

Di Marco, O.N., Baldwin, R.L., Calvert, C.C., 1989. Simulation of DNA, protein and fat accretion in growing steers. Agric. Syst. 29, 21-34.

Di Marco, O.N. 2007. ¿Cuánto forraje cuesta producir un ternero?. Disponible en: http://produccion-animal.com.ar/informacion tecnica/manejo del alimento/109forraje producir ternero.pdf Consultado: enero 2009.

DIEA. 2003. Encuesta Ganadera 2003 [en línea]. Disponible en: http://www.mgap.gub.uy/diea/Encuestas/Se226/SE226_EncuestaGanadera04.htm. Consultado en abril 2009.

DIEA. 2008. Anuario Estadístico Agropecuario 2008. Consultado en octubre 2008. Disponible en: http://www.mgap.gub.uy/Diea/Anuario2008/Anuario2008/pages/DIEAAnuario-2008-cd_000.html

DICOSE. 2008. Declaración Jurada Anual de Existencias de Ganado y Frutos del País [en línea]. Disponible en: http://www.mgap.gub.uy/DGSG/DICOSE/DatosDJ_2008.htm. Consultado: octubre 2008.

Dunn, T.G., Kaltenbach, C.C. 1980. Nutrition and the postpartum interval of the ewe, sow and cows. Journal of animal science 51 (2): 29.

Dunn, T.G., Ingalls, J.E., Zimmerman, D.R., Wiltbank, J. N. 1969. Reproductive Performance of 2-Year-Old Hereford and Angus Heifers as Influenced by Pre-and Post-Calving Energy Intake. Journal of animal science 29(5): 719-.

Faulkner, D.B., Parrett, D.F., McKeith, F.K. Berger, L.L. 1990. Prediction of fat cover and carcass composition from live and carcass measurements. Journal of Animal Science 68: 604-610. 
Feldkamp, C. 2004. Cow-Calf Operation in Argentina: a Systems Approach to Intervention Assessment. PhD dissertation, Humboldt University, Berlin, Alemania

Fernández-Perea, M.T., Alenda, R. 2004. Economic weights for a selection index in Avilena purebreed beef cattle. Livestock Production Science 89: 223-233.

Fernandez-Rivera, S., Lewis, M., Klopfenstein, T.J., Thompson, T.L., 1989. A simulation model of forage yield, quality and intake of growing cattle grazing cornstalks. Journal of Animal Science 67: 581-589.

Ferreira, G., 1997. An evolutionary approach to farming decision-making on extensive rangelands. PhD Thesis, University of Edinburgh.

Ferrell, C.L. 1982. Effects of postweaning rate of gain on onset of puberty and productive performance of heifers of different breeds. J. Anim. Sci. 55:1272-

Ferrell, C.L., Jenkins, T.G. 1985. Cow type and nutritional environment: Nutritional aspects. J. Anim. Sci. 61:725-.

Ferrel, C.L., Oltjen, J.W. 2008. ASAS CENTENNIAL PAPER: Net energy systems for beef cattle Concepts, application, and future models. J Anim Sci. 86: 2779 -2794

Forbes, J.M. 1971. Physiological changes affecting voluntary food intake in ruminants. Proc. Nutr. Soc. 30: 135-142

Formigoni, I.B., Ferraz, J.B.S., Silva, J.A. 2005. Economic value for stayability and heifer pregnancy at 14 months in beef cattle herds. Arq. Bras. Med. Vet. Zootec. 57(2): 220226.

Fox, D.G., Black, J.R. 1977. A System for Predicting Performance of Growing and Finishing Beef Cattle. In: Report of Beef Cattle-Feeding Research, Mich. Agr. Exp. Sta. Res. Rpt., 328:141-162.

Fox, D.G., Black, J.R. 1984. A system for predicting body composition and performance of growing cattle. Journal of Animal Science 58: 725-739.

Fox, D.G., Sniffen, C.J., O'connor, J.D. 1988. Adjusting nutrient requirements of beef cattle for animal and environmental variations. Journal of Animal Science 66: 1475-1495. 
Fox, D.G., Tedeschi, L.O., Tylutki, T.P., Russell, J.B., Van Amburgh, M.E., Chase, L.E., Pell, A.N. and Overton T.R. 2004. The Cornell Net Carbohydrate and Protein System model for evaluating herd nutrition and nutrient excretion. Anim. Feed Sci. Technol. $112: 29-78$.

France, J., Dijkstra, J., Thornley, J.H.M., Dhanoa, M.S., 1996. A simple but flexible growth function. Growth Dev. Aging 60, 71-83.

Freer, M., Jones, D.B. 1984. Feeding value of subterranean clover, lucerne, phalaris and Wimmera ryegrass for lambs. Aust. J. Exp. Agric. Anim. Husb. 24: 156-164.

Freetly, H.C., Cundiff, L.V. 1998. Reproductive performance, calf growth, and milk production of first-calf heifers sired by seven breeds and raised on different levels of nutrition. Journal of Animal Science 76: 1513-1522.

Frugoni, G., Oyhantçabal, W. 2008. Comportamiento del sector carne vacuna en 2008 y perspectivas para 2009. Anuario Opypa 2008 [en línea]. Disponible en: http://www.mgap.gub.uy/opypa/ANUARIOS/Anuario08/material/pdf/02.pdf.

Consultado: febrero 2009

Galli, J.R., Cangiano, C.A., Fernández, H.H. 1996. Rev. Arg Prod. Anim. 16(2): 119-42.

García, J.M. 2003. Teoría y ejercicios prácticos de dinámica de sistemas. Primera ed. Barcelona (España).

García, F., Sainz, R.D., Agabriel, J., Barioni, L.G., Oltjen, J.W. 2008. Comparative analysis of two dynamic mechanistic models of beef cattle growth. Animal Feed Science and Technology 143: 220-241

Global Trade Atlas. 2009. [En línea] Disponible en: http://www.gtis.com/gta/. Consultado: junio 2009

Graham, N.M., Searle, T.W. 1972. Growth in sheep. II. Efficiency of energy and nitrogen utilization from birth to 2 years. J. Agric. Sci. 79: 383-389.

Gregory, K. E., Cundiff, L. V., Koch, R.M. 1994. Breed effects, dietary energy density effects, and retained heterosis on different measures of gain efficiency in beef cattle. Journal of animal science 72 : 1138-1154.

Hazel, L.N. 1943. The genetic basis for constructing selection indices. Genetics 38: 476-490. 
Hamlin, K.E., Green, R.D., Cundiff, L.V., Wheeler, T.L., Dikeman, M.E. 1995. Real-time ultrasonic measurement of fat thickness and longissimus muscle area: II. Relationship between real-time ultrasound measures and carcass yield. Journal of Animal Science 73: $1725-1734$.

Heady, E.O. 1976. Systems and other models. In: Proc. Livestock Systems Analysis Workshop, lowa State Univ., Ames.

Helguera, L., Lanfranco, B. 2006. Riesgo y Rentabilidad en Empresas Ganaderas. Ed. 1, Montevideo, Editado por la Unidad de Agronegocios y Difusión de INIA, v.1, p. 60

Herrero, M., Fawcett, R.H., Dent, J.B. 1999. Bio-economic evaluation of dairy farm management scenarios using integrated simulation and multiple-criteria models. Agricultural systems 62(3): 169-.

Herrero, M., Fawcett, R.H., Silveira, V., Busqué, J., Bernués, A., Dent, J.B. 2000. Modelling the growth and utilisation of kikuyu grass (Pennisetum clandestinum) under grazing. 1. Model definition and parameterisation. Agric. Syst. 65: 73-97.

Herring, W.O., Miller, D.C., Bertrand, J.K., Benyshek, L.L. 1994. Comparison of live and carcass equations predicting percentage of cutability, retail product weight, and trimmable fat in beef cattle. Journal of Animal Science 72: 1107-1118.

Hoch, T., Agabriel, J., 2004. A mechanistic dynamic model to estimate beef cattle growth and body composition.1. Model description. Agric. Syst. 81 (1): 1-15.

Holden, N.M., Brereton, A.J., Fitzgerald, J. 2007. A dynamic dairy system simulation model. In: Making Science Work on the Farm. A Workshop on Decision Support Systems for Irish Agriculture. Ed: N. M. Holden, T. Hochstrasser, R. P. O. Schulte, S. Walsh. Dublin, Ireland

Illius, A.W., Clarke, D.A., Hodgson J. 1992. Discrimination and patch choice by sheep grazing grass-clover swards. Journal of Animal Ecology 61: 183-194.

Ingvartsen, K. L. 1994. Models of voluntary food intake in cattle. Livest. Prod. Sci. 39:19-38.

INRA, 1989. Institut National de la Recherche Agronomique. In: Jarrige, R. (Ed.), Ruminant Nutrition: Recommended Allowances and Feed Tables. John Libey, Eurotext, Montrouge, France. 
Joandet, G.E., Cartwright, T.C. 1975. Modeling Beef Production Systems. Journal of animal science 41(4): 1238-.

Johnson, I.R., Parsons, A.J., 1985. A theoretical analysis of grass growth under grazing. Journal of Theoretical Biology 112, 345-368.

Johnson, S.K. 1988. Relationships of Pelvic Structure, Body Measurements, Pelvic Area and Calving Difficulty. Journal of animal science 66(5): 1081-.

Jorge, J.J., Cardoso, V.L., Galvão de Albuquerque, L. 2006. Modelo bioeconômico para cálculo de custos e receitas em sistemas de produção de gado de corte visando à obtenção de valores econômicos de características produtivas e reprodutivas. Revista Brasileira de Zootecnia 35(5): 2187-2196.

Kahn, H., Lehrer, A.R. 1984. A dynamic model for the simulation of cattle herd production systems: III. Reproductive performance of beef cows. Agric. Systems 13:143-159.

Keele, J.W., Williams, C.B., Bennett, G.L., 1992. A computer model to predict the effects of level of nutrition on composition of empty body gain in beef cattle. I. Theory and development. J. Anim. Sci. 70: 841-857.

Klosterman, E.W. 1972. Beef Cattle Size for Maximum Efficiency. Journal of animal science, 34(5): 875-.

Kluyts, J., Neser, F., Bradfield, M. 2003. Development of breeding objectives for beef cattle breeding: derivation of economic values: review article. South African Journal of Animal Science 33(3): 142-158.

Koots, K.R., Gibson, J.P. 1998. Economic values for beef production traits from a herd level bioeconomic model. Canadian Journal of Animal Science 78: 29-45.

Kurtz, D.B., Schellberg, J., Braun, M. 2009. Ground and satellite based assessment of rangeland management in sub-tropical Argentina. Applied Geography. En prensa.

Lanfranco, B., Ois, C., Bedat, A. 2006. Variabilidad de corto plazo en la formación de precios en el mercado vacuno de reposición. INIA Las Brujas 70 p. (Serie Técnica 155).

Laster, D.B., Smith, G.M., Cundiff, L.V., Gregory, K.E. 1979. Characterization of Biological Types of Cattle (Cycle II) II. Postweaning Growth and Puberty of Heifers. Journal of animal science 48(3): 500-. 
Lesmeister, J.L., Burfening, P.J., Blackwell, R.L. 1973. Date of first calving in beef cows and subsequent calf production. J. Anim. Sci. 36:1-6.

Madalena, F.E. 2003. Objetivos económicos de la selección. In: Genética para Ejecutivos. Notas para curso dictado en Bogotá, Abril de 2003, Cap. 11.

Maquivar, M.G., Galina, C.S., Mendoza, G.D., Verduzco, A.R., Galindo, J.R., Molina, R.M., Estrada, S. 2006. Predicción de la ganancia diaria de peso mediante el uso del modelo NRC en novillas suplementadas en el trópico húmedo de Costa Rica. Revista Científica 16(6): 634-641

Martin, L. C., Brinks, J. S., Bourdon, R. M., Cundiff, L.V. 1992. Genetic effects on beef heifer puberty and subsequent reproduction. Journal of animal science 70: 4006-4017.

Mathews, K. Short, S. 2001. The Beef Cow Replacement Decision. Journal of Agribusiness 19: 191-211.

May, S.G., Mies, W.L., Edwards, J.W., Harris, J.J., Morgan, J.B., Garrett, R.P., Williams, F.L., Wise, J.W., Cross, H.R., Savell, J.W. 2000. Using live estimates and ultrasound measurements to predict beef carcass cutability. Journal of Animal Science 78: 12551261.

Melton, A.A., Riggs, J.K., Nelson, L.A., Cartwright, T.C. 1967. Milk Production, Composition and Calf Gains of Angus, Charolais and Hereford Cows. Journal of animal science 26(4): 804-.

Meyer, J.H., Lofgreen, G.P., Garrett, W.N. 1960. A proposed method for removing sources of error in beef cattle feeding experiments. Journal of animal science 19: 1123.

Mitchell, P.L., Sheehy, J.E. 1997. Comparison of predictions and observations to assess model performance: a method of empirical validation. In: Kropff, M.J., Teng, P.S., Aggarwal, P.K., Bouma, J., Bouman, B.A.M., Jones, J.W., Van Laar, H.H. (Eds.), Applications of Systems Approaches at the Field Level. Kluwer Academic Publishers, Boston, MA, pp. 437-451.

Molina, C. 2008. Programa de monitoreo de empresas ganaderas. Ejercicio 2007-2008 y evolución desde 2001-2002 [en línea]. Presentación MS Powerpoint. Disponible en: http://www.planagro.com.uy Consultado: enero 2009. 
Monje, A. 1987. Destete precoz en cría vacuna. Conceptos previos a la implementación de la práctica [en línea]. Disponible en: http://www.vetuy.com/articulos/bovinos/150/0141/bov141.htm Consultado: febrero 2009.

Monje, A.R. 1997. Intensificación de la cría vacuna. Una propuesta tecnológica. Rev. Arg. Prod. Anim.17(3) : 301-306.

Montano-Bermúdez, M., Nielsen, M.K. 1990. Reproductive performance and variation in body weight during annual cycles for crossbred beef cows with different genetic potential for milk. Journal of animal science 68(8): 2289-.

Montossi, F., Pigurina, G., Santamarina, I., Berretta, E.J. 2000. Selectividad animal y valor nutritivo de la dieta de ovinos y vacunos en sistemas ganaderos: teoría y práctica. INIA Tacuarembó 84 p. (Serie Técnica 113).

Murdick, R.G., Munson, J.C. 1988. Sistemas de Información Administrativa. Editorial Prentice Hall. $2^{\circ}$ Edición.

Nix, J.M., Spitzer, J.C., Grimes, L.W., Burns, G.L., Plyler, B.B. 1997. A retrospective analysis of factors contributing to calf mortality and dystocia in beef cattle, Theriogenology 49(8): 1515-1523.

Notter, D.R. 1977. Simulated efficiency of beef production for a cow-calf feedlot management system. Ph.D. Dissertation. Univ. of Nebraska, Lincoln.

NRC, 1981. Effect of Environment on Nutrient Requirements of Domestic Animals. National Academy Press, Washington, DC.

NRC, 1996. Nutrient Requirements of Beef Cattle, 7th Edition. National Academy Press, Washington, DC.

Núñez-Dominguez, R., Cundiff, L.V., Dickerson, G.E., Gregory, K.E., Koch, R.M. 1991. Lifetime production of beef heifers calving first at two vs three years age. J. Anim. Sci. 69:3467-.

Oesterheld, M., Dibella, C.M., Kerdiles, H. 1998. Relation between NOAA-AVHRR satellite data and stocking rate of rangelands. Ecological Applications 8(1): 207-212

Olaizola, A., Gibon, A. 1997. Bases teóricas y metodológicas para el estudio de las explotaciones ganaderas y sus relaciones con el espacio. La orientación de la escuela francesa de sistemistas. ITEA 93 (1): 17-39. 
Oltjen, J.W., Bywater, A.C., Baldwin, R.L., Garrett, W.N. 1986. Development of a dynamic model of beef cattle growth and composition. Journal of Animal Science 62: 86-97.

Pang, H., Makarechian, M.H., Basarab, J.A., Berg, R.T. 1999. Structure of a dynamic simulation model for beef cattle production systems. Can. J. Anim. Sci. 79: 409-417.

Peck, S.L., 2004. Simulation as experiment: a philosophical reassessment for biological modeling. Trends Ecol. Evol. 19: 530-534.

Pereira, G., Soca, P. 1999. Aspectos relevantes de la cría vacuna en el Uruguay [en línea]. Disponible en: http://www.fagro.edu.uy/ ccss/index publica.html Consultado: Enero 2009.

Pereira, G. 2000. Aproximación al resultado económico logrado por las Explotaciones ganaderas en el ejercicio 1999/2000 [en línea]. Documento MS Word. Disponible en: http://www.fagro.edu.uy/ ccss/index publica.html Consultado: Enero 2009.

Peyrou, J., Ilundain, M. 2006. Comportamiento del sector carne vacuna en 2006 y perspectivas para 2007. Anuario OPYPA 2006 [en línea]. Disponible en: http://www.mgap.gub.uy/opypa/ANUARIOS/Anuario06/htm/indice.htm Consultado: febrero 2009.

Phillips, R., Beeri, O., Scholljegerdes, E., Bjergaard, D., Hendrickson, J. 2009. Integration of geospatial and cattle nutrition information to estimate paddock grazing capacity in Northern US prairie. Agricultural Systems 100: 72-79

Phocas, F., Bloch, C., Chapelle, P., Bécherel, F., Renand, G., Ménissier, F., 1998. Developing a breeding objective for a French purebred beef cattle selection programme. Livestock production science 57: 49-65.

Pigurina, G., Berretta, E. 2002. Sistemas pecuarios de la region campos de Uruguay: tecnología y perspectivas [en línea]. Disponible en: http://www.inta.gov.ar/mercedes/grupocampos/Sist\%20Produccion/FigurBerreta.pdf/ Consultado: febrero 2009.

Pittroff, W., Cartwright, T.C. 2002. Modeling livestock systems. I. A descriptive formalism. Arch. Latinoam. Prod. Anim. 10(3): 193-205.

Ponzoni, R.W. 1992. Genetic improvement of hair sheep in the tropics. FAO Animal Production and Health paper 101. FAO, Rome, 168 pp. 
Ponzoni, R.W., Newman, S. 1989. Developing breeding objectives for Australian beef cattle production. Anim. Prod. 49: 35-.

Poppi, D.P. 1996. Predictions of food intake in ruminants from analyses of food composition. Australian journal of agricultural research 47: 489-.

Ponssa, E., Machado, C., Berger, H., Copes, M., Auza, N. 2003. Evaluación de los efectos productivos y económicos de algunas variables reproductivas mediante un modelo de simulación determinístico. En: $26^{\circ}$ Congreso Argentino de Producción Animal, AAPA, Mendoza, Argentina.

Ponssa, E., Sánchez, D., Rodríguez, G.A. 2007. Relaciones entre la tasa de preñez y la dinámica del rodeo en un sistema de cría bovina. Evaluación física y económica. In: XXXVIII Reunión Anual de la de Asociación Argentina de Economía Agraria, Mendoza, Argentina

Quintans, G. 2004. La productividad del rodeo de cría: nuestro gran desafío. En: Revista INIA Uruguay, número 1.

Quintans, G. 2008. Manejo del rodeo de Cría: Destete precoz. Cartilla № 2, INIA Uruguay

Ramos, R. 2008. "Teoría General de Sistemas" [en línea]. Facultad de Ingeniería de Computación y Sistemas. Lima, Perú. Disponible en: http://epicsproject.com/tgs.html Consultado: agosto 2008.

Realini, C.E., Williams, R.E., Pringle, T.D., Bertrand, J.K. 2001. Gluteus medius and rump fat depths as additional live animal ultrasound measurements for predicting retail product and trimmable fat in beef carcasses. Journal of Animal Science 79: 1378-1385.

Ritchie, H. D. 1995. The optimum cow: What criteria must she meet? Feedstuffs 67, p. 11. Weekly newspaper for agribusiness, Miller Publishing Co., Minnetonka, MN.

Rovira, J. 1996. Manejo nutritivo de los rodeos de cría en pastoreo. Editorial Hemisferio Sur. pp. 3-58.

Ruiz, R., Oregui, L. 2001. El enfoque sistémico en el análisis de la producción animal: revisión bibliográfica. Invest. Agr: Prod. Sanid. Anim. 16 (1): 29-61.

Sanders, J.O., Cartwright, T.C. 1979a. A general cattle production systems model. I: Structure of the model. Agricultural systems 4: 217-. 
Sanders, J.O., Cartwright, T.C. 1979b. A general cattle production systems model. II: Procedures used for simulating animal performance. Agricultural systems 4: 289-.

Sanz, A., Bernués, A., Villalba, D., Casasús, I., Revilla, R. 2004. Influence of management and nutrition on postpartum interval in Brown Swiss and Pirenaica cows, Livestock Production Science 86:179-191

SAS. 2007. Statistical Analysis Sistems. SAS Institute Inc., Cary, NS, USA.

SCA, 1990. Feeding Standards for Australian Livestock. In: Ruminants, Standing Committee on Agriculture and CSIRO, Melbourne, p. 266.

Selk, G.E., Wettemann, R.P., Lusby, K.S.J., Oltjen, W.S., Mobley, L., Rasby, R.J., Garmendia, J.C. 1988. Relationships among Weight Change, Body Condition and Reproductive Performance of Range Beef Cows. Journal of animal science 66(12): 3153-.

Silveira, V.C.P. 2002. Pampa corte - um modelo de simulação para o crescimento e engorda de gado de corte. Ciência Rural 32(3): 543-552

Spitzer, J.C., Morrison, D.G., Wettemann, R.P., Faulkner, L.C. 1995. Reproductive responses and calf birth and weaning weights as affected by body condition at parturition and postpartum weight gain in primiparous beef cows. J. Anim. Sci. 73:1251-1257.

Taylor, St.C.S., Moore, A.J., Tbiessen, R.B., Bailey, C.M. 1985. Efficiency of food utilization in traditional and sex-controlled systems of beef production. Anim. Prod. 40: 401.

Tedeschi, L.O., Fox, D.G., Guiroy, P.J., 2004. A decision support system to improve individual cattle management.1. A mechanistic, dynamic model for animal growth. Agric. Syst. 79: 171-204.

Ter-Mikaelian, M.T., Wagner, R.G., Shropshire, Bell, F.W., Swanton, C.J. 1997. Using a mechanistic model to evaluate sampling designs for light transmission through forest plant canopies. Can. J. For. Res. 27: 117-126.

Tobias, B., Mendoza, G.D., Arjona, E., Garcia-Bojalil, C., Suarez, M.E. 2006. A simulation model of perfomance of growing steers grazing in tropical pastures. J. Anim. Sci. 75(1): $271-$. 
Trevisan, N., Silveira, V.C.P., Quadros, F.L.F., Silva, A.C.F. 2009. Desempenho de bovinos simulado pelo modelo Pampa Corte e obtido por experimentação. Cienc. Rural 39(1): 173-181.

Unión de Exportadores del Uruguay. 2009. [En línea] http://www.uruguayexporta.com/. Consultado: mayo 2009

Urioste, J.I., Ponzoni, R.W., Aguirrezabala, M., Rovere, G., Saavedra, D. 1998. Objetivos de selección para vacunos de carne en el Uruguay. Libro en homenaje al Ing. Agr. Jaime Rovira. Montevideo, Uruguay, 200 p.

Vaz Martins, D., Mescia, M., Brit, A., Cibils, R., Aunchain, M. 2003a. Efecto de la presión de pastoreo sobre ganancia en peso y eficiencia de utilización del forraje de novillos de distinta edad. In: Avances sobre engorde de novillos en forma intensiva. INIA La Estanzuela, (Seria técnica 135)

Vaz Martins, D., Olivera, L., Cozzolino, D., Robaina, R., Abraham, D. 2003b. Terminacion de novillos en base a pasturas suplementadas con grano y en base a ensilaje de maíz y su efecto sobre la composición del corte pistola y del longíssimus dorsi. INIA La Estanzuela, (Serie Técnica 406)

Villalba, D., Casasús, I., Sanz, A., Bernués, A., Estany, J., Revilla, R. 2006. Stochastic simulation of mountain beef cattle systems. Agricultural Systems 89: 414-434.

Wang, Y., Miller, S. P., Wilton, J.W., Sullivan, P. , Banks, L. R. 2001. The relationship between birth weight and calving ease in a beef herd [en línea]. 2000/2001 Ontario Beef Research Update. Department of Animal \& Poultry Science, University of Guelph. Disponible en: http://bru.aps.uoguelph.ca/. Consultado: Noviembre 2008

Warriss, P. D. 2000. Meat Science: an introductory text. Wallingford:CABI Publishing, 310p.

Werth, L.A., Azzam, S.M., Nielsen, M.K., Kinder, J.E. 1991. Use of a simulation model to evaluate the influence of reproductive performance and management decisions on net income in beef production. Journal of animal Science 69: 4710-4721.

Weston, R. H. 1982. Animal factors affecting feed intake. In: Nutrition limits to animal production from pasture (ed. J. B. Hacker), pp. 183-198. CAB Farnham Royal, Slough. 
Williams, R.E., Bertrand, J.K., Williams, S.E., Benyshek, L.L. 1997. Biceps femoris and rump fat as additional ultrasound measurements for predicting retail product and trimmable fat in beef carcasses. Journal of Animal Science 75: 7-13.

Wiltbank, J.N., Rowden, W.W., Ingalls, J.E., Gregory, K.E., Koch, R.M. 1962. Effect of energy level on reproductive phenomena of mature Hereford cows. Journal of animal science 21: 219-.

Wiltbank, J.N., Rowden, W.W., Ingalls, J.E., Zimmerman, D.R. 1964. Influence of postpartum energy level on reproductive performance of Hereford cows restricted in energy intake before calving. Journal of animal science 23: 1049-.

Yáñez, L. Índices de selección: sugerencias para su utilización. 2005. En: Manual de Ganadería Doble Propósito. C. González-Stagnaro, E. Soto-Belloso (eds.). Ediciones Astro Data, S.A. Maracaibo-Venezuela. VIII (1): 283-290.

Yáñez, L., Méndez, J.A., Villasmil-Ontiveros, Y., Rojas, N., Chirinos, Z., Ordóñez, J. 2006. Modelo bioeconómico de simulación para orientar la definición del objetivo de selección en el sistema doble propósito. Revista Científica, FCV-LUZ / Vol. XVI, N 4: 381-392.

Yourdon, E. 1993. Análisis estructurado moderno. México, Ed. Prentice Hall, 735 págs. 

ANEXO 

Ecuación 1. Ecuación de cálculo de terneras necesarias para reposición

TerNec $=-\left((\right.$ Cub3 + Cub2 $\left.){ }^{*} \mathrm{VC}\right) /\left(\left((\right.\right.$ Cub14 -1$){ }^{*}$ Cub3 ${ }^{*}$ NoDescDef^8 ${ }^{*}$ parresto^5 ${ }^{*}$ sTpond ${ }^{*} \mathrm{sVC}^{\wedge} 6$ * sVC3a * sNa12ss * sNa2ss + (Cub14 - 1) * Cub2 * NoDescDef^8 * parresto^5 * sTpond * sVC^6 * sVC2a * sNa12ss + ( - Cub14 * Cub3 - Cub14 * Cub2) * NoDescDef^8 * parresto^5 * sTpond * sVC^6 * sVC14m) * yvc8 + (((Cub14 - 1) * Cub3 * NoDescDef^7 * parresto^4 * sTpond * sVC^5 * sVC3a * sNa12ss * sNa2ss + (Cub14 - 1) * Cub2 * NoDescDef^7 * parresto^4 * sTpond * sVC^5 * sVC2a * sNa12ss + ( - Cub14 * Cub3 - Cub14 * Cub2) * NoDescDef^7 * parresto^4 * ${ }^{*}$ Tpond * ${ }^{*}{ }^{\wedge}{ }^{\wedge}{ }^{*}$ sVC14m) ${ }^{*}$ yvc7) $+((($ Cub14 - 1) * Cub3 * NoDescDef^6 ${ }^{*}$ parresto^3 * sTpond * sVC^4 * sVC3a * sNa12ss * sNa2ss + (Cub14 - 1) * Cub2 * NoDescDef^6 * parresto^3 * ${ }^{*}$ STpond * sVC^4 * sVC2a * sNa12ss + ( - Cub14 * Cub3 - Cub14 * Cub2) * NoDescDef^6 * ${ }^{*}$ parresto^3 * ${ }^{*}$ Tpond * sVC $^{\wedge} 4{ }^{*}$ sVC14m) * yvc6) + $\left(\left((\right.\right.$ Cub14 -1$){ }^{*}$ Cub3 * NoDescDef^5 * parresto^2 * sTpond * sVC^3 * sVC3a * sNa12ss * sNa2ss + (Cub14 - 1) * Cub2 * NoDescDef^5 * parresto^2 * sTpond * sVC^3 * sVC2a * sNa12ss + ( - Cub14 * Cub3 - Cub14 * Cub2) * NoDescDef^5 * parresto^2 * sTpond * sVC^3 * sVC14m) * yvc5) + (((Cub14 - 1) * Cub3 * NoDescDef^4 * parresto * sTpond * sVC^2 + $\left(\right.$ Cub14 - 1) * Cub3 * NoDescDef^3 * ${ }^{*}$ Tpond * sVC + (Cub14 - 1) * Cub3 * NoDescDef^2 * sTpond $){ }^{*}$ sVC3a $+($ Cub14 - 1) * Cub3 * NoDescDef * sTpond $)$ * sNa12ss * sNa2ss ) + $((($ Cub14 - 1) * Cub2 * NoDescDef^4 * parresto * sTpond * sVC^2 + (Cub14 - 1) * Cub2 * NoDescDef^3 * sTpond * sVC + (Cub14 - 1) * Cub2 * NoDescDef^2 * sTpond ${ }^{*}$ sVC2a + $($ Cub14 - 1) * Cub2 * NoDescDef * sTpond $) *$ sNa12ss $)+(((-$ Cub14 * Cub3 - Cub14 * Cub2) * NoDescDef^4 * parresto * sTpond * sVC^2 + (- Cub14 * Cub3 - Cub14 * Cub2) * NoDescDef^3 * sTpond * sVC + (- Cub14 * Cub3 - Cub14 * Cub2) * NoDescDef^2 * sTpond) ${ }^{*}$ sVC14m + (- Cub14 * Cub3 - Cub14 * Cub2) * NoDescDef * sTpond)) 
Tabla A-1. Código VBA para la estimación de peso de animales en un grupo, luego de la venta del estrato de animales de peso superior a partir de un umbral (limite) asumiendo que dichos pesos siguen una distribución normal.

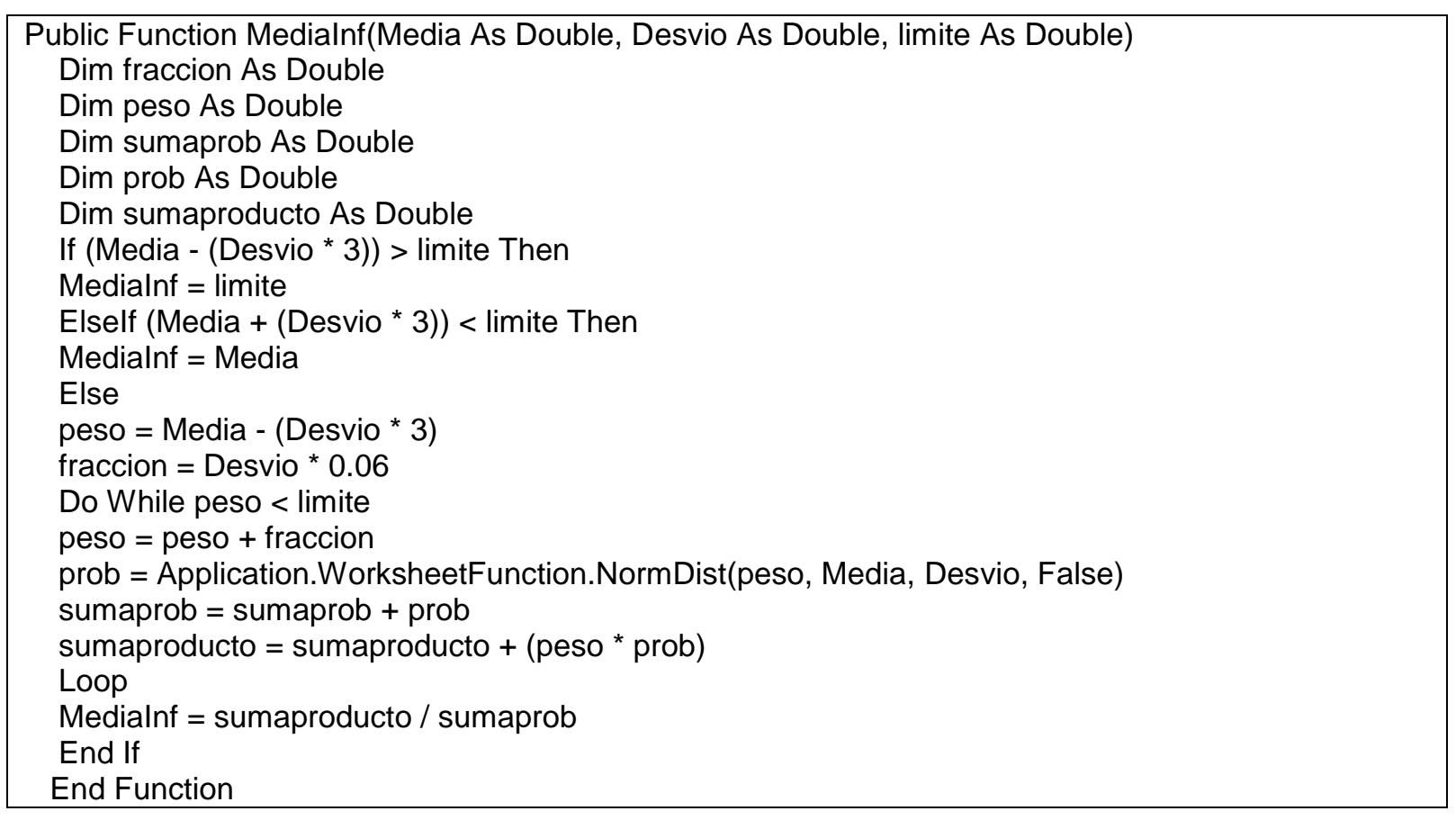

Tabla A-2. Código VBA para la estimación de peso de venta de animales seleccionados a partir de un umbral (limite) asumiendo una distribución normal de los pesos.

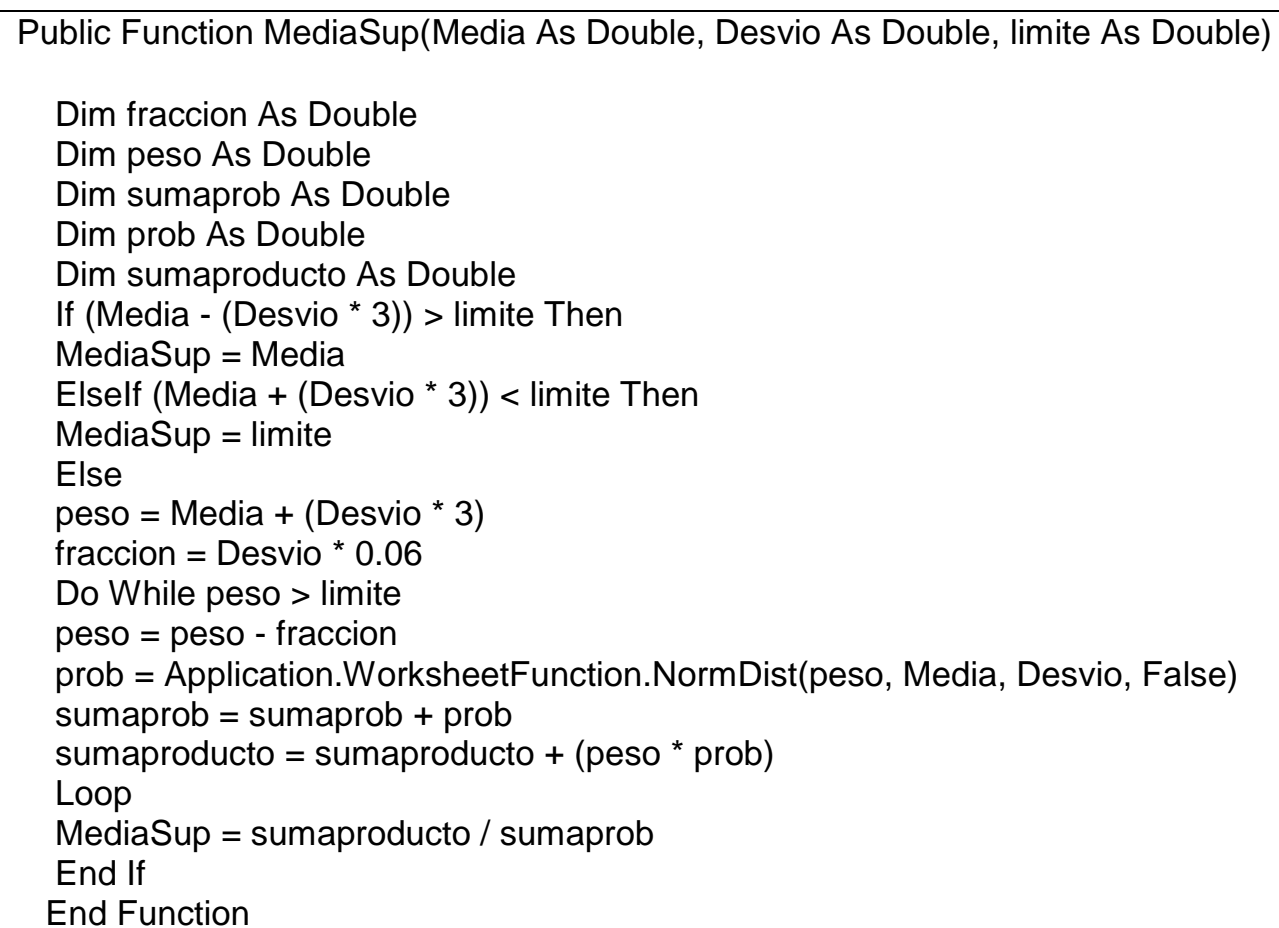


Tabla A-3. Código VBA para la estimación de la desviación en el peso de un grupo de animales, luego de la venta del estrato de animales de peso superior a partir de un umbral (limite) asumiendo que dichos pesos siguen una distribución normal.
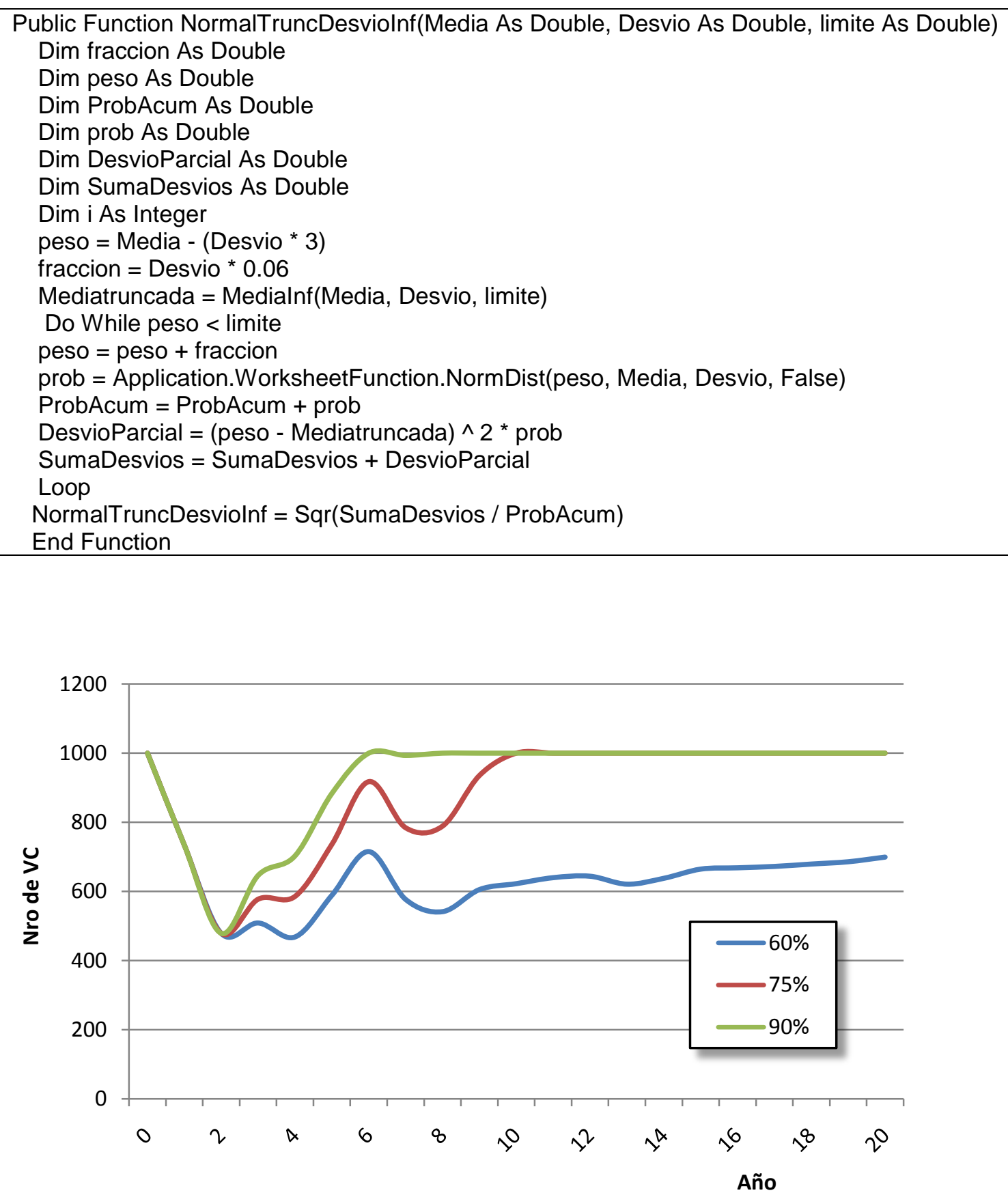

Figura 1. Evolución del número de VC en función del porcentaje de preñez con 4 estratos de edades y descarte de vacas variable 


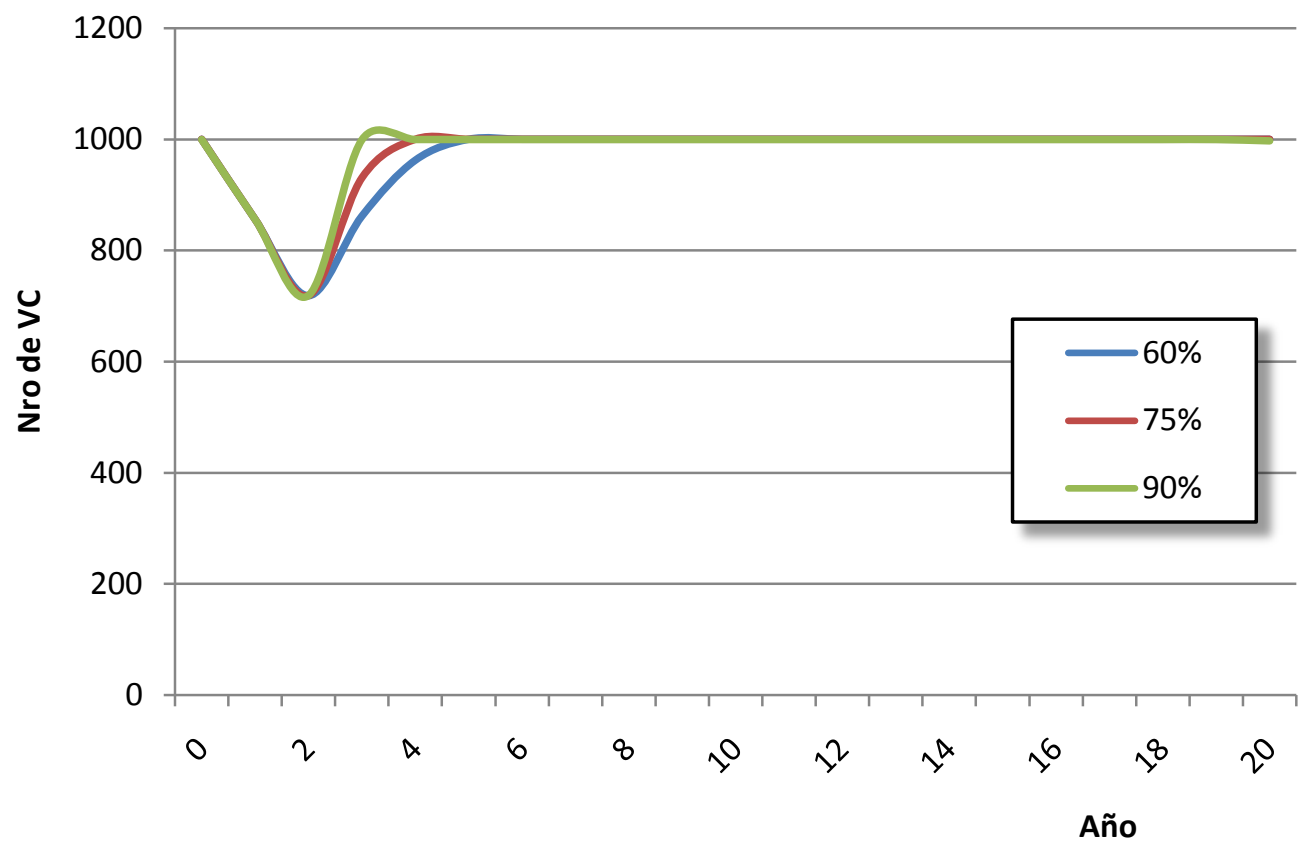

Figura 2. Evolución del número de VC en función del porcentaje de preñez con 8 estratos de edades y descarte de vacas variable.

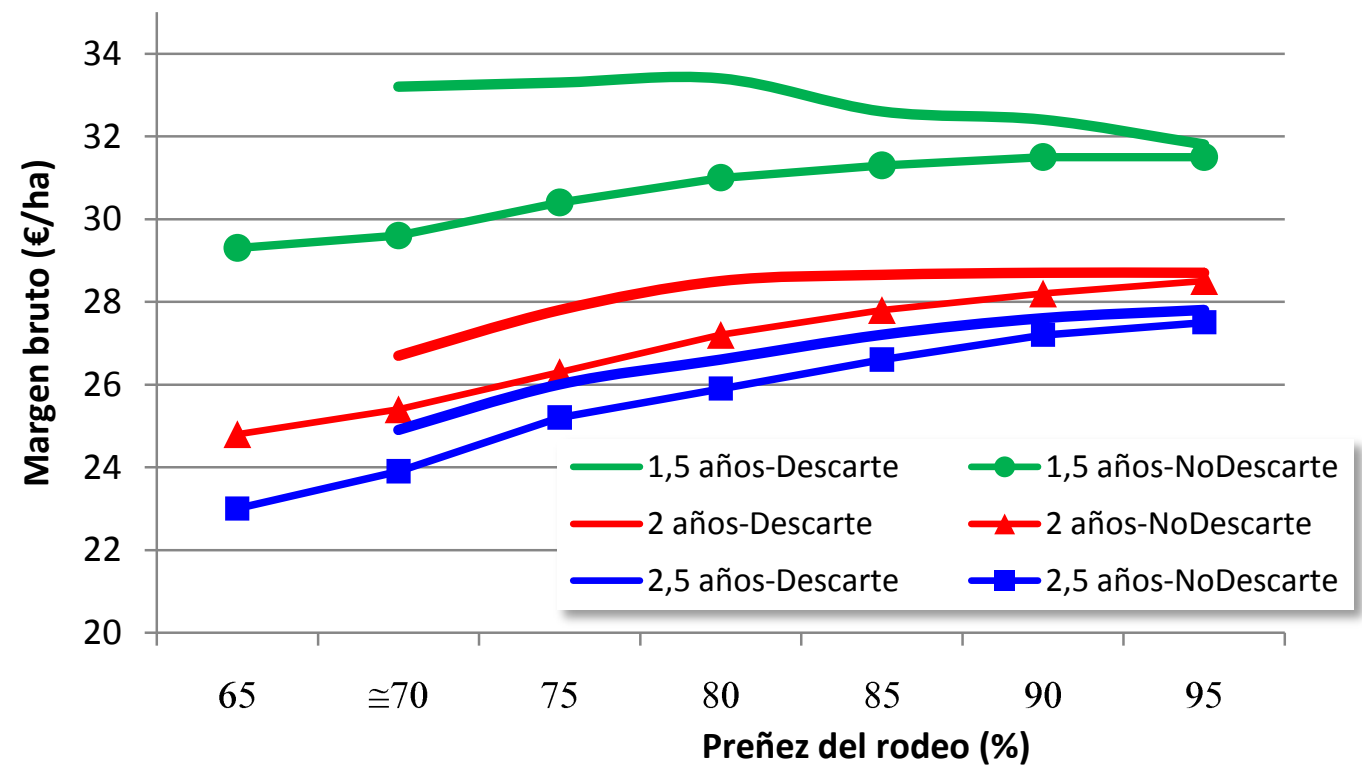

Figura 3. Efecto del porcentaje de preñez del rebaño sobre el margen bruto del sistema según combinaciones entre edad al primer servicio y política de descarte de novillas y vacas de segunda cubrición 